CENTRO UNIVERSITÁRIO FEI

BÁRBARA CARVALHO MAFRA TERRA

ESTUDO DO EFEITO DA SUBSTITUIÇÃO DO MOLIBDÊNIO POR TUNGSTÊNIO NO DESEMPENHO DE AÇOS INOXIDÁVEIS AUSTENÍTICOS

São Bernardo do Campo 
BÁRBARA CARVALHO MAFRA TERRA

\section{ESTUDO DO EFEITO DA SUBSTITUIÇÃO DO MOLIBDÊNIO POR TUNGSTÊNIO NO DESEMPENHO DE AÇOS INOXIDÁVEIS AUSTENÍTICOS}

Dissertação de Mestrado apresentada ao Centro Universitário FEI, como parte dos requisitos necessários para obtenção do título de Mestre em Engenharia Mecânica, orientado pelo Prof. Dr. Rodrigo Magnabosco.

São Bernardo do Campo 
Carvalho Mafra Terra, Bárbara.

Estudo do efeito da substituição do molibdênio por tungstênio no desempenho de aços inoxidáveis austeníticos / Bárbara Carvalho Mafra Terra. São Bernardo do Campo, 2018.

143 p. : il.

Dissertação - Centro Universitário FEI.

Orientador: Prof. Dr. Rodrigo Magnabosco.

1. aço inoxidável austenítico. 2. propriedades mecânicas. 3 . resistência à corrosão. 4. molibdênio. 5. tungstênio. I. Magnabosco, Rodrigo, orient. II. Título.

Elaborada pelo sistema de geração automática de ficha catalográfica da FEI com os dados fornecidos pelo(a) autor(a 


\section{APRESENTAÇÃO DE DISSERTAÇÃO ATA DA BANCA EXAMINADORA}

Programa de Pós-Graduação Stricto Sensu em Engenharia Mecânica
Mestrado

PGM-10

Aluno: Bárbara Carvalho Mafra Terra

Matrícula: $216103-2$

Título do Trabalho: Estudo do efeito da substituição do molibdênio por tungstênio no desempenho de aços inoxidáveis austeníticos.

Área de Concentração: Materiais e Processos

Orientador: Prof. Dr. Rodrigo Magnabosco

Data da realização da defesa: 22/02/2018

ORIGINAL ASSINADA

Avaliação da Banca Examinadora:

São Bernardo do Campo, 22 / 02 / 2018.

\section{MEMBROS DA BANCA EXAMINADORA}

Prof. Dr. Rodrigo Magnabosco

Ass. :

Prof. a Dr. a Isolda Costa

Ass. :

Prof. Dr. Rodrigo César Nascimento Liberto

Ass. :

A Banca Julgadora acima-assinada atribuiu ao aluno o seguinte resultado:

APROVADO $\bigotimes \quad$ REPROVADO

\section{VERSÃO FINAL DA DISSERTAÇÃO}

APROVO A VERSÃo FINAL DA DISSERTAÇÃO EM QUE FORAM INCLUÍDAS AS RECOMENDAÇÕES DA BANCA EXAMINADORA
Aprovação do Coordenador do Programa de Pós-graduação

Prof. Dr. Rodrigo Magnabosco 
Aos meus familiares e amigos 


\section{AGRADECIMENTOS}

À minha família, meus pais Sandra e Marcos, minha irmã Júlia e meu noivo Rodolfo, pelo amor e incentivo.

Ao prof. Dr. Rodrigo Magnabosco pela orientação, paciência, amizade e grande aprendizado que foram fundamentais para a execução deste trabalho.

Ao Dr. Rodrigo César Nascimento Liberto pelo incentivo e por aceitar fazer parte da banca julgadora deste trabalho.

À Prof ${ }^{a}$. Dr ${ }^{\mathrm{a}}$ Isolda Costa por ter aceitado o convite de fazer parte da banca julgadora deste trabalho.

À Villares Metals pelo auxílio e incentivo à Pesquisa.

A todos os colegas do Centro de Pesquisa e Desenvolvimento da Villares Metals S.A. pelo incentivo, contribuição experimental e discussões que foram imprescindíveis para realização deste trabalho.

Aos técnicos do Centro de Desenvolvimento de Materiais Metálicos (CDMatM-FEI) e do Centro de Laboratórios Químicos (CLQ-FEI) pelo auxílio nas atividades experimentais.

Ao Centro Universitário FEI pelo incentivo à pesquisa e concessão de bolsa de estudo.

A todos os professores do Departamento de Engenharia de Materiais da Universidade Federal de São Carlos, que me deram toda a base de conhecimento para que este trabalho fosse possível.

E a todos que contribuíram de alguma maneira para a realização deste trabalho. 


\section{RESUMO}

O aço inoxidável AISI 316 é o segundo mais popular aço inoxidável austenítico após o AISI 304. Esta classe de aço é amplamente disponível, tem boa resistência geral à corrosão, boa tenacidade e excelente conformabilidade e soldabilidade. A principal diferença entre os aços AISI 304 e AISI 316 está na adição de 2 a 3\% de Molibdênio (Mo) na composição química deste último, para aumento de sua resistência à corrosão por pite. O aço AISI 316 tornou-se um material muito adequado para utilização em ambientes de águas salgadas, sendo muitas vezes referido como inoxidável "tipo naval" devido à sua maior resistência à corrosão por cloreto promovida pela adição de Molibdênio, comparado ao aço AISI 304. A literatura sugere que a substituição total ou parcial do molibdênio por tungstênio (W) em aços inoxidáveis ferríticos e dúplex não só aumenta a resistência à corrosão localizada dessas ligas, como indica efeito sinérgico entre estes elementos. Essa substituição seria possível graças à similaridade em termos de propriedades físico-químicas destes elementos. Neste trabalho propôs-se o estudo do efeito sinérgico resultante da substituição parcial e total do Mo por $\mathrm{W}$ em um aço austenítico AISI 316L, analisando ligas que apresentam 0, 25, 50, 75 e 100\% de substituição do teor atômico de molibdênio presente na liga de referência por tungstênio. A análise microestrutural das amostras por microscopia ótica e EDS evidenciou que o W não provoca nenhuma mudança significativa no material em relação ao tamanho, distribuição e composição das inclusões. Porém, o tamanho de grão é sutilmente reduzido provocando um leve aumento na dureza Brinel das amostras que contêm W. Já os ensaios de tração apresentaram resultados de limite de escoamento, limite de resistência à tração, alongamento e redução em área semelhantes para todas as amostras. Os ensaios de polarização cíclica não evidenciaram nenhum efeito do $\mathrm{W}$, mas a determinação da temperatura crítica de pite mostrou que a amostra que apresenta $50 \%$ de W apresentou maior CPT de $40 \pm 4^{\circ} \mathrm{C}$ em solução de $1 \mathrm{M}$ de $\mathrm{NaCl}$ a $180 \mathrm{mV}_{\mathrm{Ag} / \mathrm{AgCl}}$, indicando que de fato há um efeito sinérgico entre W e Mo. Já em solução ácida isenta de cloreto, os resultados de polarização potenciodinâmica evidenciam que o $\mathrm{W}$ dificulta a formação da película passiva, porém, ao ser formada, esta película é mais robusta que aquela na ausência de W. Já os ensaios de DL-EPR nesta mesma solução mostrou que o W não sensitiza o material de maneira significativa, de acordo com a norma ISO 12732:2006. Portanto, este trabalho mostra que a substituição total ou parcial do molibdênio por tungstênio, mantida a proporção em fração atômica, pode ser realizada sem praticamente nenhuma alteração de propriedades para o aço inoxidável austenítico AISI 316L. Porém, quando a substituição é de $50 \%$ há um ganho expressivo no comportamento de corrosão por pite evidenciado pelos resultados dos ensaios para determinação da temperatura crítica de pite promovido certamente por um efeito sinérgico entre o Mo e W. Assim, há um ótimo primeiro indício de que sucatas de aço ferramenta ricas em W para o aumento da resistência ao desgaste nestes materiais podem ser utilizadas para a fabricação de aços inoxidáveis austeníticos. Porém, outros aspectos inerentes à processabilidade devem ser analisados com cuidado para que tal substituição seja, de fato, considerada.

Palavras-chave: aço inoxidável austenítico, propriedades mecânicas, resistência à corrosão, molibdênio (Mo), tungstênio (W). 


\begin{abstract}
AISI 316 stainless steel is the second most popular stainless steel after AISI 304. This steel class is widely available, exhibits good resistance to general corrosion, good ductility and excellent formability and weldability. The main difference between 304 and 316 stainless steels is the addition of 2-3 wt \% Mo in chemical composition of 316 for increased pitting corrosion resistance. AISI 316 stainless steel has become a proper material for marine environments, being named sometimes as "naval type stainless steel" due to its better resistance to chloride provided by Mo addition. Previous reports suggest that total or partial substitution of molybdenum by tungsten in ferritic and duplex stainless steel improve localized corrosion resistance by a synergic effect of Mo and $\mathrm{W}$. The reason for employing tungsten as a substitute for molybdenum in the alloy design of stainless steel is the similarity of chemical and electrical properties of those elements. Considering this, the purpose of this work is to study the synergic effect as a result of partial or total substitution of molybdenum by tungsten in AISI 316L austenitic stainless steel, studying alloys that contain $0,25,50,75$ and $100 \%$ of molybdenum substituted for tungsten in atomic content. The microstructural and EDS analysis showed that $\mathrm{W}$ does not cause any difference on inclusions size, distribution and composition. But the grain size and Brinel hardness is slightly reduced in those samples with $\mathrm{W}$. Tensile tests did not show any difference in their mechanical properties, but the corrosion tests showed an effect on pitting resistance. The cyclic polarization results do not show any difference between the samples with and without $\mathrm{W}$ in $3,5 \% \mathrm{NaCl}$ at room temperature. But the sample with $50 \% \mathrm{~W}$ and $50 \% \mathrm{Mo}$ showed the highest critical pitting temperature in $1 \mathrm{M} \mathrm{NaCl}$ solution and $180 \mathrm{mV} \mathrm{Vg}_{\mathrm{Ag} / \mathrm{AgCl}}, 40 \pm$ $4^{\circ} \mathrm{C}$. This result shows a synergic effect of Mo and $\mathrm{W}$ for austenitic stainless steel as showed by the literature for ferritic and duplex. In acid solution with no chlorides, the potentiodynamic polarization results showed that $\mathrm{W}$ makes the passive layer formation more difficult, but it is stronger when it forms. The DL-EPR tests in the same solution showed that $\mathrm{W}$ does not sensitize the material according to ISO 12732:2006. So, this work shows that the partial and total substitution of Mo by W can be done if the atomic content is maintained because it does not cause any significant difference in the AISI 316 austenitic stainless steel properties. However, if the substitution is $50 \%$, it pitting corrosion resistance is increased promoted by the synergic effect between Mo and W. This information can be useful for steel industries that produces both stainless steels and tool steels, because the last are usually W-rich to improve their wear resistance. So, these results can be first evidence that $\mathrm{W}$-rich tool steel scrap can be used to produce stainless steels.
\end{abstract}

Keywords: austenitic stainless steel, mechanical properties, corrosion resistance, molybdenum (Mo), tungsten (W). 


\section{LISTA DE ILUSTRAÇÕES}

Figura 1 - Influência do Cromo na corrosão atmosférica de um aço baixo carbono................20

Figura 2 - Relação entre propriedades e composições na família dos aços inoxidáveis. .........21

Figura 3 - Crescimento mundial da produção de aços inoxidáveis (em Mton) entre o período de 1950 e 2015

Figura 4 - Diagrama de Pourbaix para ligas $\mathrm{Fe}-\mathrm{Cr}$, destacando o trecho passivo incrementado pelo $\mathrm{Cr}$ em ligas de Fe.

Figura 5 - Diagrama de Pourbaix a $25^{\circ} \mathrm{C}$ para o sistema (a) $\mathrm{W}-\mathrm{H}_{2} \mathrm{O}$; (b) $\mathrm{Mo}-\mathrm{H}_{2} \mathrm{O}$.

Figura 6 - Diagrama TTP (Tempo-Temperatura-Precipitação) de um aço inoxidável AISI 316 que contém cerca de $0,066 \%$ de carbono.

Figura 7 - Representação esquemática da precipitação de carboneto de cromo $\left(\mathrm{Cr}_{23} \mathrm{C}_{6}\right) \operatorname{nos}$ contornos de grão durante a sensitização em aços inoxidáveis.

Figura 8 - Curva tempo-temperatura-sensitização, TTS, do aço inoxidável austenítico AISI 304 em função do teor de carbono devido à precipitação de carbonetos de cromo.

Figura 9 - Perfil de composição de cromo normal ao contorno de grão na vizinhança de carbonetos $\mathrm{M}_{23} \mathrm{C}_{6}$ para amostras envelhecidas (a) a $650^{\circ} \mathrm{C}$ por $50 \mathrm{~h}$; (b) a $650^{\circ} \mathrm{C}$ por $100 \mathrm{~h}$; (c) a $700^{\circ} \mathrm{C}$ por $100 \mathrm{~h}$; (d) a $700^{\circ} \mathrm{C}$ por $300 \mathrm{~h}$

Figura 10 - Variação do gradiente de concentração do aço inoxidável 304 para tratamentos térmicos a $700^{\circ} \mathrm{C}$ por diferentes tempos.

Figura 11 - Comparação entre os dois materiais estudados por Brummer e Charlot (1986), inox 316, e Hall e Briant (1984), inox 316LN para o mesmo tratamento térmico de $700^{\circ} \mathrm{C}$ por $100 \mathrm{~h}$.

Figura 12 - Formas típicas de corrosão por pite em seção transversal à superfície corroída. . 37 Figura 13 - Processo autocatalítico de crescimento do pite de um aço inoxidável na presença de íons cloreto. 38

Figura 14 - Efeito do tungstênio no potencial de pite de um aço inoxidável dúplex a $80^{\circ} \mathrm{C} . .40$ Figura 15 - Potencial de pite de aços inoxidáveis dúplex com e sem adição de $\mathrm{W}$ em solução de $20 \% \mathrm{NaCl}$ a $80^{\circ} \mathrm{C}$ em função do valor do (a) PREN; (b) PREW. Figura 16 - Curva de polarização esquemática para de um aço inoxidável, destacando os potenciais de corrosão $\left(E_{\text {corr }}\right)$, critico $\left(E_{\text {crit }}\right)$, de pite $\left(E_{\text {pite }}\right)$ e de transpassivação ( $\left.E_{\text {trans }}\right)$ e também as densidades de corrente crítica $\left(\mathrm{i}_{\text {crit }}\right)$ e passiva $\left(\mathrm{i}_{\text {pass }}\right)$.

Figura 17 - Efeito da adição de tungstênio em um aço inoxidável austenítico em soluções de (a) $0,1 \mathrm{M} \mathrm{NaCl}$ e (b) $0,1 \% \mathrm{HCl}$. 
Figura 18 - Esquema de uma curva típica de polarização cíclica de um aço inoxidável em uma solução que contém íons cloretos, sendo $\mathrm{E}_{\text {corr }} \mathrm{o}$ potencial de corrosão, $\mathrm{E}_{\text {pite }}$ o potencial de pite e E $_{\text {rep }}$ o potencial de repassivação.

Figura 19 - Curvas típicas de polarização cíclica da liga C-276 (UNS N10276) e do aço inoxidável austenítico 304 (UNS S30400) em solução de 3,56\% de $\mathrm{NaCl}$ a temperatura ambiente de $25 \pm 1^{\circ} \mathrm{C}$.

Figura 20 - Determinação da temperatura crítica de pite de um aço inoxidável utilizando a técnica potenciostática descrita na norma ASTM G150 - 99 (2004).

Figura 21 - Curvas de polarização anódica do aço inoxidável 304 em solução de $2 \mathrm{~N} \mathrm{H}_{2} \mathrm{SO}_{4}$ a $90^{\circ} \mathrm{C}$ após sensitização a $750^{\circ} \mathrm{C}$ por diferentes tempos: $\mathrm{x}=0,3,30,100$ e 1000 horas.

Figura 22 - Curva esquemática de um ensaio DL-EPR de um aço inoxidável em solução de $\mathrm{H}_{2} \mathrm{SO}_{4}+\mathrm{KSCN}$ 52

Figura 23- Efeito do teor de W nas curvas de polarização anódicas do aço inoxidável duplex Fe-22Cr-5,5Ni-0,15N a $80^{\circ} \mathrm{C}$ em uma solução de 3,5\% NaCl. (a) Diferentes teores de W; (b) Comparação do efeito sinérgico entre Mo e W.

Figura 24- Curvas de corrosão sob tensão obtidas pelo método SSRT ("slow strain rate tests" ou BTD - "Baixa Taxa de Deformação") para as ligas 3W, 3Mo e 3W-1Mo em solução de 40\% de $\mathrm{MgCl}_{2}$ a $138^{\circ} \mathrm{C}$.

Figura 25 - Curvas de polarização anódica em solução de $4 \mathrm{M}$ de $\mathrm{MgCl}_{2}$ a $80^{\circ} \mathrm{C}$ para os aços (a) Fe-29Cr-xMo (x = 0 a 4 wt $\%$ ) e (b) Fe-29Cr-yW (y = 0 a 8 wt $\%$ ).

Figura 26 - Dependência do potencial de pite no aço inoxidável ferrítico Fe-29Cr em solução de $4 \mathrm{M} \mathrm{MgCl} 2$ a $80^{\circ} \mathrm{C}$ em relação a (a) Porcentagem em massa de Mo e W; (b) porcentagem atômica de Mo e W.

Figura 27 - Dependência do potencial de pite $\left(E_{\text {pite }}\right)$ na fração atômica de $(\mathrm{Mo}+\mathrm{W})$ no aço inoxidável Fe-29Cr em solução de $4 \mathrm{M} \mathrm{MgCl}_{2}$ a $80^{\circ} \mathrm{C}$ ).

Figura 28 - Curvas de polarização anódica em solução de $20 \% \mathrm{H}_{2} \mathrm{SO}_{4}$ a $30^{\circ} \mathrm{C}$ para os aços (a) Fe-29Cr-xMo (x = 0 a 4 wt $\%$ ) e (b) Fe-29Cr-yW (y = 0 a 8 wt $\%$ ).

Figura 29 - Diagrama esquemático mostrando o efeito da adição de Mo e W no comportamento da polarização anódica do aço inoxidável ferrítico Fe-29Cr numa solução de ácido sulfúrico.

Figura 30 - Polarização potenciodinâmica (a) e "scratch test" (b) do aço inoxidável 317LMN substituindo parcialmente o teor de Mo por $\mathrm{W}$ em solução de $0,5 \mathrm{M} \mathrm{H}_{2} \mathrm{SO}_{4}+3,5 \% \mathrm{Cl}^{-}$a $25^{\circ} \mathrm{C}$. 
Figura 31- Polarização potenciodinâmica (a) e "scratch test" (b) do aço inoxidável 317LMN substituindo parcialmente o teor de Mo por W em solução de $1 \mathrm{M} \mathrm{MgCl}_{2}$ a $50^{\circ} \mathrm{C}$.

Figura 32 - Fração em massa das fases em função da temperatura para cada um dos materiais em estudo calculada com auxílio do software ThermoCalc $\AA$ e a base de dados TCFE8, destacando a faixa de temperatura em que a microestrutura é $100 \%$ austenítica

Figura 33 - Fusão e conformação dos lingotes do aço inoxidável AISI 316XL realizados no Centro de Pesquisa \& Desenvolvimento da Villares Metals. (a) Forno de Indução a Vácuo em escala piloto, VIM; (b) Lingotes de 50kg obtidos; (c) Tarugos forjados para quadrado de 80 mm; (d) Barras redondas laminadas de 15,87 mm de diâmetro.

Figura 34 - Microscópio ZEISS modelo Axiovert 200 MAT do Centro de Pesquisa \& Desenvolvimento da Villares Metals utilizado para caracterização microestrutural do material em estudo.

Figura 35 - Transformação das micrografias observadas em microscópio ótico com aumento de 500x em imagens binárias no software Image J 1.45s a fim de possibilitar o cálculo da fração de inclusões em cada um dos materiais.

Figura 36 - Microscópio eletrônico de varredura CAMSCAN CS3200LV do CDMatM-FEI utilizado na análise das inclusões das amostras solubilizadas.

Figura 37 - Método dos interceptos médios utilizado para avaliar o tamanho de grão da seção longitudinal das amostras com grades na horizontal (a) e vertical (b) para verificar a anisotropia dos grãos. Os pontos vermelhos delimitam os interceptos medidos nestes exemplos. 76 Figura 38 - Durômetro Wilson Hardness, modelo Wolpert UH930, do Centro de Pesquisa \& Desenvolvimento da Villares Metals utilizado para realização das medidas de dureza Brinell do material em estudo.

Figura 39 - (a) Instron modelo 30T do Centro de Pesquisa \& Desenvolvimento utilizada para obtenção dos resultados dos ensaios de tração do material estudado; (b) Corpos-de-prova usinados para os ensaios de tração dos materiais analisados; (c) Dimensões dos corpos-de-prova 2 5D [EM8] utilizados. 78

Figura 40 - Preparação das amostras utilizadas para os ensaios eletroquímicos. (a) corte das amostras; (b) amostras a serem embutidas; (c) embutimento em resina fenólica e furação para realização do contato elétrico; (d) conexão à haste metálica para contato elétrico. Figura 41 - Potenciostato AUTOLAB (PGSTAT 12) do CDMatM-FEI utilizado para realização dos ensaios eletroquímicos dos materiais em estudo.

Figura 42- Configuração da célula eletroquímica utilizada nos ensaios eletroquímicos, sendo que E.R. representa o eletrodo de referência $\mathrm{Ag} / \mathrm{AgCl}$, C.E. representa o contra-eletrodo 
fabricado com um fio de platina e E.T. representa o eletrodo de trabalho que corresponde à amostra analisada.

Figura 43 - Banho ultratermostático microprocessado com circulador da marca Quimis do CDMatM-FEI utilizado acoplado à célula eletroquímica encamisada para controle da temperatura dos ensaios eletroquímicos.

Figura 44 - Equipamentos utilizados para obtenção das curvas de temperatura crítica de pite no CDMatM-FEI: Potenciostato, Banho Ultratermostático, Célula Eletroquímica e Quantum X.

Figura 45 - Ensaio de Temperatura crítica de pite realizado em acordo com a norma ASTM G150 - 99 (2004) evidenciando que o potencial recomendado de $700 \mathrm{mV}$ não é adequado para os materiais analisados. (a) Curva Densidade de Corrente versus Temperatura; (b) Presença de pites na amostra imediatamente após o ensaio utilizando potencial de $700 \mathrm{mV}$ com 50x de aumento e (c) amostra levemente polida até diamante de $1 \mu \mathrm{m}$ 200x. 85

Figura 46- Micrografias da seção longitudinal das amostras brutas de laminação do aço inoxidável AISI 316XL (a) e (b) Material de Referência, corrida 1107046 (100\%at Mo), 100 e 500x de aumento, respectivamente; (c) e (d) Corrida 1107047 (25\%at W e 75\% at Mo), 100 e 500x de aumento, respectivamente; (e) e (f) Corrida 1107048 (50\%at W e 50\%at Mo), 100 e 500x de aumento, respectivamente; (g) e (h) Corrida 1107049 (75\%at W e 25\%at Mo), 100 e 500x de aumento, respectivamente; (i) e (j) Corrida 1107050 (100\%at W), atacado com Marble, 100 e 500x de aumento, respectivamente.

Figura 47 - Micrografias das amostras solubilizadas a $1100^{\circ} \mathrm{C}$ por $1 \mathrm{~h}$ e resfriadas em água atacadas eletroliticamente, $5 \mathrm{~V} / 20 \mathrm{~s}$, com solução de 60\% ácido nítrico e $40 \%$ água; (a) e (b) Material de Referência, corrida 1107046 (100\% Mo), 100 e 500x de aumento, respectivamente; (c) e (d) Corrida $1107047(25 \% \mathrm{~W}$ e $75 \% \mathrm{Mo}), 100$ e 500x de aumento, respectivamente; (e) e (f) Corrida $1107048(50 \% \mathrm{~W}$ e $50 \% \mathrm{Mo}), 100$ e 500x de aumento, respectivamente; (g) e (h) Corrida 1107049 (75\%W e 25\%Mo, 100 e 500x de aumento, respectivamente; (i) e (j) Corrida $1107050(100 \% \mathrm{~W}), 100$ e 500x de aumento, respectivamente.

Figura 48 - Micrografias das amostras solubilizadas a $1100^{\circ} \mathrm{C}$ por $1 \mathrm{~h}$ e resfriadas em água sem ataque; (a) e (b) Material de Referência, corrida 1107046 (100\% Mo), 100 e 500x de aumento, respectivamente; (c) e (d) Corrida 1107047 (25\%W e 75\%Mo), 100 e 500x de aumento, respectivamente; (e) e (f) Corrida 1107048 (50\%W e 50\%Mo), 100 e 500x de aumento, respectivamente; (g) e (h) Corrida 1107049 (75\%W e 25\%Mo, 100 e 500x de aumento, respectivamente; (i) e (j) Corrida $1107050(100 \% \mathrm{~W}), 100$ e 500x de aumento, respectivamente. 
Figura 49 - Resultados de fração em área de inclusões obtidas por análise de imagem de micrografias com aumento de 500x das amostras solubilizadas do aço inoxidável AISI 316XL variando-se o teor de Mo e W.

Figura 50 - Análise pontual típica das amostras solubilizadas do aço inoxidável AISI 316XL variando-se o teor de Mo e W obtida por MEV-EDS no microscópio CAMSCAN CS3200LV do CDMatM-FEI. Os detalhes referentes aos elementos presentes nos pontos 1, 2, 3 e 4 e seus respectivos teores encontram-se na Tabela 12.

Figura 51 - Espectros de EDS das inclusões analisadas na Figura 50 e composições mostradas na Tabela 12 .

Figura 52- Resultados de tamanho de grão obtidos pelo método dos interceptos médios da seção longitudinal das amostras solubilizadas do aço inoxidável AISI 316XL variando-se o teor de Mo e W com grades na vertical e longitudinal para verificar a anisotropia dos grãos.

Figura 53 - Intercepto médio de cada amostra, considerando as medidas em grades horizontais e verticais, e média global dos interceptos médios de todas as amostras. 101

Figura 54 - Dados obtidos de dureza Brinell das amostras solubilizadas do material em estudo.

Figura 55 - Resultados dos ensaios de tração das amostras solubilizadas obtidos pelos ensaios de tração. (a) Limite de resistência e limite à tração (LR) e limite de escoamento $0,2 \%$ (LE 0,2\%). (b) Redução em área (RA) e alongamento 5D........................................................ 104 Figura 56 - Curva típica de polarização cíclica do material que contém 0\% de W (c.1107046) em solução de $3,5 \%$ de $\mathrm{NaCl}$ e temperatura ambiente.

Figura 57 - Curva típica de polarização cíclica do material que contém 25\% de W (c.1107047) em solução de $3,5 \%$ de $\mathrm{NaCl}$ e temperatura ambiente.

Figura 58 - Curva típica de polarização cíclica do material que contém 50\% de W (c.1107048) em solução de $3,5 \%$ de $\mathrm{NaCl}$ e temperatura ambiente.

Figura 59 - Curva típica de polarização cíclica do material que contém 75\% de W (c.1107049) em solução de $3,5 \%$ de $\mathrm{NaCl}$ e temperatura ambiente.

Figura 60 - Curva típica de polarização cíclica do material que contém 100\% de W (c.1107050) em solução de $3,5 \%$ de $\mathrm{NaCl}$ e temperatura ambiente.

Figura 61 - Comparação entre as curvas de polarização cíclica em 3,5\% $\mathrm{NaCl}$ de todas as ligas solubilizadas apresentadas anteriormente, variando o teor atômico de $\mathrm{W}$ em cada uma delas em relação ao teor nominal de Mo na liga de referência $(0 \% \mathrm{~W})$. 
Figura 62 - Resultados de potencial de corrosão, $E_{\text {corr }}$ obtidos por meio das curvas de polarização cíclica em 3,5\% de $\mathrm{NaCl}$ das amostras solubilizadas, em função da porcentagem atômica de $\mathrm{W}$ em relação ao teor nominal de Mo presente na liga de referência $(0 \% \mathrm{~W}) \ldots 110$ Figura 63 - Resultados de potencial de pite, $\mathrm{E}_{\text {pite }}$ obtidos por meio das curvas de polarização cíclica em 3,5\% de $\mathrm{NaCl}$ das amostras solubilizadas, em função da porcentagem atômica de $\mathrm{W}$ em relação ao teor nominal de Mo presente na liga de referência $(0 \% \mathrm{~W})$......

Figura 64 - Resultados de temperatura crítica de pite (CPT) obtidos em solução de $1 \mathrm{M}$ de $\mathrm{NaCl}$ das amostras solubilizadas, em função da porcentagem atômica de $\mathrm{W}$ em relação ao teor nominal de Mo presente na liga de referência $(0 \% \mathrm{~W})$.

Figura 65 - Curva de polarização potenciodinâmica do aço inoxidável AISI 316L que contém $0 \% \mathrm{~W}$ (c.1107046) em solução de $0,5 \mathrm{M} \mathrm{H}_{2} \mathrm{SO}_{4}+0,01 \mathrm{M} \mathrm{KSCN}$ a $30^{\circ} \mathrm{C}$.

Figura 66 - Curva de polarização potenciodinâmica do aço inoxidável AISI 316L que contém $25 \% \mathrm{~W}$ (c.1107047) em solução de $0,5 \mathrm{M} \mathrm{H}_{2} \mathrm{SO}_{4}+0,01 \mathrm{M} \mathrm{KSCN}$ a $30^{\circ} \mathrm{C}$. 114

Figura 67 - Curva de polarização potenciodinâmica do aço inoxidável AISI 316L que contém $50 \%$ W (c.1107048) em solução de $0,5 \mathrm{M} \mathrm{H}_{2} \mathrm{SO}_{4}+0,01 \mathrm{M} \mathrm{KSCN}$ a $30^{\circ} \mathrm{C}$.

Figura 68 - Curva de polarização potenciodinâmica do aço inoxidável AISI 316L que contém $75 \% \mathrm{~W}$ (c.1107049) em solução de $0,5 \mathrm{M} \mathrm{H}_{2} \mathrm{SO}_{4}+0,01 \mathrm{M} \mathrm{KSCN}$ a $30^{\circ} \mathrm{C}$.

Figura 69 - Curva de polarização potenciodinâmica do aço inoxidável AISI 316L que contém $100 \% \mathrm{~W}$ (c.1107050) em solução de $0,5 \mathrm{M} \mathrm{H}_{2} \mathrm{SO}_{4}+0,01 \mathrm{M} \mathrm{KSCN}$ a $30^{\circ} \mathrm{C}$.

Figura 70 - Comparação entre as curvas de polarização potenciodinâmica em solução de $0,5 \mathrm{M}$ $\mathrm{H}_{2} \mathrm{SO}_{4}+0,01 \mathrm{M} \mathrm{KSCN}$ a $30^{\circ} \mathrm{C}$ de todas as ligas solubilizadas apresentadas anteriormente, variando o teor atômico de $\mathrm{W}$ em cada uma delas em relação ao teor nominal de Mo na liga de referência $(0 \% \mathrm{~W})$.

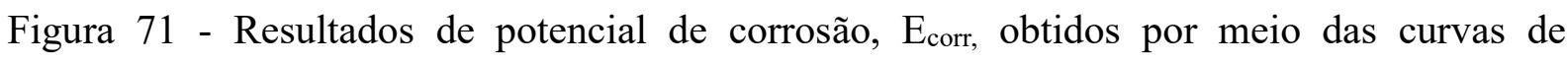
polarização potenciodinâmica em solução de $0,5 \mathrm{M} \mathrm{H}_{2} \mathrm{SO}_{4}+0,01 \mathrm{M} \mathrm{KSCN}$ a $30^{\circ} \mathrm{C}$ das amostras solubilizadas, em função da porcentagem atômica de $\mathrm{W}$ em relação ao teor nominal de Mo presente na liga de referência $(0 \% \mathrm{~W})$.

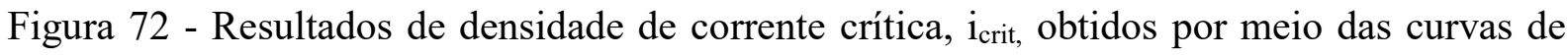
polarização potenciodinâmica em solução de $0,5 \mathrm{M} \mathrm{H}_{2} \mathrm{SO}_{4}+0,01 \mathrm{M} \mathrm{KSCN}$ a $30^{\circ} \mathrm{C}$ das amostras solubilizadas, em função da porcentagem atômica de $\mathrm{W}$ em relação ao teor nominal de Mo presente na liga de referência $(0 \% \mathrm{~W})$.

Figura 73 - Comparação entre as curvas de polarização potenciodinâmica em solução de $0,5 \mathrm{M}$ $\mathrm{H}_{2} \mathrm{SO}_{4}+0,01 \mathrm{M} \mathrm{KSCN}$ a $30^{\circ} \mathrm{C}$ de todas as ligas solubilizadas apresentadas anteriormente, 
variando o teor atômico de $\mathrm{W}$ em cada uma delas em relação ao teor nominal de Mo na liga de referência $(0 \% \mathrm{~W})$, destacando a variação da densidade de corrente crítica, $\mathrm{i}_{\text {crit. }}$.

Figura 74 - Resultados de potencial crítico, $\mathrm{E}_{\text {crit, }}$ obtidos por meio das curvas de polarização potenciodinâmica em solução de $0,5 \mathrm{M} \mathrm{H}_{2} \mathrm{SO}_{4}+0,01 \mathrm{M} \mathrm{KSCN}$ a $30^{\circ} \mathrm{C}$ das amostras solubilizadas, em função da porcentagem atômica de $\mathrm{W}$ em relação ao teor nominal de Mo xpresente na liga de referência $(0 \% \mathrm{~W})$. 120

Figura 75 - Resultados de densidade de corrente passiva, $i_{\text {pass, }}$ obtidos por meio das curvas de polarização potenciodinâmica em solução de $0,5 \mathrm{M} \mathrm{H}_{2} \mathrm{SO}_{4}+0,01 \mathrm{M} \mathrm{KSCN}$ a $30^{\circ} \mathrm{C}$ das amostras solubilizadas, em função da porcentagem atômica de $\mathrm{W}$ em relação ao teor nominal de Mo presente na liga de referência $(0 \% \mathrm{~W})$.

Figura 76 - Resultados obtidos de potencial crítico ( $\left.E_{\text {crit }}\right)$, densidade de corrente crítica (i $\left.\mathrm{i}_{\text {crit }}\right)$ e densidade de corrente passiva ( $i_{\text {pass }}$ ) obtidos nos ensaios de polarização potenciodinâmica em solução de $0,5 \mathrm{M} \mathrm{H}_{2} \mathrm{SO}_{4}+0,01 \mathrm{M} \mathrm{KSCN}$ a $30^{\circ} \mathrm{C}$ em função do teor atômico de Mo substituído por $\mathrm{W}$ destacando a liga para $50 \%$ de substituição.

Figura 77 - Curva típica de DL-EPR do material que contém 0\% de W (c.1107046) em solução de $0,5 \mathrm{M}$ de $\mathrm{H}_{2} \mathrm{SO}_{4}+0,01 \mathrm{M} \mathrm{KSCN}$ a $30^{\circ} \mathrm{C}$ destacando a densidade de corrente de ativação $\left(\mathrm{I}_{\mathrm{a}}\right)$ e a densidade de corrente de reativação $\left(I_{\mathrm{r}}\right)$.

Figura 78 - Curva típica de DL-EPR do material que contém 25\% de W (c.1107047) em solução de $0,5 \mathrm{M}$ de $\mathrm{H}_{2} \mathrm{SO}_{4}+0,01 \mathrm{M} \mathrm{KSCN}$ a $30^{\circ} \mathrm{C}$ destacando a densidade de corrente de ativação $\left(\mathrm{I}_{\mathrm{a}}\right)$ e a densidade de corrente de reativação $\left(I_{r}\right)$. 125

Figura 79 - Curva típica de DL-EPR do material que contém 50\% de W (c.1107048) em solução de $0,5 \mathrm{M}$ de $\mathrm{H}_{2} \mathrm{SO}_{4}+0,01 \mathrm{M} \mathrm{KSCN}$ a $30^{\circ} \mathrm{C}$ destacando a densidade de corrente de ativação $\left(\mathrm{I}_{\mathrm{a}}\right)$ e a densidade de corrente de reativação $\left(I_{r}\right)$.

Figura 80 - Curva típica de DL-EPR do material que contém 75\% de W (c.1107049) em solução de $0,5 \mathrm{M}$ de $\mathrm{H}_{2} \mathrm{SO}_{4}+0,01 \mathrm{M} \mathrm{KSCN}$ a $30^{\circ} \mathrm{C}$ destacando a densidade de corrente de ativação $\left(\mathrm{I}_{\mathrm{a}}\right)$ e a densidade de corrente de reativação $\left(I_{r}\right)$. 126

Figura 81 - Curva típica de DL-EPR do material que contém 100\% de W (c.1107050) em solução de $0,5 \mathrm{M}$ de $\mathrm{H}_{2} \mathrm{SO}_{4}+0,01 \mathrm{M} \mathrm{KSCN}$ a $30^{\circ} \mathrm{C}$ destacando a densidade de corrente de ativação $\left(\mathrm{I}_{\mathrm{a}}\right)$ e a densidade de corrente de reativação $\left(\mathrm{I}_{\mathrm{r}}\right)$. 126 Figura 82 - Comparação entre as curvas de DL-EPR em solução de $0,5 \mathrm{M} \mathrm{H}_{2} \mathrm{SO}_{4}+0,01 \mathrm{M} \mathrm{KSCN}$ a $30^{\circ} \mathrm{C}$ de todas as ligas solubilizadas apresentadas anteriormente, variando o teor atômico de W em cada uma delas em relação ao teor nominal de Mo na liga de referência. Figura 83 - Dados obtidos de grau de sensitização (\%DOS) obtidos por meio das curvas de DLEPR em solução de $0,5 \mathrm{M} \mathrm{H}_{2} \mathrm{SO}_{4}+0,01 \mathrm{M} \mathrm{KSCN}$ a $30^{\circ} \mathrm{C}$ das amostras solubilizadas, em função 
da porcentagem atômica de $\mathrm{W}$ em relação ao teor nominal de Mo presente na liga de referência. 


\section{LISTA DE TABELAS}

Tabela 1 - Composição química (\% wt) típica da liga AISI 316 .........................................22

Tabela 2 - Composição química (\%wt) das ligas estudadas por Oh et al. (1993). 53

Tabela 3 - Composições químicas (\%wt) do aço inoxidável súplex $25 \mathrm{Cr}$ estudados por Kim e Kwon. (1996) 56

Tabela 4 - Composições químicas (\%wt) do aço inoxidável Fe-29Cr estudadas por Ahn, Kwon e Lee (1998).

Tabela 5 - Propriedades elétricas e químicas dos principais elementos dos aços inoxidáveis. 62 Tabela 6 - Composição química (\%wt) dos aços Fe-29Cr estudados por Park et al. (2005)...62 Tabela 7 - Composição química (\%wt) do aço inoxidável austenítico AISI 317LMN estudado por Kim, Xiang e Kim (2005).

Tabela 8 - Composição desejada em teor em massa (\%wt) e atômico (\%at) dos materiais em estudo

Tabela 9 - Composição química final em teor de massa (\%wt) e atômico (\%at) obtida do aço inoxidável AISI 316L variando a proporção atômica entre Mo e W.

Tabela 10 - Tabela de Análise de Variância ou Tabela ANOVA.

Tabela 11 - Análise de variância dos dados obtidos de fração em área das inclusões dos materiais em estudo utilizando nível de significância de 0,05 .

Tabela 12 - Análise pontual (\%wt) das inclusões apresentadas na Figura 50 e espectros da Figura 51

Tabela 13- Análise de variância dos interceptos médios entre os grãos medidos na vertical e na horizontal do material de referência, corrida 1107046 (100\% Mo) utilizando nível de significância de 0,05 .

Tabela 14 - Análise de variância dos interceptos médios entre os grãos medidos na vertical e na horizontal da corrida 1107047 (75\% Mo e 25\%W) utilizando nível de significância de 0,05.

Tabela 15 - Análise de variância dos interceptos médios entre os grãos medidos na vertical e na horizontal corrida 1107048 (50\% Mo e 50\% W) utilizando nível de significância de 0,05. . 100 Tabela 16- Análise de variância dos interceptos médios entre os grãos medidos na vertical e na horizontal corrida 1107049 (25\% Mo e 75\% W) utilizando nível de significância de 0,05. . 100 Tabela 17 - Análise de variância dos interceptos médios entre os grãos medidos na vertical e na horizontal corrida $1107050(100 \%$ W) utilizando nível de significância de 0,05. 101 
Tabela 18 - Análise de variância dos dados obtidos de intercepto médio dos grãos dos materiais em estudo utilizando nível de significância de 0,05

Tabela 19 - Análise de variância dos dados obtidos de dureza Brinel dos materiais em estudo utilizando nível de significância de 0,05 .

Tabela 20 - Análise de variância dos dados de Limite de Resistência à tração (LR) obtidos por meio de ensaios de tração dos materiais em estudo utilizando nível de significância de 0,05.

Tabela 21 - Análise de variância dos dados de Limite de Escoamento a 0,2\% (LE 0,2\%) obtidos por meio de ensaios de tração dos materiais em estudo utilizando nível de significância de 0,05.

Tabela 22 - Análise de variância dos dados de Redução em Área (RA) obtidos por meio de ensaios de tração dos materiais em estudo utilizando nível de significância de 0,05. 105

Tabela 23 - Análise de variância dos dados de Alongamento 5D obtidos por meio de ensaios de tração dos materiais em estudo utilizando nível de significância de 0,05 105

Tabela 24 - Análise de variância dos dados de potencial de corrosão obtidos por ensaios de polarização cíclica em solução de $3,5 \% \mathrm{NaCl}$ a temperatura ambiente utilizando nível de significância de 0,05 .

Tabela 25 - Análise de variância dos dados de potencial de pite obtidos por ensaios de polarização cíclica em solução de $3,5 \% \mathrm{NaCl}$ a temperatura ambiente utilizando nível de significância de 0,05 .

Tabela 26 - Análise de variância dos dados de temperatura crítica de pite (CPT) em solução de $1 \mathrm{M}$ de $\mathrm{NaCl}$ utilizando nível de significância de 0,05 .

Tabela 27 - Análise de variância dos dados de potencial de corrosão ( $\mathrm{E}_{\text {corr }}$ ) obtidos por meio do ensaios de polarização potenciodinâmica em solução de $0,5 \mathrm{M} \mathrm{H}_{2} \mathrm{SO}_{4}+0,01 \mathrm{M} \mathrm{KSCN}$ a $30^{\circ} \mathrm{C}$ utilizando nível de significância de 0,05 .

Tabela 28 - Análise de variância dos dados de densidade de corrente crítica ( $\mathrm{i}_{\text {crit }}$ ) obtidos por meio do ensaios de polarização potenciodinâmica em solução de $0,5 \mathrm{M} \mathrm{H}_{2} \mathrm{SO}_{4}+0,01 \mathrm{M} \mathrm{KSCN}$ a $30^{\circ} \mathrm{C}$ utilizando nível de significância de 0,05 .

Tabela 29 - Análise de variância dos dados de potencial crítico ( $\left.\mathrm{E}_{\text {crit }}\right)$ obtidos por meio do ensaios de polarização potenciodinâmica em solução de $0,5 \mathrm{M} \mathrm{H}_{2} \mathrm{SO}_{4}+0,01 \mathrm{M} \mathrm{KSCN} \mathrm{a} 30^{\circ} \mathrm{C}$ utilizando nível de significância de 0,05 .

Tabela 30 - Análise de variância dos dados de densidade de corrente passiva ( $\mathrm{i}_{\text {pass }}$ ) obtidos por meio do ensaios de polarização potenciodinâmica em solução de $0,5 \mathrm{M} \mathrm{H}_{2} \mathrm{SO}_{4}+0,01 \mathrm{M} \mathrm{KSCN}$ a $30^{\circ} \mathrm{C}$ utilizando nível de significância de 0,05 . 
Tabela 31 - Correlação entre o valor de $\mathrm{I}_{\mathrm{r}} / \mathrm{I}_{\mathrm{a}}$ e o grau de sensitização de acordo com a norma

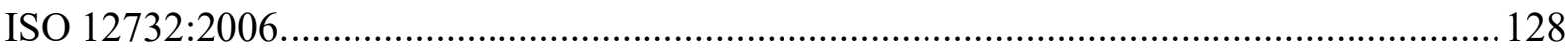

Tabela 32 - Análise de variância dos dados de grau de sensitização (\%) obtidos por meio do ensaios DL-EPR em solução de $0,5 \mathrm{M} \mathrm{H}_{2} \mathrm{SO}_{4}+0,01 \mathrm{M} \mathrm{KSCN}$ a $30^{\circ} \mathrm{C}$ utilizando nível de significância de 0,05 . 


\section{SUMÁRIO}

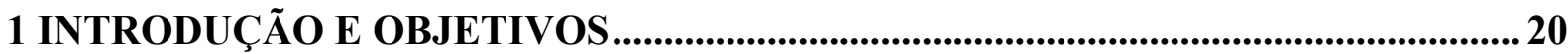

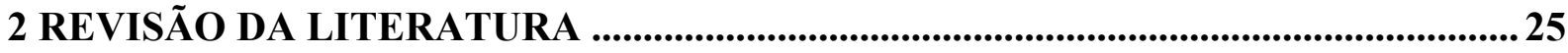

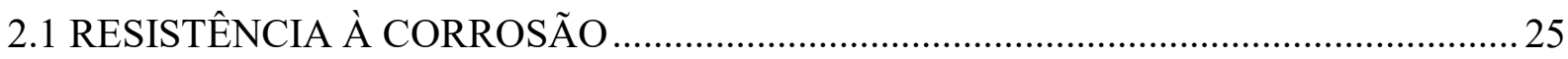

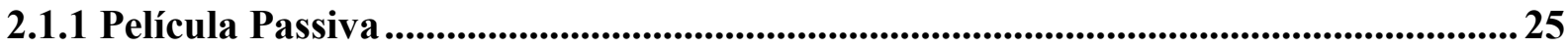

2.1.2 Sensitização ..........................................................................................................................30

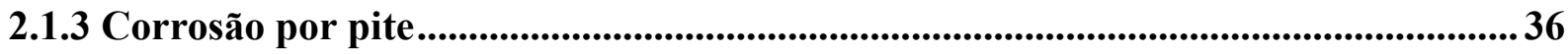

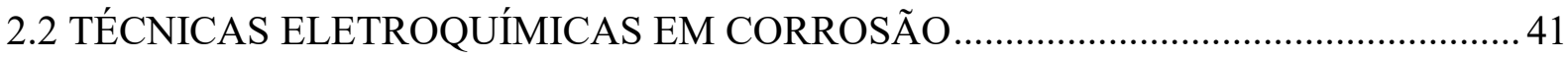

2.2.1 Polarização Potenciodinâmica ..................................................................................... 42

2.2.2 Polarização Cíclica ...................................................................................................... 45

2.2.3 Temperatura crítica de pite ..........................................................................48

2.2.4 Técnica Eletroquímica de Reativação Potenciodinâmica de Ciclo Duplo (DL-

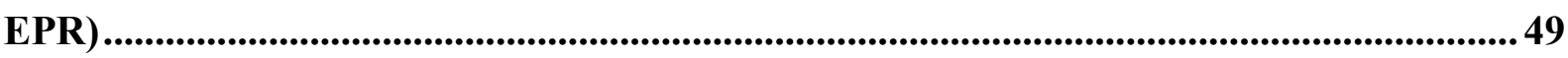

2.3 SUBSTITUIÇÃO DE MOLIBDÊNIO POR TUNGSTÊNIO .................................... 52

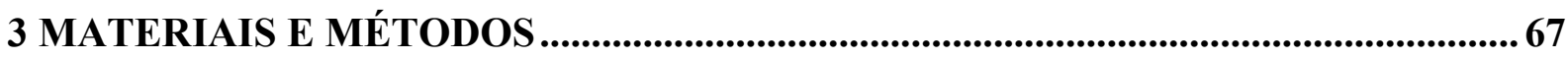

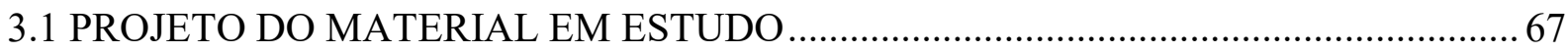

3.2 FUSÃO E CONFORMAÇÃO MECÂNICA DO MATERIAL EM ESTUDO .................. 68

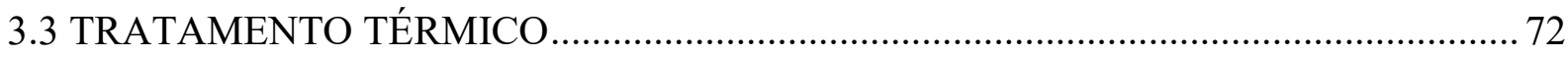

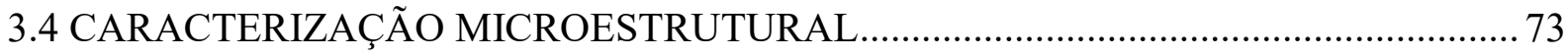

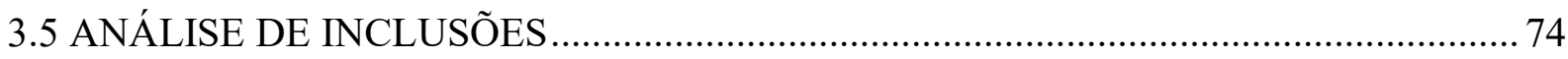

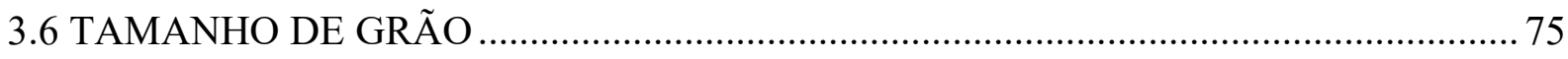

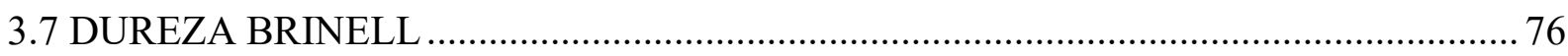

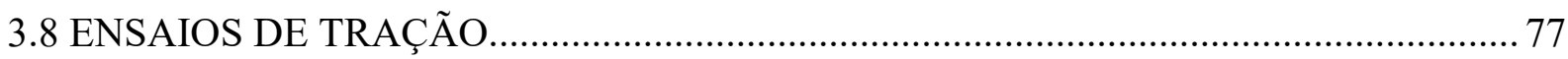

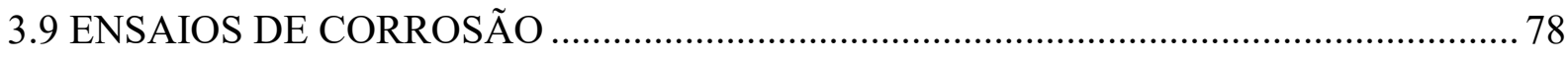

3.9.1 Polarização Potenciodinâmica ...................................................................................................... 81

3.9.2 Técnica Eletroquímica de Reativação Potenciodinâmica de Ciclo Duplo (DL-

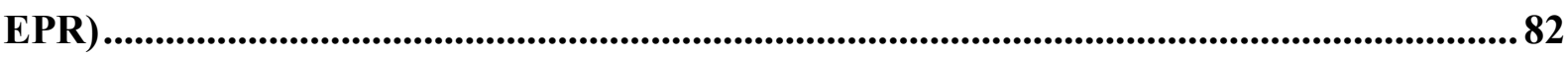

3.9.3 Polarização Cíclica ................................................................................................................ 83 


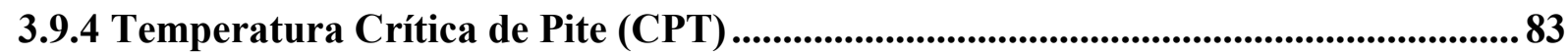

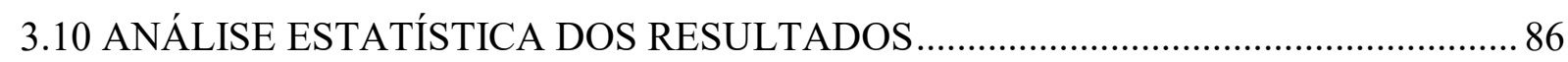

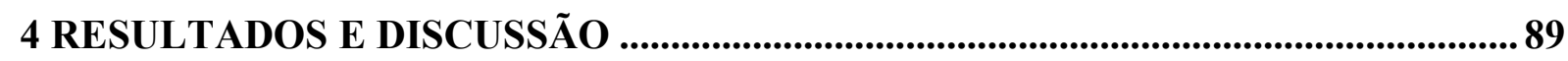

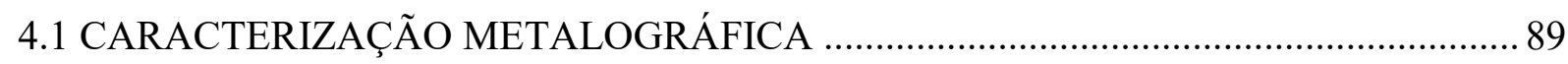

4.1.1 Amostras Brutas de Laminação ......................................................................... 89

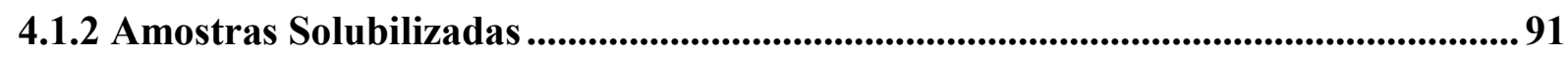

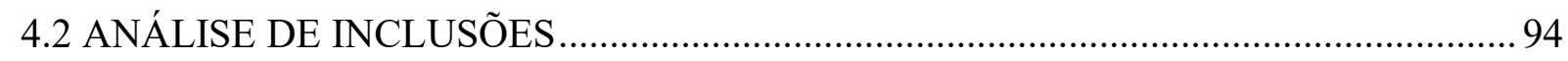

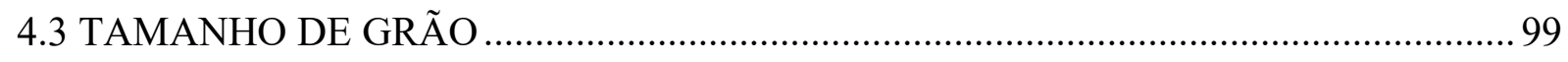

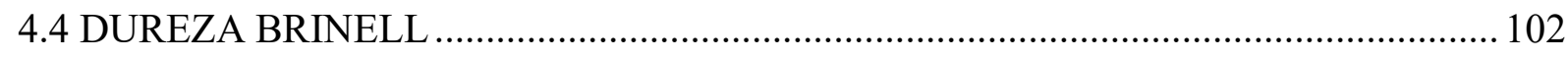

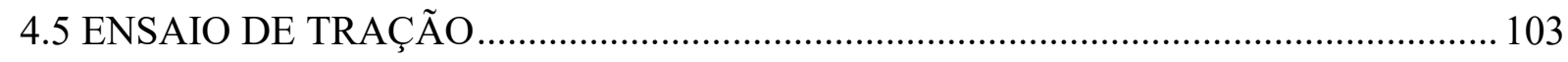

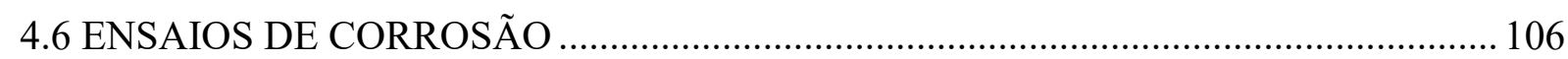

4.6.1 Polarização Cíclica .............................................................................................................. 106

4.6.2 Temperatura Crítica de Pite (CPT) ................................................................. 111

4.6.3 Polarização Potenciodinâmica ............................................................................. 113

4.6.4 Técnica Eletroquímica de Reativação Potenciodinâmica de Ciclo Duplo (DL-

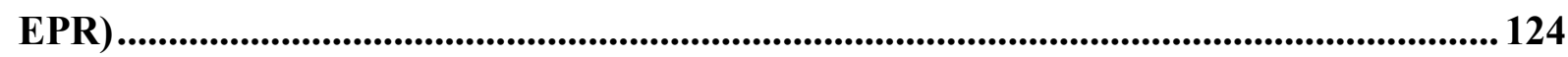

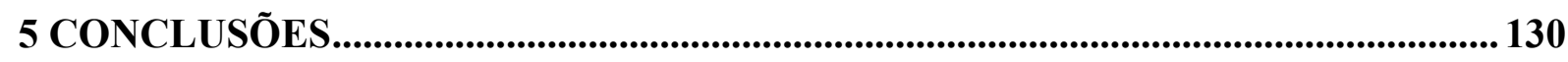

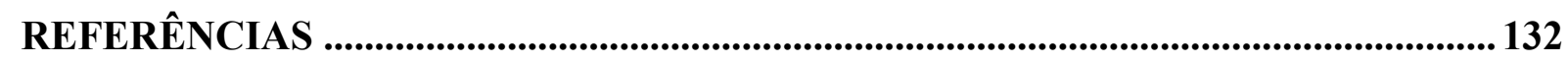




\section{INTRODUÇÃO E OBJETIVOS}

Aços inoxidáveis são ligas a base de ferro que contêm no mínimo aproximadamente $11 \%$ de Cr em solução sólida, teor necessário para evitar a oxidação em atmosferas poluídas, como mostrado na Figura 1 (SEDRIKS, 1979). Esses materiais atingem suas características inoxidáveis por meio da formação de uma invisível, aderente, não porosa e auto-regerativa camada composta por cromo e oxigênio na superfície que os protegem contra a corrosão em meios atmosféricos, aquosos ou orgânicos, chamada de película passiva.

Figura 1 - Influência do Cromo na corrosão atmosférica de um aço baixo carbono.

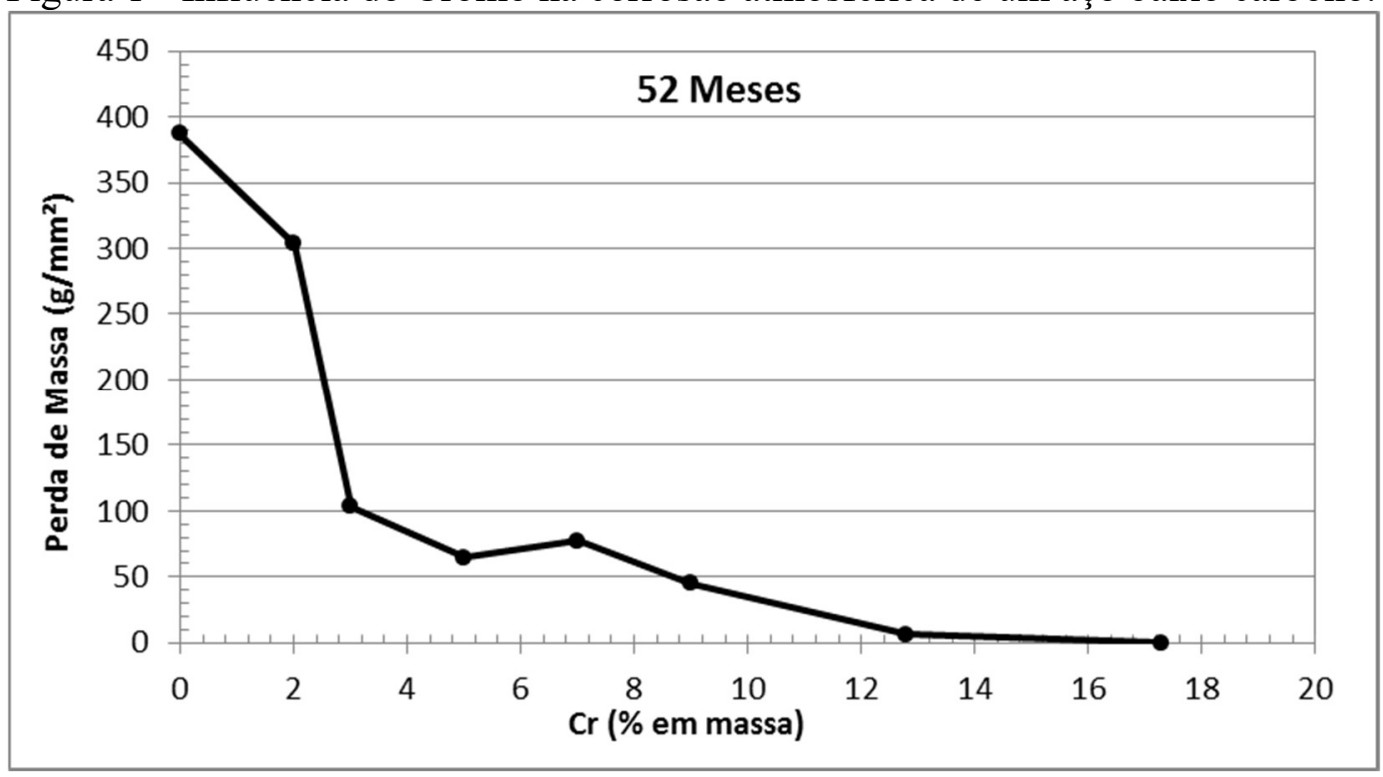

Fonte: Autor “adaptado de" Sedriks, 1979.

Outros elementos, como níquel, molibdênio, cobre, titânio, alumínio, silício, nióbio, nitrogênio e enxofre, são adicionados a fim de melhorar outras propriedades. Já o teor de carbono varia de menos de $0,03 \%$ até quantidades maiores que $1,0 \%$ em alguns aços martensíticos. A Figura 2 apresenta um resumo da família dos aços inoxidáveis em termos de propriedades e composições (AMERICAN SOCIETY FOR METALS, 1999). 
Figura 2 - Relação entre propriedades e composições na família dos aços inoxidáveis.

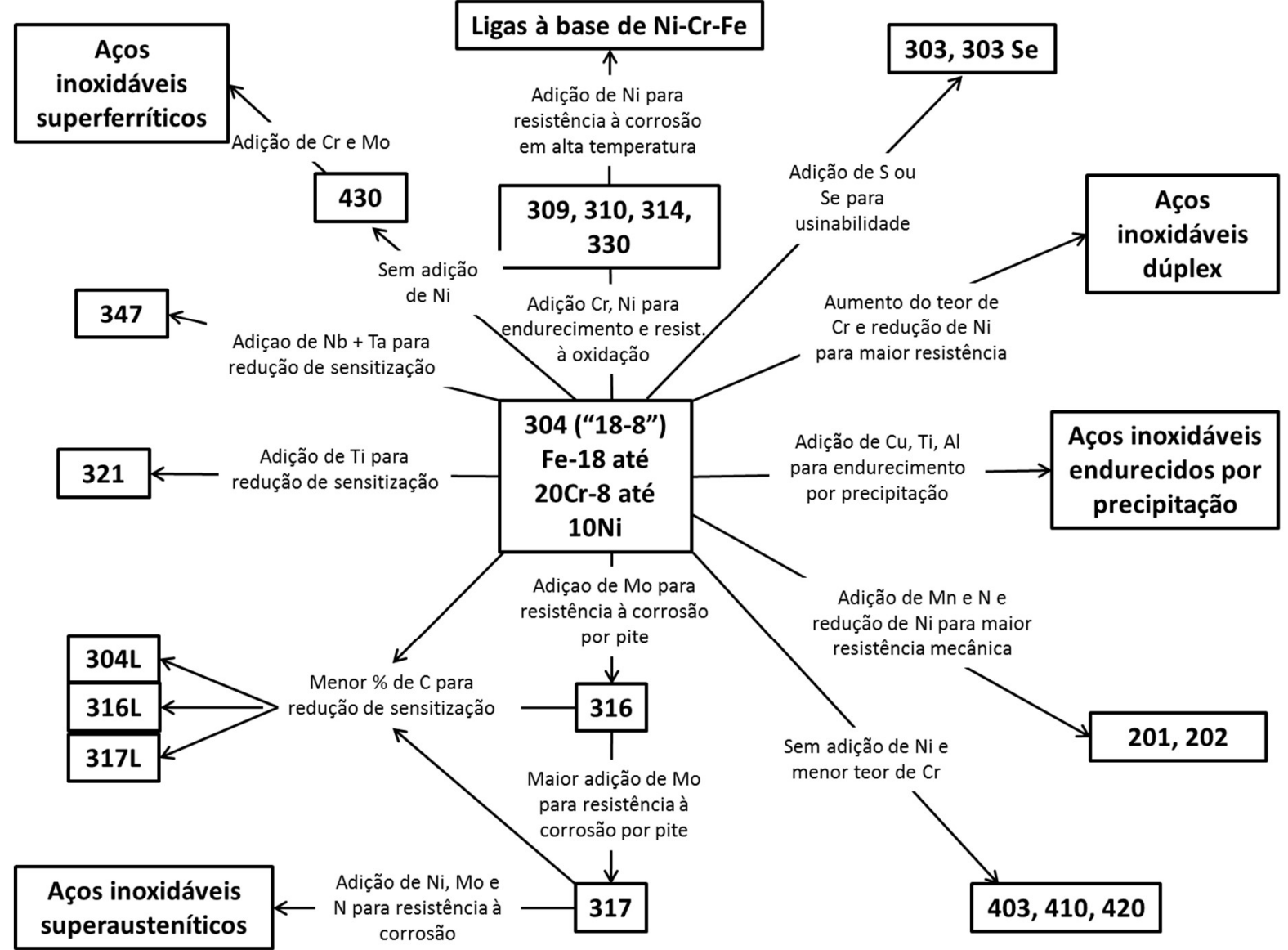

Fonte: Autor "adaptado de” DAVIS, J. R., 1999.

Em 1912, as duas primeiras patentes de aços inoxidáveis foram depositadas pela empresa Krupp Stahl na Alemanha, sendo que uma delas representava um aço inoxidável austenítico precursor daquele que hoje é conhecido como o tipo 304. Hoje, os dois principais aços inoxidáveis austeníticos, 304 e 316, representam 70\% do mercado total de aço inoxidável do mundo. Nenhuma outra classe de aços inoxidáveis pode ser utilizada num intervalo tão grande de temperaturas quanto os austeníticos, já que esta classe mantém sua tenacidade em temperaturas criogênicas e também boa parte de sua resistência mecânica em temperaturas elevadas, até cerca de $1000^{\circ} \mathrm{C}$, em que a resistência a deformação por fluência é o principal requisito necessário do material. Assim, desde o surgimento da primeira patente em 1912 até os dias de hoje, esta classe de aço é largamente utilizada em diversos segmentos industriais, sendo essencial ao desenvolvimento tecnológico devido à sua boa combinação entre resistência mecânica, ductilidade e sua característica única de resistência à corrosão até mesmo em altas temperaturas. A Figura 3 apresenta o aumento contínuo na produção de aços inoxidáveis desde 1950, demonstrando a importância desta classe de materiais (NILSSON, 2017); (OUTOKUMPU STAINLESS AB, 2013). 
Figura 3 - Crescimento mundial da produção de aços inoxidáveis (em Mton) entre o período de 1950 e 2015.

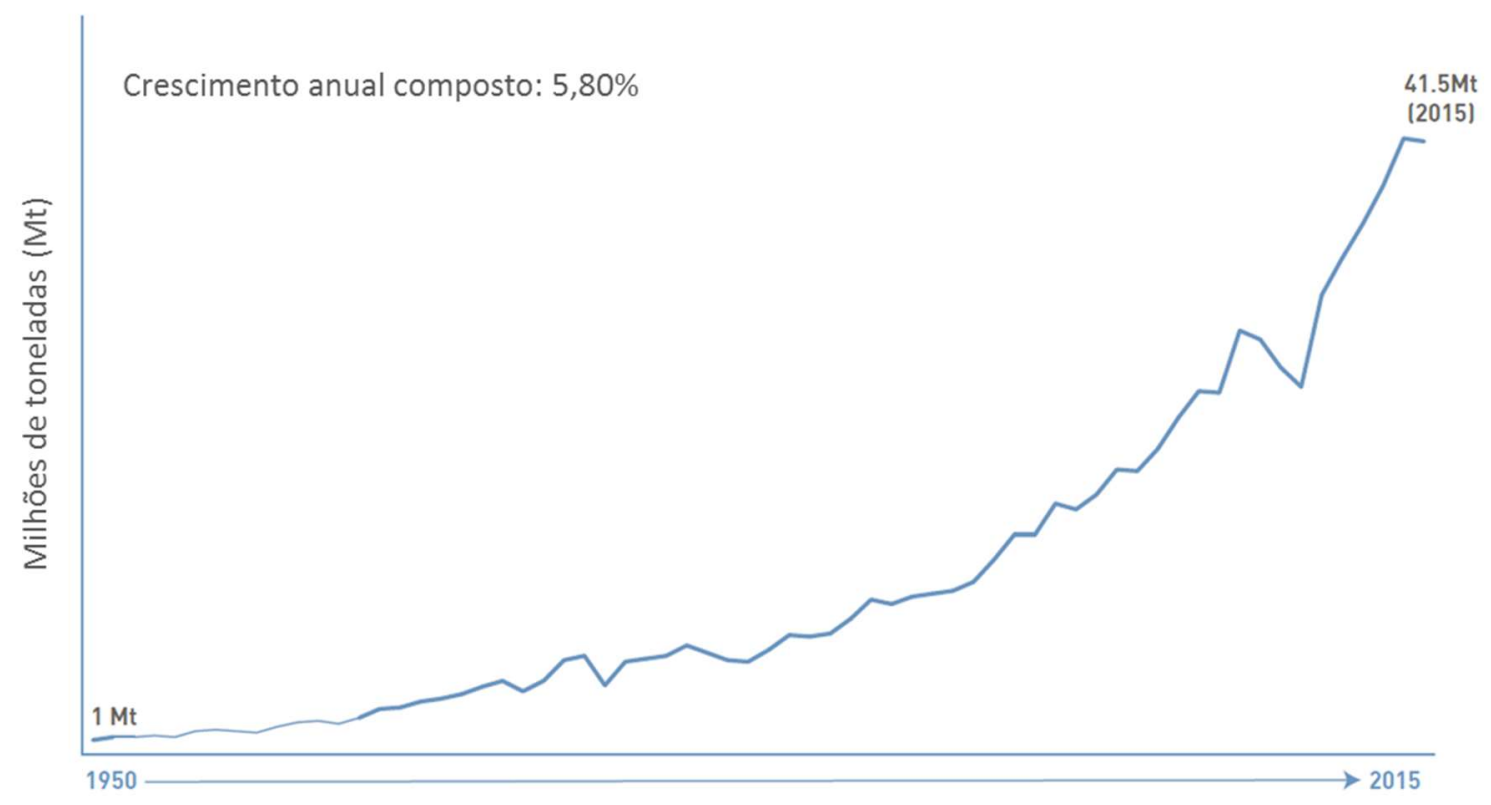

Fonte: Autor “adaptado de” International Stainless Steel Forum, 2016.

Conforme dito anteriormente, o aço inoxidável AISI 316 é o segundo mais popular aço inoxidável após o AISI 304, e ambos fazem parte da série 300, que engloba um grupo de ligas cromo-níquel austeníticas. Os aços inoxidáveis austeníticos como o AISI 316 são amplamente disponíveis, têm boa resistência geral à corrosão, boa tenacidade, excelente conformabilidade e soldabilidade. A principal diferença entre o AISI 304 e AISI 316 está na adição de 2 a 3\% de Molibdênio (Mo) na composição química deste último (Tabela 1) que promove um aumento da resistência à corrosão por pite em relação ao primeiro. Assim, o aço AISI 316 tornou-se um material adequado para utilização em ambientes de águas salgadas, sendo muitas vezes referido como inoxidável "tipo naval" devido à sua maior resistência à corrosão por cloreto promovida pela adição de Molibdênio, comparado ao aço AISI 304 (PARK, AHN e KWON, 2006).

Tabela 1 - Composição química (\% wt) típica da liga AISI 316.

\begin{tabular}{c|c|c|c|c|c|c|c}
\hline $\mathbf{C}$ & $\mathbf{S i}$ & $\mathbf{M n}$ & $\mathbf{P}$ & $\mathbf{S}$ & $\mathbf{C r}$ & $\mathbf{M o}$ & $\mathbf{N i}$ \\
\hline 0,08 & 1,00 & 2,00 & 0,045 & 0,030 & $16,0-18,0$ & $2,00-3,00$ & $10,0-14.0$ \\
\hline
\end{tabular}

Fonte: American Society for Metals, 1999.

Alguns estudos mostram que a substituição total ou parcial do molibdênio por tungstênio $(\mathrm{W})$ em aços inoxidáveis ferríticos e dúplex não só aumenta a resistência à corrosão localizada dessas ligas por meio de um efeito sinérgico destes elementos, como também influencia fortemente a formação de algumas fases, como a fase $\sigma$ (GOETZ, BOBAND e 
LANDOLT, 1981); (OKAMOTO, 1992); (OH, et al., 1993); (OKAMOTO, et al., 1994); (AHN, KWON e LEE, 1998); (KIM, et al., 1998); (KIM e KWON, 1999); (PARK e KWON, 2002); (KIM, XIANG e KIM, 2005); (PARK, AHN e KWON, 2006); (JEON, et al., 2012); (HAUGAN, et al., 2017). Isso ocorre pois ambos, Mo e W, são fortes formadores de ferrita, estão na mesma coluna da Tabela Periódica e, consequentemente, apresentam propriedades físico-químicas similares. Algumas ligas já patenteadas como o aço inoxidável dúplex japonês DP-3W da Nippon Steel \& Sumitomo Metal e o britânico Zeron 100 (UNS S32760, WNr 1.4501) da Rolled alloys apresentam teor máximo de tungstênio 2,5 e 1\%, respectivamente, e dentre suas principais propriedades encontram-se a alta resistência à corrosão por pite em temperaturas de até $80^{\circ} \mathrm{C}$ (NIPPON STEEL \& SUMITOMO METAL CORPORATION, 2013); (ROLLED ALLOYS INC., 2017).

Haugan et. al. (2017) destaca que ainda há muito debate na comunidade de Óleo e Gás da Noruega e nos comitês de normatização da ISO (“International Organization for Standardization") sobre a inclusão dos efeitos do W nas propriedades de corrosão por pite nas próximas revisões das especificações presentes na NORSOK M-001 para este setor, pois enquanto o comitê da ISO já inclui o W no cálculo do PREN, a NORSOK ainda é resistente à esta inclusão. Segundo os autores, os oponentes à inclusão do W argumentam que as siderúrgicas poderão adicionar o $\mathrm{W}$ ao invés de $\mathrm{Cr}$ e Mo a fim de aumentar o valor do PREN do material a fim de cumprir a especificação, criando dúvidas em relação à resistência à corrosão do material em água do mar. Porém, os autores reforçam que este raciocínio é duvidoso uma vez que o W seria mais caro que o Mo e Cr. Portanto, as adições de tungstênio seriam intencionais visando o aumento das propriedades de resistência à corrosão do material, em vez de uma mera estratégia de redução de custos por parte das siderúrgicas (HAUGAN, et al., 2017).

Porém estas substituições podem, de fato, estar fortemente relacionadas ao preço de mercado de cada um destes elementos de liga, dependendo do momento econômico, das relações comerciais entre os países detentores das jazidas e da facilidade geográfica associada ao transporte dessa matéria-prima. As jazidas de molibdênio estão localizadas principalmente na China (56\%), Estados Unidos da América (18\%) e Chile (12\%). Consequentemente, a produção de molibdênio metálico é liderada por estes três países, sendo que a China é responsável por 40,3\% da produção mundial anual, o Chile por 23,3\% e os Estados Unidos por 14,1\%. Já as jazidas de Tungstênio estão predominantemente localizadas na China (60,5\%) e a produção anual de tungstênio metálico é majoritariamente liderada por este país, 81,5\%. Assim, países que apresentam relações comerciais mais estreitas com estes países serão fortemente 
influenciados pelos preços das matérias-primas para produção do aço (U.S. GEOLOGICAL SURVEY, 2016); (U.S. MINERAL SURVEY, 2016).

A literatura mostra que, de fato, países asiáticos como Japão e Coréia do Sul apresentam bastante interesse no tungstênio, já que grande parte dos trabalhos encontrados na literatura sobre a investigação dos efeitos deste elemento de liga nos aços inoxidáveis são oriundos destes países (AHN, KWON e LEE, 1998) (JEON, et al., 2012) (KIM, XIANG e KIM, 2005) (KIM e KWON, 1999) (KIM, et al., 1998) (OH, et al., 1993) (OKAMOTO, 1992) (OKAMOTO, et al., 1994) (PARK e KWON, 2002) (PARK, AHN e KWON, 2006) (JEON, et al., 2012). Então, não se sabe ao certo se este interesse pelo tungstênio estaria associado a seu efeito benéfico como elemento de liga ou se as condições comerciais favoráveis a este produto despertaram o interesse desses países.

Além disso, indústrias siderúrgicas que atuam no segmento de aços inoxidáveis e, ao mesmo tempo, de aços ferramenta (como a Villares Metals S.A.) têm interesse particular no reaproveitamento de sucatas oriundas do processo de produção interno. Assim, caso sejam apresentadas evidências suficientes de que o Mo e o W atuam de maneira similar no mecanismo de corrosão desses materiais, a utilização de sucatas de aço ferramenta ricas em W pode ser possível na fabricação de aços inoxidáveis.

Diante disso, este trabalho tem como objetivo estudar o efeito da substituição parcial ou total do Mo por W no aço inoxidável AISI 316XL em suas propriedades mecânicas e, principalmente, suas propriedades de corrosão, particularmente corrosão por pite. 


\section{REVISÃO DA LITERATURA}

A revisão da literatura apresentada a seguir engloba o estudo da resistência à corrosão em relação à película passiva formada nos aços inoxidáveis, assim como os conceitos de sensitização e corrosão por pite dessa classe de materiais. São descritas também as técnicas eletroquímicas estudadas e os resultados já encontrados na literatura para a substituição parcial e total do Mo por W em aços inoxidáveis.

\subsection{RESISTÊNCIA À CORROSÃO}

Pode-se definir corrosão metálica como a deterioração de um metal por ação química ou eletroquímica do meio ambiente aliada ou não a esforços mecânicos. Esta deterioração causada pela interação físico-química entre o metal e o meio causa alterações prejudiciais ao metal como desgaste, variações químicas e modificações estruturais, tornando-o inadequado para o uso. As sérias consequências do processo de corrosão são um problema bastante significativo em todo o mundo, uma vez que esta forma de degradação pode causar desperdício de recursos valiosos, perda ou contaminação de produtos, redução em eficiência, custos de manutenção e superdimensionamento dos componentes. Sendo assim, é muito importante o reconhecimento e a compreensão dos mecanismos de corrosão para que a resistência à corrosão dos materiais metálicos seja um fator decisivo no projeto e dimensionamentos de componentes, máquinas e equipamentos de forma adequada e segura (GENTIL, 1996); (ROBERGE, 1999).

Em geral, a resistência à corrosão dos aços inoxidáveis é definida por sua capacidade de passivação e também pela habilidade de permanecer neste estado passivo no ambiente agressivo a que são submetidos. Assim, essas propriedades de corrosão não são apenas determinadas pela composição química destes aços, mas também por uma série de outros fatores como tamanho de grão, distribuição de inclusões, precipitação de fases intermetálicas, acabamento, presença de frestas, interfaces e soldas, entre outros (NICHOLLS, 1994).

\subsubsection{Película Passiva}

Os aços inoxidáveis podem ser drasticamente modificados pela adição ou remoção de elementos de liga, pois a composição e as propriedades da película passiva que promovem a resistência à corrosão desses materiais dependem fortemente da composição da liga. Muitas investigações têm contribuído para o entendimento do processo que governa a formação, o 
crescimento e a quebra dessa película, em função de sua composição e do ambiente a que o material é submetido (OLSSON e LANDOLT, 2003).

Essa película resistente à corrosão é formada durante a exposição do metal passivado a ambientes corrosivos, sendo que sua composição e espessura dependem do ambiente a que são expostos, ou seja, do potencial, do $\mathrm{pH}$, da temperatura, da presença de haletos, entre outros. Uma vez que a película é formada, a taxa de reação entre o metal e o ambiente é drasticamente reduzida. Assim, as propriedades dinâmicas da película passiva tornam-se a chave para o alcance de uma alta resistência à corrosão em ambientes agressivos (OLSSON e LANDOLT, 2003).

Segundo Olsson e Landolt (2003), a espessura da película passiva em aços inoxidáveis cresce linearmente com aumento do potencial. Mas a taxa de espessamento desta película em soluções básicas é maior que a taxa observada para o mesmo material em soluções ácidas. Segundo estes autores, a composição química do filme também varia de acordo com o potencial (OLSSON e LANDOLT, 2003). Para ligas $\mathrm{Fe}-\mathrm{Cr}$, o enriquecimento de $\mathrm{Cr}$ no filme ocorre na região passiva de baixo potencial, formando $\mathrm{Cr}_{2} \mathrm{O}_{3}$, já que na região passiva de altos potenciais a estabilidade do Fe ultrapassa a estabilidade do $\mathrm{Cr}$, predominando a presença de $\mathrm{Fe}_{2} \mathrm{O}_{3}$, conforme mostrado no diagrama de Pourbaix para as ligas Fe-Cr na Figura 4, que correspondem às condições teóricas de imunidade e passivação do sistema $\mathrm{Fe}-\mathrm{Cr}-\mathrm{H}_{2} \mathrm{O}$. Assim, as ligas $\mathrm{Fe}-\mathrm{Cr}$ são estáveis em potenciais mais altos que o $\mathrm{Cr}$ puro e também em faixas de $\mathrm{pH}$ em que o $\mathrm{Fe}$ puro não é estável. Este intervalo incrementado pelo cromo nas ligas de Fe é mostrado pelo trecho verde na Figura 4. 
Figura 4 - Diagrama de Pourbaix para ligas $\mathrm{Fe}-\mathrm{Cr}$, destacando o trecho passivo incrementado pelo $\mathrm{Cr}$ em ligas de $\mathrm{Fe}$.

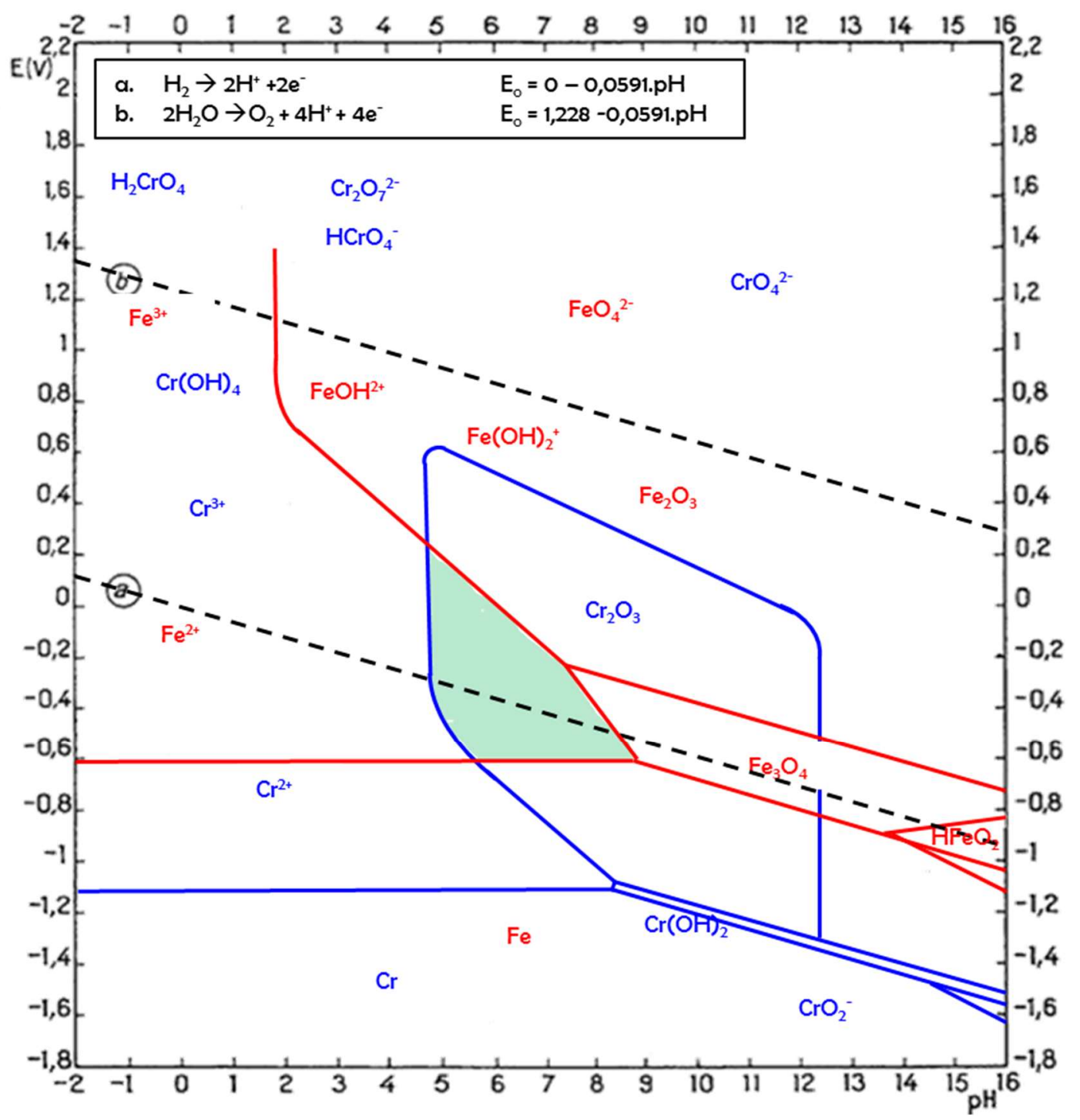

Fonte: Autor "adaptado de" Pourbaix, 1974.

Outro parâmetro apontado pelos autores que influencia a dissolução da película passiva é o pH (OLSSON e LANDOLT, 2003). Segundo eles, o aumento do pH provoca uma redução na taxa de dissolução deste filme e, consequentemente, uma película mais espessa, já que os óxidos de ferro são mais estáveis em soluções básicas. Já o aumento da temperatura não provoca grandes diferenças na composição e espessura destas películas. Jin e Atrens (1988) estudaram o efeito da temperatura na película passiva em aços inoxidáveis utilizando a técnica XPS (" $X$ ray Photoelectron Spectroscopy", Espectroscopia de Fotoelétrons Excitados por Raios-X). Os autores não observaram diferenças na composição e espessura das películas passivas à temperatura ambiente e a $90^{\circ} \mathrm{C}$ numa solução de $0,5 \mathrm{M}$ de $\mathrm{NaCl}$ (JIN e ATRENS, 1988). Já Mischler et al. (1991) notaram que a espessura das películas formadas em ligas Fe-Cr-Mo 
aumentaram ligeiramente a $65^{\circ} \mathrm{C}$ comparada à temperatura ambiente (MISCHLER, et al., 1991). Por outro lado, a presença de heterogeneidades na microestrutura como inclusões e segregações podem causar defeitos na película passiva e provocar a ocorrência de processos de corrosão localizada, como pites e frestas (OLSSON e LANDOLT, 2003).

A adição de Mo em aços inoxidáveis beneficia fortemente a resistência à corrosão por pite. O molibdênio puro não apresenta a formação de uma camada passiva, mas quando usado como elemento de liga em aços inoxidáveis, é incorporado no filme passivo gerado pelo cromo por meio de diferentes estados de oxidação. Um estudo de Olsson e Hornstrom (1994) mostra que a superfície do filme em aços inoxidáveis é enriquecida em Mo hexavalente, enquanto que os estados tetravalentes são encontrados ao longo do filme (OLSSON e HORNSTROM, 1994). Já o tungstênio apresenta propriedades muito semelhantes ao molibdênio como elemento de liga, mas uma diferença importante entre esses dois elementos está relacionada à estabilidade de seus óxidos em soluções ácidas. De acordo com o Diagrama de Pourbaix do W apresentado na Figura 5 (a), em soluções neutras e ácidas ( $\mathrm{pH}$ abaixo de 7,0), a estabilidade do óxido de tungstênio $\left(\mathrm{WO}_{3}\right)$ se estende desde potenciais próximos ao de evolução de hidrogênio até potenciais anódicos de várias dezenas de volts. Por outro lado, o Diagrama de Pourbaix do Mo Figura 5 (b) mostra que o Mo hexavalente é dissolvido em potenciais abaixo do potencial de evolução do oxigênio em soluções ácidas. Desta maneira, a maior proteção promovida pelo tungstênio em certos meios quando comparada à proteção promovida pelo Mo pode estar relacionada à formação de $\mathrm{WO}_{3}$ em baixos potenciais, uma vez que o óxido $\mathrm{MoO}_{3}$ é estável apenas em potenciais mais altos (OLSSON e LANDOLT, 2003); (DI PAOLA, DI QUARTO e SERRAVALLE, 1975); (POURBAIX, 1974). 
Figura 5 - Diagrama de Pourbaix a $25^{\circ} \mathrm{C}$ para o sistema (a) $\mathrm{W}-\mathrm{H}_{2} \mathrm{O}$; (b) $\mathrm{Mo}-\mathrm{H}_{2} \mathrm{O}$.

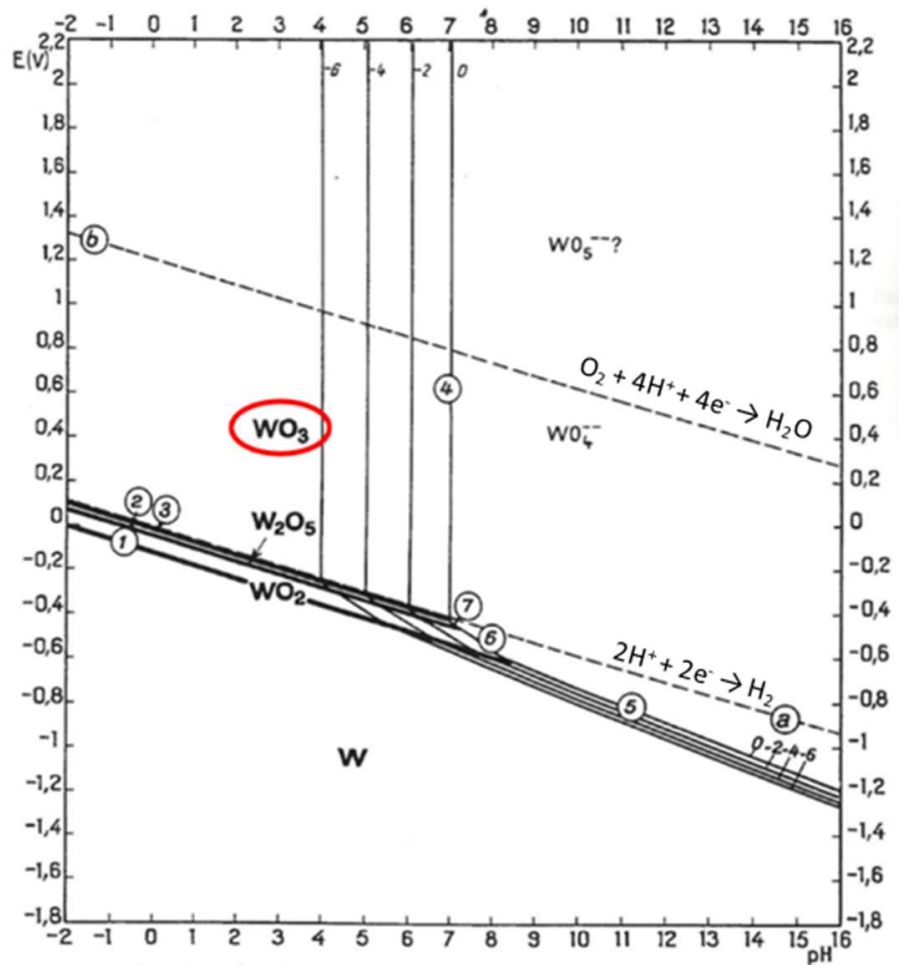

(a)

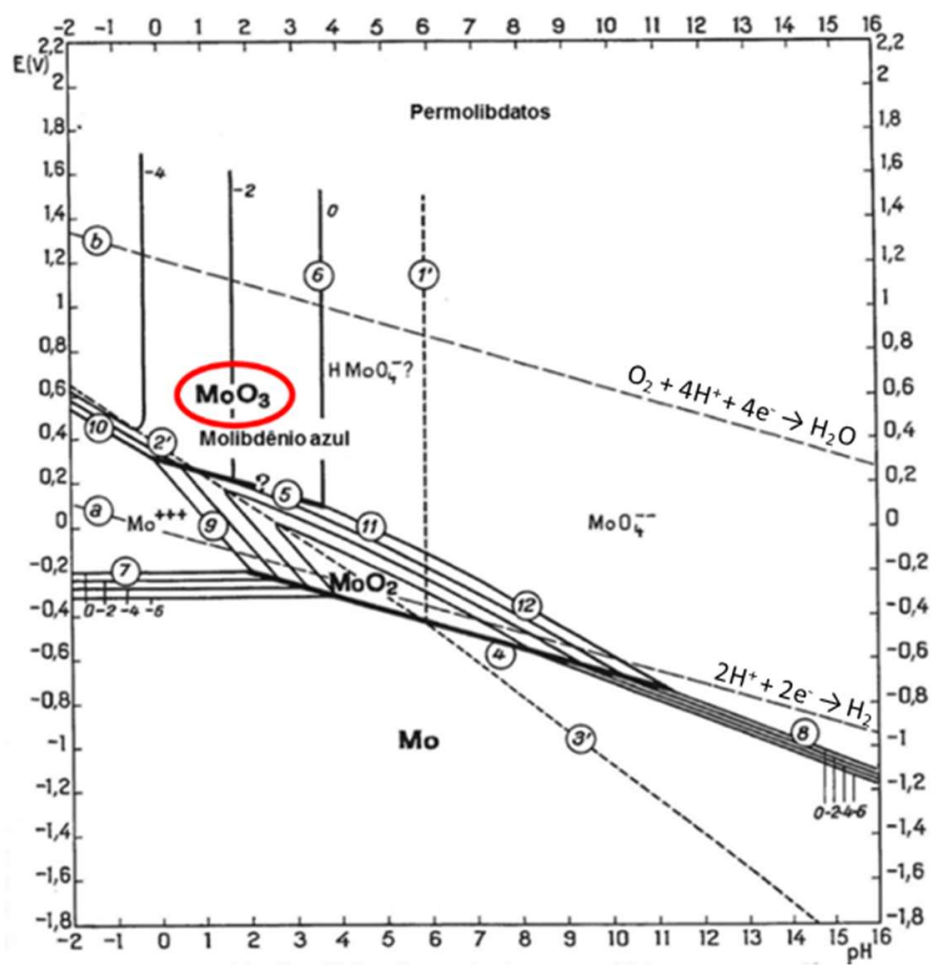

(b)

Fonte: Autor "adaptado de" Pourbaix, M.,1994. 


\subsubsection{Sensitização}

A exposição dos aços inoxidáveis a determinados ciclos térmicos pode provocar mudanças microestruturais que provocam a susceptibilidade deste material à corrosão intergranular devido à precipitação de algumas fases nos contornos de grão. Os contornos de grão são regiões relativamente desordenadas que separam dois ou mais grãos de diferentes orientações cristalográficas. Assim, tornam-se sítios favoráveis para a segregação de solutos ou para a precipitação de segundas fases, como carbonetos e fase sigma, devido à alta taxa de difusão de elementos de liga nesta região. A formação dessas fases é geralmente descrita por um diagrama TTP (tempo-temperatura-precipitação), como aquele mostrado na Figura 6 para o aço inoxidável em estudo, AISI 316, em que podem ser visualizadas as condições de tempo e temperatura para precipitação das fases chi $(\chi)$, Laves $(\eta)$, sigma $(\sigma)$ e também do carboneto $\mathrm{M}_{23} \mathrm{C}_{6}$ (SEDRIKS, 1979); (LAI, 1983); (MATULA, et al., 2001).

Figura 6 - Diagrama TTP (Tempo-Temperatura-Precipitação) de um aço inoxidável AISI 316 que contém cerca de $0,066 \%$ de carbono.

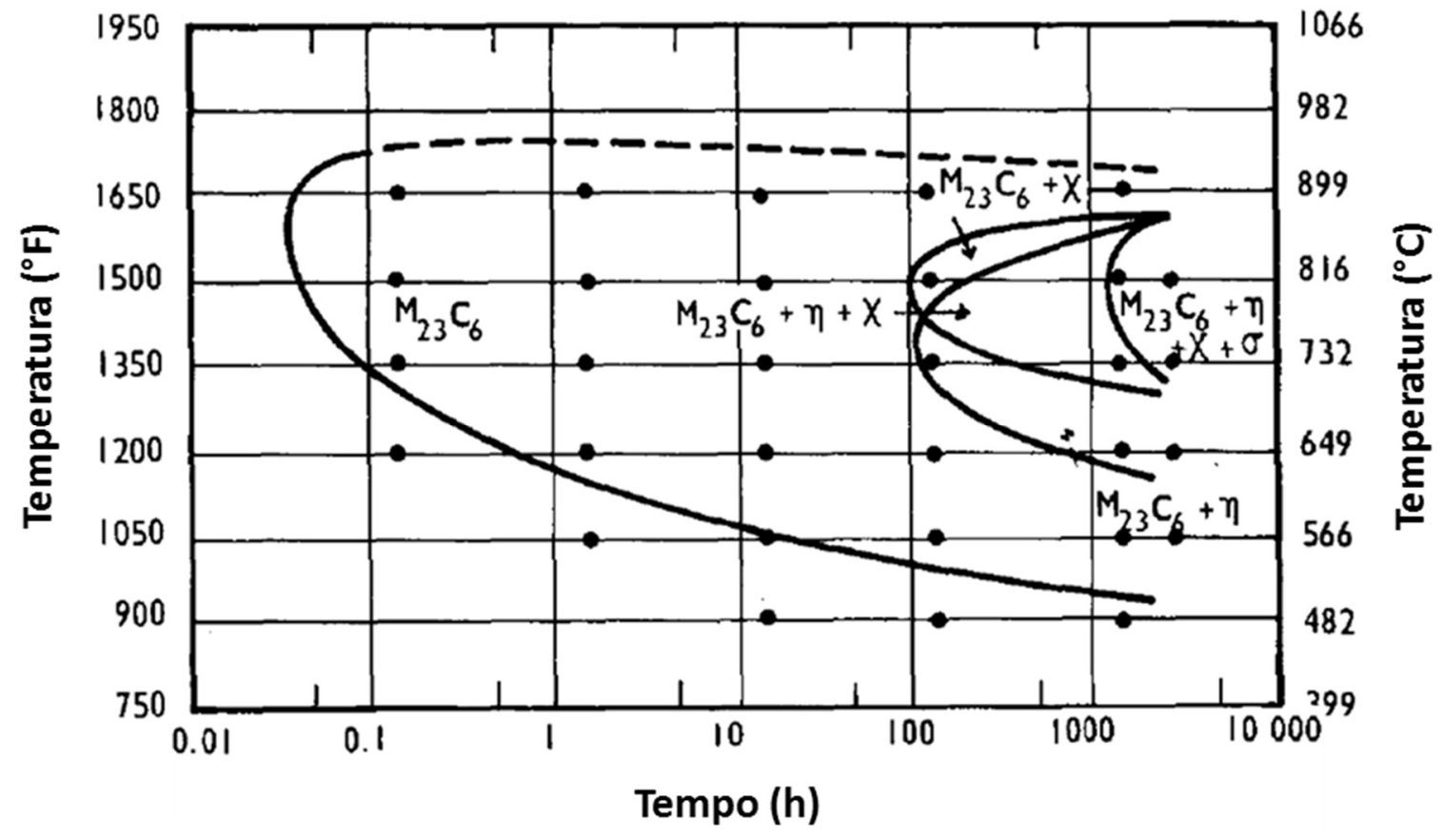

Fonte: Autor “adaptado de" Lai, J. K. L, 1983.

No diagrama da Figura 6 é possível observar que a precipitação do carboneto $\mathrm{M}_{23} \mathrm{C}_{6}$ pode ocorrer em tempos relativamente curtos, quando comparado aos outros precipitados. Nesse processo, o carbono, um elemento intersticial na matriz de ferro, se difunde para o 
contorno de grão relativamente rápido, enquanto que o cromo, por ser um elemento substitucional na matriz de ferro, é difundido muito mais lentamente. Assim, com a precipitação desses carbonetos no contorno de grão, é formada uma zona empobrecida em cromo na região ao redor dos contornos e dos precipitados que se torna altamente susceptível à corrosão intergranular, já que o cromo é o principal responsável pela resistência à corrosão dos aços inoxidáveis, Figura 7. Este fenômeno, caracterizado pela maior susceptibilidade dos contornos de grão à corrosão, é chamado de "sensitização" (SEDRIKS, 1979); (LAI, 1983); (MATULA, et al., 2001).

Figura 7 - Representação esquemática da precipitação de carboneto de cromo $\left(\mathrm{Cr}_{23} \mathrm{C}_{6}\right)$ nos contornos de grão durante a sensitização em aços inoxidáveis.

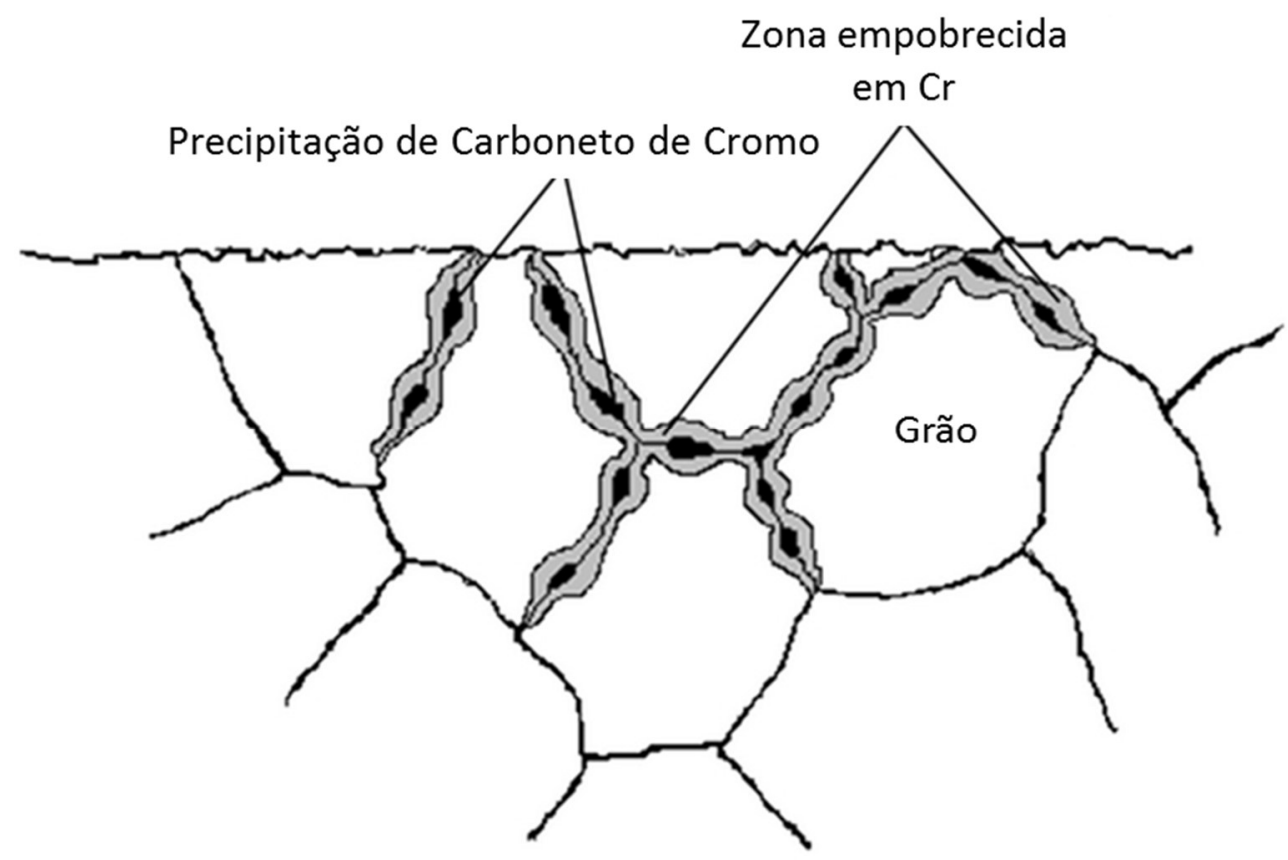

Fonte: Autor “adaptado de” Almubarak, Abuhaimed e Almazrouee, 2013.

Como a causa da sensitização está relacionada à exposição dos aços inoxidáveis a determinados ciclos térmicos, a solução mais intuitiva para evitar tal problema seria não permitir a exposição desses materiais a tratamentos térmicos que envolvem a variação de temperatura em faixas que provoquem a precipitação de carbonetos $\mathrm{M}_{23} \mathrm{C}_{6}$. Porém, infelizmente, usualmente são necessários tratamentos térmicos de alívio de tensões que precisam ser conduzidos nesta faixa de temperatura. Além disso, processos de fabricação de peças e componentes geralmente também necessitam expor algumas áreas da peça a altas temperaturas, como nas operações de soldagem. Então, a total eliminação de uma 
microestrutura não-sensitizada seria praticamente impossível. Buscando reduzir e/ou controlar este fenômeno, surgiram alguns mecanismos a fim de contornar a sensitização nos aços inoxidáveis como: (i) utilização de ligas baixo carbono (“low-carbon”), máximo 0,03\% C, designadas como grau "L" (isto é, 304L, 316L, 317L,...); (ii) tratamentos térmicos pós-solda (PWHT, "post weld heat treatment") a fim de permitir que o cromo seja novamente difundido para as regiões empobrecidas; (iii) utilização de elementos estabilizadores como titânio (AISI 321), ou nióbio e tântalo (AISI 347) para precipitação de outros carbonetos que não sejam ricos em cromo. Para estes materiais estabilizados, AISI 321 e 347, são realizados tratamentos térmicos de estabilização entre 900 e $925^{\circ} \mathrm{C}$ para maximizar a precipitação de carbonetos de titânio ou nióbio. Os aços estabilizados são usualmente preferenciais em aplicações que demandem serviços por longos tempos em altas temperaturas, por exemplo entre 425 e $900^{\circ} \mathrm{C}$ (NICKEL DEVELOPMENT INSTITUT (NIDI), 2017).

Desde que os equipamentos disponíveis para fabricação dessa classe de materiais foram modernizados, dentre estes três mecanismos disponíveis para contornar a sensitização dos aços inoxidáveis, a utilização de ligas baixo carbono (grau "L") tem sido a preferencial. Assim, a utilização de ligas cujo teor de carbono é menor que $0,03 \%$ possibilita a utilização de menores taxas de resfriamento sem que o material seja sensitizado. A Figura 8 apresenta a curva TTS, tempo-temperatura-sensitização, do aço inoxidável austenítico AISI 304 em função do teor de carbono. Esta curva representa o tempo necessário em determinada temperatura para que ocorra a sensitização dos contornos de grão causada pela precipitação de carbonetos de cromo. $\mathrm{Ou}$ seja, a sensitização ocorrerá se a condição avaliada estiver à direita da curva analisada. Nesta curva, pode-se observar que a sensitização ocorre mais rapidamente em temperaturas entre $600^{\circ} \mathrm{C}$ e $750^{\circ} \mathrm{C}$. Para ligas que contêm cerca de $0,062 \% \mathrm{C}$, a sensitização ocorre de 2 a 3 minutos a $750^{\circ} \mathrm{C}$. Por outro lado, num aço AISI 304L, que contém no máximo $0,03 \% \mathrm{C}$, a sensitização demora cerca de 8 horas a $600^{\circ} \mathrm{C}$. Do ponto de vista prático, isso significa que em tratamentos térmicos de alívio de tensões ou operações de soldagem de componentes, a sensitização será reduzida nos materiais "grau L" devido a menor (ou até nenhuma) precipitação de carbonetos de cromo (NICKEL DEVELOPMENT INSTITUT (NIDI), 2017). 
Figura 8 - Curva tempo-temperatura-sensitização, TTS, do aço inoxidável austenítico AISI 304 em função do teor de carbono devido à precipitação de carbonetos de cromo.

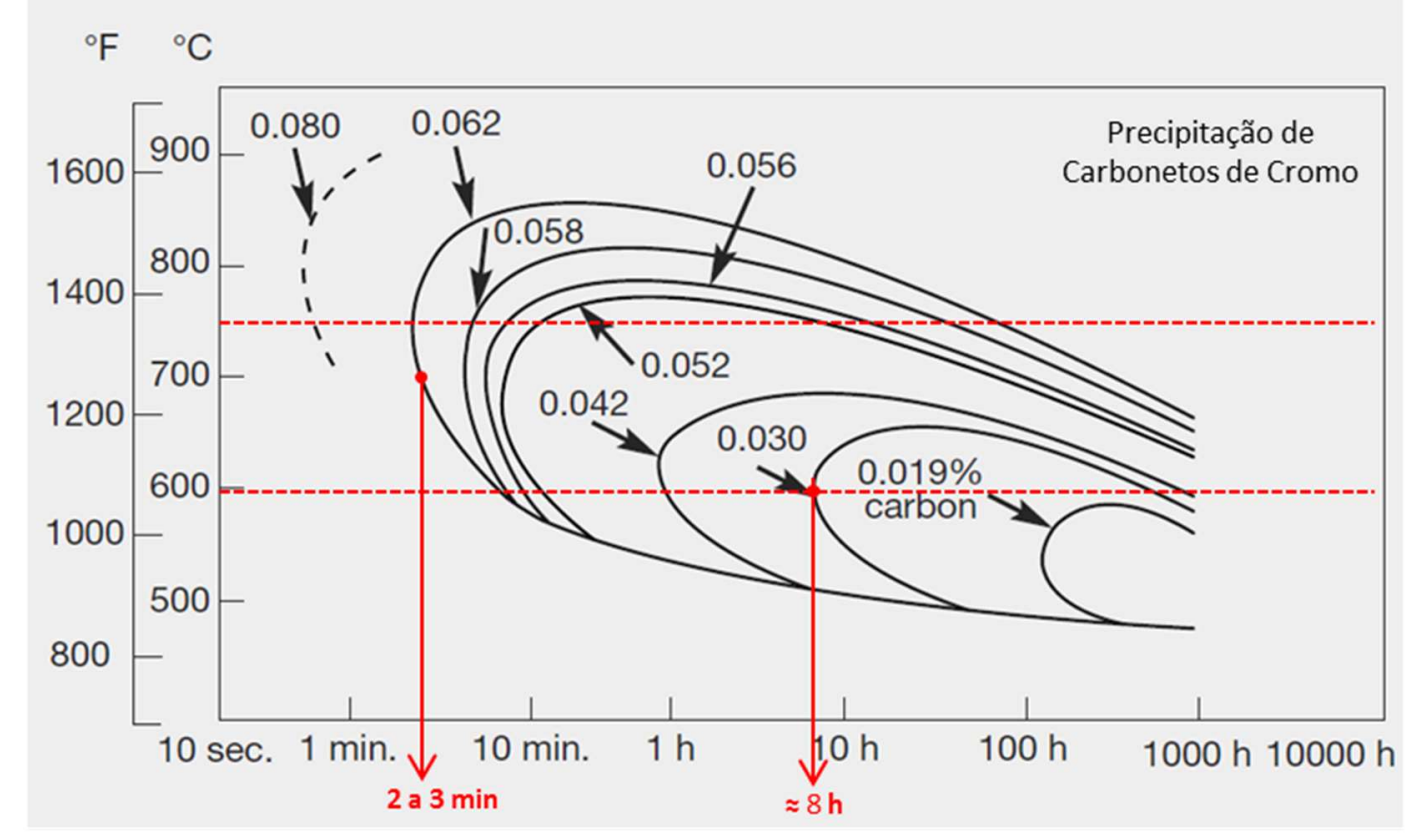

Fonte: Autor "adaptado de" International Molybdenum Association, IMOA, 2014.

As curvas de polarização, descritas mais adiante, tornaram-se técnicas eficientes para detecção indireta de corrosão intergranular devido ao empobrecimento de $\mathrm{Cr}$, mas com o desenvolvimento da microscopia eletrônica foi possível determinar diretamente o teor de cromo ao redor dos contornos de grão sensitizados. Hall e Briant (1984) determinaram o perfil de concentração de cromo e molibdênio em um aço inoxidável AISI 316LN, cujos teores de carbono variaram de 0,025 a $0,028 \%$, em função do tempo e da temperatura $\left(650\right.$ e $\left.700^{\circ} \mathrm{C}\right) \mathrm{de}$ envelhecimento, conduzido após solubilização a $1100^{\circ} \mathrm{C}$ por $1 \mathrm{~h}$ em atmosfera de argônio e resfriamento em água (HALL e BRIANT, 1984). Segundo os autores, o perfil de cromo na direção normal aos contornos de grão próximos aos carbonetos precipitados no tratamento térmico de envelhecimento é diretamente proporcional à temperatura ou ao tempo de envelhecimento, ou seja, aumentando estes parâmetros, a região empobrecida em cromo aumenta, tornando o material ainda mais sensitizado, conforme mostrado na Figura 9. Os autores destacam ainda que o perfil de empobrecimento do Mo é bastante similar àquele observado para o $\mathrm{Cr}$ devido à incorporação de molibdênio no carboneto $\mathrm{M}_{23} \mathrm{C}_{6}$ (HALL e BRIANT, 1984). 
Figura 9 - Perfil de composição de cromo normal ao contorno de grão na vizinhança de carbonetos $\mathrm{M}_{23} \mathrm{C}_{6}$ para amostras envelhecidas (a) a $650^{\circ} \mathrm{C}$ por $50 \mathrm{~h}$; (b) a $650^{\circ} \mathrm{C}$ por $100 \mathrm{~h}$; (c) a $700^{\circ} \mathrm{C}$ por $100 \mathrm{~h}$; (d) a $700^{\circ} \mathrm{C}$ por $300 \mathrm{~h}$.

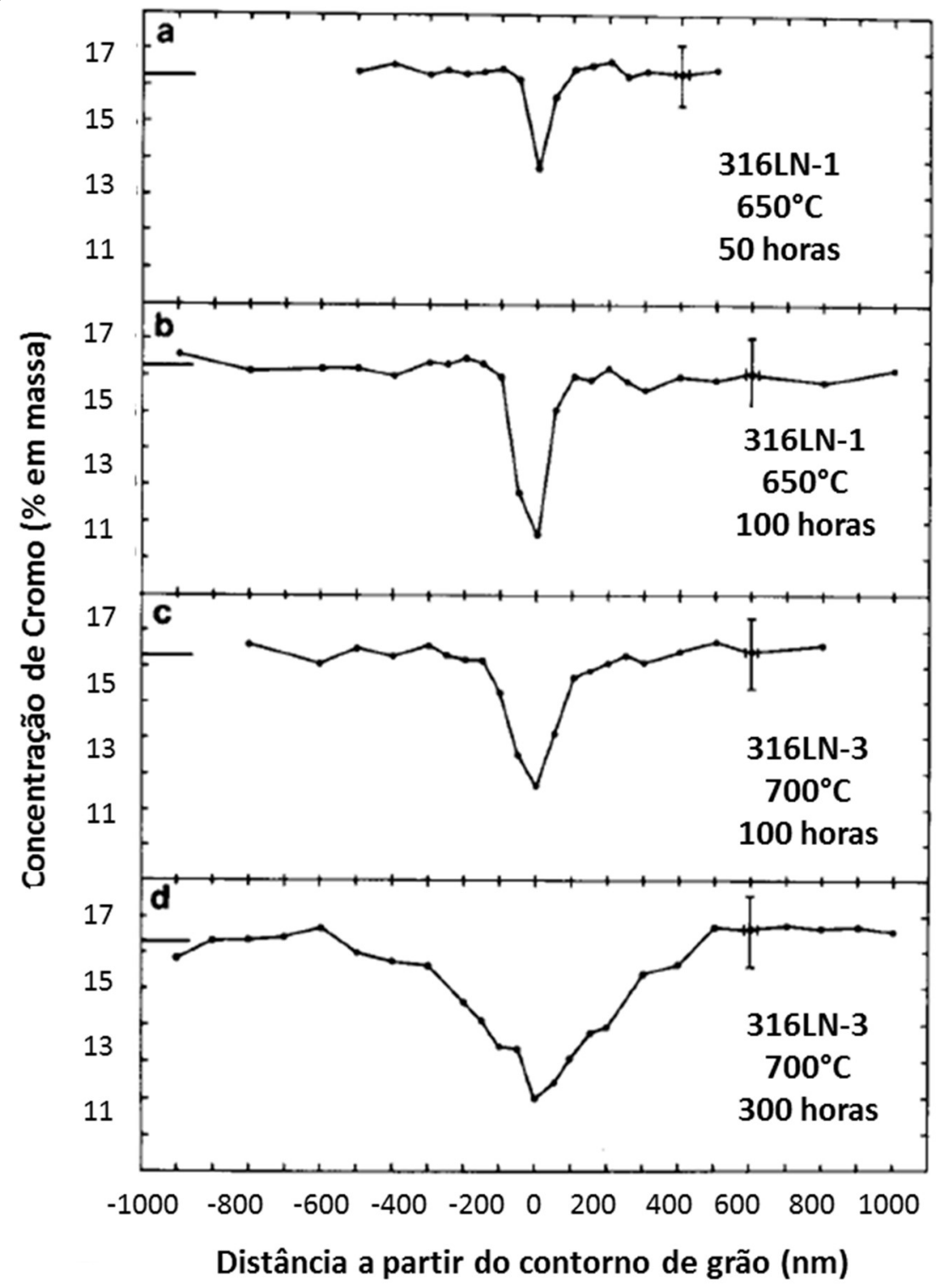

Fonte: Autor "adaptado de" Hall e Briant, 1984.

Já Bruemmer e Charlot (1986) determinaram o perfil do teor de cromo nos aços inoxidáveis auteníticos 304 e 316, cujos teores de carbono foram de 0,060 e 0,054\%, após tratamento térmico de solubilização de $1100^{\circ} \mathrm{C}$ e tratamentos térmicos entre 480 e $900^{\circ} \mathrm{C}$ por intervalos de tempo de 0,5 a 5000 horas. Segundo os autores, o teor nominal de cromo do aço 304 era de $18,48 \%$, enquanto que para o 316 este teor era de $17,40 \%$. O menor teor de cromo medido nessas ligas foi de 8,9 e $10,0 \%$, após tratamentos térmicos de $480^{\circ} \mathrm{C}$ por $5000 \mathrm{~h} \mathrm{e} 700^{\circ} \mathrm{C}$ por 10 horas, respectivamente. Segundo eles, o 316 apresentou uma zona empobrecida em cromo de $500 \mathrm{~nm}$ após $100 \mathrm{~h}$ de tratamento térmico a $700^{\circ} \mathrm{C}$. Já a zona empobrecida do 304 
chegou a $320 \mathrm{~nm}$ para o mesmo tratamento térmico, $700^{\circ} \mathrm{C}$ por 100 horas, e também para $800^{\circ} \mathrm{C}$ por 10 horas. Assim, os autores concluíram que o teor mínimo de Cr nos contornos de grão e a amplitude da zona empobrecida variam com o tratamento térmico, sendo que o mínimo teor diminui com a redução da temperatura e a amplitude aumenta com o aumento do tempo de tratamento térmico. A Figura 10 apresenta a variação do gradiente de concentração de cromo do aço inoxidável 304 para tratamentos térmicos a $700^{\circ} \mathrm{C}$ por diferentes tempos (BRUEMMER e CHARLOT, 1986).

Figura 10 - Variação do gradiente de concentração do aço inoxidável 304 para tratamentos térmicos a $700^{\circ} \mathrm{C}$ por diferentes tempos.

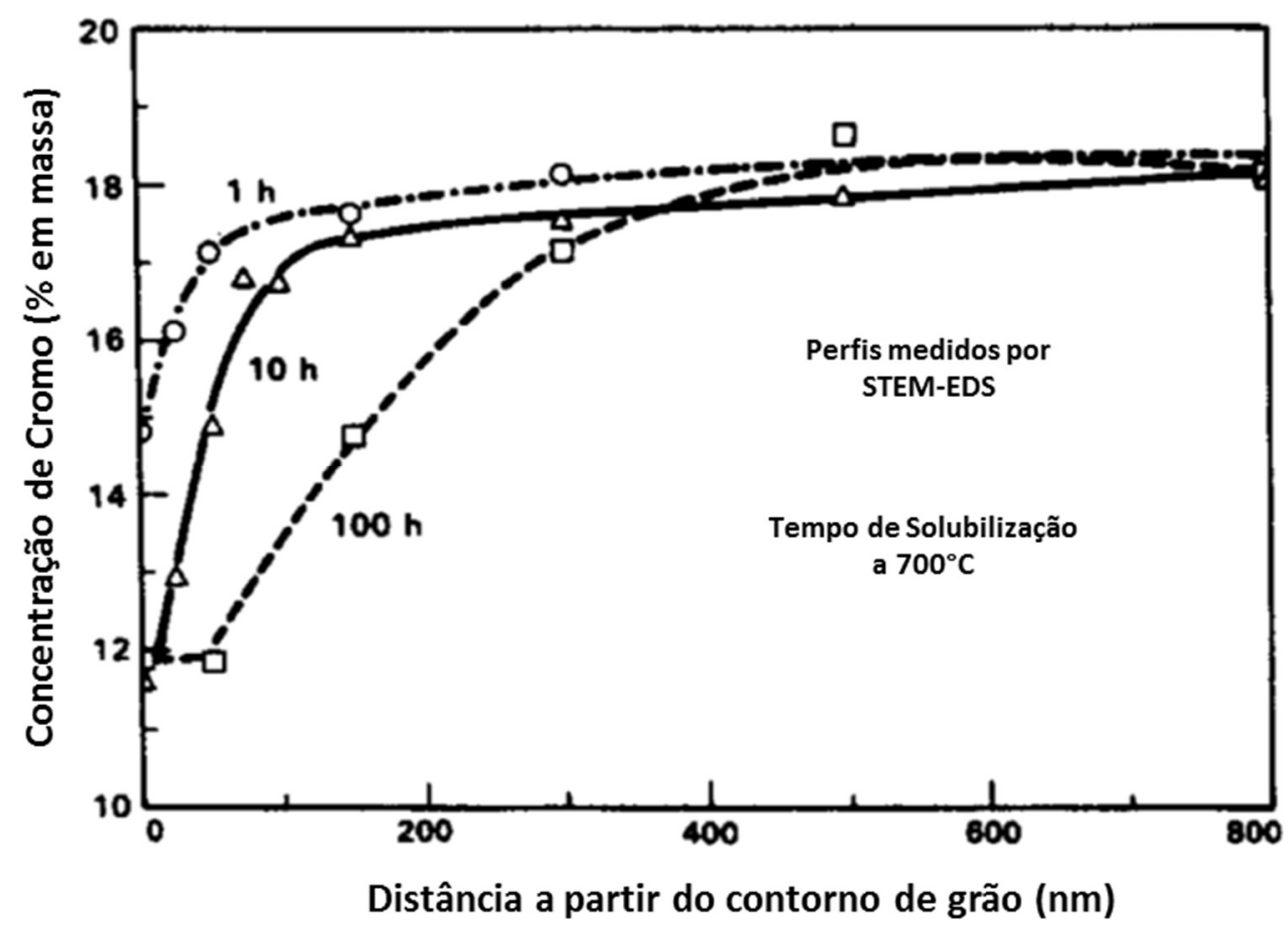

Fonte: Autor "adaptado de" Bruemmer e Charlot, 1986.

Desta forma, a Figura 11 apresenta a comparação entre os dois materiais estudados por Brummer e Charlot (1986) e Hall e Briant (1984) para o mesmo tratamento térmico de $700^{\circ} \mathrm{C}$ por $100 \mathrm{~h}$, sendo que o primeiro corresponde ao aço 316 e o segundo ao 316LN (BRUEMMER e CHARLOT, 1986); (HALL e BRIANT, 1984). Neste gráfico é possível notar que, de fato, o material que apresenta maior teor de carbono apresenta uma zona empobrecida em cromo mais larga e menos rica neste elemento de liga que os materiais que apresentam um menor teor de carbono, comprovando que a redução do teor de $\mathrm{C}$ na liga realmente reduz o empobrecimento de $\mathrm{Cr}$ causado pela precipitação de carbonetos de cromo do tipo $\mathrm{M}_{23} \mathrm{C}_{6}$ devido à exposição a 
altas temperaturas e longos tempos e, consequentemente, reduz o grau de sensitização do material.

Figura 11 - Comparação entre os dois materiais estudados por Brummer e Charlot (1986), inox 316, e Hall e Briant (1984), inox 316LN para o mesmo tratamento térmico de $700^{\circ} \mathrm{C}$ por $100 \mathrm{~h}$.

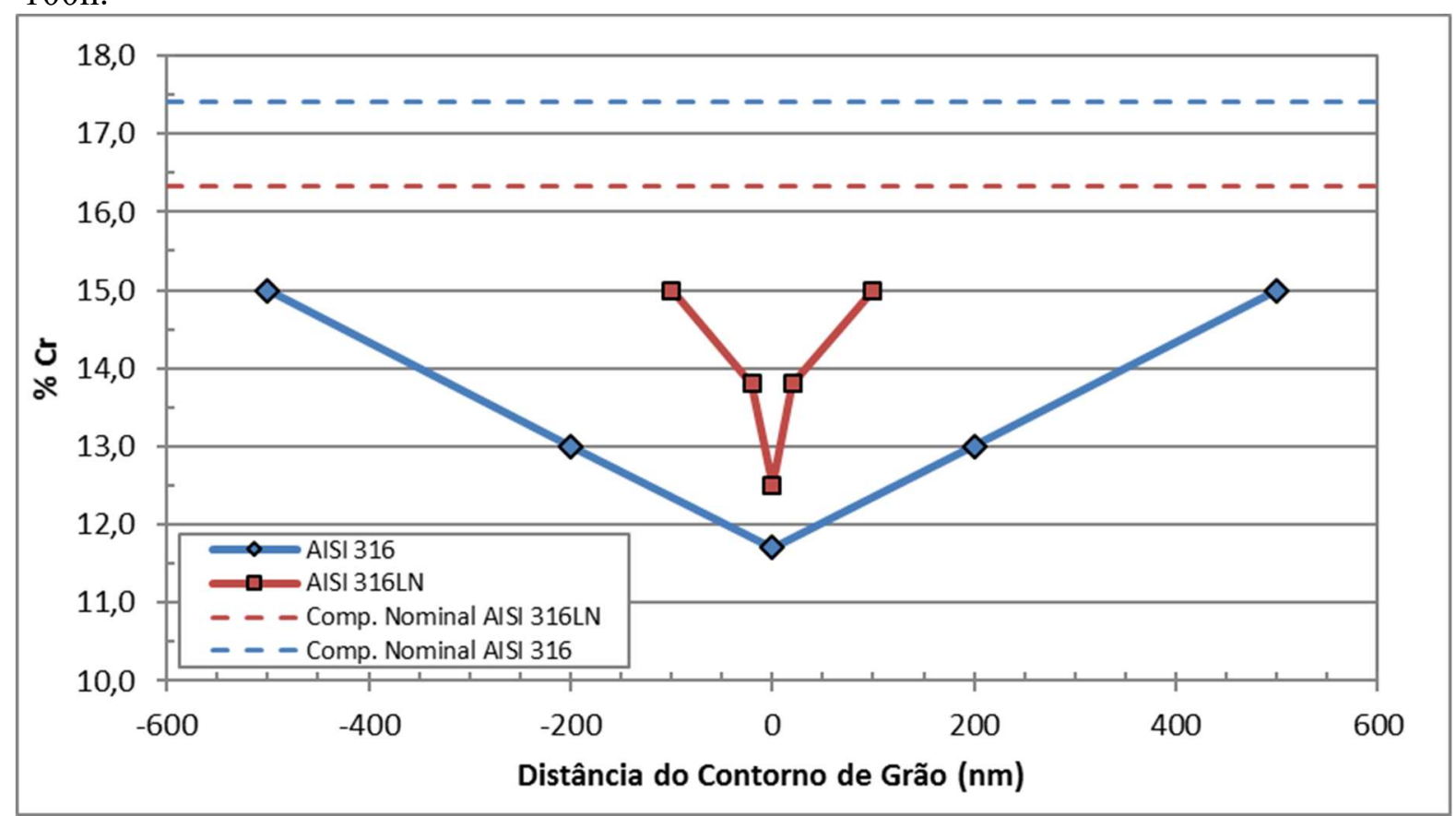

Fonte: Autor "adaptado de" Bruemmer e Clarlot, 1986, e Hall e Briant, 1983.

\subsubsection{Corrosão por pite}

A corrosão por pite é uma forma de corrosão localizada caracterizada pela formação de pequenas cavidades profundas e de pequenas extensões, usualmente denominadas por "pite". Este fenômeno é iniciado a partir da quebra da película passiva em regiões onde há a presença de heterogeneidades como defeitos superficiais, inclusões, segregações, discordâncias, contornos de grão e interfaces (SEDRIKS, 1979); (NUNES, 2007). Os pites podem assumir diferentes formas, conforme apresentado na Figura 12. 
Figura 12 - Formas típicas de corrosão por pite em seção transversal à superfície corroída.

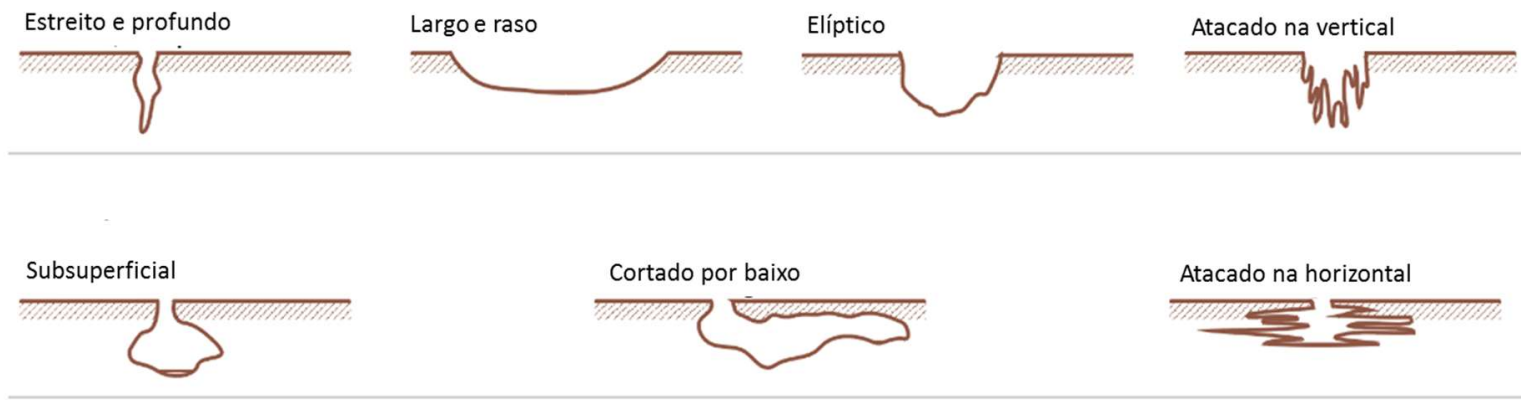

Fonte: Autor "adaptado de" Nace International, 2017.

Segundo Roberge (2008), a corrosão por pite é mais perigosa que a corrosão generalizada, pois é mais difícil detectá-la, predizê-la e elaborar projetos apropriados para preveni-la. Um pequeno e estreito pite, que causa uma perda de massa quase que insignificante, pode levar à ruptura um sistema de engenharia inteiro devido à perfuração de componentes, gerando custos inimagináveis e riscos incalculáveis para a sociedade. Além da perfuração de componentes, a presença de pites pode levar também a falhas por corrosão sob tensão, fratura por hidrogênio e fadiga associada à corrosão (ROBERGE, 2008).

A corrosão por pite é causada pela presença de íons halogêneos $\left(\mathrm{Cl}^{-}, \mathrm{Br}^{-}, \mathrm{I}^{-}\right.$e $\left.\mathrm{F}^{-}\right)$, principalmente cloretos, que substituem moléculas de água na película passiva, causando a formação de íons complexos e, consequentemente, a remoção da película de proteção. Assim, a região desprotegida torna-se susceptível à corrosão, onde tem início um processo corrosivo localizado, de acordo com as reações anódicas e catódicas apresentadas na Equação 1 e na Equação 2 abaixo:

$$
\begin{aligned}
& \mathrm{M} \rightarrow \mathrm{M}^{+\mathrm{n}}+\text { ne } \\
& \mathrm{O}_{2}+2 \mathrm{H}_{2} \mathrm{O}+4 \mathrm{e} \rightarrow 4 \mathrm{OH}^{-}
\end{aligned}
$$

Após a ruptura da película passiva, a repassivação é inibida e a taxa de dissolução do metal aumentada devido à presença destes íons cloretos. Para balancear a presença de cátions metálicos oriundos da reação anódica, os íons cloreto migram para a região afetada pelo dano localizado, formando um cloreto metálico $\mathrm{MCl}$. Então, o cloreto metálico formado sofre hidrólise pela água resultando em ácido clorídrico, conforme Equação 3.

$$
\mathrm{MCl}+\mathrm{H}_{2} \mathrm{O} \rightarrow \mathrm{MOH}+\mathrm{HCl}
$$


A formação de $\mathrm{HCl}$ leva à redução do $\mathrm{pH}$ local, aumenta a taxa de corrosão e, consequentemente conduz ao aumento da concentração de cloretos, tornando o processo de crescimento do pite um processo autocatalítico, ilustrado na Figura 13.

Figura 13 - Processo autocatalítico de crescimento do pite de um aço inoxidável na presença de íons cloreto.

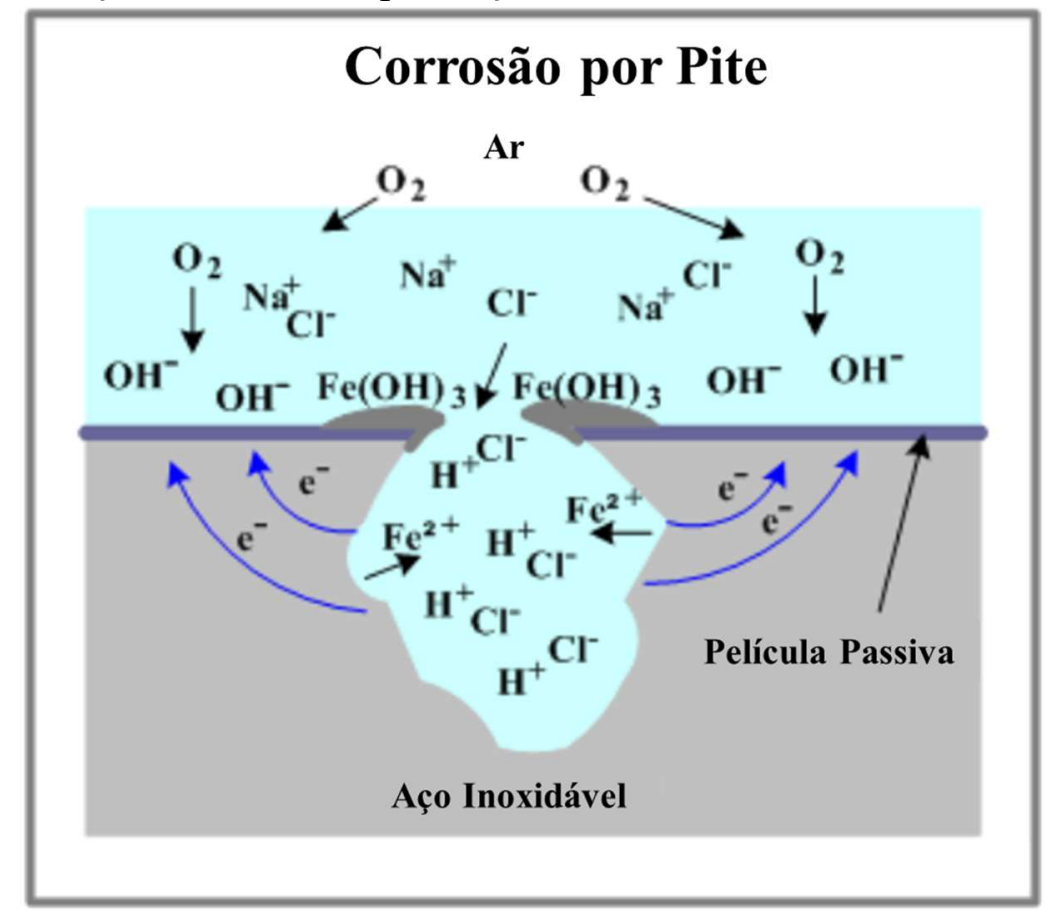

Fonte: Autor "adaptado de" Kopeliovich, 2015.

Assim, acredita-se que o processo de corrosão por pite ocorra em três estágios consecutivos: quebra da película passiva, formação de pites metaestáveis e crescimento de pites estáveis, sendo que cada um desses estágios pode ser considerado como estágios críticos para prevenção desse tipo de deterioração (ZAKERI, NAKHAIE e MOAYED, 2015).

Conforme mencionado anteriormente, os principais elementos de liga que contribuem para o aumento da resistência à corrosão nos aços inoxidáveis austeníticos são o cromo, nitrogênio e molibdênio. Apesar da principal diferença entre os aços inoxidáveis austeníticos AISI 304 e 316 ser a adição de Mo para a obtenção de maior resistência à corrosão por pite, segundo Sedriks (1979), a quantidade deste elemento que pode ser adicionada aos aços inoxidáveis austeníticos é limitada pelo início da precipitação das fases sigma e chi, que fragilizam o material e reduzem drasticamente a resistência à corrosão por pite. Contudo, de acordo com o autor, mesmo adições de Mo de até 8,4\% não são capazes de prevenir pites a 
$60^{\circ} \mathrm{C}$ na presença de cloretos, mas níveis maiores de resistência à corrosão por pite podem ser alcançados com a adição de nitrogênio associada a de molibdênio (SEDRIKS, 1979).

Os efeitos benéficos de alguns elementos de liga à resistência à corrosão por pite são descritos pelo índice de resistência à corrosão por pite conhecido como PREN ("Pitting Resistance Equivalent Number"), Equação 4, considerando o teor de cada elemento em porcentagem em massa na liga estudada (SEDRIKS, 1979).

$P R E N=C r+3,3 M o+16 N$

Contudo, a similaridade entre os efeitos causados pelo tungstênio em relação ao molibdênio na resistência à corrosão por pite dos aços inoxidáveis tem sido discutida na literatura (GOETZ, BOBAND e LANDOLT, 1981); (BUI, et al., 1983); (OKAMOTO, 1992); (OH, et al., 1993); (BARTERI, MECOZZI e NEMBRINI, 1994); (OKAMOTO, et al., 1994); (AHN, KWON e LEE, 1998); (KIM, et al., 1998); (PARK e KWON, 2002); (KIM, XIANG e KIM, 2005); (PARK, AHN e KWON, 2006); (JEON, et al., 2012). Okamoto (1992) observou que o potencial de pite (o potencial eletroquímico de iniciação de pites, que será melhor discutido em item posterior) de aços inoxidáveis dúplex com adições de tungstênio aumenta proporcionalmente ao teor deste elemento, Figura 14 (OKAMOTO, 1992). Assim, o autor sugeriu uma nova fórmula para índice de resistência à corrosão por pite $\left(\mathrm{PREW}_{1}\right)$ que inclui os efeitos proporcionados pela adição de tungstênio a esta propriedade importante dos aços inoxidáveis, Equação 5.

$P R E W_{1}=C r+3,3(M o+0,5 W)+16 N$ 
Figura 14 - Efeito do tungstênio no potencial de pite de um aço inoxidável dúplex a $80^{\circ} \mathrm{C}$.

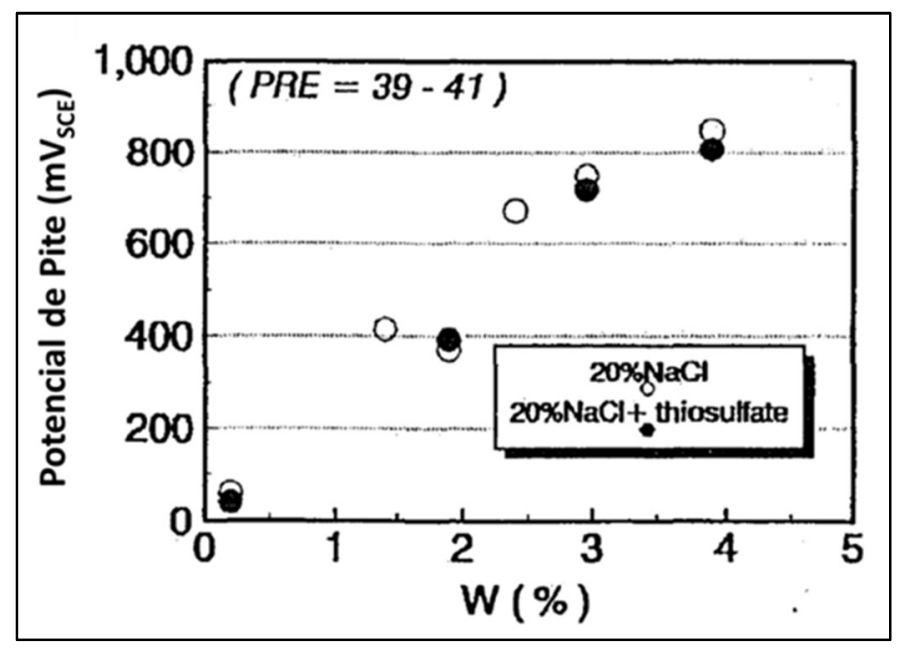

Fonte: Autor "adaptado de" Okamoto, 1992.

O autorjustifica esta adaptação baseando-se nos gráficos mostrados na Figura 15, em que são plotados os potenciais de pite observados para amostras convencionais, que não apresentam adição de $\mathrm{W}$, e outras que apresentam este elemento de liga em relação ao PREN usual, (Equação 4), (Figura 15 (a)) e o PREW 1 estabelecido por ele (Figura 15 (b)) (OKAMOTO, 1992). Nestes gráficos é possível observar claramente que, de fato, o aumento do potencial de pite é acompanhado pelo aumento no $\mathrm{PREW}_{1}$, enquanto que este efeito não é descrito adequadamente pelo PREN.

Figura 15 - Potencial de pite de aços inoxidáveis dúplex com e sem adição de $\mathrm{W}$ em solução de $20 \% \mathrm{NaCl}$ a $80^{\circ} \mathrm{C}$ em função do valor do (a) PREN; (b) PREW.

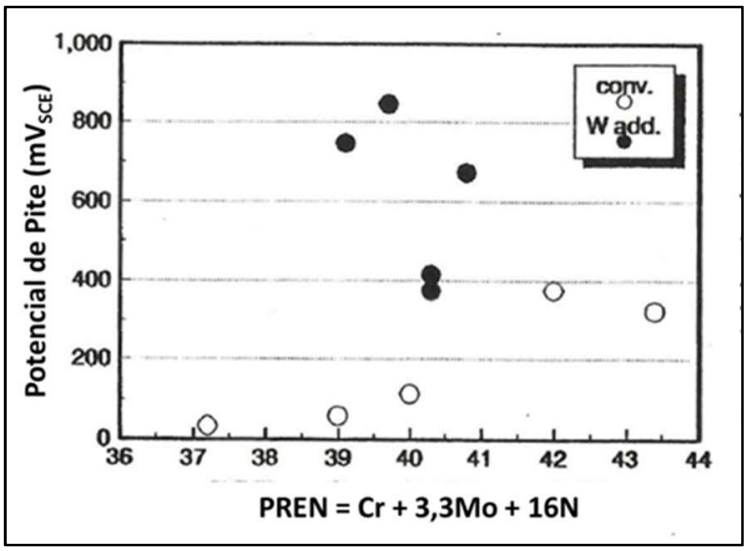

(a)

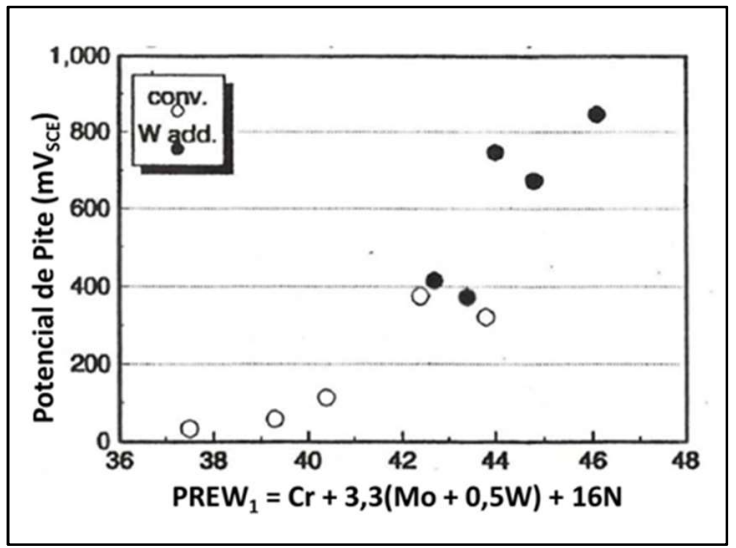

(b)

Fonte: Autor "adaptado de" Okamoto, 1992. 
Porém, alguns autores destacam que nos aços inoxidáveis dúplex, a partição do nitrogênio entre as duas fases presentes, austenita e ferrita, aumenta dramaticamente o teor de nitrogênio na austenita (BERNHARDSSON, 1991); (BARTERI, MECOZZI e NEMBRINI, 1994); (NICHOLLS, 1994); (KIM e KWON, 1999). Além disso, segundo Barteri, Mecozzi e Nembrini (1994), o nitrogênio também altera o coeficiente de partição de outros elementos, particularmente cromo e molibdênio (BARTERI, MECOZZI e NEMBRINI, 1994). Consequentemente, o nitrogênio aumenta consideravelmente o PREN da austenita que, neste tipo de aço, é tido como uma fase fraca para as propriedades de corrosão por pite. Desta maneira, Bernhardsson (1991) propôs uma alteração no coeficiente do nitrogênio, descrito na Equação 4, de 16 para 30 (BERNHARDSSON, 1991). Assim, alterando o coeficiente do nitrogênio para 30 na Equação 5, Barteri, Mecozzi e Nembrini (1994) sugeriram que o PREW 2 dos aços inoxidáveis dúplex fosse descrito pela Equação 6.

$P R E W_{2}=C r+3,3(M o+0,5 W)+30 N$

Os autores destacam ainda que utilizando esta nova fórmula (Equação 6) para o cálculo do $\mathrm{PREW}_{2}$, uma ótima correlação entre a temperatura crítica de pite ("critical pitting temperature”, CPT) e o $\mathrm{PREW}_{2}$ é obtida para diversos aços inoxidáveis dúplex, justificando o uso deste novo PREW 2 (BARTERI, MECOZZI e NEMBRINI, 1994).

\subsection{TÉCNICAS ELETROQUÍMICAS EM CORROSÃO}

A corrosão metálica manifesta-se em diferentes meios, sendo que na maioria deles este fenômeno tem natureza eletroquímica. De acordo com Kelly, et al. (2003), "técnicas eletroquímicas, quando conduzidas de maneira inteligente e interpretadas baseando-se no conhecimento, são ferramentas valiosas para solucionar, compreender e prevenir problemas relacionados à corrosão" (KELLY, et al., 2003). Assim, essas técnicas podem ser utilizadas na avaliação, no controle e na investigação do desempenho dos materiais sofrendo diferentes mecanismos de corrosão por meio da elaboração de estratégias e monitoramento dos diferentes meios que o material pode vir a ser exposto. Quando utilizadas de maneira adequada, estas técnicas têm muitas vantagens em relação aos ensaios por imersão como reduzido tempo de ensaio, alta resolução, possibilidade em adquirir informações sobre mecanismos de corrosão e, em alguns casos, apresentar características não destrutivas (WOLYNEC, 2003); (KELLY, et al., 2003). 
Usualmente, o equipamento utilizado para realização das técnicas eletroquímicas em corrosão é um potenciostato, que pode ser definido como um equipamento eletrônico capaz de controlar a diferença de potencial entre dois eletrodos, sendo um deles o eletrodo de trabalho e o outro um contra-eletrodo, geralmente fabricado de platina. O potenciostato é capaz de realizar o controle por meio da medição da diferença de potencial aplicada através de um eletrodo auxiliar chamado eletrodo de referência. Assim, é possível descrever as reações eletroquímicas que se estabelecem na interface entre o material e o meio em estudo, tendo-se a medição da corrente entre os eletrodos de trabalho e contra-eletrodo em função do potencial aplicado, determinado pelo eletrodo de referência, auxiliando na compreensão de, por exemplo, susceptibilidade deste material a diferentes formas de corrosão.

\subsubsection{Polarização Potenciodinâmica}

O processo de corrosão metálica é um fenômeno eletroquímico caracterizado pela transferência de elétrons por meio de reações de oxidação e redução. As reações de oxidação ocorrem nos sítios anódicos do metal num processo de corrosão em uma célula eletroquímica, sendo que a principal delas corresponde à oxidação do metal, Equação 1. Segundo a teoria dos potenciais mistos, em uma situação de equilíbrio eletroquímico, todos os elétrons gerados nesta reação anódica são consumidos pelas correspondentes reações catódicas. As reações catódicas ou reações de redução de natureza eletroquímica mais comuns em meio aquoso são: reação de hidrogênio (Equação 7), redução do oxigênio em soluções ácidas (Equação 8), redução do oxigênio em soluções básicas e neutras (Equação 9), redução do íon metálico (Equação 10) e deposição de metal (Equação 11), mostradas aqui no sentido catódico.

$$
\begin{aligned}
& 2 \mathrm{H}^{+}+2 \mathrm{e} \rightarrow \mathrm{H}_{2} \\
& \mathrm{O}_{2}+4 \mathrm{H}^{+}+4 \mathrm{e} \rightarrow 2 \mathrm{H}_{2} \mathrm{O} \\
& \mathrm{O}_{2}+\mathrm{H}_{2} \mathrm{O}+4 \mathrm{e} \rightarrow 4 \mathrm{OH}^{-} \\
& \mathrm{M}^{+\mathrm{n}}+\mathrm{e} \rightarrow \mathrm{M}^{+(\mathrm{n}-1)} \\
& \mathrm{M}^{\mathrm{n}}+\text { ne } \rightarrow \mathrm{M}
\end{aligned}
$$

Durante o processo de corrosão, mais de uma reação anódica e mais de uma reação catódica podem operar. Assim, o potencial misto, chamado usualmente de potencial de corrosão e denotado por $\mathrm{E}_{\text {corr, }}$ corresponde ao potencial em que a somatória das reações anódicas é igual à somatória das reações catódicas. Já a densidade de corrente no potencial de corrosão é 
chamada de densidade de corrente de corrosão, $\mathrm{i}_{\text {corr, }}$ e fornece o valor da taxa de corrosão do sistema (SEDRIKS, 1979).

Desta forma, a técnica de polarização potenciodinâmica consiste na aplicação de um potencial a uma taxa constante, acompanhando a resposta do sistema em corrente elétrica. Usualmente, a corrente é medida em relação à área da amostra exposta, caracterizando então a densidade de corrente, usualmente dada em $\mathrm{A} / \mathrm{cm}^{2}$. Assim, a curva de polarização potenciodinâmica é dada pelo potencial aplicado (E), em relação ao potencial de referência, em função da densidade de corrente, conforme esquema mostrado na Figura 16, onde são apresentadas três regiões típicas de uma curva deste tipo: região catódica, região anódica ativa e região anódica passiva. A região catódica é caracterizada pela predominância de reações catódicas como, por exemplo, a de evolução de hidrogênio (Equação 7) e, consequentemente, baixa dissolução do metal devido ao maior potencial de corrosão do material. Aumentando-se o potencial continuamente, o potencial de corrosão $\left(E_{\text {corr }}\right)$ é atingido causando a reversão do sentido da corrente, marcando o início do trecho anódico ativo. Nesta região ativa, caracterizada pelo aumento da densidade de corrente com o aumento do potencial até que o potencial crítico ( $\left.\mathrm{E}_{\text {crit }}\right)$ e a densidade de corrente crítica ( $\mathrm{i}_{\text {crit }}$ ) sejam atingidos, há predominância de reações anódicas do metal que podem ocasionar sua oxidação (SEDRIKS, 1979); (LOTHONGKUM, VONGBANDIT e NONGLUCK, 2006). 
Figura 16 - Curva de polarização esquemática para de um aço inoxidável, destacando os potenciais de corrosão ( $\left.E_{\text {corr }}\right)$, critico ( $\left.E_{\text {crit }}\right)$, de pite $\left(E_{\text {pite }}\right)$ e de transpassivação ( $\left.E_{\text {trans }}\right)$ e também as densidades de corrente crítica ( $\left.i_{\text {crit }}\right)$ e passiva ( $\left.i_{\text {pass }}\right)$.

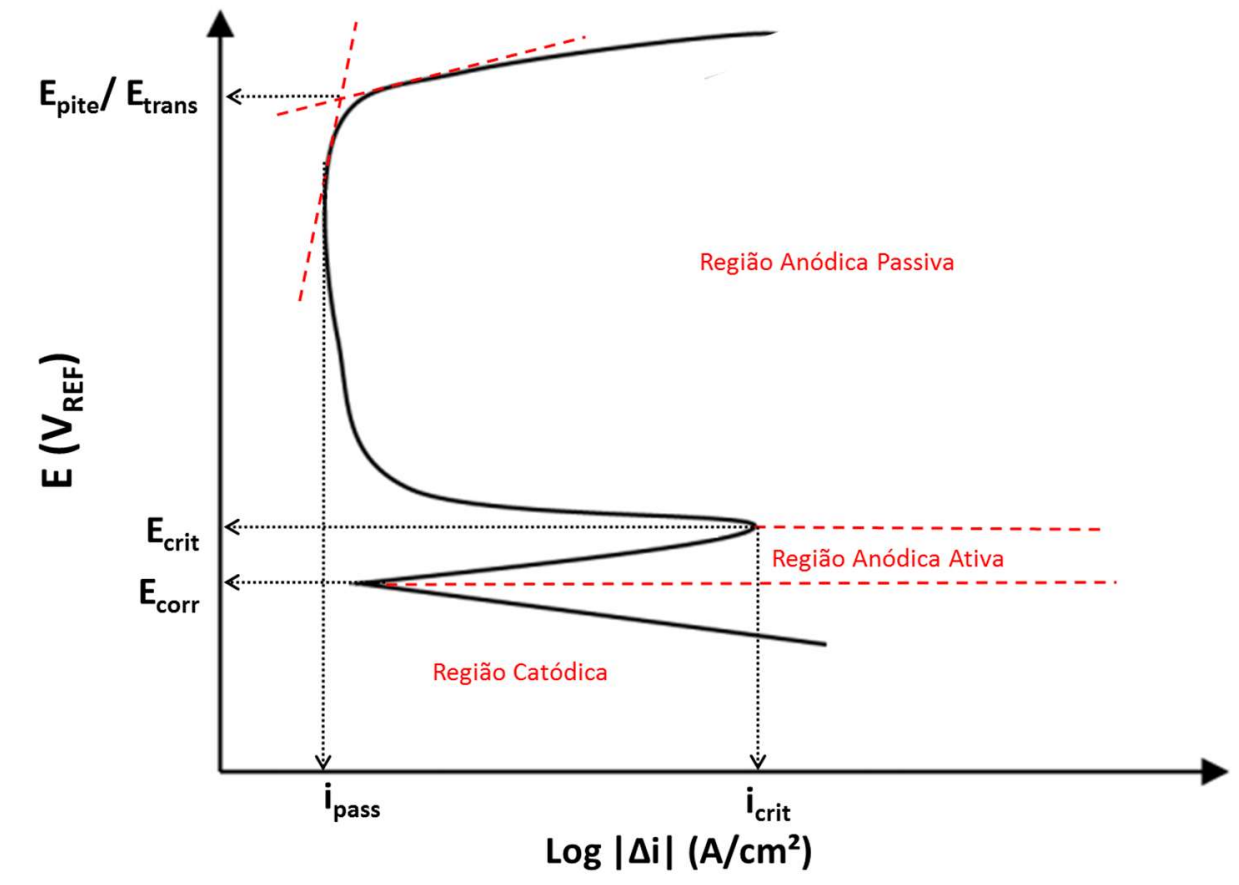

Fonte: Autor “adaptado de” Lothongkum, Vongbandit e Nongluck, 2006.

Então, após o $\mathrm{E}_{\text {crit, }}$ a densidade de corrente decresce consideravelmente, caracterizando o início da transição ativo-passiva em que ocorre a formação da película passiva, descrita no item 2.1.1, e reduz drasticamente a dissolução do metal. Nesta região, encontra-se a densidade de corrente passiva ( $\left.\mathrm{i}_{\text {pass }}\right)$ que corresponde à menor densidade de corrente atingida nesta região, que nos aços inoxidáveis corresponde à densidade de corrente inferior a $10^{-5} \mathrm{~A} / \mathrm{cm}^{2}$. Aumentando-se ainda mais o potencial na direção mais nobre, atinge-se um novo aumento drástico na densidade de corrente que pode ser caracterizado por diferentes mecanismos em aços inoxidáveis, dependendo do meio em questão. Em uma solução livre de cloretos como, por exemplo, solução de ácido sulfúrico, este potencial de quebra representa a evolução do oxigênio (Equação 9), devido à eletrólise da água, sendo chamado neste caso de potencial de transpassivação, Etrans. Entretanto, na presença de cloretos, este potencial, se inferior ao potencial de equilíbrio da Equação 9, pode estar relacionado ao rompimento local da película passiva, dando origem à corrosão por pite explicitada anteriormente, sendo chamado, portanto, de potencial de pite, $\mathrm{E}_{\mathrm{pite}}$ ou $\mathrm{E}_{\mathrm{p}}$. Este parâmetro representa a resistência do material ao início da formação de pites, sendo que quando estes se iniciam e começam a crescer, a densidade de corrente aumenta rapidamente, conforme apresentado na Figura 16. Assim, 
usualmente define-se o intervalo de passivação como sendo $\left(E_{\text {corr }}-E_{\text {pite }}\right)$, ou ainda $\left(E_{\text {corr }}-E_{\text {trans }}\right)$ na ausência de corrosão por pite.

Bui et al. (1983) utilizaram esta técnica de polarização potenciodinâmica para investigar o efeito do tungstênio em um aço inoxidável austenítico $16 \mathrm{Cr}-14 \mathrm{Ni}$ variando o teor deste elemento de 0 a 12\% em massa em soluções de $0,1 \mathrm{M} \mathrm{NaCl}$ e $0,1 \% \mathrm{HCl}$ (BUI, et al., 1983). Em ambos os casos, o potencial de pite do material aumenta com o aumento do teor de $\mathrm{W}$, conforme apresentado na Figura 17, ou seja, a adição de W aumenta a resistência à corrosão por pite deste aço inoxidável austenítico.

Figura 17 - Efeito da adição de tungstênio em um aço inoxidável austenítico em soluções de (a) $0,1 \mathrm{M} \mathrm{NaCl}$ e (b) $0,1 \% \mathrm{HCl}$.

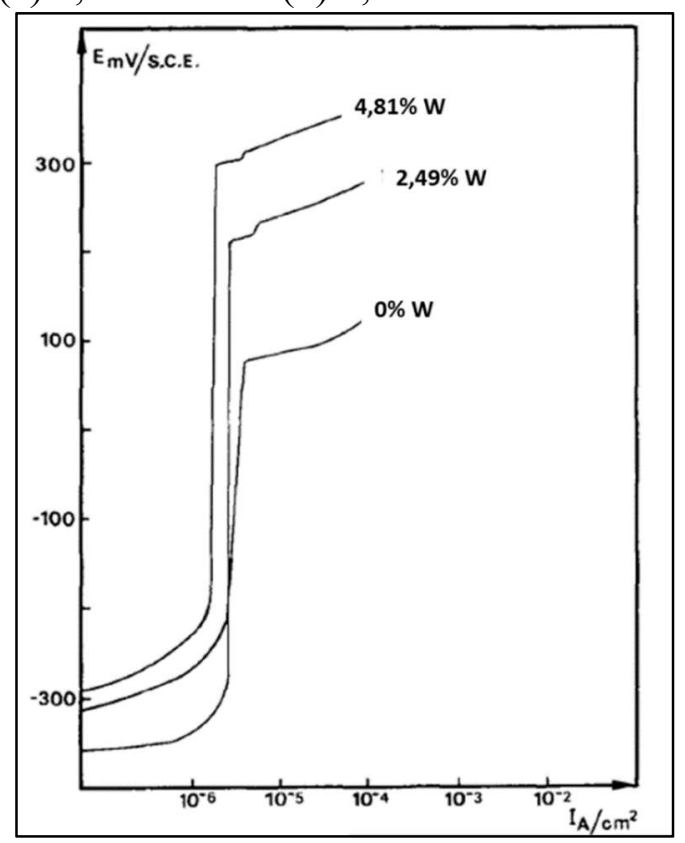

(a)

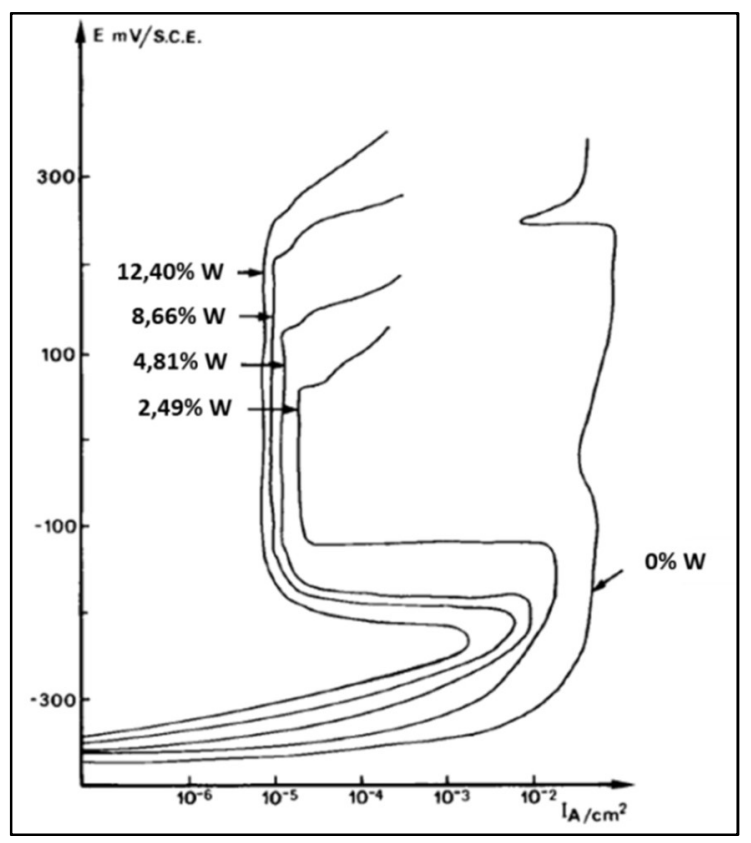

(b)

Fonte: Autor “adaptado de” Bui, N. et al., 1983.

\subsubsection{Polarização Cíclica}

A técnica de polarização potenciodinâmica apresentada anteriormente é usualmente estendida para a técnica de polarização cíclica para os estudos de corrosão localizada, pois além do potencial de pite, $E_{\text {pite, }}$, esta técnica pode fornecer o chamado potencial de repassivação, $E_{\text {rep, }}$ do material estudado. Esta técnica corresponde inicialmente ao mesmo procedimento descrito anteriormente. Ou seja, o potencial tem início no potencial de corrosão e é continuamente elevado a uma taxa constante. Porém, neste caso, ao atingir uma determinada densidade de corrente, ocorre a reversão da direção de varredura do potencial na mesma taxa de varredura. 
Assim, a densidade de corrente volta a diminuir e a varredura na direção catódica é continuada até que a curva descendente cruze a curva ascendente obtida (KELLY, 1995); (WOLYNEC, 2003). A Figura 18 apresenta o esquema de uma curva típica de polarização cíclica de um aço inoxidável em uma solução que contém íons cloretos.

Figura 18 - Esquema de uma curva típica de polarização cíclica de um aço inoxidável em uma solução que contém íons cloretos, sendo $E_{\text {corr }} \mathrm{o}$ potencial de corrosão, $E_{\text {pite }}$ o potencial de pite e $\mathrm{E}_{\text {rep }}$ o potencial de repassivação.

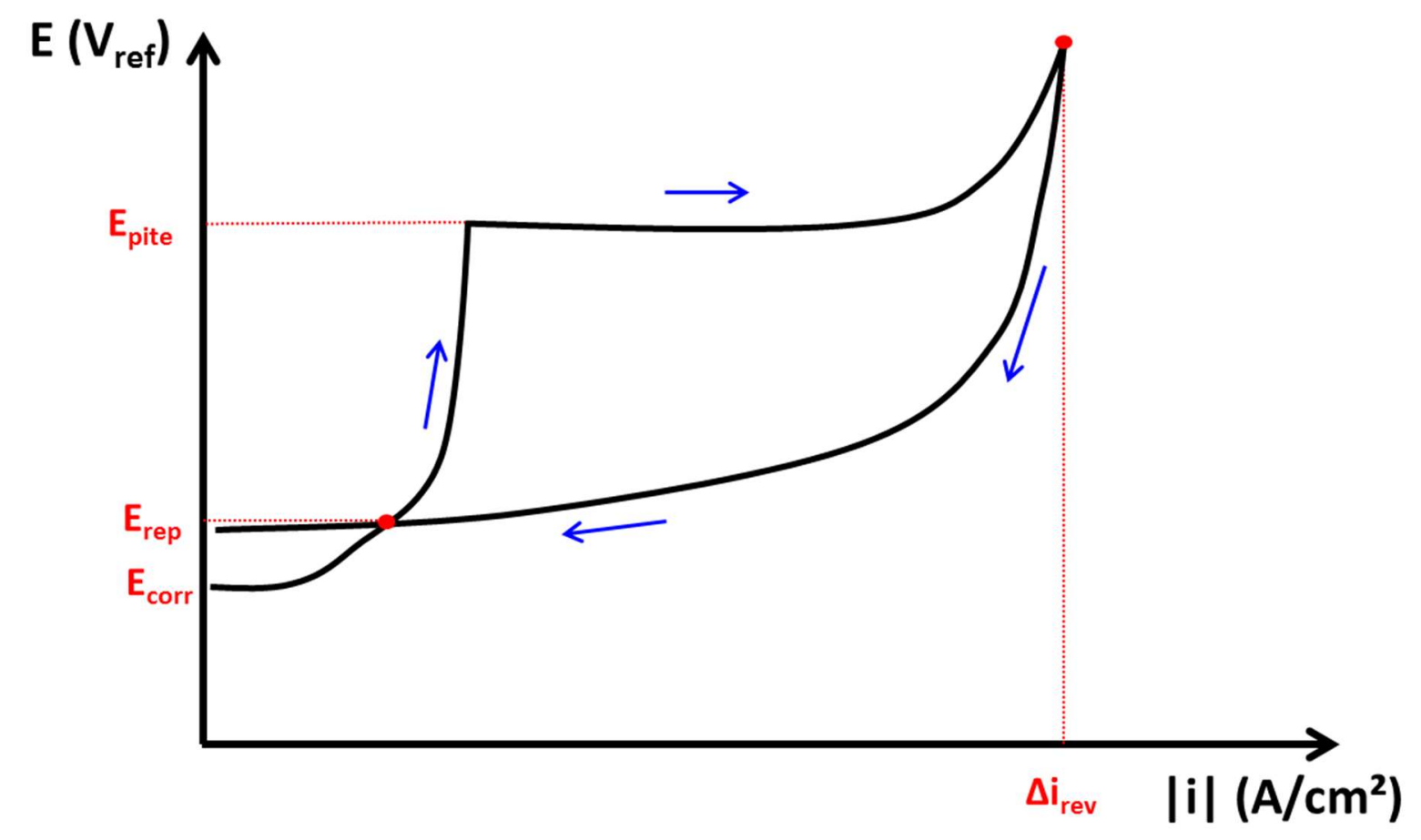

Fonte: Autor.

Conforme mencionado anteriormente, o potencial de pite $\left(E_{\text {pite }}\right)$ representa o potencial em que se tem a nucleação de pites estáveis e, consequentemente, a resistência do material ao início deste fenômeno. Assim, quanto maior o potencial de pite dos materiais estudados, maior será sua resistência. Já a densidade de corrente de reversão $\left(\Delta \mathrm{i}_{\text {rev }}\right)$ é previamente definida antes do ensaio, sendo que quanto maior seu valor, maior será a profundidade ou alargamento do pite nucleado, ou ainda, maior será a quantidade de pites nucleados. Assim que a densidade de corrente de reversão é atingida, evoluindo para potenciais catódicos, e a curva descendente atinge a curva ascendente, tem-se o potencial de repassivação, $E_{\text {rep, }}$ que representa o potencial em que os pites são repassivados. Então, quanto maior o $E_{\text {rep }}$, mais facilmente os pites nucleados serão repassivados e, consequentemente, seu crescimento interrompido. Como nos potenciais entre $E_{\text {pite }}$ e $E_{\text {rep}}$, os pites nucleados crescerão, quanto menor a diferença entre estes potenciais, mais resistente a corrosão por pites será o material. Portanto, apenas a determinação do 
potencial de pite não é suficiente para diferenciar materiais resistentes à corrosão por pite, uma vez que apenas nos potenciais abaixo de $E_{\text {rep }}$ é que o material estará imune à propagação de pites, enquanto que entre $E_{\text {rep }}$ e $E_{\text {pite }}$ não há potencial para a nucleação de pite, mas se este tiver sido formado, não terá seu crescimento impedido.

O ensaio de polarização cíclica é descrito pela norma ASTM G61-86 (2014) (AMERICAN SOCIETY FOR TESTING AND MATERIALS, 2014b). Neste documento são encontradas duas curvas típicas de polarização cíclica em solução de 3,56\% de $\mathrm{NaCl}$ a temperatura ambiente de $25 \pm 1{ }^{\circ} \mathrm{C}$ para duas ligas diferentes: liga C-276 (UNS N10276) e aço inoxidável austenítico 304 (UNS S30400), Figura 19. Nestas curvas é possível observar que apenas o aço 304 sofre corrosão por pite, apresentando um potencial de pite (E $E_{\text {pite }}$ ) da ordem de $0,015 \mathrm{~V}_{\mathrm{SCE}}$ e um potencial de repassivação $\left(\mathrm{E}_{\text {rep }}\right)$ de $-0,21 \mathrm{~V}_{\mathrm{SCE}}$. Já a curva mostrada para a liga C-276 não é resultante de corrosão localizada, mas sim, de corrosão generalizada na região transpassiva ou de evolução de oxigênio. Como os potenciais de corrosão das duas ligas são próximos, as curvas indicam que a liga C-276 é mais resistente ao início e propagação da corrosão localizada do que o aço inoxidável 304. 
Figura 19 - Curvas típicas de polarização cíclica da liga C-276 (UNS N10276) e do aço inoxidável austenítico 304 (UNS S30400) em solução de $3,56 \%$ de $\mathrm{NaCl}$ a temperatura ambiente de $25 \pm 1{ }^{\circ} \mathrm{C}$.

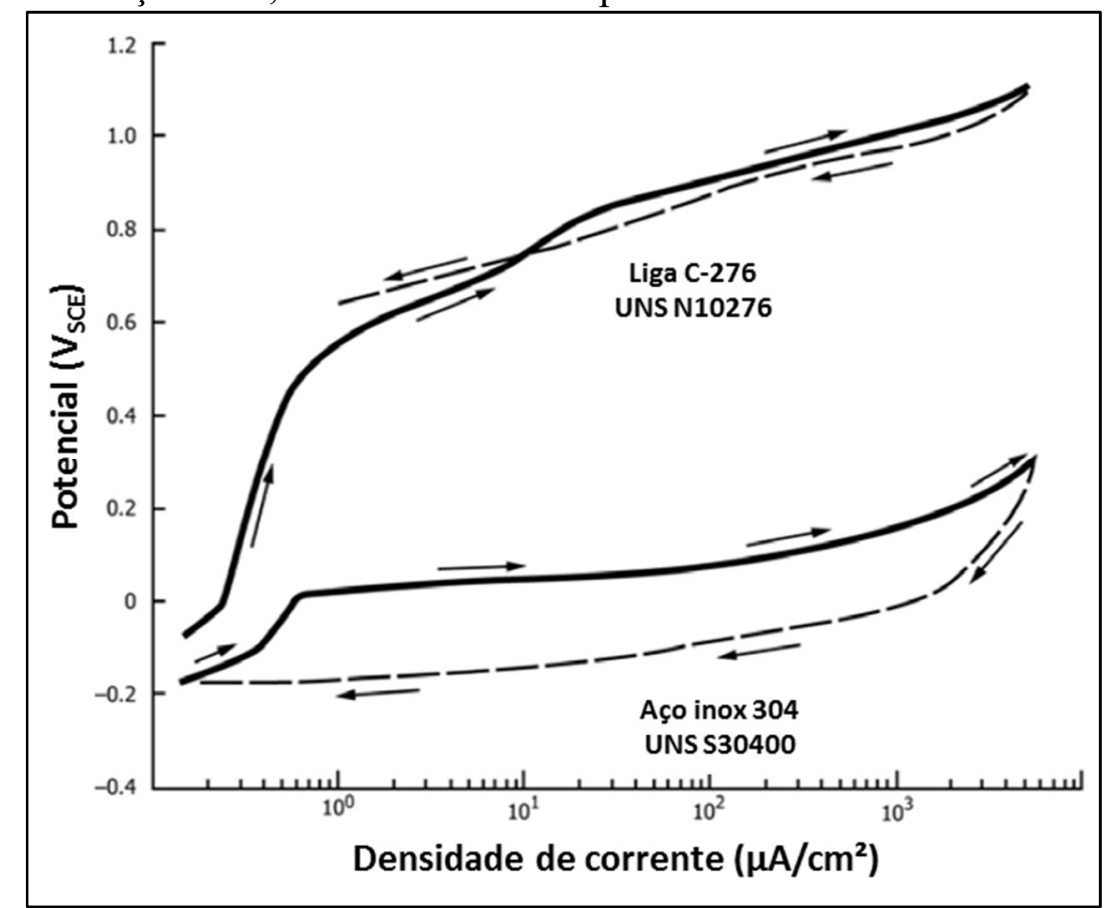

Fonte: Autor "adaptado de" ASTM International, 2014b.

\subsubsection{Temperatura crítica de pite}

A produção de materiais altamente resistentes à corrosão que contêm elementos de liga como Mo e $\mathrm{N}$ introduziu ao mercado uma grande variedade de aços inoxidáveis que não sofre corrosão por pite em temperatura ambiente em determinados meios. Porém, ensaios de corrosão por pite em temperaturas elevadas ao longo do tempo mostrou que esta propriedade é altamente dependente da temperatura. Assim, na década de 1970, Brigham e Tozer introduziram o conceito de temperatura crítica de pite, do inglês CPT ("Critical Pitting Temperature"), que corresponde à menor temperatura na qual o material não sofre corrosão por pite independente do tempo de exposição ou do potencial aplicado (BRIGHAM e TOZER, 1973); (BRIGHAM e TOZER, 1974); (EBRAHIMI, MOMENI, et al., 2012). Assim, abaixo da CPT, a quebra da película passiva observada em altos potenciais corresponde à dissolução transpassiva. Entretanto, uma vez que a temperatura ultrapasse a CPT, podem surgir pites estáveis em potenciais abaixo de potenciais transpassivos.

As duas técnicas mais comuns para obtenção da temperatura crítica de pite são descritas pelas normas ASTM G48 -11 e ASTM G150 - 99 (2004) que correspondem, respectivamente, ao ensaio por imersão e ao ensaio potenciostático (AMERICAN SOCIETY FOR TESTING AND MATERIALS, 2004) (AMERICAN SOCIETY FOR TESTING AND MATERIALS, 
2011). A técnica por imersão consiste em imergir os corpos-de-prova em solução de $10 \%$ de cloreto de ferro $\left(\mathrm{FeCl}_{3}\right)$ aquecida inicialmente em temperaturas abaixo da temperatura crítica suspeita por $72 \mathrm{~h}$. Então, as amostras são examinadas em baixo aumento (20x) a fim de verificar a presença de pites. Caso não seja detectada a presença de pites, a norma recomenda que o ensaio seja repetido subindo a temperatura de $5 \mathrm{em} 5^{\circ} \mathrm{C}$ até que o início do fenômeno de corrosão por pite seja observado. Então, a temperatura crítica será aquela máxima em que não são detectados pites. A maior limitação desta técnica está relacionada ao longo tempo necessário para que os dados sejam obtidos. Além disso, o meio analisado pode não representar o meio de interesse, o que poderia invalidar a análise (AMERICAN SOCIETY FOR TESTING AND MATERIALS, 2011).

Já na técnica eletroquímica, o corpo de prova é exposto a uma solução de $1 \mathrm{M}$ de cloreto de sódio $(\mathrm{NaCl})$ inicialmente a $0^{\circ} \mathrm{C}$ e potencial de $700 \mathrm{mV}$. Então, a solução é aquecida a uma taxa de $1^{\circ} \mathrm{C} / \mathrm{min}$ e a corrente elétrica é monitorada. A CPT é definida quando a corrente aumenta bruscamente, excedendo $100 \mu \mathrm{A} / \mathrm{cm}^{2}$ por mais de 60 segundos, Figura 20. Após a finalização do ensaio, a presença de pites é confirmada visualmente com o auxílio de um microscópio ótico (AMERICAN SOCIETY FOR TESTING AND MATERIALS, 2004).

Figura 20 - Determinação da temperatura crítica de pite de um aço inoxidável utilizando a técnica potenciostática descrita na norma ASTM G150 - 99 (2004).

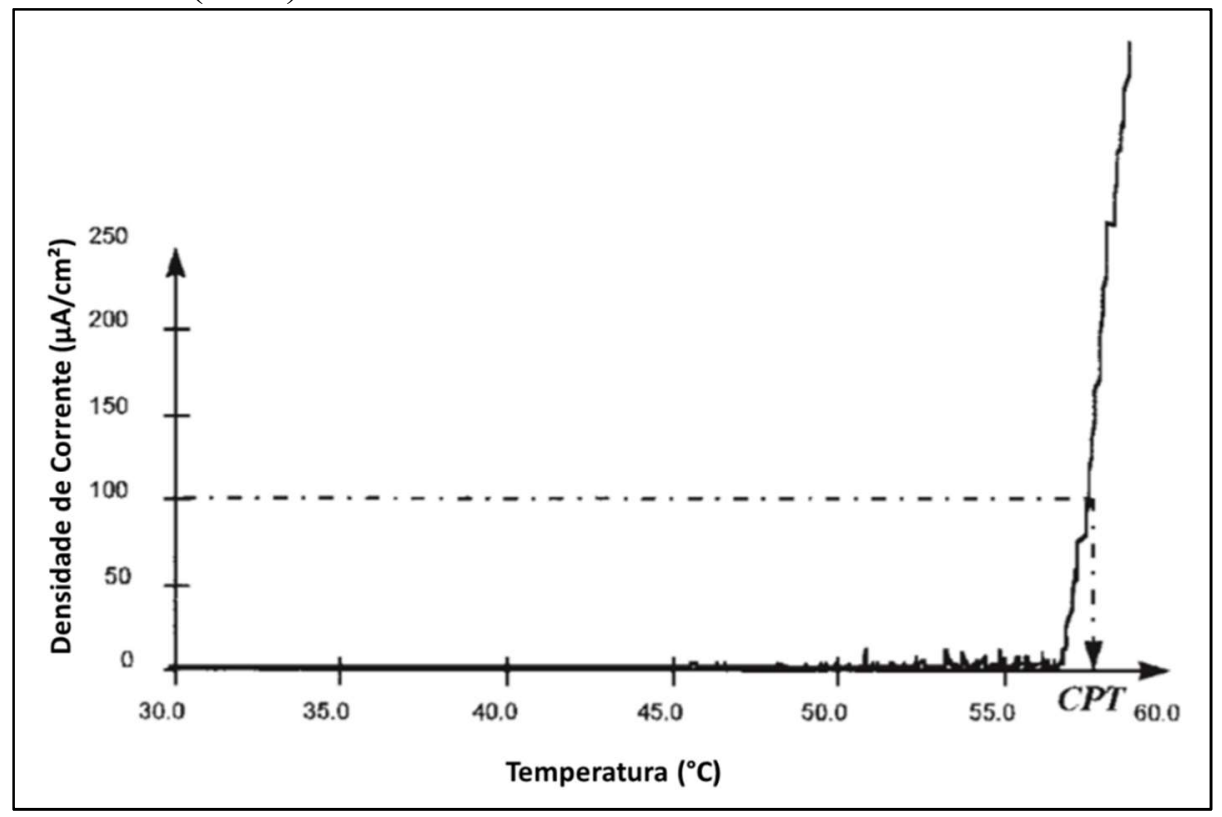

Fonte: Autor "adaptado de" American Society for Testing and Materials, 2004. 


\subsubsection{Técnica Eletroquímica de Reativação Potenciodinâmica de Ciclo Duplo (DL-EPR)}

Para a avaliação da resistência à corrosão intergranular, ou para a determinação do grau de sensitização, de aços inoxidáveis usualmente é utilizada a técnica eletroquímica de reativação potenciodinâmica, conhecida como EPR ("Electrochemical Potentiodynamic Reactivation"). Assim como as técnicas de polarização descritas anteriormente, o princípio da técnica EPR consiste em medir a corrente elétrica gerada em resposta a uma varredura de potencial aplicado, avaliando as características da curva Potencial (E) versus Corrente (i). Esta técnica é baseada na identificação de pontos anódicos nos contornos de grão causados pela formação de fases ricas em de cromo e, consequentemente, depleção de cromo ao redor destas regiões, usualmente contornos de grão, como descrito anteriormente.

Curvas de polarização potenciodinâmica dos mesmos materiais sensitizados e nãosensitizados permitem observar que a depleção de cromo afeta principalmente parâmetros como a densidade de corrente crítica ( $i_{\text {crit }}$ ) e a densidade de corrente passiva ( $i_{\text {pass }}$ ), Figura 21 (OSOZAWA, BOHNENKAMP e ENGEL, 1966). Porém diferenças mais pronunciadas são observadas no "nariz anódico" desta curva, que corresponde à transição ativo-passivo, sendo que materiais que apresentam maior grau de sensitização tendem a apresentar maior área desta região da curva. Assim, surgiram dois métodos eletroquímicos de reativação para avaliação do grau de sensitização de aços inoxidáveis: ciclo simples e ciclo duplo (SEDRIKS, 1979); (CIHAL, LASEK, et al., 2007); (CIHAL, 1980). 
Figura 21 - Curvas de polarização anódica do aço inoxidável 304 em solução de $2 \mathrm{~N} \mathrm{H}_{2} \mathrm{SO}_{4}$ a $90^{\circ} \mathrm{C}$ após sensitização a $750^{\circ} \mathrm{C}$ por diferentes tempos: $\mathrm{x}=0,3,30$, 100 e 1000 horas.

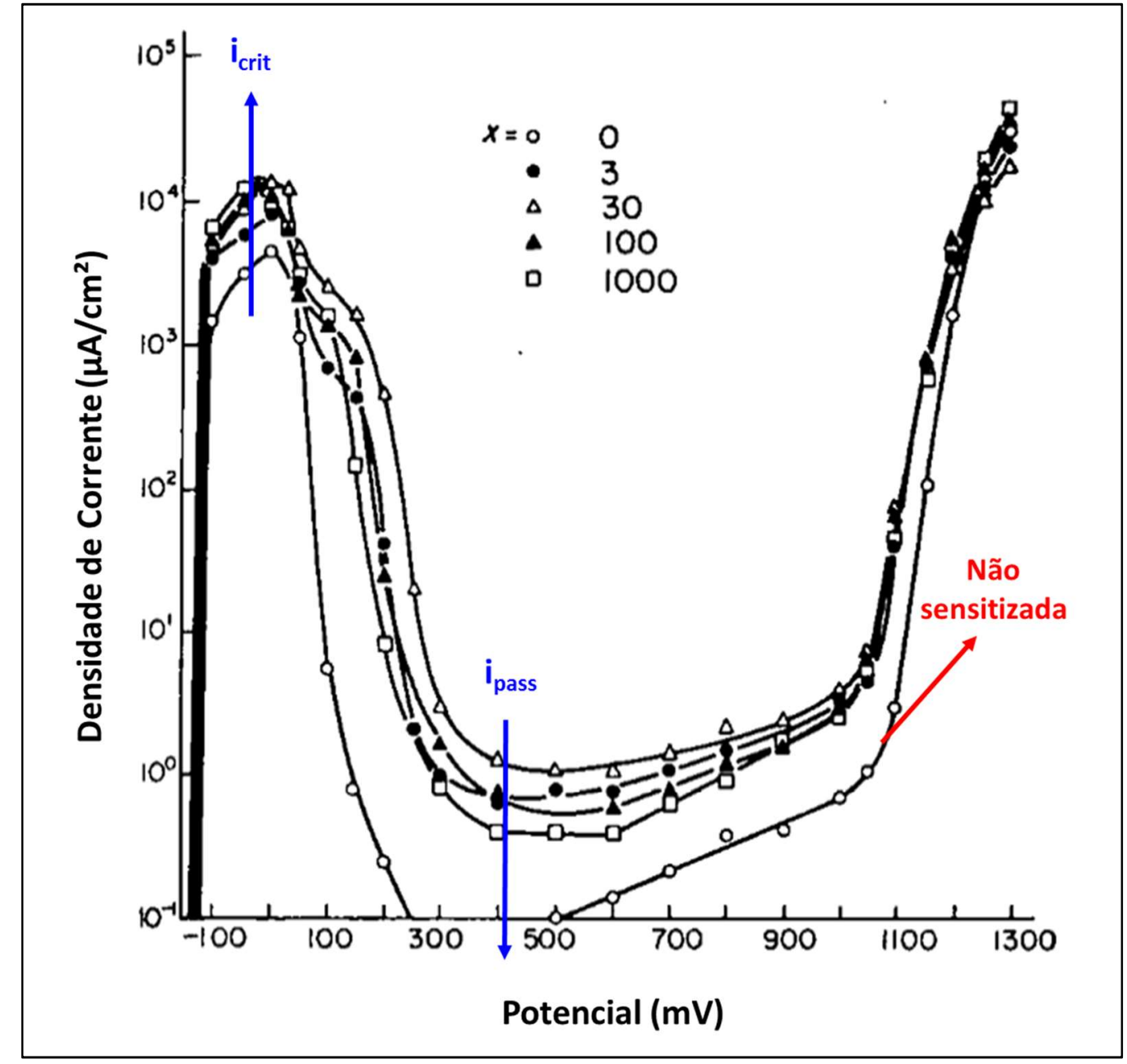

Fonte: Autor "adaptado de" Osozawa, Bohnenkamp e Engel, 1966.

O método de ciclo simples (SL-EPR, Single-Loop EPR), normatizado pela ASTM G108 - 94 (2010), consiste em realizar um ensaio de polarização potenciodinâmica "reverso" iniciando a varredura de potenciais positivos para negativos, ou seja, de potenciais passivos, ou além da passividade, em direção ao potencial de corrosão ( $\left.E_{\text {corr }}\right)$ (AMERICAN SOCIETY FOR TESTING AND MATERIALS, 2010). Já na técnica de ciclo duplo (DL-EPR, “Double-Loop $E P R$ ”), ISO 12732 (2006), a amostra é inicialmente polarizada anodicamente até potenciais de passividade incompleta, etapa chamada de ativação, seguida por uma varredura reversa até o potencial de circuito aberto, representando a etapa de reativação (INTERNATIONAL ORGANIZATION FOR STANDARDIZATION, 2006). Como a etapa de reativação é iniciada em um estado de passividade incompleta, em ambos os métodos é possível identificar mudanças locais de composição química causadas pelos diferentes teores de Cromo em solução sólida devido à precipitação, pois apesar da depleção de cromo ao redor dos contornos de grão, estas 
áreas também são cobertas por uma película passiva, porém imperfeita. Então, aumentando o potencial em direção à região ativa, estas regiões mais fracas da película tendem a ser dissolvidas preferencialmente, pois são ativadas primeiro, enquanto que as regiões que apresentam maior teor de cromo em solução sólida necessitam de condições mais agressivas para serem dissolvidas. Graças a esse atraso na dissolução das regiões mais ricas em cromo durante a reativação, é possível detectar o ataque não uniforme revelado na curva obtida por meio da razão entre o pico de corrente de ativação $\left(I_{a}\right)$ e o pico de corrente de reativação $\left(I_{r}\right)$ e obter então o grau de sensitização de cada material, (DOS, "Degree of Sensitization") comparando-o à condição solubilizada, Figura 22 (CIHAL, 1980); (CIHAL, LASEK, et al., 2007); (RÉQUIZ e ALVAREZ, 1998).

Figura 22 - Curva esquemática de um ensaio DL-EPR de um aço inoxidável em solução de $\mathrm{H}_{2} \mathrm{SO}_{4}+\mathrm{KSCN}$.

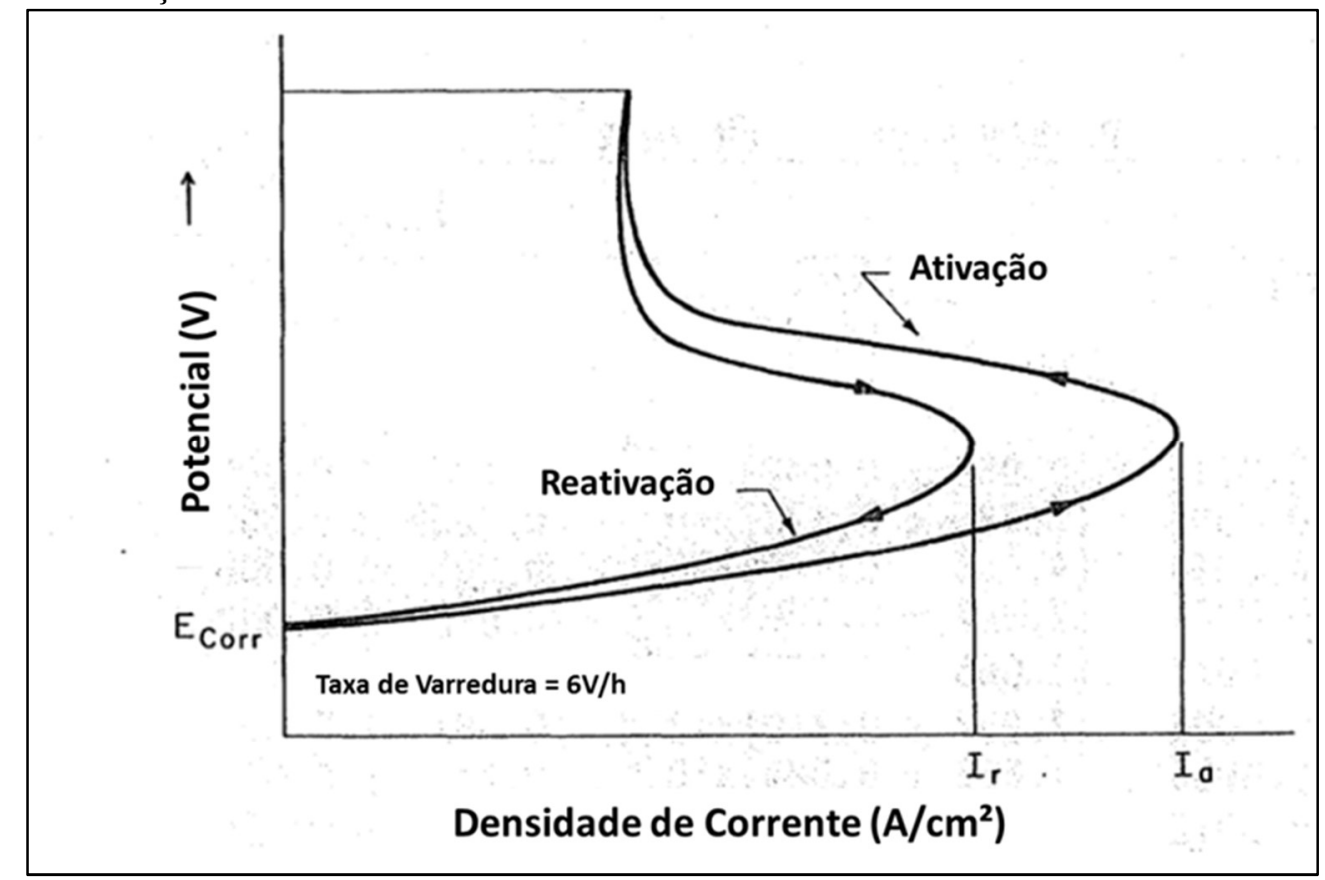

Fonte: Autor “adaptado de” Majidi e Streicher, 1984.

A vantagem da técnica de ciclo duplo em relação a de ciclo simples está relacionada à independência do tamanho de grão do material analisado e à menor sensitividade ao acabamento superficial. Porém, o método de ciclo simples pode ser aplicado em campo se utilizada uma célula de corrosão adaptada (SEDRIKS, 1979). 


\subsection{SUBSTITUIÇÃO DE MOLIBDÊNIO POR TUNGSTÊNIO}

Existem na literatura alguns estudos relacionados à adição de $\mathrm{W}$ em aços inoxidáveis dúplex e ferríticos, e outros que avaliam a substituição efetiva do Mo por este elemento de liga. Oh, et al. (1993), por exemplo, estudaram o efeito do W na resistência à corrosão de aços inoxidáveis dúplex Fe-22Cr-5,5Ni-0,15N na ausência e na presença de Mo, Tabela 2.

Tabela 2 - Composição química (\%wt) das ligas estudadas por Oh et al. (1993).

\begin{tabular}{c|c|c|c|c|c}
\hline Liga & $\mathbf{C r}$ & $\mathbf{N i}$ & $\mathbf{W}$ & Mo & $\mathbf{N}$ \\
\hline $\mathbf{0 W}$ & 20,0 & 5,7 & - & - & 0,15 \\
\hline $\mathbf{3 W}$ & 21,8 & 5,27 & 2,94 & - & 0,134 \\
\hline $\mathbf{6 W}$ & 21,0 & 6,13 & 6,0 & - & 0,15 \\
\hline $\mathbf{8 W}$ & 22,0 & 5,5 & 8,0 & - & 0,15 \\
\hline $\mathbf{3 M o}$ & 21,9 & 5,63 & - & 2,78 & 0,171 \\
\hline 3W-1Mo & 22,0 & 5,22 & 2,7 & 1,05 & 0,166 \\
\hline
\end{tabular}

Fonte: Oh, et al., 1993.

Segundo os autores, curvas de polarização anódica determinadas potenciodinamicamente em uma solução desaerada de $3,5 \% \mathrm{NaCl}$ a $80^{\circ} \mathrm{C}$ e uma taxa de 0,5 $\mathrm{mV} / \mathrm{s}$ mostraram que o aumento de $\mathrm{W}$ na liga provoca um aumento considerável nos potenciais de pite $\left(\mathrm{E}_{\text {pite }}\right)$ e de corrosão ( $\left.\mathrm{E}_{\text {corr }}\right)$, além de um aumento gradual na região passiva da liga $(\mathrm{OH}$, et al., 1993). Portanto, o aumento do teor de $\mathrm{W}$ aumentaria não só a resistência à corrosão por pite, mas também a estabilidade do filme passivo dos aços inoxidáveis dúplex na presença de cloretos, assim como o Mo, Figura 23 (a).

Os autores observaram também que comparando os efeitos do Mo e W em porcentagem em massa equivalente, os materiais com Mo apresentam potencial de pite maior $(\mathrm{OH}$, et al., 1993). Mas, quando pequenas quantidades de Mo são adicionadas juntamente com o W, o potencial de pite aumenta consideravelmente, mostrando um efeito sinérgico entre os dois elementos de liga, Figura 23 (b) (OH, et al., 1993). Segundo Bui, et al. (1983), o efeito benéfico do $\mathrm{W}$ estaria associado à interação do $\mathrm{WO}_{3}$ com alguns outros óxidos, tais como $\mathrm{Cr}_{2} \mathrm{O}_{3}$ e $\mathrm{MoO}_{3}$, no filme passivo, aumentando assim a estabilidade e a amorfização da camada passiva (BUI, et al., 1983. 
Figura 23- Efeito do teor de W nas curvas de polarização anódicas do aço inoxidável duplex Fe-22Cr-5,5Ni-0, $15 \mathrm{~N}$ a $80^{\circ} \mathrm{C}$ em uma solução de 3,5\% NaCl. (a) Diferentes teores de W; (b) Comparação do efeito sinérgico entre Mo e W.

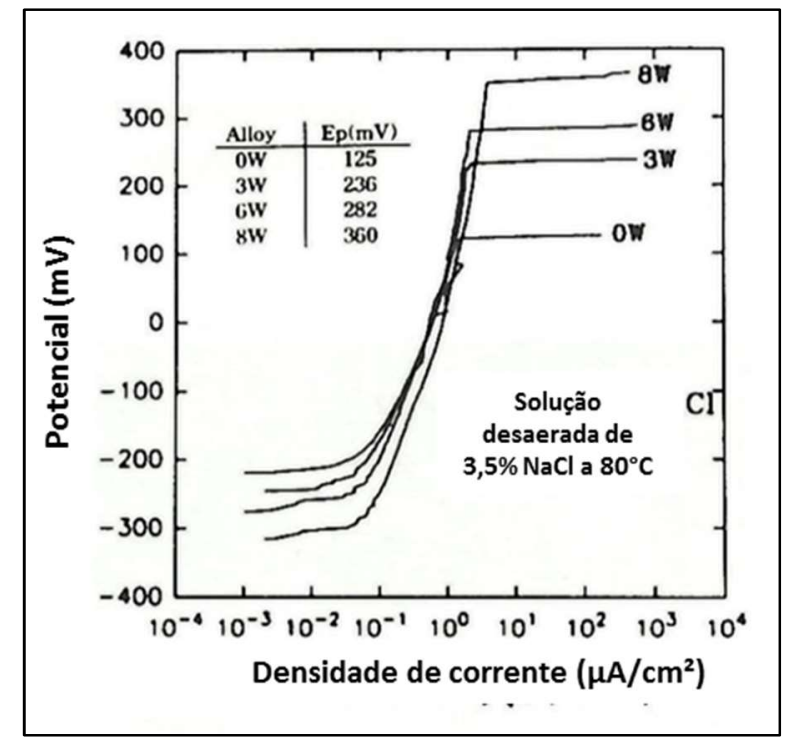

(a)

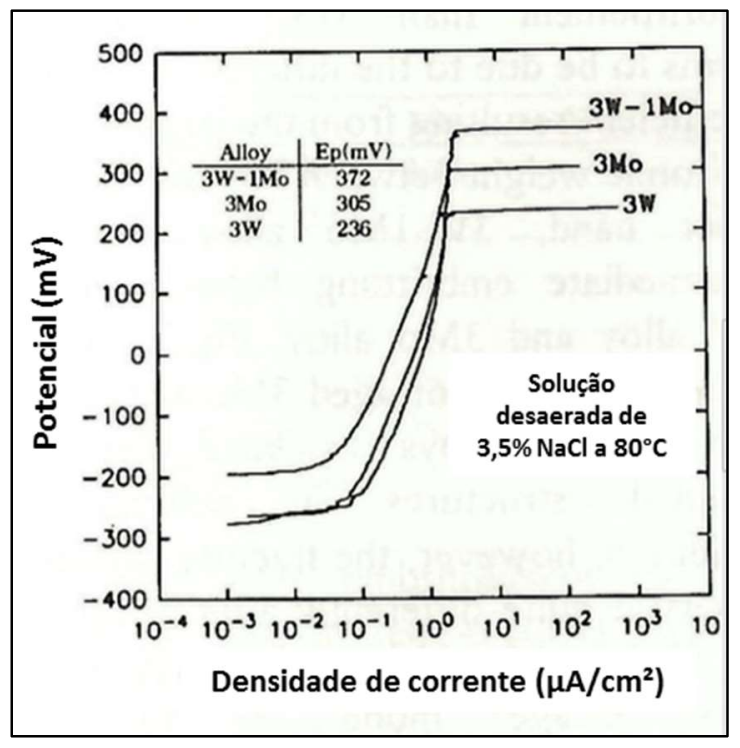

(b)

Fonte: Autor "adaptado de" Oh, et al., 1993.

No mesmo trabalho, Oh, et al. (1993) estudaram a resistência à corrosão sob tensão da liga Fe-22Cr-5,5Ni-0,15N pelo método SSRT ( "slow strain rate tests" ou BTD - "Baixa Taxa de Deformação"), Figura 24, utilizando uma taxa de deformação de $2,1 \times 10^{-6} \mathrm{~s}^{-1}$ numa solução desaerada de $40 \%$ de $\mathrm{MgCl}_{2}$ a $138^{\circ} \mathrm{C}$ e, dentre as ligas estudadas (3W, $3 \mathrm{Mo}$ e $3 \mathrm{~W}-1 \mathrm{Mo}$ ), a liga $3 \mathrm{~W}-1 \mathrm{Mo}$ apresentou o melhor resultado de resistência à corrosão sob tensão. Segundo os autores, este resultado estaria associado à maior taxa de repassivação desta entre as ligas estudadas (OH, et al., 1993). 
Figura 24- Curvas de corrosão sob tensão obtidas pelo método SSRT ("slow strain rate tests" ou BTD - "Baixa Taxa de Deformação") para as ligas 3W, 3Mo e 3W$1 \mathrm{Mo}$ em solução de $40 \%$ de $\mathrm{MgCl}_{2}$ a $138^{\circ} \mathrm{C}$.

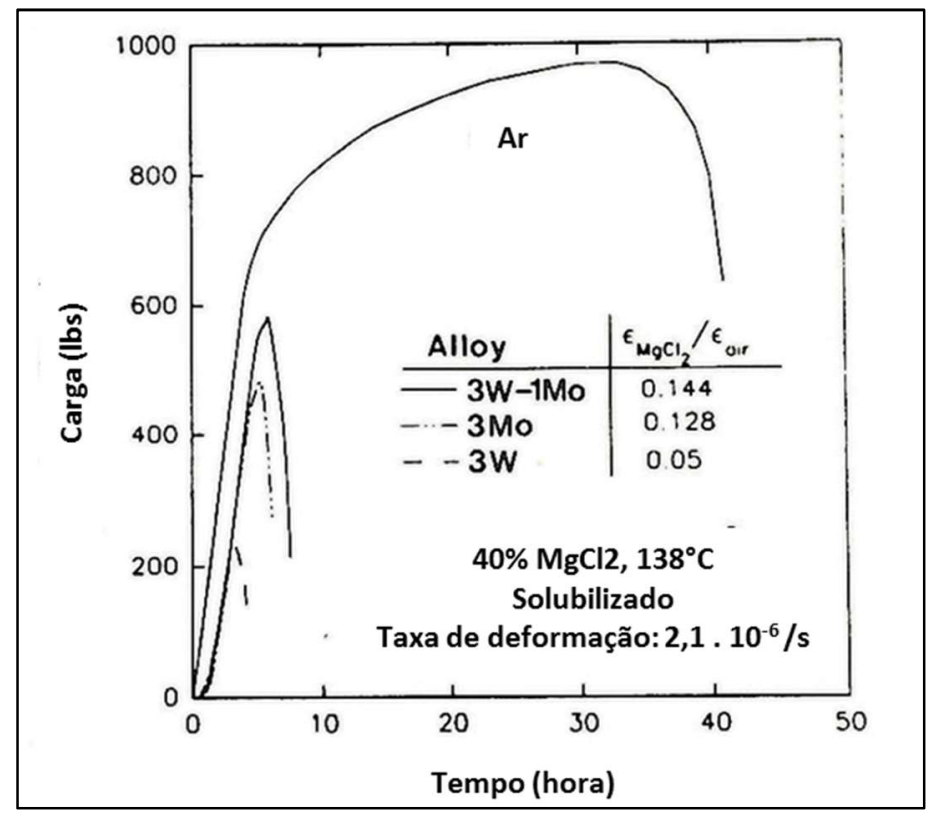

Fonte: Autor “adaptado de" Oh, et al., 1993.

É importante salientar que, como a massa atômica do molibdênio corresponde a cerca de $52 \%$ da massa atômica do tungstênio, $96 \mathrm{~g} / \mathrm{mol}$ do primeiro contra $184 \mathrm{~g} / \mathrm{mol}$ do segundo, é natural que a liga que contém cerca de $3 \%$ em massa de $\mathrm{W}$ apresente desempenho pior que aquela que apresenta cerca de 3\% em massa de Mo, uma vez que existem menos átomos de $\mathrm{W}$ disponíveis para participar de mecanismos que colaboram com o aumento da resistência à corrosão na superfície em contato com o meio corrosivo. De fato, comparando os resultados apresentados pelos autores para a liga que apresenta 6\% em massa de W (Figura 23 (a)) com aquela que apresenta 3\% em massa de Mo (Figura 23 (b)), os potenciais de pite das duas ligas são bastante próximos, $282 \mathrm{mV}$ da primeira contra $305 \mathrm{mV}$ da segunda.

Da mesma forma, Kim e Kwon (1999) destacaram que, de acordo com a Equação 6, que descreve o índice de resistência à corrosão por pite $\left(\mathrm{PREW}_{2}\right)$ para aços inoxidáveis dúplex, uma mesma quantidade em massa de $\mathrm{W}$ proporciona apenas $50 \%$ do aumento da resistência à corrosão que o Mo proporciona a esta classe de materiais (KIM e KWON, 1999). Porém, observando a Figura 23, é possível notar que o potencial de pite obtido pelos autores para o aço inox dúplex que contém 3\% em massa de Mo é igual a $305 \mathrm{mV}$, enquanto que o mesmo parâmetro obtido para a liga que apresenta 3\% em massa de $\mathrm{W}$ é igual a $236 \mathrm{mV}$. Ou seja, o potencial de pite do aço que apresenta $3 \%$ em massa de $\mathrm{W}$ corresponde a $77 \%$ do potencial de 
pite da liga que apresenta a mesma proporção em massa de Mo. Portanto, o valor correto do coeficiente que multiplica a fração mássica de W na Equação 6 deveria estar em torno de 0,7. Dessa forma, Kim e Kwon (1999) destacam que o valor deste coeficiente para esta classe de materiais deve ser melhor entendido e estudado a fim de representar de maneira mais efetiva o real efeito do W nos aços inoxidáveis dúplex. Estes autores estudaram os efeitos da substituição parcial de Mo por W na resistência à corrosão e formação da fase $\sigma$, observando as alterações nas propriedades mecânicas e distribuições de fase nos tratamentos térmicos de envelhecimento no aço inoxidável dúplex $25 \mathrm{Cr}$, cujas composições são mostradas na Tabela 3 (KIM e KWON, 1999).

Tabela 3 - Composições químicas (\%wt) do aço inoxidável súplex 25Cr estudados por Kim e Kwon. (1996).

\begin{tabular}{c|c|c|c|c|c|c}
\hline Liga & $\mathbf{C r}$ & $\mathbf{N i}$ & $\mathbf{M o}$ & $\mathbf{W}$ & $\mathbf{N}$ & $\mathbf{F e}$ \\
\hline $\mathbf{3 W}$ & 25,26 & 6,39 & 2,72 & - & 0,232 & Bal. \\
\hline 3W-1,5Mo & 25,29 & 6,89 & 1,55 & 2,86 & 0,260 & Bal. \\
\hline $\mathbf{2 W - 2 M o}$ & 25,70 & 7,00 & 1,94 & 2,05 & 0,251 & Bal. \\
\hline
\end{tabular}

Assim como Oh, et al (1993), segundo Kim e Kwon (1999), a resistência à corrosão por pite e à corrosão sob tensão em soluções que contêm cloretos aumentaram com o aumento da proporção entre W e Mo, sendo que a liga que contém 3\%W e 1,5\%Mo em massa (3W-1,5Mo) apresentou o melhor desempenho em todos os ensaios: polarização anódica em solução desaerada de $4 \mathrm{M}$ de $\mathrm{NaCl}$ a $80^{\circ} \mathrm{C}$, temperatura crítica de pite obtida em polarização a 600 $\mathrm{mV}_{\mathrm{SCE}}$ em solução desaerada de $4 \mathrm{M}$ de $\mathrm{NaCl}$ nas condições solubilizada e envelhecidas, e corrosão sob tensão utilizando o método SSRT ("slow strain rate tests" ou BTD - "Baixa Taxa de Deformação") em solução de $72 \% \mathrm{MgCl}_{2}$ em ebulição (KIM e KWON, 1999); (OH, et al., 1993).

Os autores concluíram também que o aumento do teor de $\mathrm{W}$ neste aço inoxidável dúplex contribuiu para a redução da taxa de fragilização induzida por envelhecimento e manteve um alto valor de impacto Charpy, $103 \mathrm{~J}$, sem perdas consideráveis em ductilidade após o envelhecimento (KIM e KWON, 1999). Segundo eles, o W se comporta como um forte estabilizador da fase $\chi$, que contém altos teores de Mo e W. A precipitação preferencial desta fase nas ligas que contêm $\mathrm{W}$ durante o início do envelhecimento contribuiu para retardar a nucleação e crescimento da fase $\sigma$ por meio do empobrecimento de Mo e W nos contornos de grão. Os autores acreditam que, como a fase $\sigma$ na liga $3 \mathrm{~W}-1,5 \mathrm{Mo}$ apresenta alto teor de $\mathrm{W}$, a 
menor difusividade do W comparado ao Mo contribuiu para este atraso na nucleação e crescimento desta fase durante o envelhecimento (KIM e KWON, 1999).

A resistência à corrosão dos aços inoxidáveis dúplex que contêm adições de $\mathrm{W}$ também foi estudada por Park e Kwon (2002). Contudo, estes autores estudaram o efeito do tungstênio especificamente nos tratamento térmicos de envelhecimento a $475^{\circ} \mathrm{C}$. Os autores variaram os teores de Mo e $\mathrm{W}$ de 0 a 3\% e de 0 a 6\%, respectivamente, no aço inoxidável dúplex Fe-25Cr7Ni-0,25N (PARK e KWON, 2002). De acordo com as curvas de polarização anódica em solução de $4 \mathrm{M} \mathrm{NaCl}$ a $80^{\circ} \mathrm{C}$, em $1 \mathrm{M} \mathrm{HCl}$ a $30^{\circ} \mathrm{C}$ e também curvas de DL-EPR em $0,5 \mathrm{M}$ de $\mathrm{H}_{2} \mathrm{SO}_{4}+0,001$ M TA (tioacetamida), o aumento do teor de $\mathrm{W}$ reduziu a taxa de degradação das propriedades mecânicas e de resistência à corrosão deste material mesmo na condição envelhecida. Os autores atribuem este efeito à precipitação da fase $\alpha$, sugerindo que este elemento retarda a formação desta fase devido à menor taxa de difusão do $\mathrm{W}$ em relação ao Mo (PARK e KWON, 2002).

Já Ahn, Kwon e Lee (1998) estudaram a influência do W e do Mo na passivação do aço inoxidável ferrítico Fe-29Cr, cujas composições são mostradas na Tabela 4. Curvas de polarização anódica conduzidas potenciodinamicamente, e com uma taxa de varredura de 0,5 $\mathrm{mV} / \mathrm{s}$ em uma solução de $4 \mathrm{M}$ de $\mathrm{MgCl}_{2}$ a $80^{\circ} \mathrm{C}$ mostraram que o potencial de pite ( $\mathrm{E}_{\text {pit }}$ ) para as ligas Fe-29Cr aumentou linearmente com o aumento dos teores de Mo e W, Figura 25 (AHN, KWON e LEE, 1998).

Tabela 4 - Composições químicas (\%wt) do aço inoxidável $\mathrm{Fe}-29 \mathrm{Cr}$ estudadas por Ahn, Kwon e Lee (1998).

\begin{tabular}{c|c|c|c}
\hline Liga & Cr & Mo & W \\
\hline 29Cr & 28,93 & 0,012 & 0,011 \\
\hline 29Cr-1W & 28,89 & 0,011 & 1,08 \\
\hline 29Cr-2W & 28,88 & 0,011 & 2,08 \\
\hline 29Cr-4W & 28,85 & 0,01 & 4,10 \\
\hline 29Cr-8W & 28,78 & 0,011 & 8,17 \\
\hline 29Cr-1Mo & 28,97 & 1,04 & 0,010 \\
\hline 29Cr-2Mo & 29,06 & 2,07 & 0,010 \\
\hline 29Cr-4Mo & 29,1 & 4,19 & 0,011 \\
\hline 29Cr-1Mo-3W & 28,86 & 1,09 & 3,10 \\
\hline 29Cr-2Mo-2W & 28,89 & 2,11 & 2,07 \\
\hline 29Cr-3Mo-1W & 29,04 & 3,15 & 1,06 \\
\hline
\end{tabular}

Fonte: Ahn, Kwon e Lee, 1998. 
Figura 25 - Curvas de polarização anódica em solução de $4 \mathrm{M}$ de $\mathrm{MgCl}_{2}$ a $80^{\circ} \mathrm{C}$ para os aços (a) Fe-29Cr-xMo (x = 0 a 4 wt\%) e (b) Fe-29Cr-yW (y=0 a 8 wt $\%$ ).

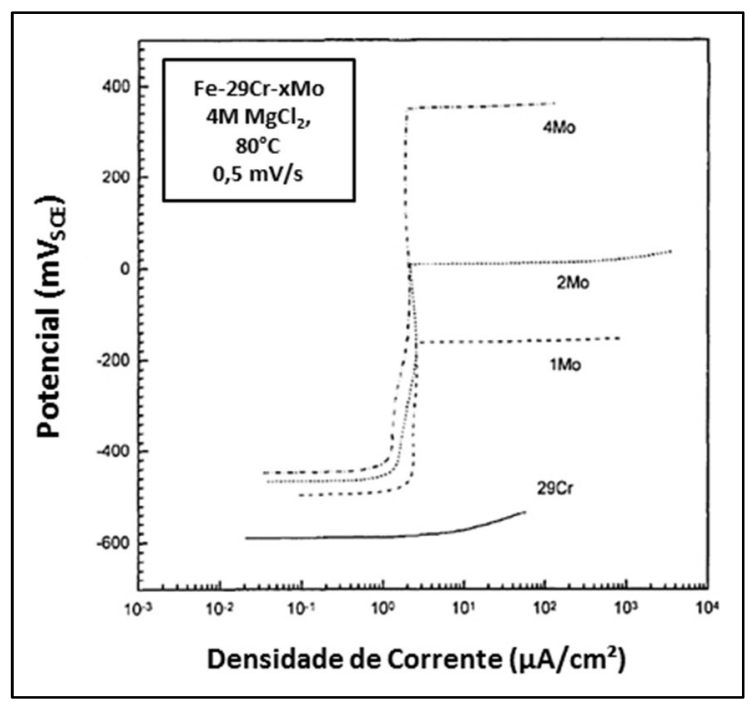

(a)

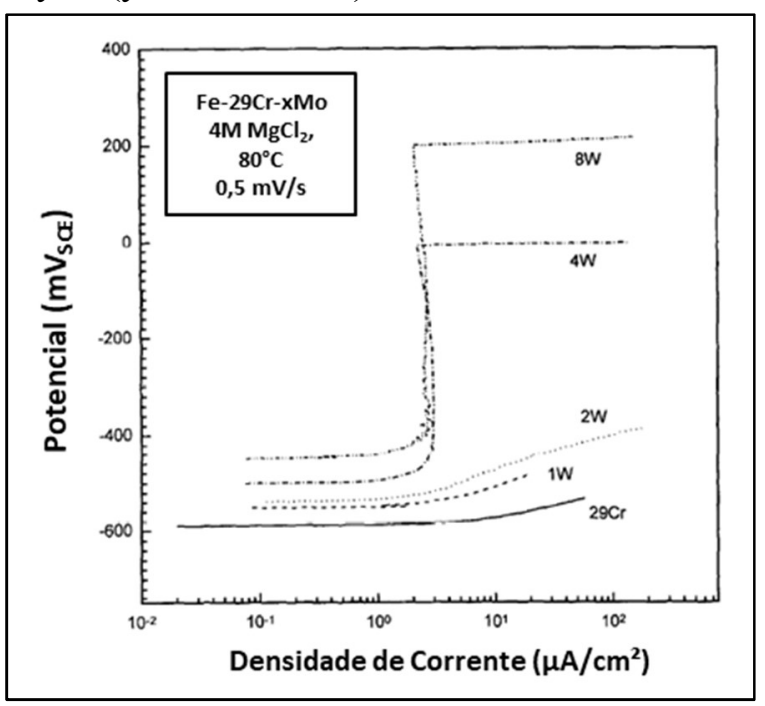

(b)

Fonte: Autor "adaptado de" Ahn, Kwon e Lee, 1998.

Entretanto, segundo os autores, a taxa de aumento no $\mathrm{E}_{\text {pite }} \mathrm{em}$ função da porcentagem em massa (wt\%) de Mo é quase o dobro daquela em função da wt $\% \mathrm{~W}$, indicando que a adição de Mo na liga Fe-29Cr é duas vezes mais efetiva no aumento da resistência à corrosão por pite que a adição de W, Figura 26 (a). Assim, mais uma vez, baseando-se na porcentagem atômica (\%at) de cada um destes elementos na liga Fe-29Cr, o efeito no aumento do $E_{\text {pite }}$ é praticamente equivalente para o Mo e W, como mostra a Figura 26 (b) (AHN, KWON e LEE, 1998). 
Figura 26 - Dependência do potencial de pite no aço inoxidável ferrítico Fe-29Cr em solução de $4 \mathrm{M} \mathrm{MgCl} 2$ a $80^{\circ} \mathrm{C}$ em relação a (a) Porcentagem em massa de $\mathrm{Mo} \mathrm{e} \mathrm{W;} \mathrm{(b)} \mathrm{porcentagem}$ atômica de Mo e W.

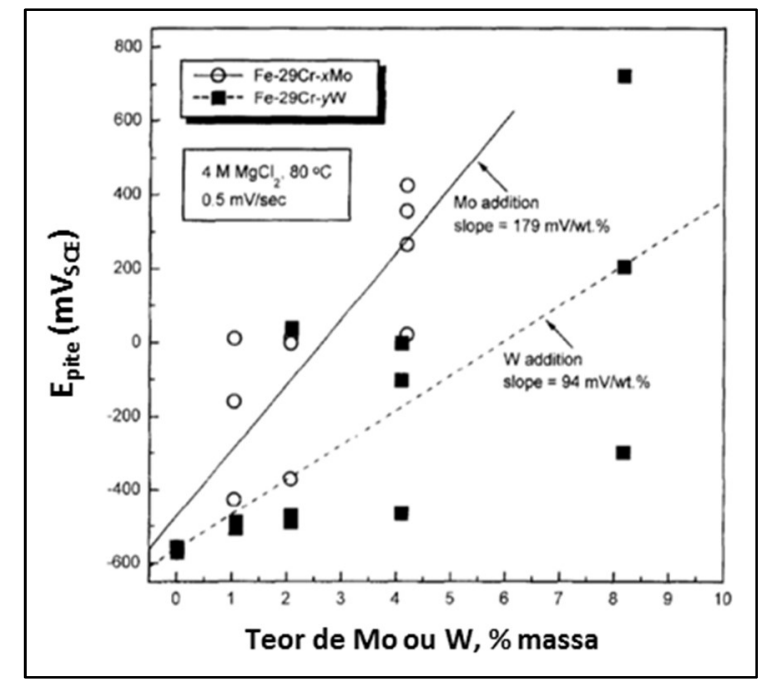

(a)

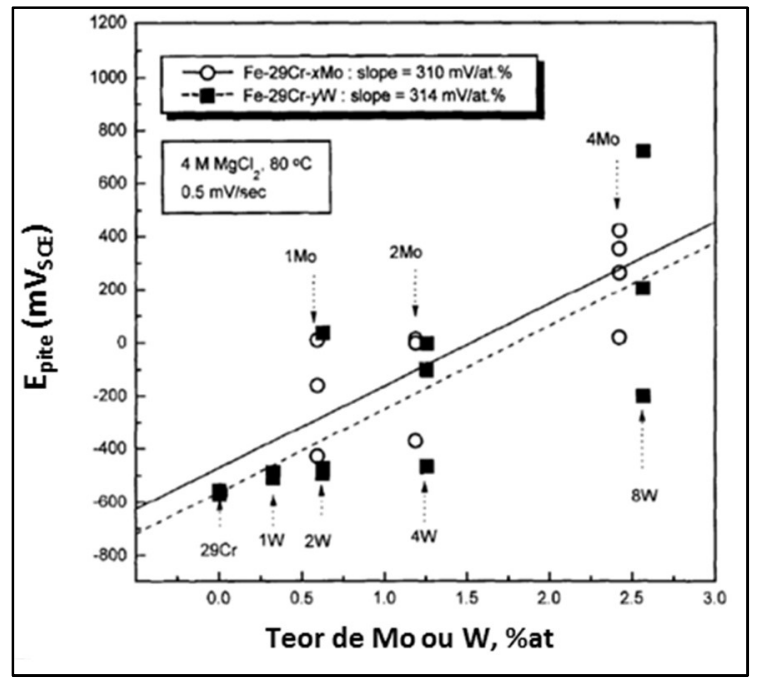

(b)

Fonte: Autor "adaptado de" Ahn, Kwon e Lee, 1998.

Assim, baseando-se nos resultados obtidos, os autores chegaram numa fórmula empírica que relaciona o $\mathrm{E}_{\text {pite }} \mathrm{e}$ o teor de $\mathrm{W}$ e Mo na liga estudada em fração atômica, Equação 12.

$E_{\text {pite }}=A_{1}+B_{1} X_{M o(W)}$

Onde, $A_{1}$ e $B_{1}$ são constantes e $X_{M o(W)}$ é o teor de Mo ou W em \%wt ou \%at.

Ainda neste mesmo trabalho, Ahn, Kwon e Lee (1998) estudaram o efeito sinérgico do Mo e W na liga Fe-29Cr, Figura 27. Segundo os autores, o $\mathrm{E}_{\text {pite }}$ aumenta linearmente com o aumento dos teores de $(\mathrm{Mo}+\mathrm{W})$ at $\%$. Segundo os autores, a taxa de aumento no $\mathrm{E}_{\text {pite }}$ em função da porcentagem atômica de $(\mathrm{Mo}+\mathrm{W})$ é praticamente igual à taxa de aumento das ligas que apresentam Mo e W puros. Portanto, não haveria um efeito sinérgico entre os elementos de liga Mo e W na liga Fe-29Cr (AHN, KWON e LEE, 1998). 
Figura 27 - Dependência do potencial de pite $\left(\mathrm{E}_{\text {pite }}\right)$ na fração atômica de $(\mathrm{Mo}+\mathrm{W})$ no aço inoxidável $\mathrm{Fe}-29 \mathrm{Cr}$ em solução de $4 \mathrm{M} \mathrm{MgCl} 2$ a $80^{\circ} \mathrm{C}$ ).

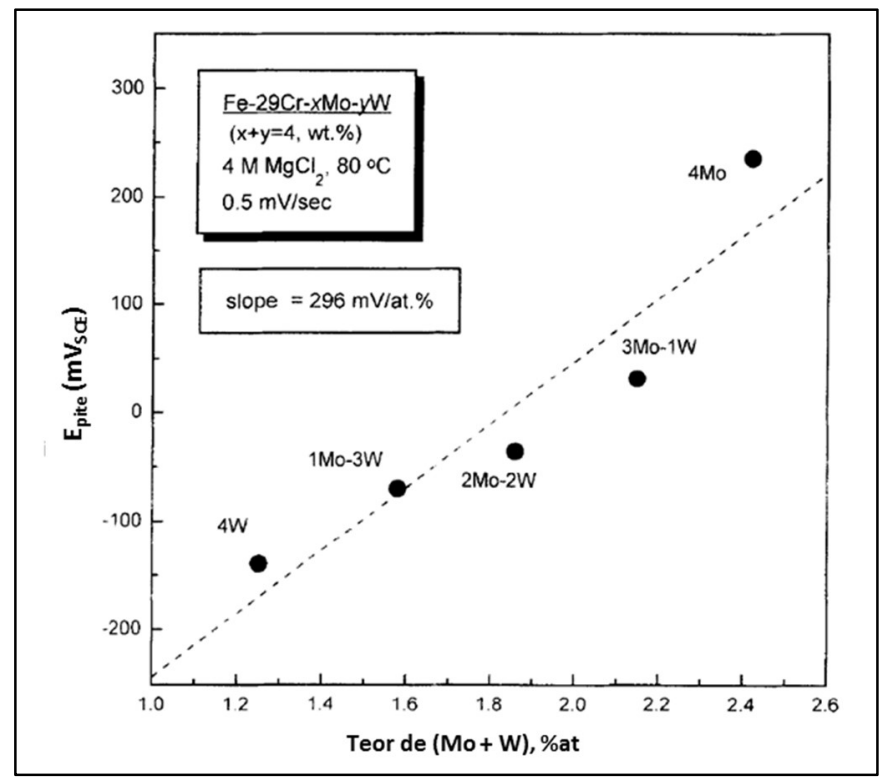

Fonte: Autor "adaptado de" Ahn, Kwon e Lee, 1998.

Os autores Ahn, Kwon e Lee (1998) determinaram também o potencial crítico ( $\left.\mathrm{E}_{\text {crit }}\right)$ e a densidade de corrente anódica crítica $\left(\mathrm{I}_{\text {crit }}\right)$ para cada uma das ligas estudadas por meio de ensaio de polarização anódica após a determinação do potencial de corrosão ( $\left.E_{\text {corr }}\right)$ em uma solução de $20 \%$ de $\mathrm{H}_{2} \mathrm{SO}_{4}$ a $30^{\circ} \mathrm{C}$, Figura 28 (AHN, KWON e LEE, 1998).

Figura 28 - Curvas de polarização anódica em solução de $20 \% \mathrm{H}_{2} \mathrm{SO}_{4}$ a $30^{\circ} \mathrm{C}$ para os aços (a) Fe-29Cr-xMo (x = 0 a 4 wt $\%$ ) e (b) Fe-29Cr-yW (y=0 a 8 wt $\%$ ).

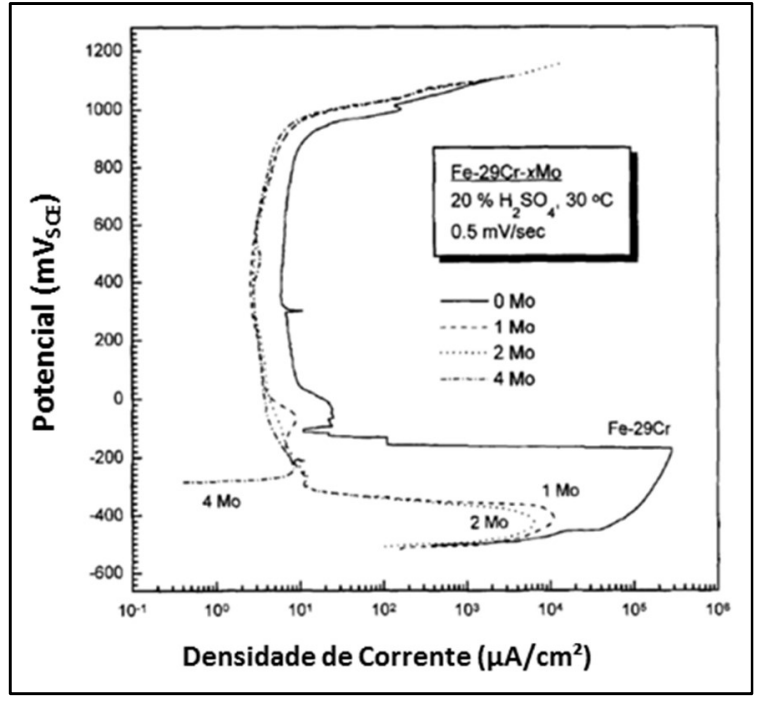

(a)

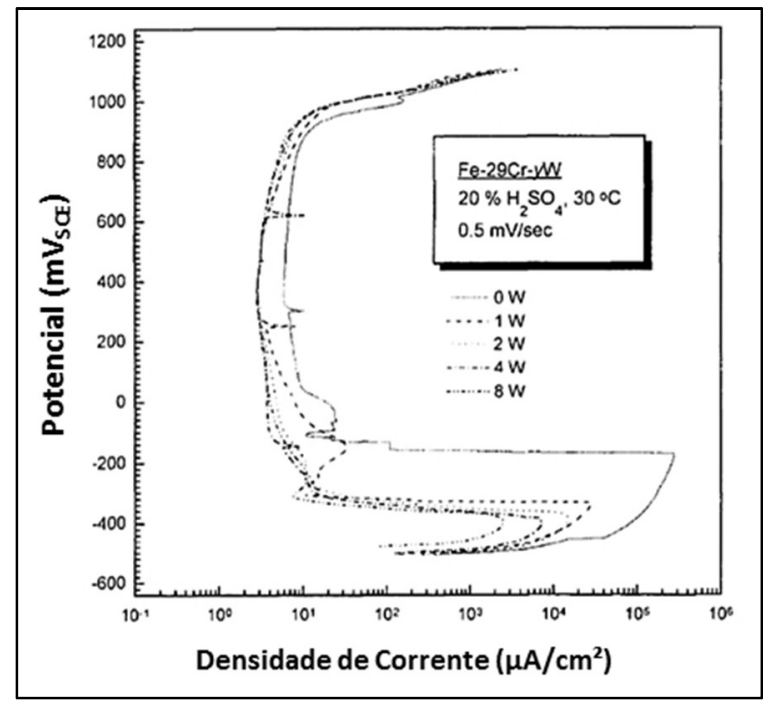

(b)

Fonte: Autor "adaptado de" Ahn, Kwon e Lee, 1998. 
Segundo os autores, adições de Mo e W à liga Fe-29Cr provocaram o deslocamento do $E_{\text {crit }}$ em direção à região ativa, ou seja, expandindo então a região passiva, e a redução da $i_{\text {crit }}$ (AHN, KWON e LEE, 1998). Além disso, o $E_{\text {crit }} \mathrm{e} \mathrm{i}_{\text {crit }}$ reduziram significativamente com o aumento os teores de W e Mo. Portanto, o aumento de Mo e W aumenta a estabilidade da película passiva da liga Fe-29Cr, como mostrado no esquema da Figura 29, em que os teores de Mo e $\mathrm{W}$ aumentam de $1 \rightarrow 2 \rightarrow 3$ e a curva 4 representa uma simulação da curva de polarização anódica da liga Fe-29Cr-4Mo.

Figura 29 - Diagrama esquemático mostrando o efeito da adição de Mo e W no comportamento da polarização anódica do aço inoxidável ferrítico Fe-29Cr numa solução de ácido sulfúrico.

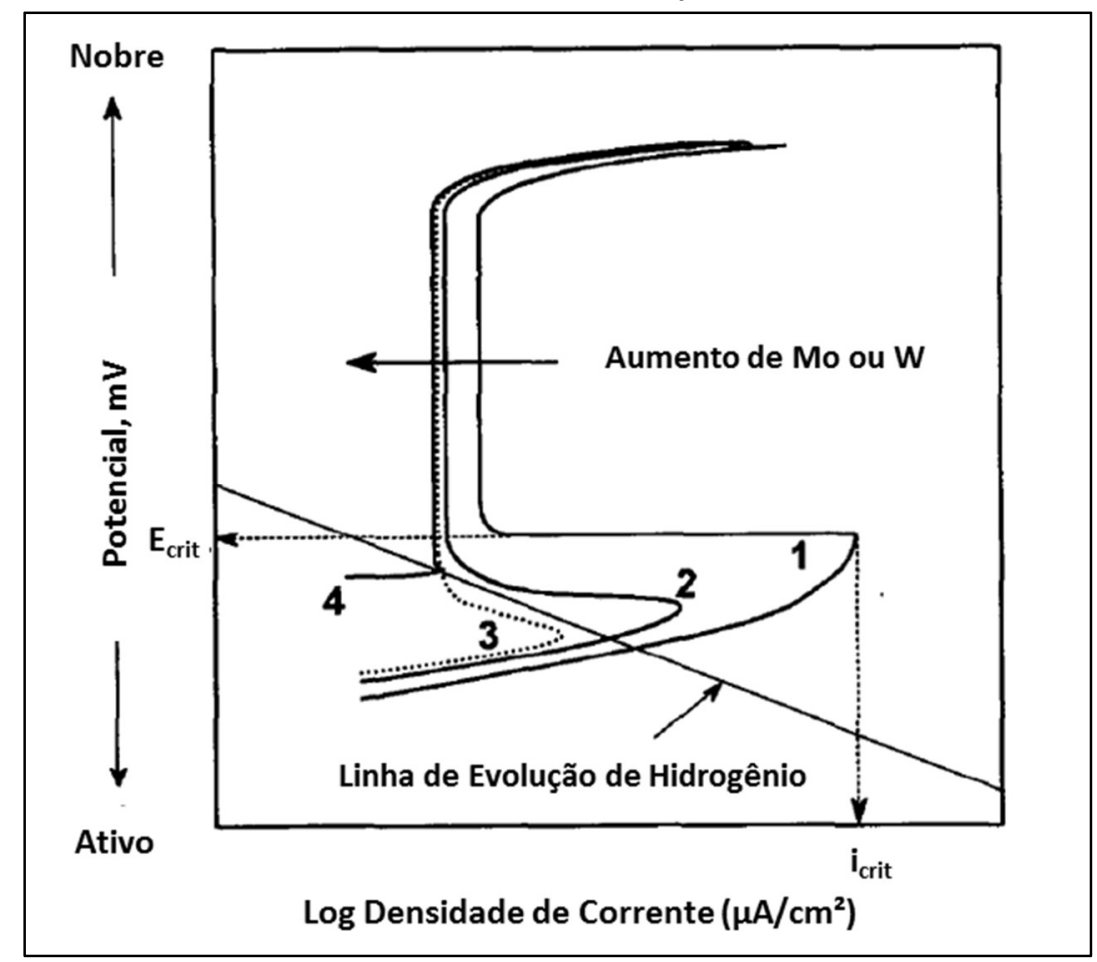

Fonte: Autor “adaptado de” Ahn, Kwon e Lee, 1998.

Assim, por meio dos dados experimentais obtidos, os autores obtiveram uma relação logarítmica entre o $\mathrm{E}_{\text {crit }}$ e a \%at dos elementos Mo e W $\left(X_{M o(W)}\right)$, onde $A_{2}$ e $B_{2}$ são constantes, Equação 13 (AHN, KWON e LEE, 1998). Segundo os autores, o efeito do Mo no $E_{\text {crit }}$ é ligeiramente melhor ou quase equivalente àquele do $\mathrm{W}$ quando comparados em \%at.

$$
E_{\text {crit }}=A_{2}+B_{2} \log X_{M o(W)}
$$


Da mesma forma, os autores chegaram a uma relação linear entre $\log \mathrm{I}_{\text {crit }} \mathrm{e} \%$ at de Mo, onde $A_{3}$ e $B_{3}$ são constantes, Equação 14. Segundo eles, o efeito do Mo e do W na $\mathrm{I}_{\mathrm{c}}$ é praticamente equivalente.

$\log I_{\text {crit }}=A_{3}+B_{3} \log X_{M o(W)}$

A similaridade entre os efeitos do W e do Mo na liga Fe-29Cr em termos de $\mathrm{E}_{\text {pite, }} \mathrm{E}_{\text {crit }} \mathrm{e}$ $I_{\text {crit }}$ foi justificada pelos autores por meio da comparação das propriedades elétricas e químicas destes elementos, Tabela 5. Evidentemente, Mo e W apresentam muitas similaridades como estados de oxidação, condutividade elétrica e eletronegatividade, que são propriedades importantes para a determinação das propriedades eletroquímicas dos filmes passivos (AHN, KWON e LEE, 1998).

Tabela 5 - Propriedades elétricas e químicas dos principais elementos dos aços inoxidáveis.

\begin{tabular}{c|c|c|c|c|c}
\hline Elemento & Fe & Ni & $\mathbf{C r}$ & Mo & W \\
\hline Coluna da Tabela Periódica & VIII & VIII & VIA & VIA & VIA \\
\hline Estado de Oxidação & $3 ; 2$ & $3 ; 2$ & $6 ; 3 ; 2$ & $6 ; 5 ; 4 ; 3 ; 2$ & $6 ; 5 ; 4 ; 3 ; 2$ \\
\hline Cond. elétrica $\left.\mathbf{( 1 0}^{6} \mathbf{c m}^{-1} \mathbf{\Omega}^{-1}\right)$ & 0.0993 & 0.143 & 0.0774 & 0.187 & 0.189 \\
\hline Eletronegatividade & 1.83 & 1.91 & 1.66 & 2.16 & 2.36 \\
\hline
\end{tabular}

Fonte: Ahn, Kwon e Lee, 1998.

Assim como Kim e Kwon (1999), Park, Ahn e Kwon (2006) estudaram a influência da substituição do Mo por W em relação à cinética de precipitação de segundas fases associada à corrosão localizada e fragilidade, mas no aço inoxidável ferrítico $29 \mathrm{Cr}$. Os materiais estudados correspondem a Fe-29Cr com adições de Mo e W de acordo com a Tabela 6 (KIM e KWON, 1999); (PARK, AHN e KWON, 2006).

Tabela 6 - Composição química (\%wt) dos aços Fe-29Cr estudados por Park et al. (2005).

\begin{tabular}{c|c|c|c|c|c|c|c|c}
\hline Liga & $\mathbf{C r}$ & $\mathbf{M o}$ & $\mathbf{W}$ & $\mathbf{S i}$ & $\mathbf{C}$ & $\mathbf{N}$ & $\mathbf{N b}$ & $\mathbf{F e}$ \\
\hline $\mathbf{4 W}$ & 28,85 & - & 4,10 & 0,44 & 0,0055 & 0,0009 & 0,12 & Balanço \\
\hline $\mathbf{8 W}$ & 28,78 & - & 8,17 & 0,46 & 0,0071 & 0,0010 & 0,10 & Balanço \\
\hline $\mathbf{4 M o}$ & 29,10 & 4,19 & - & 0,44 & 0,0042 & 0,0015 & 0,10 & Balanço \\
\hline
\end{tabular}

Fonte: Park, Ahn e Kwon, 2006.

Segundo os autores, após a homogeneização e laminação dos lingotes para placas, as amostras foram solubilizadas e envelhecidas isotermicamente a $850^{\circ} \mathrm{C}$, variando o tempo de tratamento de 5 a $100 \mathrm{~h}$. Segundo os autores, todas as amostras apresentaram as fases $\chi \mathrm{e} \sigma$. 
Porém, segundo eles, da mesma forma que Kim e Kwon (1999), a taxa de formação dessas fases é determinada pela taxa de difusão de Mo e W, assim como pela afinidade dessas fases por estes elementos. Eles observaram que a precipitação de fase $\sigma$ foi significativamente reduzida nas ligas que contêm $\mathrm{W}$ devido à maior afinidade da fase $\chi$ por $\mathrm{W}$ e também à menor taxa de difusão do W comparada àquela do Mo (PARK, AHN e KWON, 2006); (KIM e KWON, 1999).

Enquanto a maioria dos trabalhos encontrados na literatura referem-se a aços inoxidáveis dúplex, Kim, Xiang e Kim (2005) também estudaram o efeito da substituição parcial de Mo por W no aço inoxidável austenítico 317LMN, Tabela 7.

Tabela 7 - Composição química (\%wt) do aço inoxidável austenítico AISI 317LMN estudado por Kim, Xiang e Kim (2005).

\begin{tabular}{c|c|c|c|c|c|c|c|c|c|c}
\hline Liga & $\mathbf{C}$ & $\mathbf{S i}$ & $\mathbf{M n}$ & $\mathbf{P}$ & $\mathbf{S}$ & $\mathbf{C r}$ & $\mathbf{N i}$ & $\mathbf{M o}$ & $\mathbf{W}$ & $\mathbf{N}$ \\
\hline $\mathbf{3 1 7}$-Mo & 0,017 & 0,50 & 1,54 & 0,029 & 0,003 & 18,70 & 13,83 & 3,79 & - & 0,2 \\
\hline $\mathbf{3 1 7}$-MoW & 0,020 & 0,52 & 1,52 & 0,029 & 0,003 & 17,92 & 14,04 & 2,05 & 4,16 & 0,2 \\
\hline
\end{tabular}

Fonte: Autor "adaptado de Kim, Xiang e Kim, 2005.

Por meio de curvas de polarização potenciodinâmica em solução desaerada de $0,5 \mathrm{M}$ $\mathrm{H}_{2} \mathrm{SO}_{4}+3,5 \% \mathrm{Cl}^{-}$a $25^{\circ} \mathrm{C}$, os autores observaram que a liga que apresenta $\mathrm{W}$ apresentou densidade de corrente passiva ( $\left.\mathrm{i}_{\text {pass }}\right)$ menor e maior densidade de corrente crítica ( $\left.\mathrm{i}_{\text {crit }}\right)$, Figura 30 (a). Além disso, o teste de risco, do inglês "scratch test", nesta mesma solução mostrou que a taxa de repassivação é maior no material que contém W substituindo parcialmente o Mo, indicando que esta substituição é efetiva para repassivação em soluções ácidas que contêm cloretos para esta classe de material, Figura 30 (b) (KIM, XIANG e KIM, 2005). 
Figura 30 - Polarização potenciodinâmica (a) e "scratch test" (b) do aço inoxidável 317LMN substituindo parcialmente o teor de Mo por W em solução de $0,5 \mathrm{M} \mathrm{H}_{2} \mathrm{SO}_{4}+3,5 \% \mathrm{Cl}^{-}$a $25^{\circ} \mathrm{C}$.

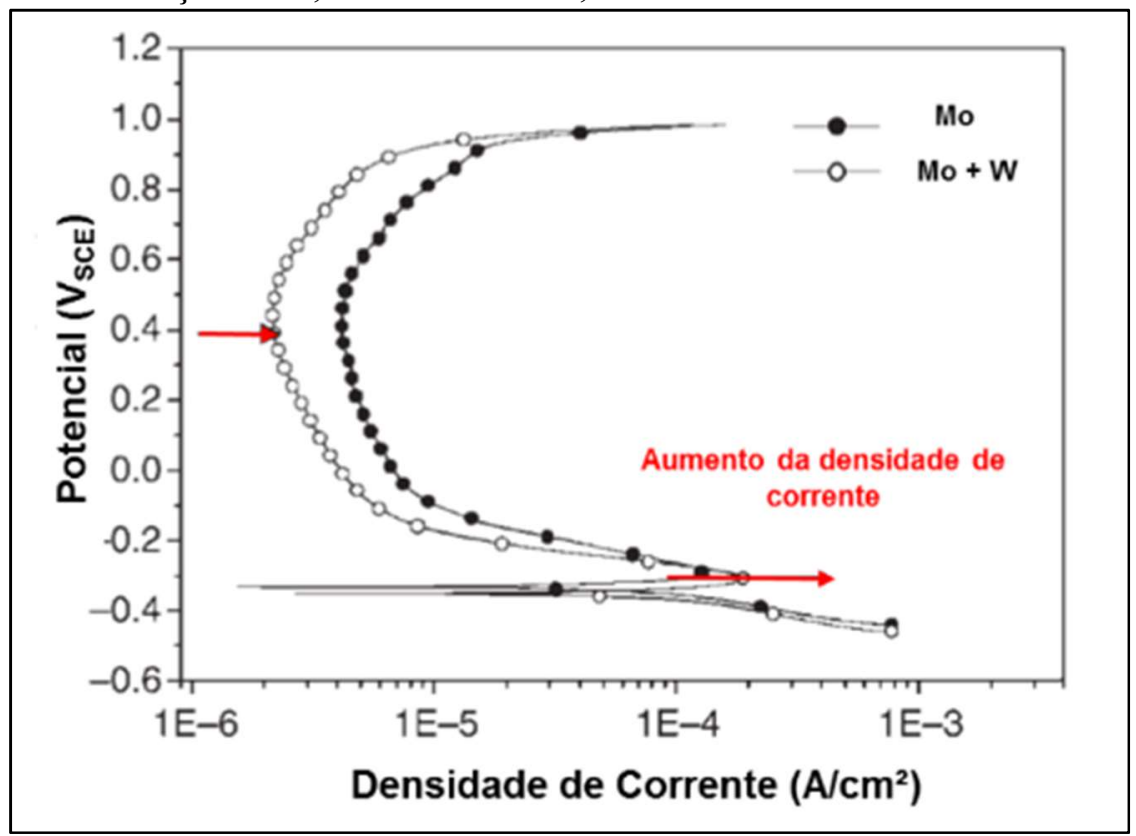

(a)

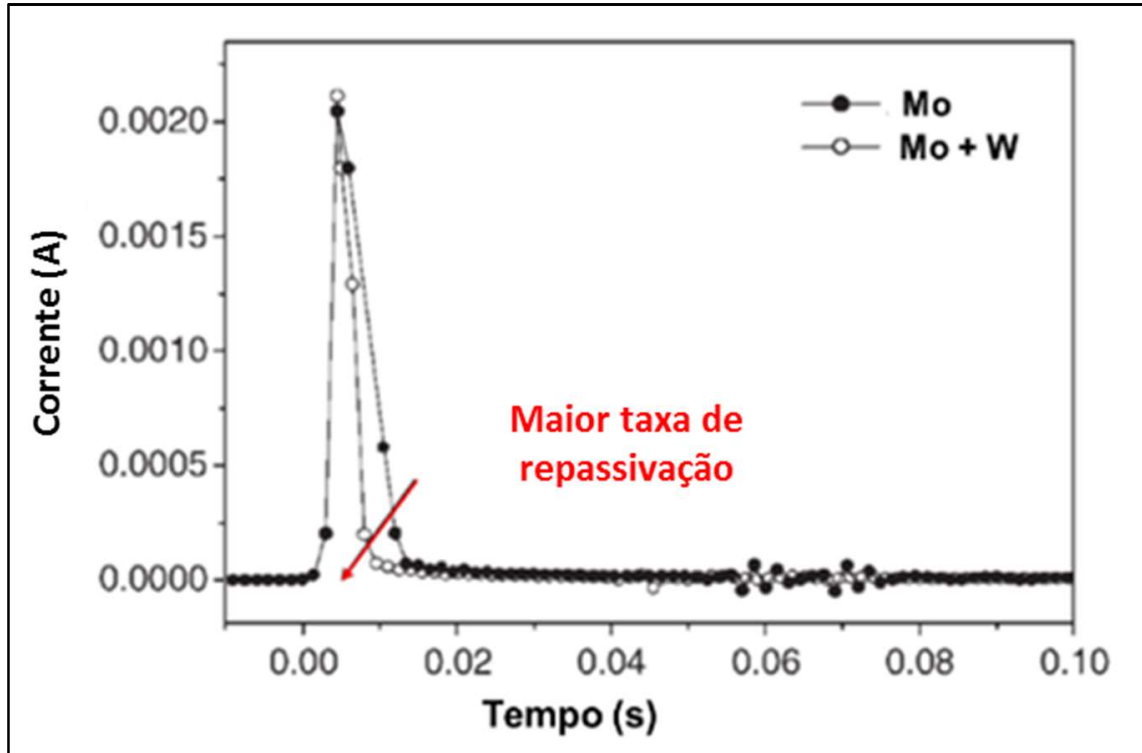

(b)

Fonte: Autor "adaptado de Kim, Xiang e Kim, 2005.

Os autores realizaram também os mesmos ensaios em solução neutra de $1 \mathrm{M} \mathrm{MgCl}_{2}$ a $50^{\circ} \mathrm{C}$, Figura 31 (KIM, XIANG e KIM, 2005). As curvas de polarização mostraram uma diferença significativa no potencial de pite das amostras, sendo que aquela que contém $\mathrm{W}$ como substituto parcial do Mo apresentou maior resistência à corrosão por pite, Figura 31 (a). Já o teste de risco mostrou que além do tempo para repassivação ser menor, o pico de corrente atingida pelo material que contém $\mathrm{W}$ também é menor, ou seja, a carga total necessária para 
repassivação desta liga é menor, Figura 31 (b). Dessa forma, esses resultados mostram que a substituição do Mo por W nos aços inoxidáveis austeníticos é efetiva para maior estabilização da película passiva formada e repassivação mais rápida (KIM, XIANG e KIM, 2005).

Figura 31- Polarização potenciodinâmica (a) e "scratch test" (b) do aço inoxidável 317LMN substituindo parcialmente o teor de Mo por $\mathrm{W}$ em solução de $1 \mathrm{M} \mathrm{MgCl}_{2}$ a $50^{\circ} \mathrm{C}$.

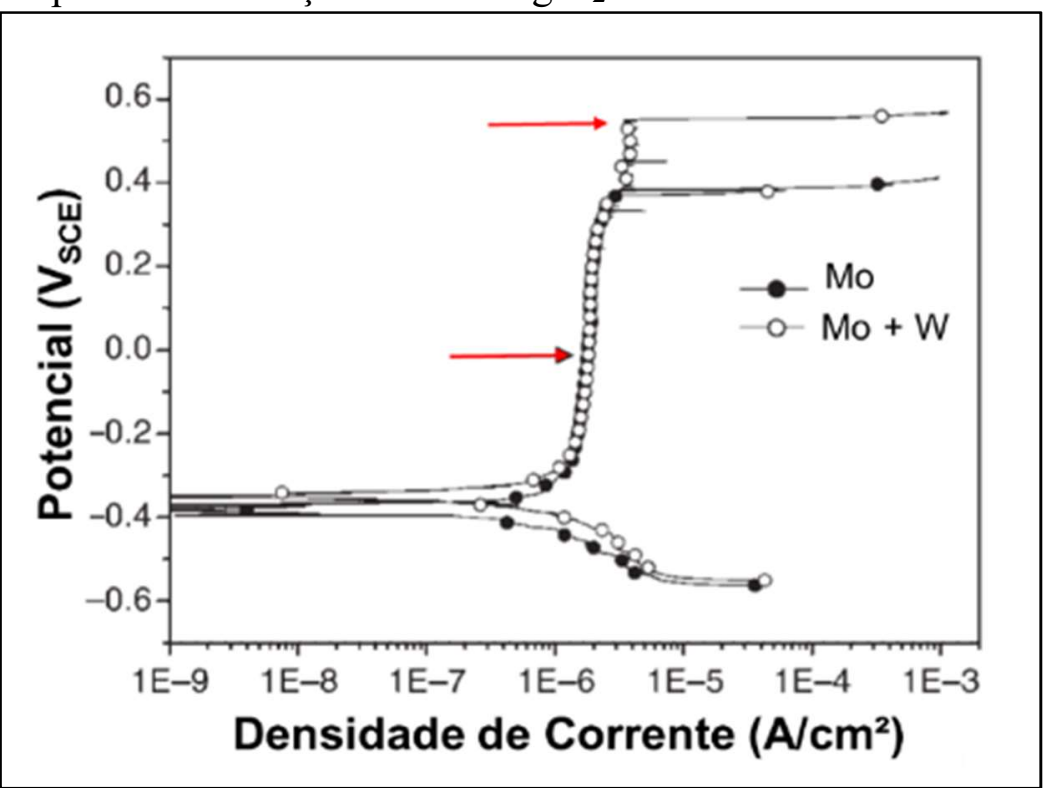

(a)

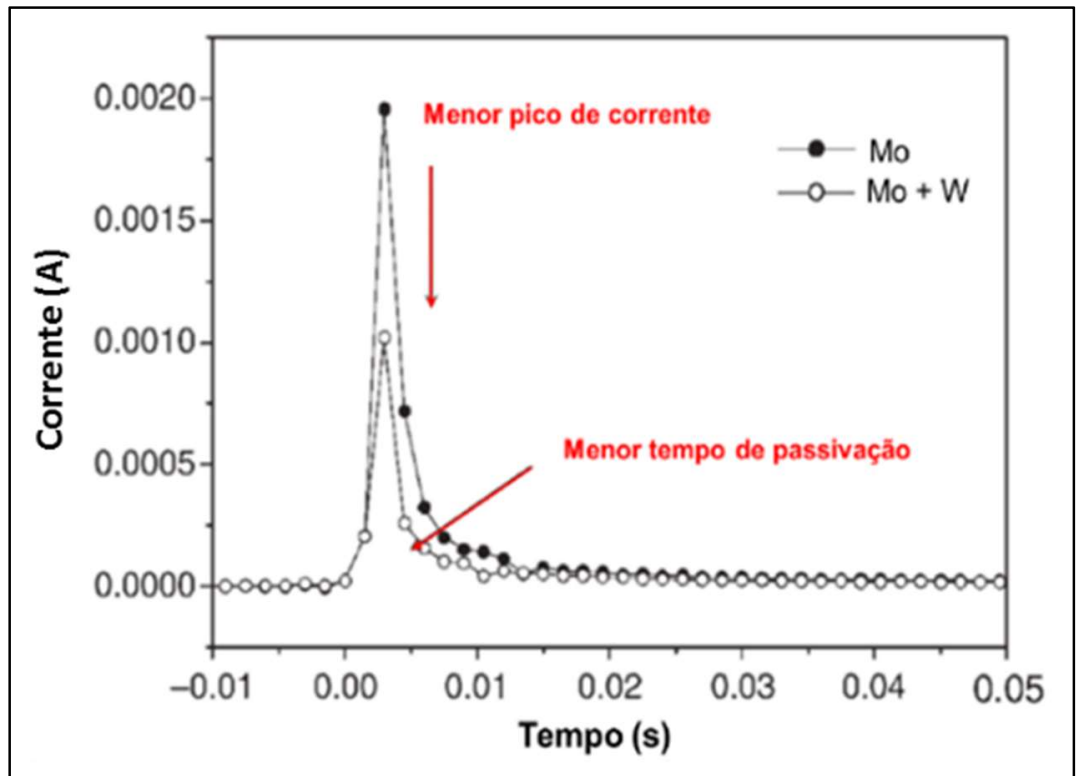

(b)

Fonte: Autor "adaptado de Kim, Xiang e Kim, 2005.

No mesmo trabalho, Kim, Xiang e Kim (2005) submeteram o material a ensaios de corrosão sob tensão utilizando o método SSRT ("Slow Strain Rate Tests") em solução de 42\% $\mathrm{MgCl}_{2}$ em ebulição e taxa de deformação de $5.10^{-6} / \mathrm{s}$, e reportaram que a substituição parcial de 
Mo por W no aço inoxidável austenítico 317LMN aumentou consideravelmente a resistência à corrosão sob tensão do material em relação ao alongamento e resistência à tração (UTS) (KIM, XIANG e KIM, 2005). Por meio de analises de AES (espectroscopia por elétrons Auger, do inglês "Auger electron spectroscopy"), os autores observaram que a substituição parcial de Mo por W neste material provocou o aumento do acúmulo de Mo na superfície do aço na região ativa e, segundo eles, este acúmulo resulta na formação de uma película passiva mais estável. Além disso, as análises de XPS mostraram que essa substituição também aumentou a dissolução dos íons $\mathrm{Fe}^{2+}$, que contribuíram para a estabilidade da película passiva por meio da formação de $\mathrm{FeMoO}_{4}$. Dessa maneira, os autores concluíram que o $\mathrm{W}$ altera positivamente a estabilidade e as propriedades de repassivação do material. (KIM, XIANG e KIM, 2005)

Portanto, de acordo com a revisão bibliográfica realizada, nota-se a presença de poucos trabalhos referentes ao real efeito causado pelo $\mathrm{W}$ nos aços inoxidáveis austeníticos, indicando a necessidade de mais estudos acerca do efeito da substituição do Mo associado ao W na resistência à corrosão desta classe de materiais, já que os trabalhos encontrados na literatura aqui descritos são majoritariamente dedicados a aços dúplex e ferríticos $(\mathrm{OH}$, et al., 1993); (AHN, KWON e LEE, 1998); (KIM, et al., 1998); (KIM e KWON, 1999); (PARK e KWON, 2002); (PARK, AHN e KWON, 2006); (PARK e KWON, 2002); (KIM, XIANG e KIM, 2005); (JEON, et al., 2012); (HAUGAN, et al., 2017). 


\section{MATERIAIS E MÉTODOS}

Nos itens a seguir são apresentados o projeto e a rota de fabricação do material em estudo, bem como a metodologia utilizada para caracterização das propriedades microestruturais, mecânicas e de resistência à corrosão deste material.

\subsection{PROJETO DO MATERIAL EM ESTUDO}

O teor de Mo considerado neste trabalho para o aço inoxidável AISI316L foi de 2,3\% em massa. Buscando avaliar o real efeito da substituição parcial e total do Mo por W, este teor de referência foi parcial ou totalmente substituído por W. Porém, esta substituição foi realizada em relação à porcentagem atômica de Mo na liga de referência para que o efeito real dos dois elementos possa ser devidamente comparado, conforme mostrado no trabalho de Ahn, Kwon e Lee (1998) (AHN, KWON e LEE, 1998). Assim, a composição química dos materiais em estudo foi desenhada baseando-se na composição atômica de cada elemento na liga de referência, considerando que o peso total do lingote fosse de 56,500 kg. Para isso, calculou-se o número de átomos de cada elemento de liga $\left(N_{\text {elem }}\right)$ e, em seguida, a porcentagem atômica (\%atelem) de cada um deles no lingote final, conforme mostrado nas Equações 15 e 16, em que $\% w t_{\text {elem }}$ é o teor em massa do elemento na liga, $P_{\text {TOTAL }}$ é o peso total do lingote em gramas, $N_{A}$ corresponde à constante de Avogadro $\left(6,022.10^{23} \mathrm{~mol}^{-1}\right), M M_{\text {elem }}$ a massa molar em gramas $/ \mathrm{mol}$ e $N_{T O T A L}$ o número total de átomos no lingote.

$$
\begin{aligned}
& N_{\text {elem }}=\frac{\left(\% w t_{\text {elem }} / 100\right) \cdot P_{T O T A L} N_{A}}{M M_{\text {elem }}} \\
& \% a t_{\text {elem }}=\left(\frac{N_{\text {elem }}}{N_{\text {TOTAL }}}\right) \cdot 100
\end{aligned}
$$

Dessa forma, baseando-se na composição química da liga de referência, o teor atômico de $1,33 \%$ de Mo $(2,3 \%$ wt) foi substituído parcialmente $(25,50$ e $75 \%)$ e totalmente por W. Então, a composição desejada no projetos das ligas a estudar em teor em massa e atômico pode ser calculada, e é mostrada na Tabela 8. É possível observar que, como esperado, o teor em massa de $\mathrm{W}$ esperado para a liga que contém apenas $\mathrm{W}, 4,32 \% \mathrm{wt}$ é quase o dobro daquela de Mo na liga de referência, $2,3 \%$ wt, uma vez que a massa molar do primeiro é quase o dobro daquela do segundo 
Tabela 8 - Composição desejada em teor em massa (\%wt) e atômico (\%at) dos materiais em estudo.

\begin{tabular}{c|c|c|c|c|c|c|c|c|c|c}
\hline Liga & \multicolumn{2}{|c|}{ V316L (REF) } & \multicolumn{2}{c|}{$\mathbf{2 5 \%} \mathbf{W}$} & \multicolumn{2}{c|}{$\mathbf{5 0 \%} \mathbf{W}$} & \multicolumn{2}{c}{$\mathbf{7 5 \%} \mathbf{W}$} & \multicolumn{2}{c}{$\mathbf{1 0 0 \% W}$} \\
\hline Elemento & \%wt & \%at & \%wt & \%at & \%wt & \%at & \%wt & \%at & \%wt & \%at \\
\hline $\mathbf{C}$ & 0,03 & 0,14 & 0,03 & 0,14 & 0,03 & 0,14 & 0,03 & 0,14 & 0,03 & 0,14 \\
\hline $\mathbf{S i}$ & 0,5 & 0,99 & 0,5 & 0,99 & 0,5 & 1,00 & 0,5 & 1,00 & 0,5 & 1,01 \\
\hline $\mathbf{M n}$ & 1,6 & 1,62 & 1,6 & 1,62 & 1,6 & 1,63 & 1,6 & 1,64 & 1,6 & 1,65 \\
\hline $\mathbf{P}$ & 0,035 & 0,06 & 0,035 & 0,06 & 0,035 & 0,06 & 0,035 & 0,06 & 0,035 & 0,06 \\
\hline $\mathbf{S}$ & 0,028 & 0,05 & 0,028 & 0,05 & 0,028 & 0,05 & 0,028 & 0,05 & 0,028 & 0,05 \\
\hline $\mathbf{C r}$ & 16,5 & 17,60 & 16,5 & 17,69 & 16,5 & 17,79 & 16,5 & 17,88 & 16,5 & 17,97 \\
\hline $\mathbf{M o}$ & 2,3 & 1,33 & 1,72 & 1,00 & 1,14 & 0,67 & 0,57 & 0,33 & - & - \\
\hline $\mathbf{W}$ & - & - & 1,09 & 0,33 & 2,18 & 0,66 & 3,25 & 1,00 & 4,32 & 1,33 \\
\hline $\mathbf{N i}$ & 10,5 & 9,92 & 10,5 & 9,98 & 10,5 & 10,03 & 10,5 & 10,08 & 10,5 & 10,13 \\
\hline $\mathbf{N}$ & 0,06 & 0,24 & 0,06 & 0,24 & 0,06 & 0,24 & 0,06 & 0,24 & 0,06 & 0,24 \\
\hline $\mathbf{F e}$ & 68,507 & 68,05 & 67,997 & 67,89 & 67,487 & 67,73 & 66,987 & 67,58 & 66,487 & 67,42 \\
\hline
\end{tabular}

Fonte: Autor

\subsection{FUSÃO E CONFORMAÇÃO MECÂNICA DO MATERIAL EM ESTUDO}

Os materiais estudados foram fundidos em escala piloto no forno de indução a vácuo (vacuum induction melting, VIM) do Centro de Pesquisa e Desenvolvimento da Villares Metals, Figura 33 (a). A composição química final obtida é apresentada na Tabela 9. 
Tabela 9 - Composição química final em teor de massa (\%wt) e atômico (\%at) obtida do aço inoxidável AISI 316L variando a proporção atômica entre Mo e W.

\begin{tabular}{|c|c|c|c|c|c|c|c|c|c|c|}
\hline Corrida & \multicolumn{2}{|c|}{1107046} & \multicolumn{2}{|c|}{1107047} & \multicolumn{2}{|c|}{1107048} & \multicolumn{2}{|c|}{1107049} & \multicolumn{2}{|c|}{1107050} \\
\hline Liga & V316 & EF) & $25 \%$ & $\mathbf{W}$ & $50 \%$ & $\mathbf{W}$ & $75 \%$ & $\mathbf{W}$ & $100^{\circ}$ & oW \\
\hline Elemento & $\% w t$ & $\%$ at & $\% w t$ & $\%$ at & $\% w t$ & $\%$ at & $\% w t$ & $\%$ at & $\% w t$ & $\%$ at \\
\hline $\mathbf{C}$ & 0,021 & 0,10 & 0,03 & 0,14 & 0,024 & 0,11 & 0,027 & 0,13 & 0,023 & 0,11 \\
\hline Si & 0,5 & 0,99 & 0,49 & 0,97 & 0,5 & 1,00 & 0,49 & 0,98 & 0,5 & 1,01 \\
\hline Mn & 1,56 & 1,58 & 1,55 & 1,57 & 1,59 & 1,62 & 1,56 & 1,60 & 1,59 & 1,64 \\
\hline $\mathbf{P}$ & 0,039 & 0,07 & 0,037 & 0,07 & 0,035 & 0,06 & 0,038 & 0,07 & 0,037 & 0,07 \\
\hline $\mathbf{S}$ & 0,027 & 0,05 & 0,028 & 0,05 & 0,029 & 0,05 & 0,027 & 0,05 & 0,027 & 0,05 \\
\hline $\mathrm{Cr}$ & 16,44 & 17,54 & 16,38 & 17,56 & 16,47 & 17,75 & 16,5 & 17,87 & 16,51 & 17,96 \\
\hline Mo & 2,3 & 1,33 & 1,74 & 1,01 & 1,14 & 0,67 & 0,57 & 0,33 & - & - \\
\hline $\mathbf{W}$ & - & - & 1,09 & 0,33 & 2,12 & 0,65 & 3,17 & 0,97 & 4,18 & 1,29 \\
\hline $\mathrm{Co}$ & 0,02 & 0,02 & 0,02 & 0,02 & 0,02 & 0,02 & 0,02 & 0,02 & 0,03 & 0,03 \\
\hline $\mathbf{N i}$ & 10,56 & 9,94 & 10,66 & 10,08 & 10,56 & 10,04 & 10,5 & 10,03 & 10,32 & 9,91 \\
\hline $\mathbf{V}$ & 0,019 & 0,02 & 0,019 & 0,02 & 0,019 & 0,02 & 0,018 & 0,02 & 0,019 & 0,02 \\
\hline $\mathbf{N}$ & 0,0608 & 0,24 & 0,0712 & 0,28 & 0,0618 & 0,25 & 0,0633 & 0,25 & 0,0629 & 0,25 \\
\hline $\mathbf{O}$ & 0,0072 & 0,02 & 0,0096 & 0,03 & 0,0084 & 0,03 & 0,0106 & 0,04 & 0,0073 & 0,03 \\
\hline $\mathrm{Fe}$ & 68,553 & 68,11 & 67,975 & 67,86 & 67,512 & 67,74 & 67,098 & 67,64 & 66,783 & 67,65 \\
\hline
\end{tabular}

Fonte: Autor

Após a fusão das corridas e com base nas composições químicas obtidas mostradas na Tabela 9, foram calculados os diagramas de fases em equilíbrio termodinâmico utilizando o software ThermoCalc ${ }^{\circledR}$ e a base de dados TCFE8 buscando determinar a temperatura adequada para conformação mecânica dos lingotes e posterior tratamento térmico, que deve se situar na faixa de temperatura em que a microestrutura é 100\% austenítica. Os diagramas de fases em equilíbrio para cada um dos materiais em estudo são mostrados na Figura 32. A partir desta simulação é possível notar que entre 1000 e $1300^{\circ} \mathrm{C}$ todos os materiais apresentam microestrutura composta somente por austenita. Definiu-se então que o tratamento termomecânico deveria acontecer entre 1200 e $1250^{\circ} \mathrm{C}$ e o posterior tratamento térmico de solubilização a $1100^{\circ} \mathrm{C}$. 
Figura 32 - Fração em massa das fases em função da temperatura para cada um dos materiais em estudo calculada com auxílio do software ThermoCalc $®$ e a base de dados TCFE8, destacando a faixa de temperatura em que a microestrutura é $100 \%$ austenítica.

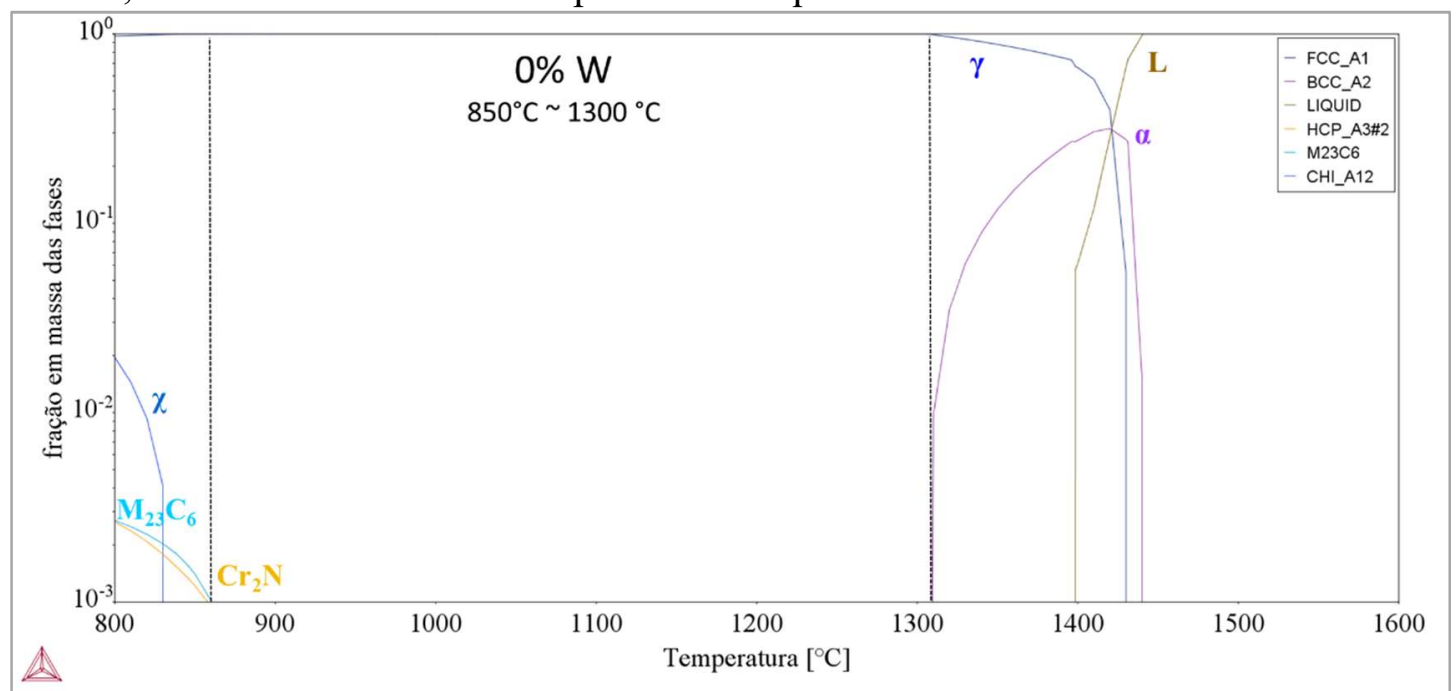

(a)

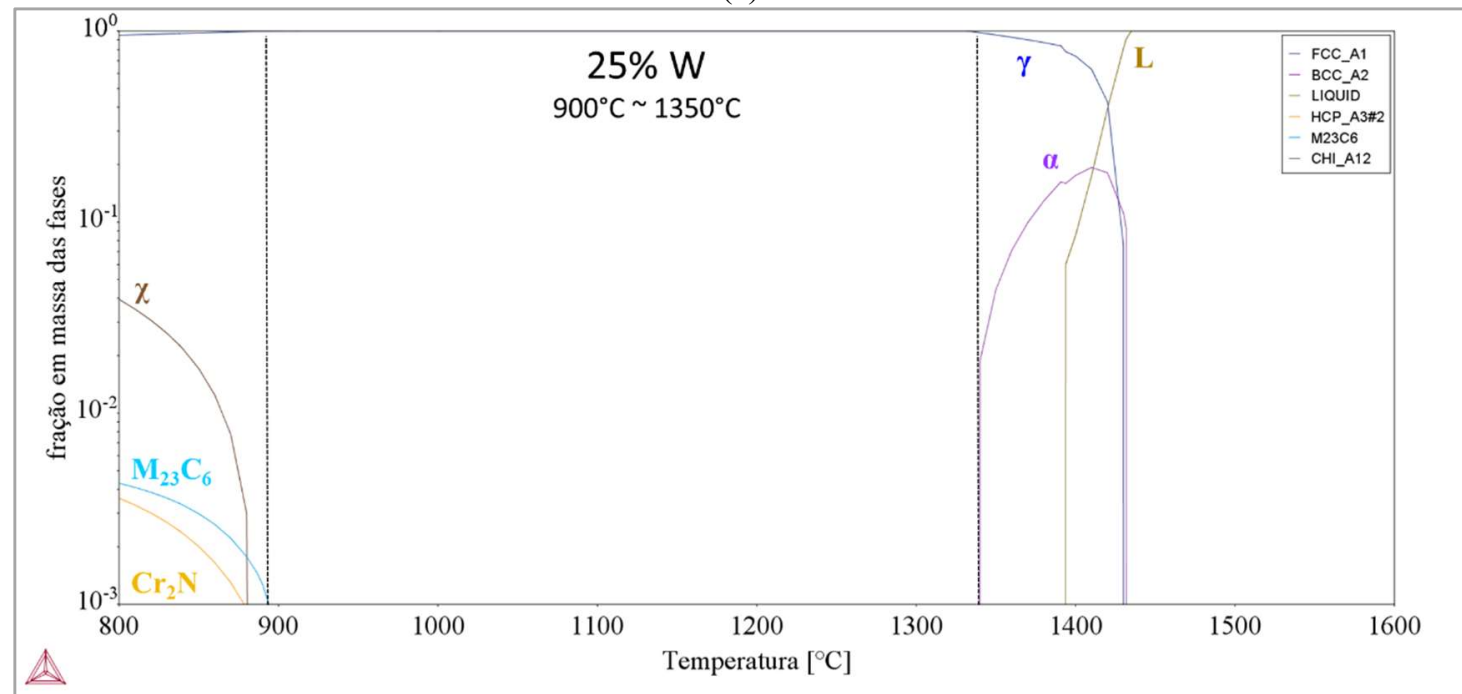

(b)

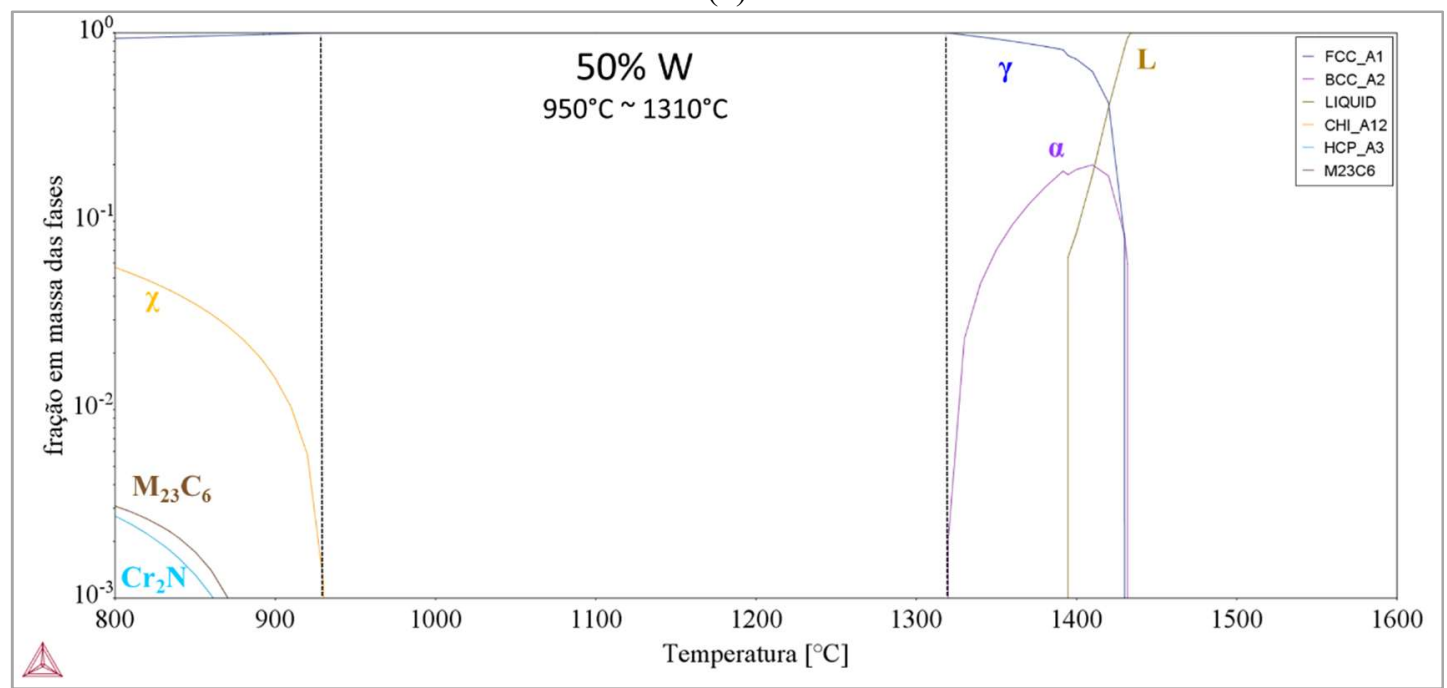

(c) 


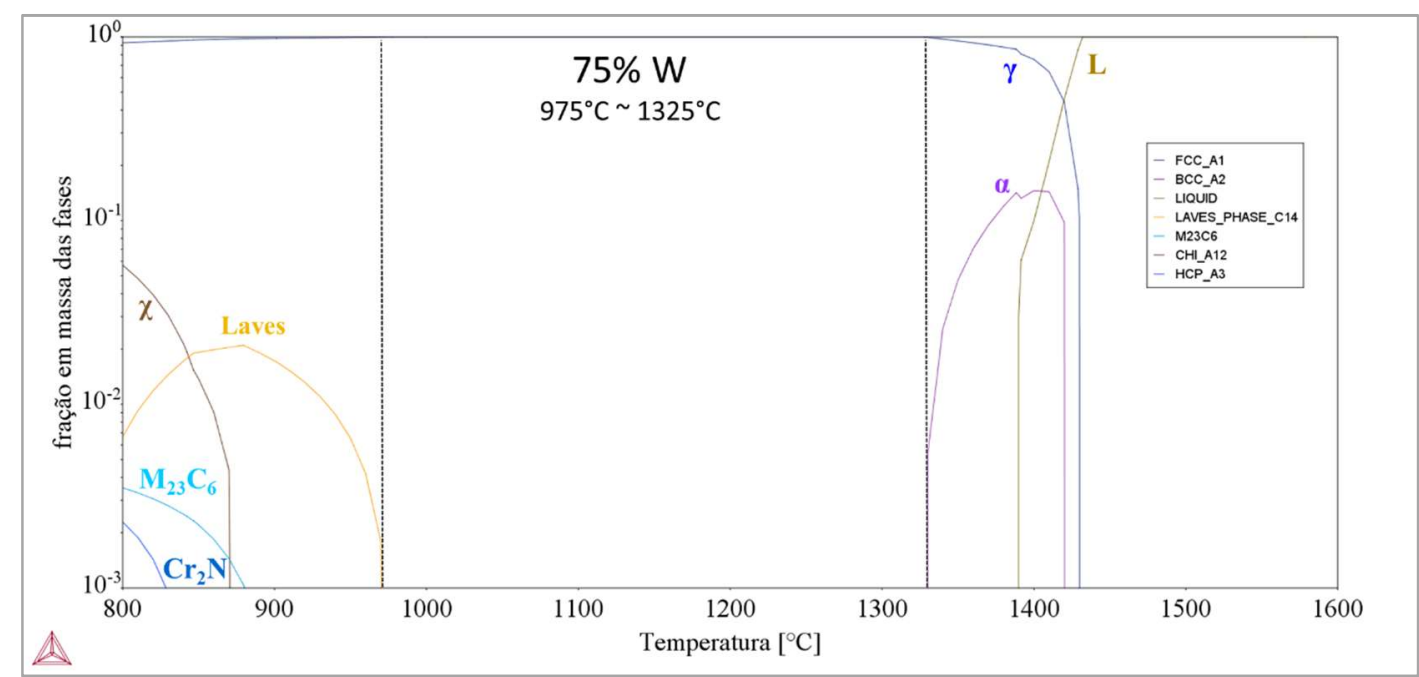

(d)

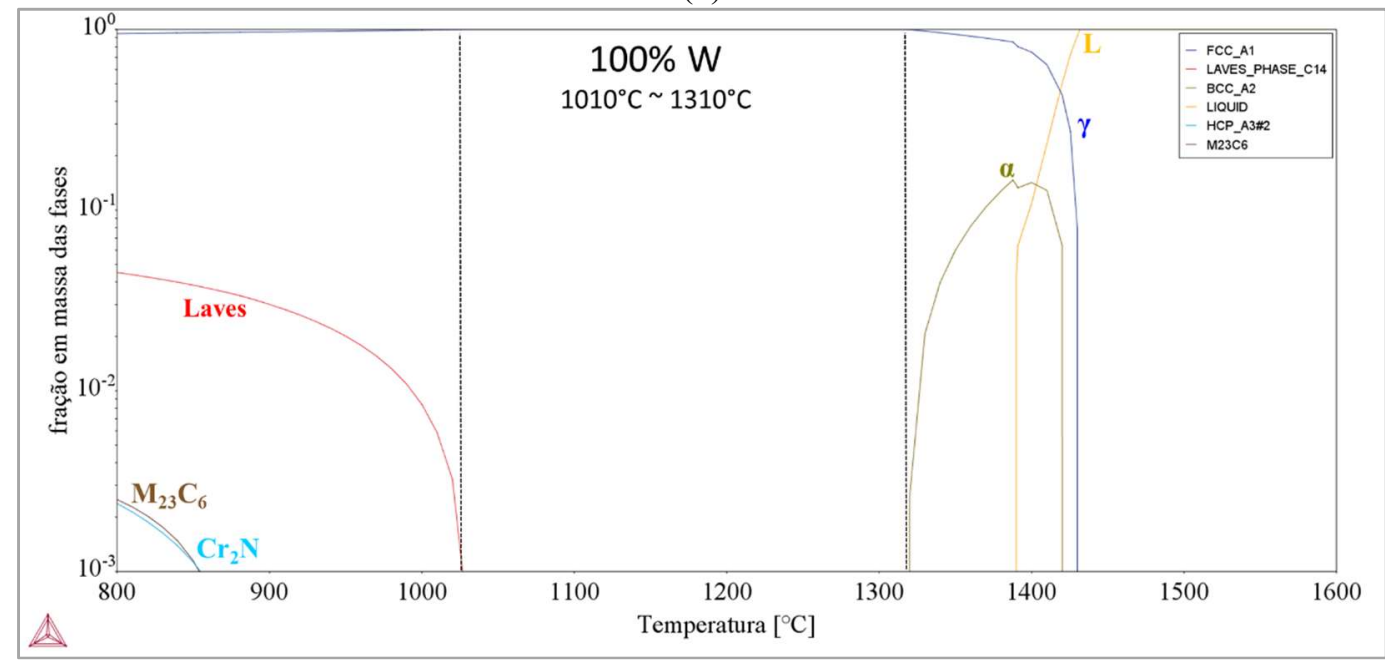

(e)

Fonte: Autor

Os lingotes de $50 \mathrm{~kg}$ obtidos, Figura 33 (b), foram então homogeneizados a $1200^{\circ} \mathrm{C}$ por no mínimo $8 \mathrm{~h}$ e máximo $10 \mathrm{~h}$ e então forjados para forma de seção transversal quadrada de 80 $\mathrm{mm}$, Figura 33 (c). Os tarugos foram então reaquecidos a $1220^{\circ} \mathrm{C}$ e laminados para barras redondas de 15,87 mm de diâmetro, Figura 33 (d). É importante ressaltar que, apesar de aspectos de plasticidade a quente não estarem sendo analisados, todos os materiais foram facilmente processados, ou seja, nenhum deles apresentou trincas, podendo indicar que a substituição parcial e total do Mo por W não prejudica a conformabilidade à quente do aço inoxidável austenítico AISI 316L. 
Figura 33 - Fusão e conformação dos lingotes do aço inoxidável AISI 316XL realizados no Centro de Pesquisa \& Desenvolvimento da Villares Metals. (a) Forno de Indução a Vácuo em escala piloto, VIM; (b) Lingotes de 50kg obtidos; (c) Tarugos forjados para quadrado de $80 \mathrm{~mm}$; (d) Barras redondas laminadas de 15,87 mm de diâmetro.

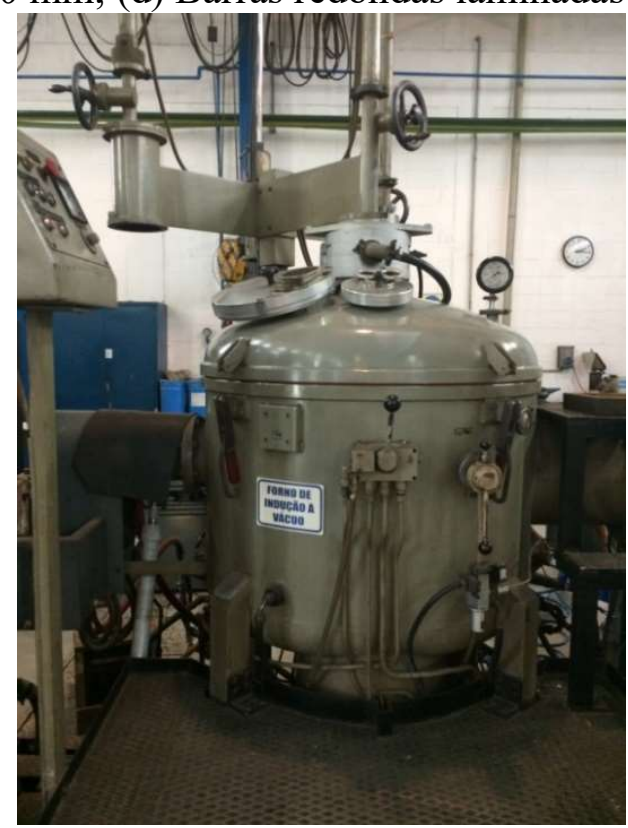

(a)

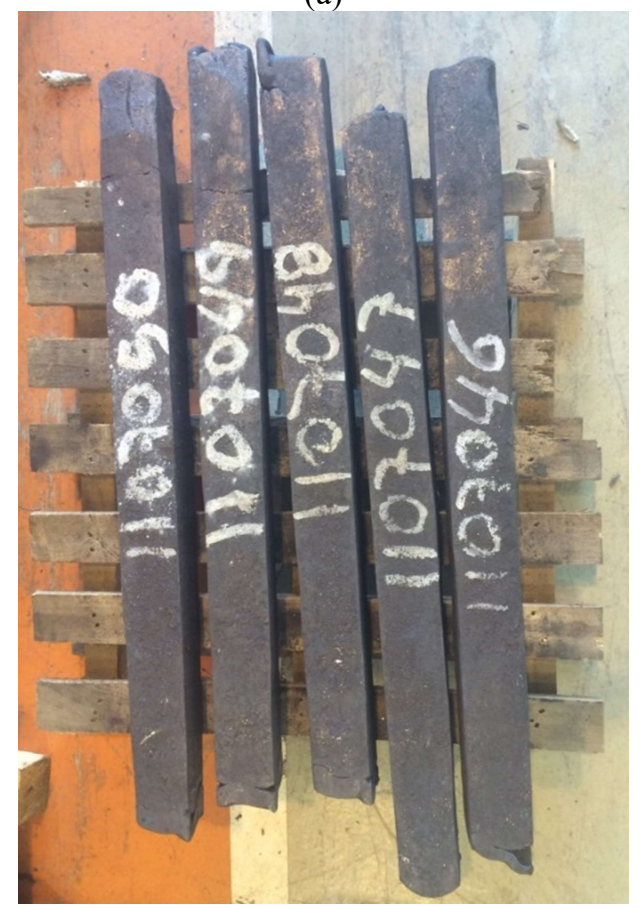

(c)

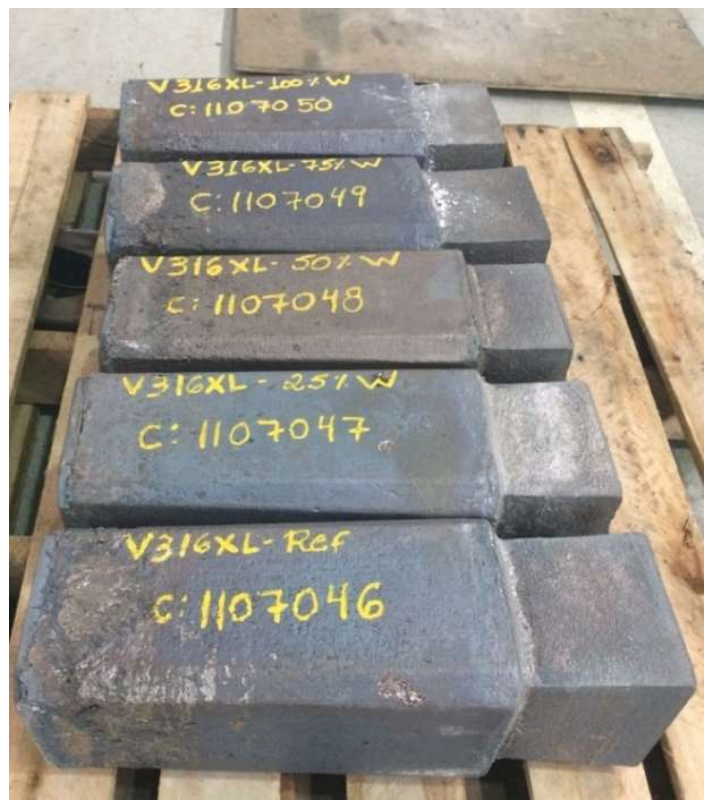

(b)

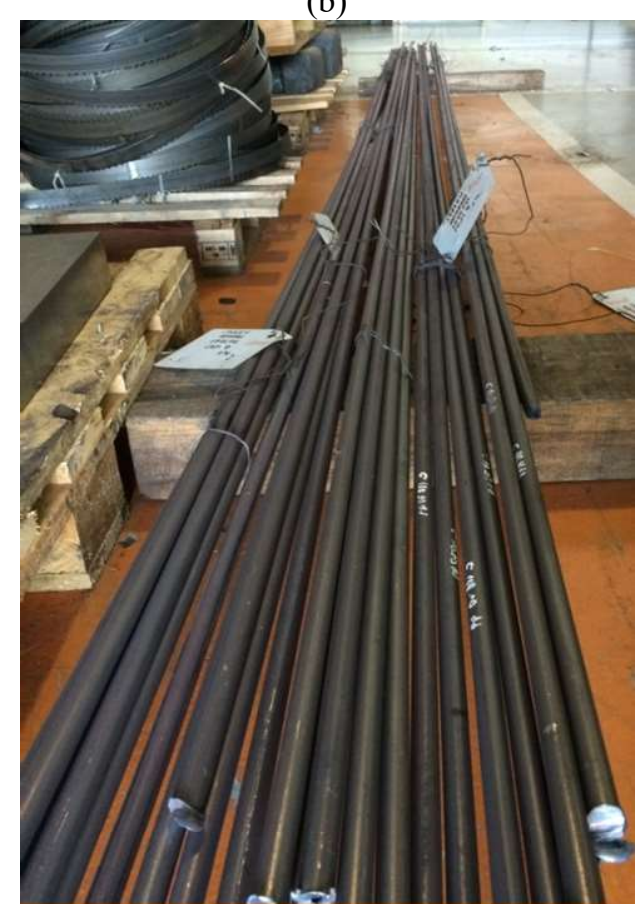

(d)

Fonte: Autor

\subsection{TRATAMENTO TÉRMICO}

As amostras brutas de laminação foram solubilizadas a $1100^{\circ} \mathrm{C}$ por 1 hora e resfriadas em água, pois de acordo com os diagramas de fases em equilíbrio obtidos pelo software

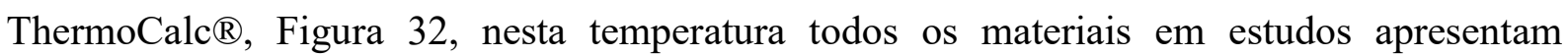


microestrutura composta somente por austenita. Os tratamentos térmicos foram realizados em forno tipo mufla no Centro de Pesquisa \& Desenvolvimento da Villares Metals, sendo que o tempo previsto de tratamento passou a ser considerado após as amostras atingirem o patamar isotérmico.

\subsection{CARACTERIZAÇÃO MICROESTRUTURAL}

As amostras foram preparadas para metalografia seguindo-se as condições padrão de preparação que consistiram de lixamento em lixas de granas crescentes até \#1200, polimento em pasta de diamante de $6 \mu \mathrm{m}$ e $1 \mu \mathrm{m}$ e polimento final com suspensão coloidal de alumina. As amostras foram então avaliadas por microscopia ótica com ataque metalográfico eletrolítico, $5 \mathrm{~V}_{\mathrm{cc}} / 20 \mathrm{~s}$, em solução de $60 \%$ ácido nítrico e $40 \%$ água. Como a amostra que apresenta $100 \%$ de W não sofreu alterações com este ataque, esta foi atacada com o reagente Marble (4 gramas de sulfato de cobre (II), $\mathrm{CuSO}_{4}, 20 \mathrm{~mL}$ de ácido clorídrico, $\mathrm{HCl}$, e $20 \mathrm{~mL}$ de água destilada). Todas as amostras preparadas metalograficamente foram observadas no microscópio ZEISS Modelo Axiovert 200 MAT do Centro de Pesquisa \& Desenvolvimento da Villares Metals, Figura 34.

Figura 34 - Microscópio ZEISS modelo Axiovert 200 MAT do Centro de Pesquisa \& Desenvolvimento da Villares Metals utilizado para caracterização microestrutural do material em estudo.

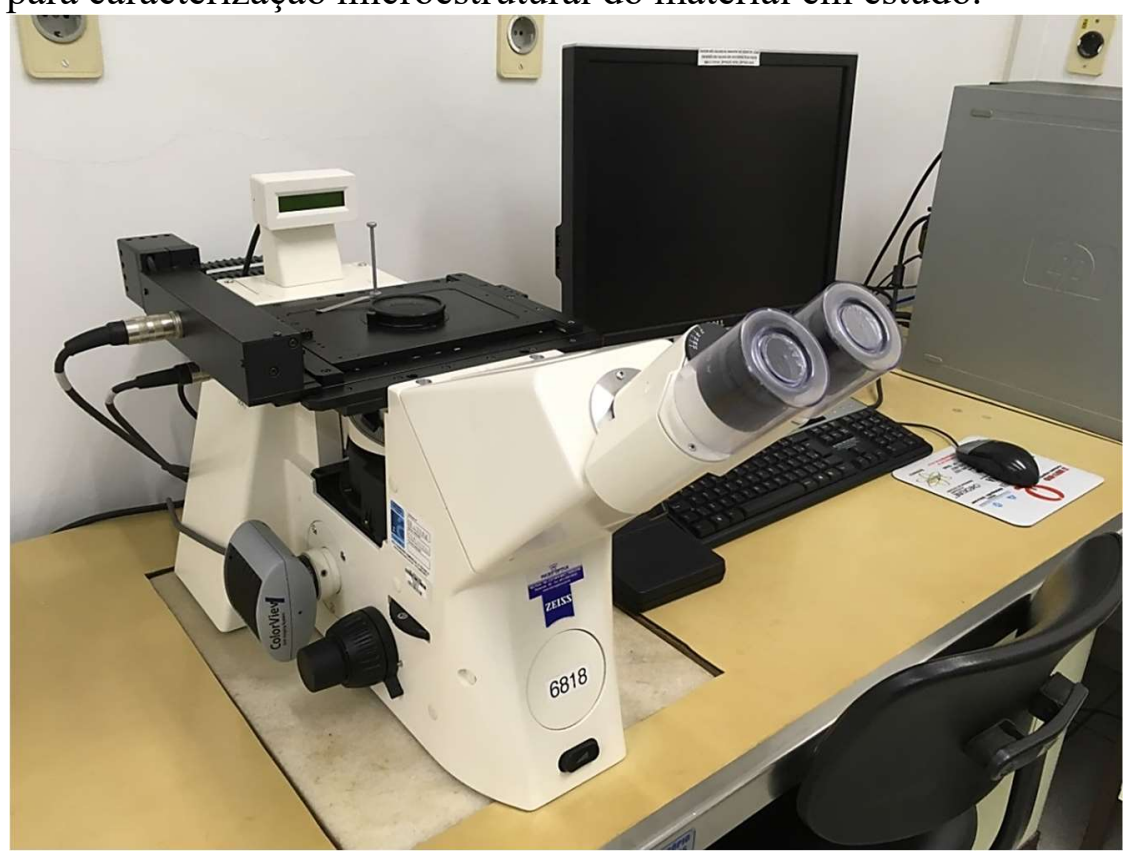

Fonte: Autor 


\subsection{ANÁLISE DE INCLUSÕES}

As inclusões observadas por microscopia ótica nas amostras solubilizadas foram analisadas semi-quantitativamente em relação à fração em área utilizando o software de análise de imagens Image J 1.45s. Para isso, os corpos-de-prova analisados por microscopia ótica foram repreparados seguindo o processo de preparação padrão até lixa \#1200, seguido de polimento em pasta de diamante de $6 \mu \mathrm{m}, 1 \mu \mathrm{m}$ e, por fim polimento final com suspensão coloidal de alumina. Então, as amostras foram observadas novamente no microscópio ótico apresentado anteriormente sob aumento de 500x e, utilizando o software citado, a imagem foi transformada em um binário para que o software fosse capaz de calcular a fração de pixels pretos, que corresponde à fração de inclusões, em relação ao número total de pixels da imagem, Figura 35. Desta forma, este procedimento foi repetido para 20 campos escolhidos aleatoriamente para cada material e os dados analisados estatisticamente.

Figura 35 - Transformação das micrografias observadas em microscópio ótico com aumento de $500 \mathrm{x}$ em imagens binárias no software Image $J 1.45 \mathrm{~s}$ a fim de possibilitar o cálculo da fração de inclusões em cada um dos materiais.

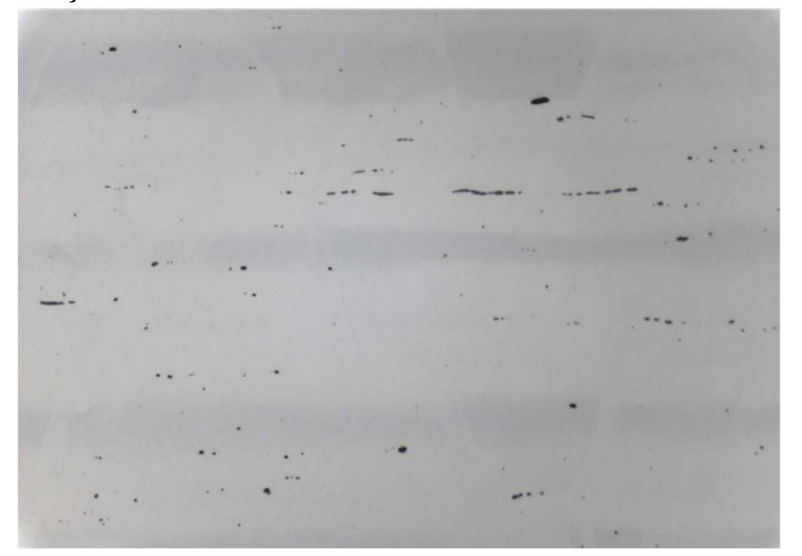

(a)

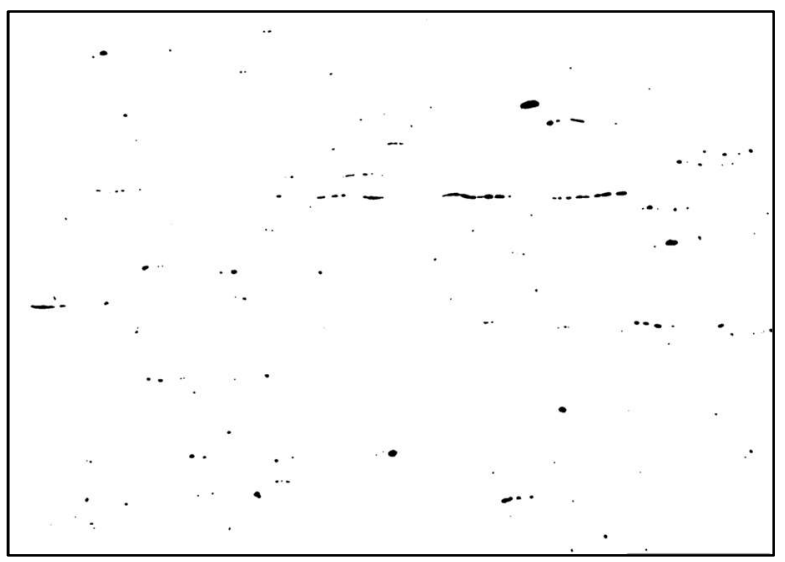

(b)

Fonte: Autor

Além disso, as amostras foram submetidas à análise por microscopia eletrônica de varredura utilizando o microscópio CAMSCAN CS3200LV do CDMatM-FEI, Figura 36, com o objetivo de identificar a composição química das inclusões presentes nas amostras solubilizadas por meio da análise semi-quantitativa por espectroscopia de energia dispersiva (EDS). 
Figura 36 - Microscópio eletrônico de varredura CAMSCAN CS3200LV do CDMatM-FEI utilizado na análise das inclusões das amostras solubilizadas.

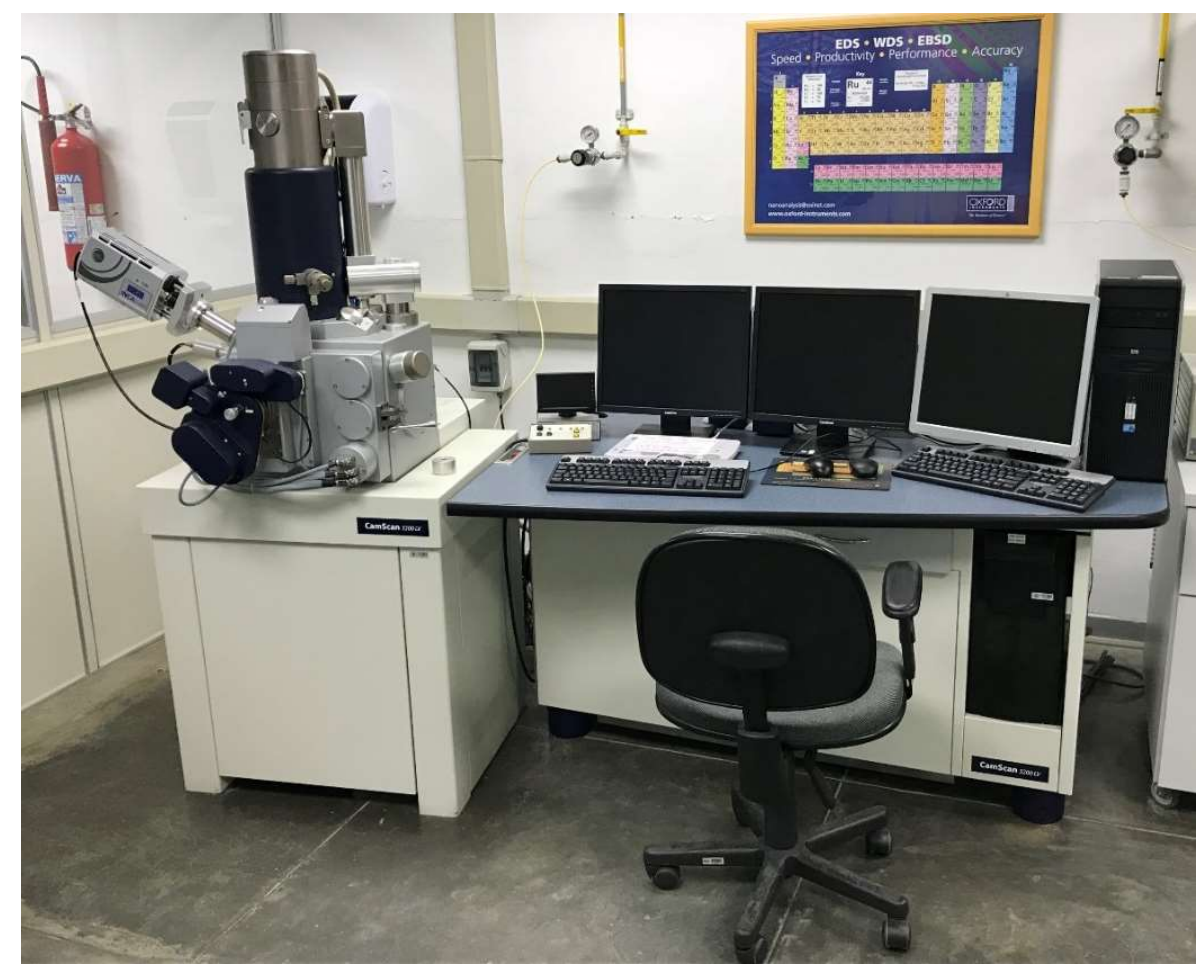

Fonte: Autor

\subsection{TAMANHO DE GRÃO}

O tamanho de grão das amostras foi avaliado de acordo com o método do intercepto médio realizado com a ajuda do software AnalySIS auto licenciado pela Olympus Soft Imaging Solutions $\mathrm{GmbH}$ acoplado ao microscópio ZEISS modelo Axiovert 200 MAT do Centro de Pesquisa \& Desenvolvimento da Villares Metals. A análise foi realizada nas seções longitudinais das amostras, em 10 campos diferentes, com grades na vertical e horizontal a fim de verificar a anisotropia dos grãos, conforme exemplificado nas micrografias da Figura 37. 
Figura 37 - Método dos interceptos médios utilizado para avaliar o tamanho de grão da seção longitudinal das amostras com grades na horizontal (a) e vertical (b) para verificar a anisotropia dos grãos. Os pontos vermelhos delimitam os interceptos medidos nestes exemplos.

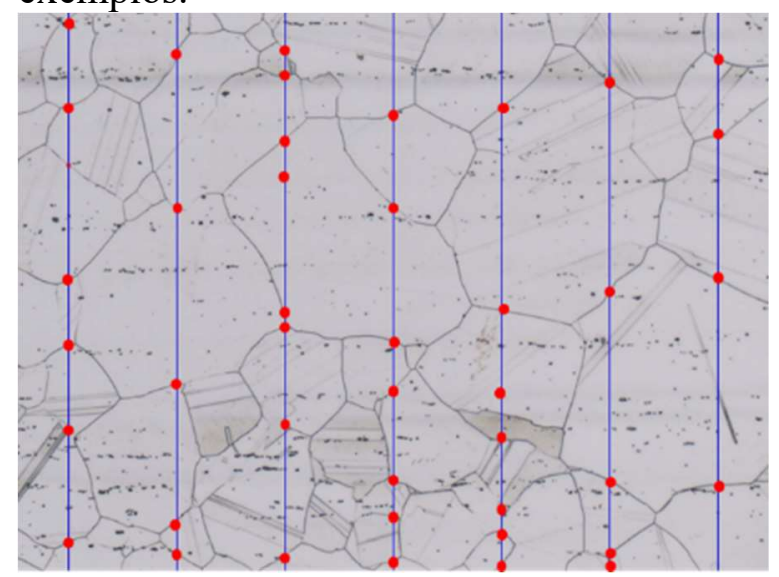

(a)

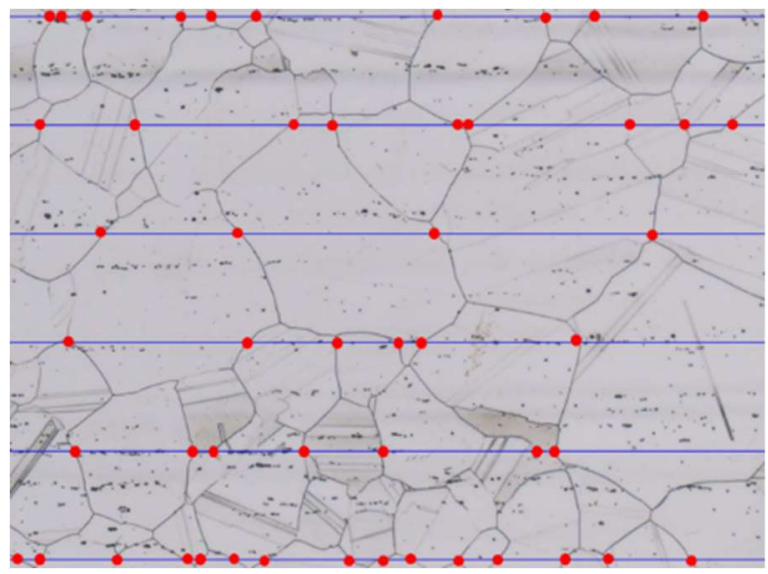

(b)

Fonte: Autor

\subsection{DUREZA BRINELL}

As medidas de dureza Brinell das amostras foram realizadas em 4 pontos da seção transversal de cada uma delas no durômetro Wilson Hardness, modelo Wolpert UH930, do Centro de Pesquisa \& Desenvolvimento da Villares Metals, Figura 38. 
Figura 38 - Durômetro Wilson Hardness, modelo Wolpert UH930, do Centro de Pesquisa \& Desenvolvimento da Villares Metals utilizado para realização das medidas de dureza Brinell do material em estudo.

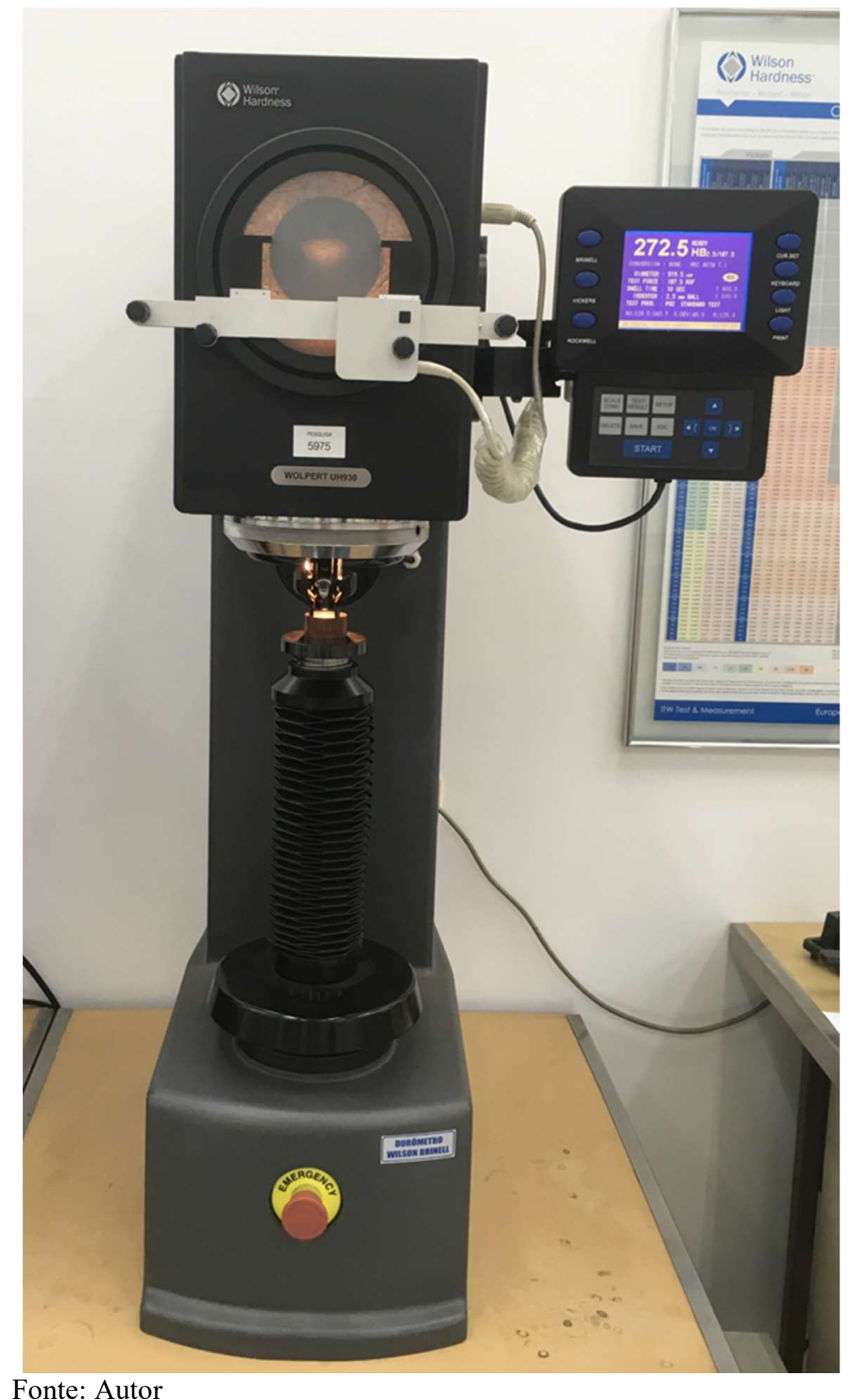

\subsection{ENSAIOS DE TRAÇÃO}

Os ensaios de tração presentes neste trabalho foram realizados na máquina Instron, modelo 30T, Figura 39 (a), utilizando os corpos-de-prova 2 5D [EM8] da norma ASTM E8/E8M - 15a, Figura 39 (b) e (c), no Centro de Pesquisa \& Desenvolvimento da Villares Metals. Para cada material, foram realizados três ensaios na mesma condição, em temperatura ambiente, utilizando uma velocidade de $0,6 \mathrm{~mm} / \mathrm{min}$. 
Figura 39 - (a) Instron modelo 30T do Centro de Pesquisa \& Desenvolvimento utilizada para obtenção dos resultados dos ensaios de tração do material estudado; (b) Corpos-de-prova usinados para os ensaios de tração dos materiais analisados; (c) Dimensões dos corpos-deprova $25 \mathrm{D}$ [EM8] utilizados.

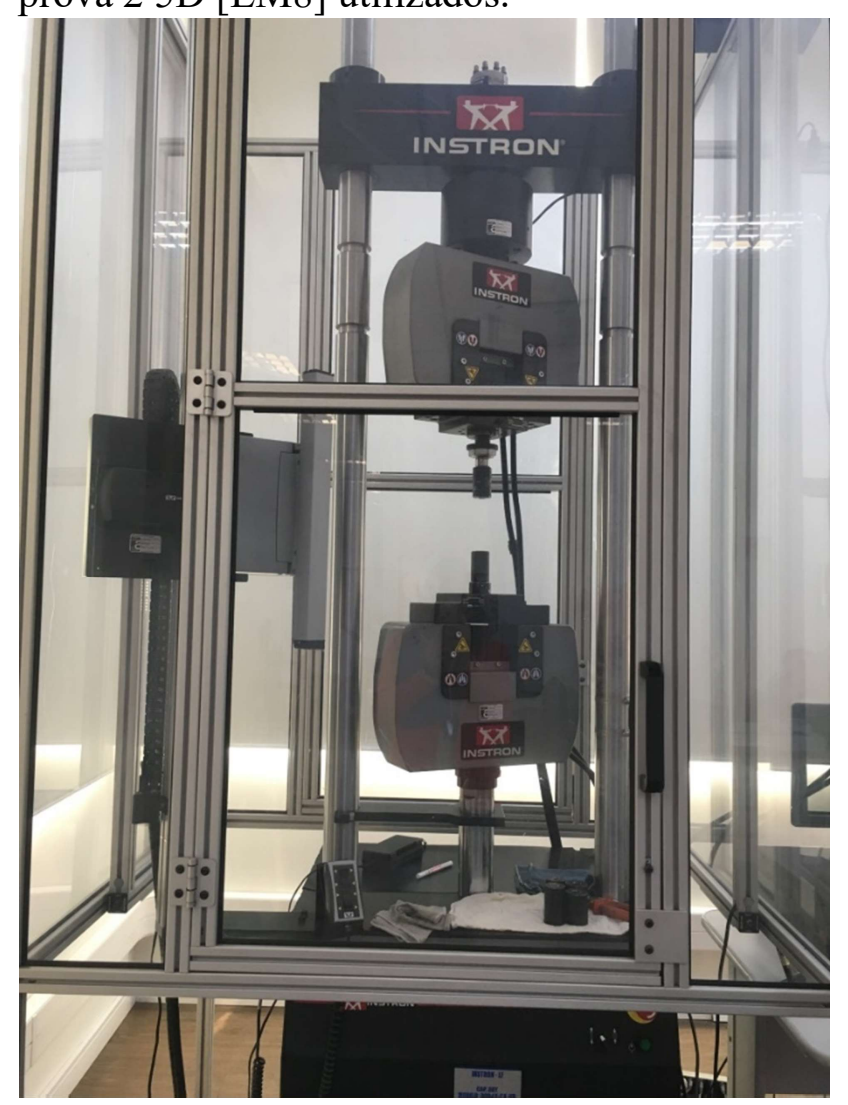

$\left(\right.$ a) ${ }^{1}$

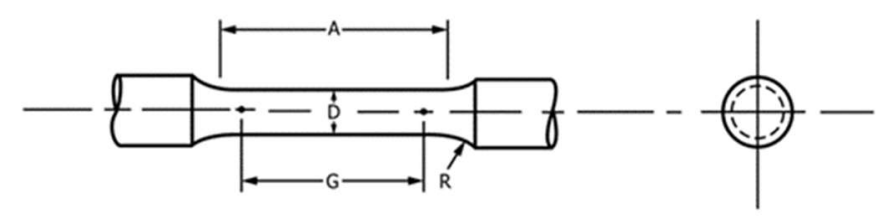

$(\mathrm{c})^{2}$

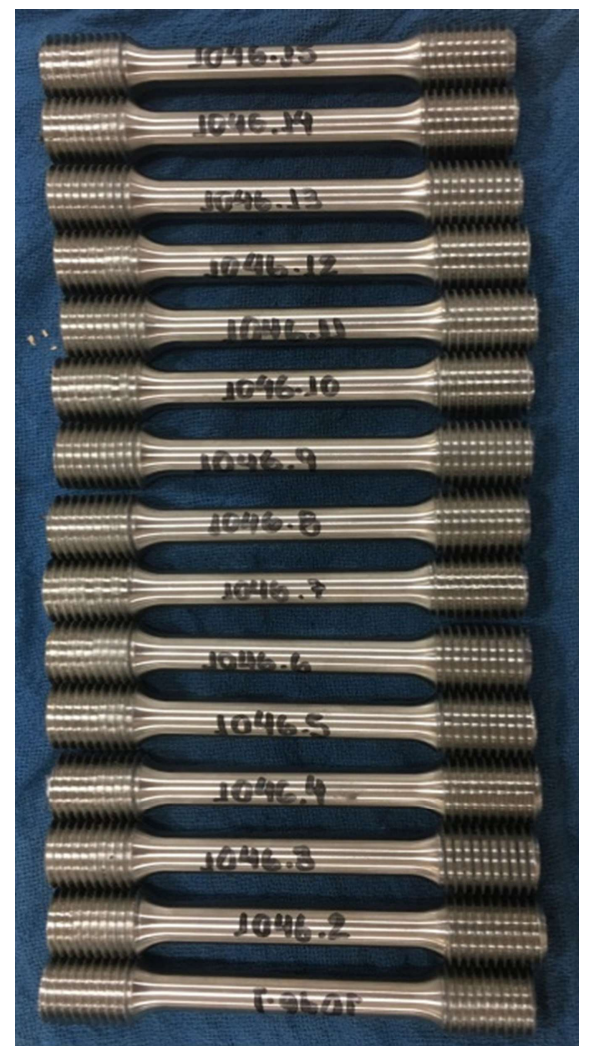

(b) ${ }^{1}$

\begin{tabular}{|c|c|}
\hline$G(\mathrm{~mm})$ & $45,0 \pm 0,1$ \\
\hline$D(\mathrm{~mm})$ & $9,0 \pm 0,1$ \\
\hline$R(\mathrm{~mm})$ & 8 \\
\hline$A(\mathrm{~mm})$ & 54 \\
\hline
\end{tabular}

Fonte: ${ }^{1}$ Autor; ${ }^{2}$ Autor “adaptado de" ASTM E8/E8M - 15a, 2015.

\subsection{ENSAIOS DE CORROSÃO}

As amostras utilizadas para realização dos ensaios eletroquímicos foram usinadas para retirada de toda a carepa superficial oriunda do processo de laminação e, em seguida, cortadas de forma que a superfície longitudinal exposta variasse entre 0,45 e $0,55 \mathrm{~cm}^{2}$, conforme mostrado na Figura 40 (a) e (b). Então, as amostras foram embutidas em resina fenólica de cura a quente, gerando os corpos-de-prova de acordo com o esquema apresentado na Figura 40 (c). Assim como os corpos-de-prova utilizados para a caracterização microestrutural, os corpos-deprova utilizados para os ensaios eletroquímicos passaram pelo procedimento padrão de 
preparação até a lixa de grana \#600. Antes dos ensaios eletroquímicos as amostras foram analisadas em microscópio ótico a fim de verificar a ausência de trincas na resina e/ou defeitos de adesão que pudessem conduzir à corrosão por frestas. Em seguida, as amostras foram furadas lateralmente e uma rosca foi gerada para possibilitar a conexão elétrica do eletrodo de trabalho ao potenciostato, Figura 40 (d).

Figura 40 - Preparação das amostras utilizadas para os ensaios eletroquímicos. (a) corte das amostras; (b) amostras a serem embutidas; (c) embutimento em resina fenólica e furação para realização do contato elétrico; (d) conexão à haste metálica para contato elétrico.

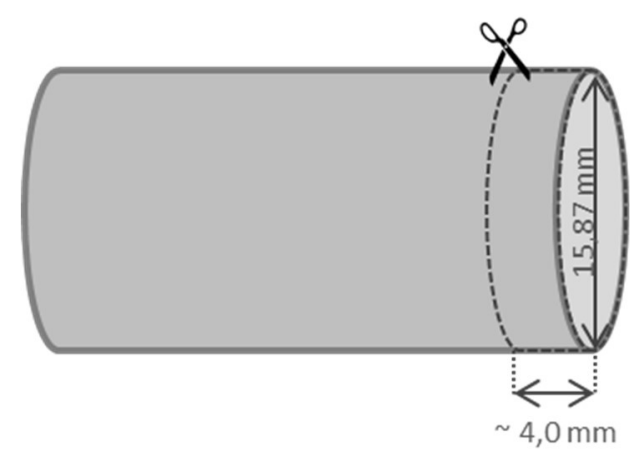

(a)
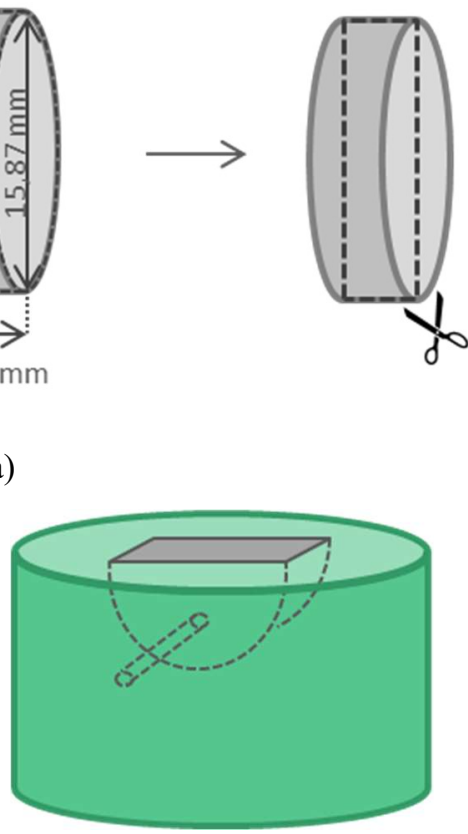

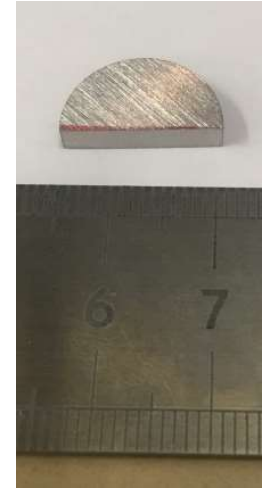

(b)

(c)

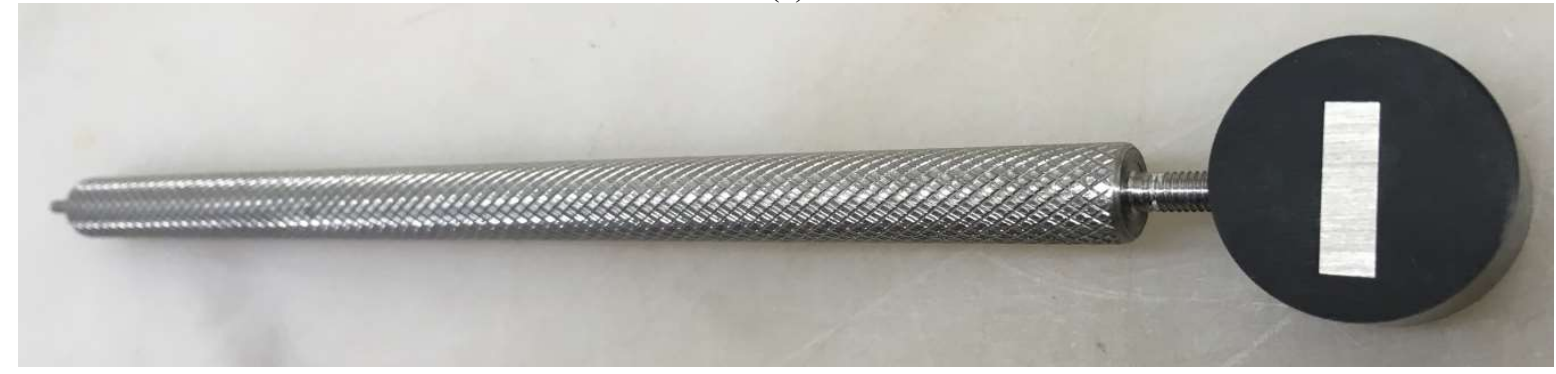

(d)

Fonte: Autor

Os ensaios eletroquímicos foram realizados com o auxílio do potenciostato AUTOLAB (PGSTAT 12) do CDMatM-FEI (Figura 41) e controlados pelo programa NOVA 2.0 do mesmo fabricante por meio de um computador. As soluções utilizadas encontravam-se naturalmente aeradas, preparadas com reagente padrão analítico e água destilada e deionizada e foram 
reutilizadas por, no máximo, três vezes para evitar contaminações. Imediatamente antes de todos os ensaios, as amostras foram lixadas em lixa \#600 para remoção da camada passiva e, após cada ensaio, as amostras foram lavadas com água destilada e deionizada e secas com álcool etílico e jato de ar para posterior análise via microscopia.

Figura 41 - Potenciostato AUTOLAB (PGSTAT 12) do CDMatM-FEI utilizado para realização dos ensaios eletroquímicos dos materiais em estudo.

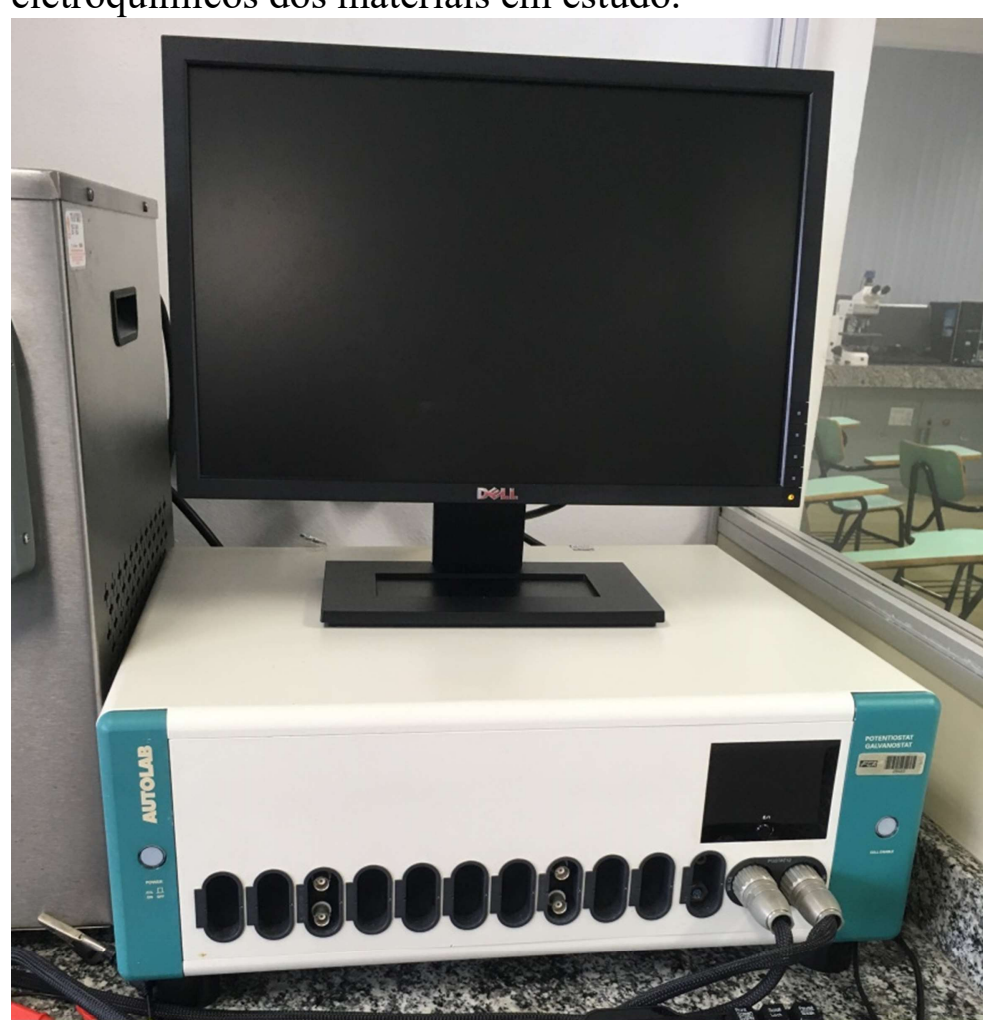

Fonte: Autor

Para cada material e cada tipo de técnica eletroquímica utilizada foram realizados pelo menos cinco ensaios para que a variabilidade estatística analisada fosse adequada. Além disso, para obtenção destas curvas, utilizou-se um eletrodo de prata/cloreto de prata como eletrodo de referência e como contra-eletrodo, um fio de platina, conforme apresentado na Figura 42, e as amostras em estudo foram usadas como eletrodo de trabalho. 
Figura 42- Configuração da célula eletroquímica utilizada nos ensaios eletroquímicos, sendo que E.R. representa o eletrodo de referência $\mathrm{Ag} / \mathrm{AgCl}$, C.E. representa o contraeletrodo fabricado com um fio de platina e E.T. representa o eletrodo de trabalho que corresponde à amostra analisada.

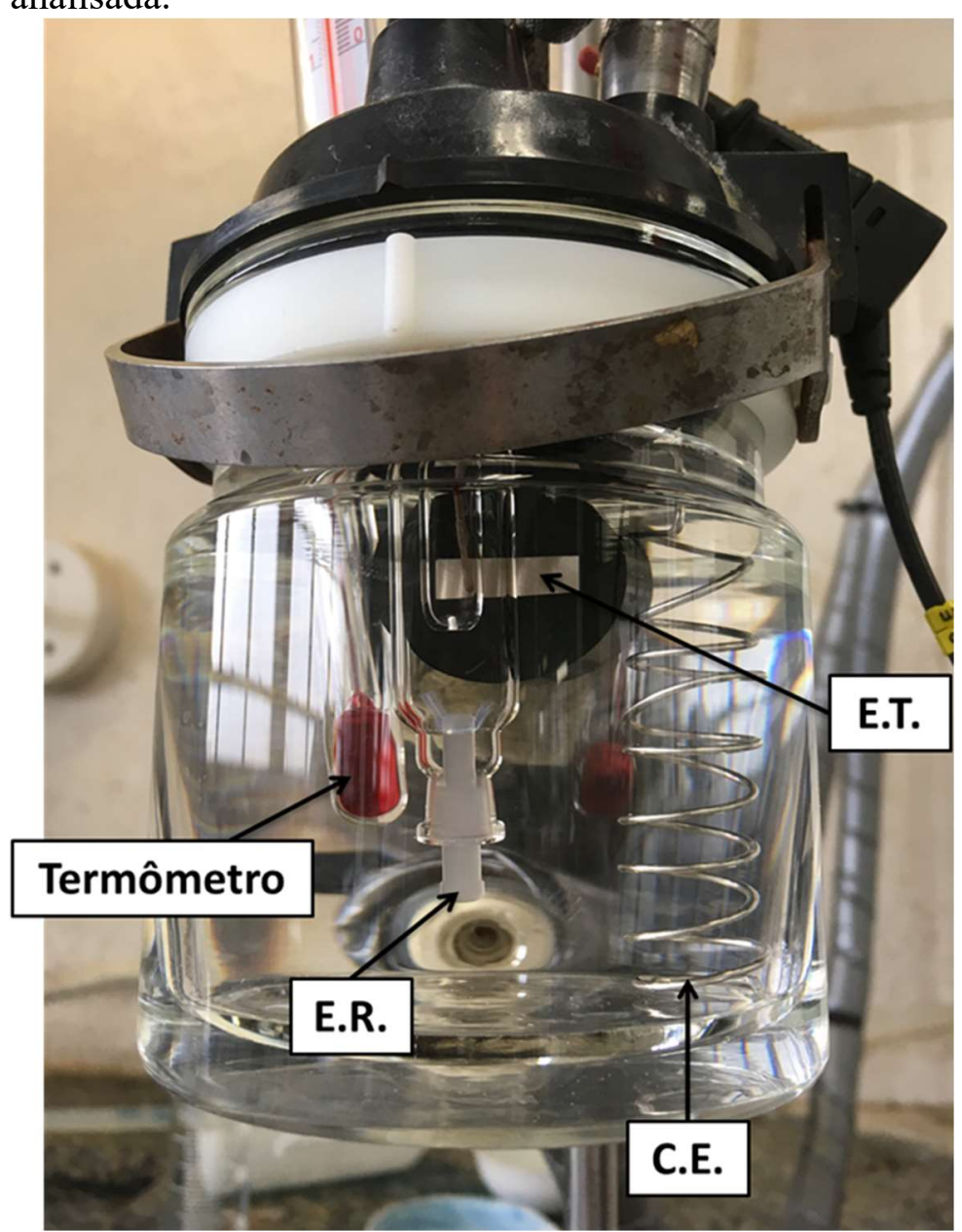

Fonte: Autor

\subsubsection{Polarização Potenciodinâmica}

Buscando a avaliação do trecho passivo dos materiais em estudo em meio isento de cloretos, foram obtidas curvas de polarização potenciodinâmica em solução de $0,5 \mathrm{M} \mathrm{H}_{2} \mathrm{SO}_{4}+$ $0,01 \mathrm{M} \mathrm{KSCN}$ a $30^{\circ} \mathrm{C}$, sendo que o tiocianato de potássio (KSCN) foi adicionado à solução imediatamente antes do ensaio.

O ensaio de polarização foi iniciado após 5 minutos de imersão a partir do potencial de circuito aberto, com velocidade de varredura de $1 \mathrm{mV} / \mathrm{s}$ até que o potencial atingido fosse 1,2 $\mathrm{V}_{\mathrm{Ag} / \mathrm{AgCl}}$. Utilizou-se uma célula eletroquímica encamisada conectada a um banho ultratermostático microprocessado com circulador da marca Quimis, Figura 43, para manutenção da temperatura em $30 \pm 2{ }^{\circ} \mathrm{C}$. 
Figura 43 - Banho ultratermostático microprocessado com circulador da marca Quimis do CDMatM-FEI utilizado acoplado à célula eletroquímica encamisada para controle da temperatura dos ensaios eletroquímicos.

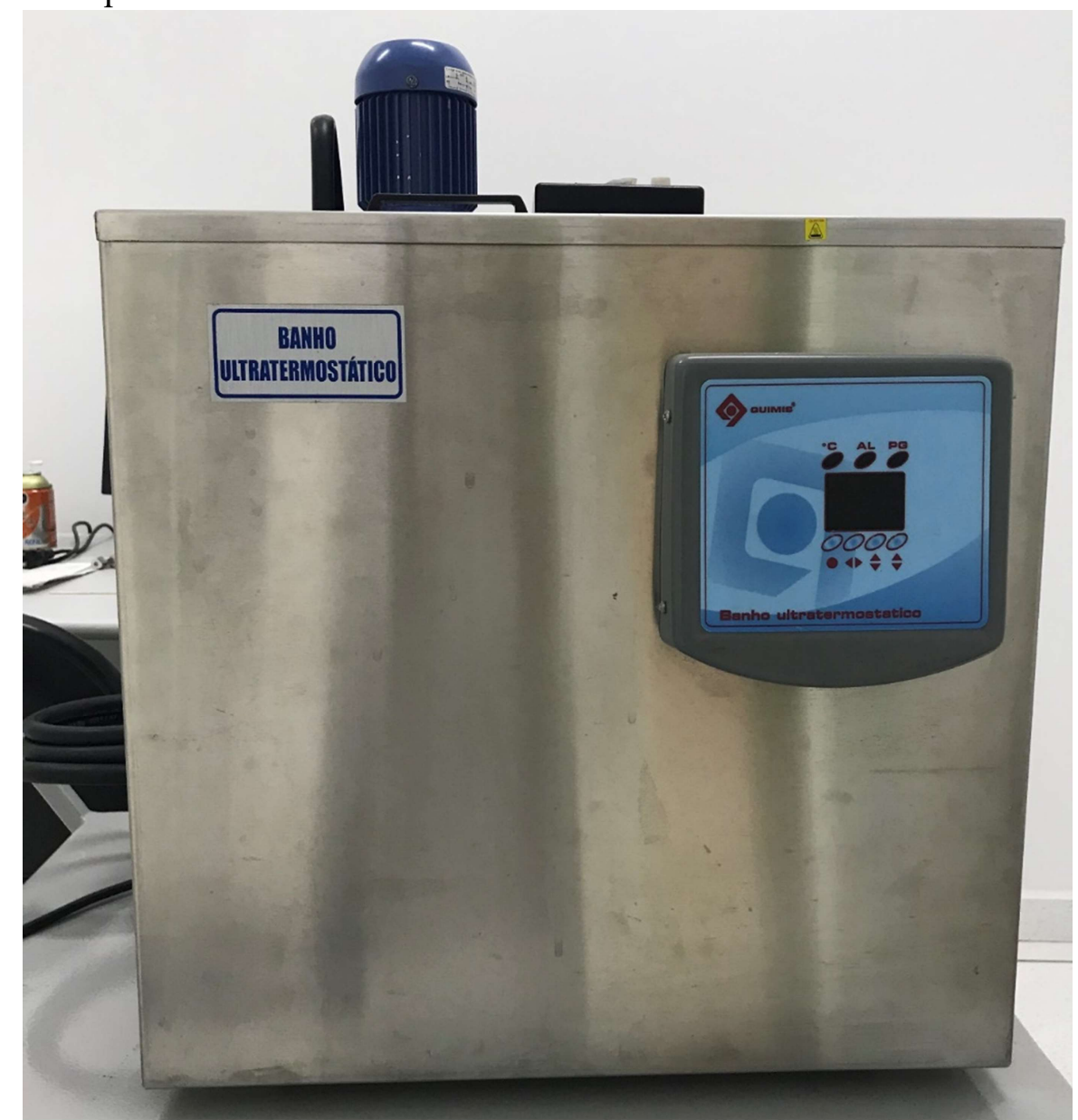

Fonte: Autor

\subsubsection{Técnica Eletroquímica de Reativação Potenciodinâmica de Ciclo Duplo (DL-EPR)}

A fim de avaliar a susceptibilidade dos materiais em estudo à corrosão intergranular, utilizou-se a técnica eletroquímica de reativação potenciodinâmica de ciclo duplo ("Double Loop Electrochemical Potentiodynamic Reactivation Method", DL-EPR) para determinar o grau de sensitização de cada um deles em uma solução de $0,5 \mathrm{M} \mathrm{H}_{2} \mathrm{SO}_{4}+0,01 \mathrm{M} \mathrm{KSCN}$ a $30^{\circ} \mathrm{C}$, sendo que, assim como no ensaio citado anteriormente, o tiocianato de potássio (KSCN) foi adicionado à solução imediatamente antes do ensaio. Para este ensaio especificamente, os corpos-de-prova foram preparados seguindo o procedimento padrão de preparação até lixa \#600 seguido pelo polimento em diamante de $6 \mu \mathrm{m}$ e $1 \mu \mathrm{m}$, sendo que imediatamente antes dos ensaios, estes corpos-de-prova eram novamente polidos em diamante de $1 \mu \mathrm{m}$. Neste ensaio a célula eletroquímica encamisada utilizada também foi conectada ao banho ultratermostático 
microprocessado com circulador da marca Quimis, Figura 43, para que a manutenção da temperatura de $30 \pm 2{ }^{\circ} \mathrm{C}$ fosse eficiente.

Os ensaios foram realizados em acordo com a norma ISO 12732:2006 e iniciados após 5 minutos de imersão a partir do potencial de circuito aberto, com velocidade de varredura de $1 \mathrm{mV} / \mathrm{s}$ até que fosse atingido o potencial de $400 \mathrm{mV}_{\mathrm{Ag} / \mathrm{AgCl}}$. O potencial de reversão foi escolhido baseando-se no intervalo de passivação mostrado pelas curvas de polarização potenciodinâmica obtidas nas mesmas condições, conforme item 3.9.2. Ao atingir este potencial, o sentido de varredura foi invertido sob a mesma taxa e finalizado quando o potencial de circuito aberto fosse novamente atingido. Então, o grau de sensitização (DOS, "Degree of Sensitization") de cada uma das amostras foi calculado de acordo com a razão entre a densidade de corrente de reativação $\left(\mathrm{I}_{\mathrm{r}}\right)$ e a densidade de corrente de ativação $\left(\mathrm{I}_{\mathrm{a}}\right)$, Equação 17.

$\% D O S=\frac{I_{r}}{I_{a}} \cdot 100$

\subsubsection{Polarização Cíclica}

Buscando a determinação da susceptibilidade dos materiais estudados à corrosão por pite, realizaram-se curvas de polarização cíclica das amostras em uma solução de 3,5\% de cloreto de sódio $(\mathrm{NaCl})$ naturalmente aerada e temperatura ambiente, utilizando o potenciostato citado.

Após o lixamento em lixa \#600 imediatamente antes do ensaio, as amostras foram imersas na solução e o ensaio iniciado após 300 segundos (5 minutos) a partir do potencial de corrosão, a uma taxa de varredura de $1 \mathrm{mV} / \mathrm{s}$, sendo que o sentido de varredura era revertido quando a corrente atingia $10^{-3} \mathrm{~A}$. Ao atingir o potencial de início, o ensaio era encerrado e as amostras lavadas, conforme mencionado anteriormente.

\subsubsection{Temperatura Crítica de Pite (CPT)}

Procurando verificar se o W provoca alguma alteração na temperatura de início do fenômeno de corrosão por pite, levantou-se a temperatura crítica de pite dos materiais estudados em solução de 1M de $\mathrm{NaCl}$ em acordo com a norma ASTM G150 - 99 (2004). Para esta análise acoplou-se ao potenciostato um equipamento para aquisição de dados chamado Quantum X capaz de registrar a corrente elétrica em função da temperatura da solução medida por um 
termopar tipo Pt100 com encapsulamento de aço inox conectado ao Quantum X, Figura 44. Assim, a curva Densidade de Corrente Elétrica $\left(\mathrm{A} / \mathrm{cm}^{2}\right)$ versus Temperatura da Solução $\left({ }^{\circ} \mathrm{C}\right)$ foi obtida. Os ensaios foram iniciados entre 0 e $5^{\circ} \mathrm{C}$ e a solução aquecida a uma taxa de $1^{\circ} \mathrm{C} / \mathrm{min}$ com o auxílio do banho ultratermostático microprocessado com circulador da marca Quimis, Figura 43, até que houvesse um aumento abrupto na densidade de corrente. Assim, a temperatura crítica de pite foi definida como a temperatura na qual a densidade de corrente atingisse $100 \mu \mathrm{A} / \mathrm{cm}^{2}$ e permanecesse acima deste valor por pelo menos 60 segundos.

Figura 44 - Equipamentos utilizados para obtenção das curvas de temperatura crítica de pite no CDMatM-FEI: Potenciostato, Banho Ultratermostático, Célula Eletroquímica e Quantum X.

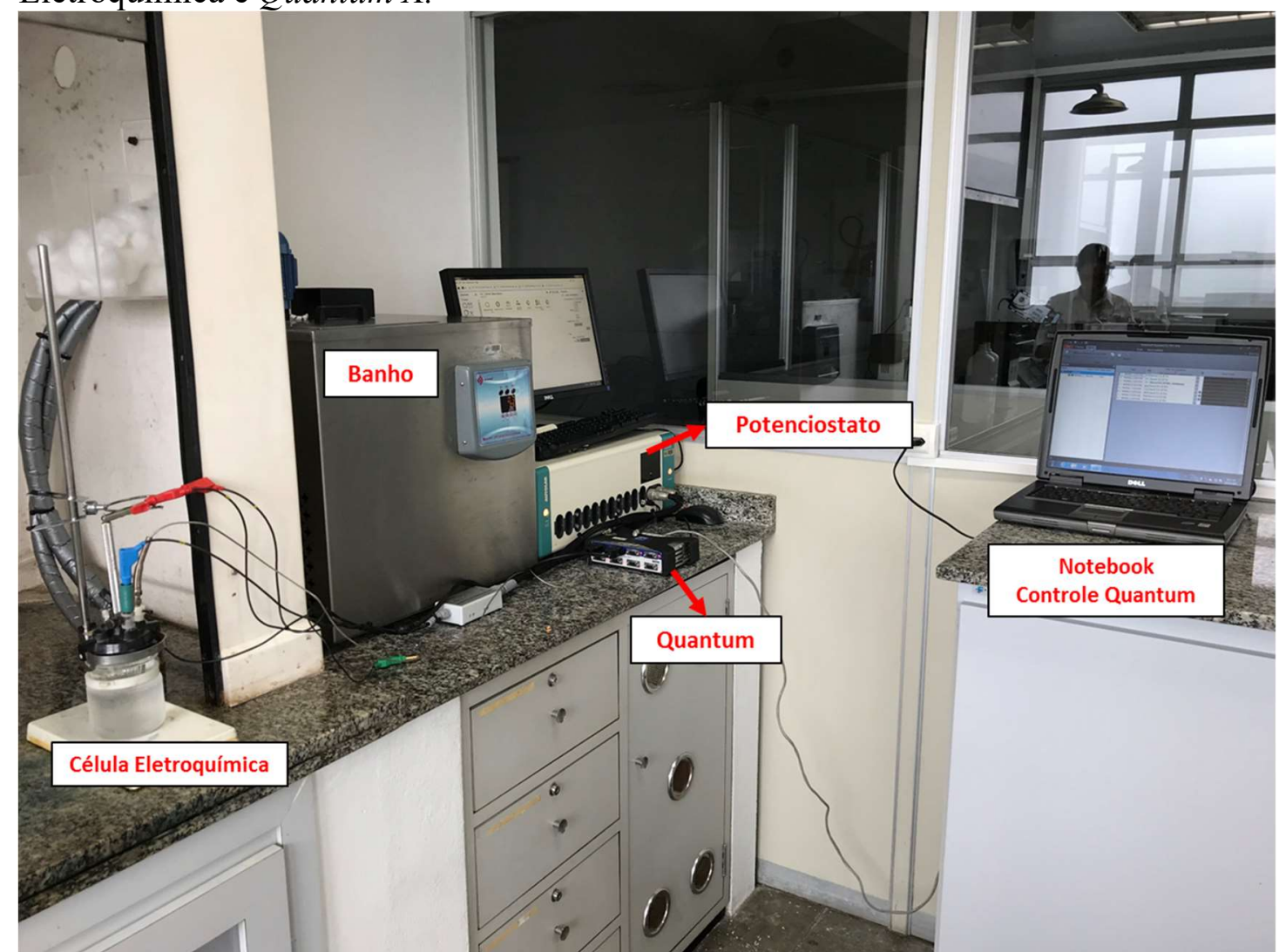

Fonte: Autor

De acordo com a norma ASTM G150-99 (2004) o potencial deve ser mantido constante a $700 \mathrm{mV}$ durante todo o ensaio. Porém, verificou-se que os materiais estudados apresentam CPT menor que $4^{\circ} \mathrm{C}$ a $700 \mathrm{mV}_{\mathrm{Ag} / \mathrm{AgCl}}$, o que dificulta o estudo do efeito do $\mathrm{W}$ nestes materiais, como pode ser observado na Figura 45. Nesta Figura é possível observar que imediatamente após o aumento do potencial para $700 \mathrm{mV}_{\mathrm{Ag} / \mathrm{AgCl}}$ e início do ensaio, a densidade de corrente aumenta constantemente até cerca de $1000 \mu \mathrm{A} / \mathrm{cm}^{2}$, Figura 45 (a). As micrografias analisadas após este ensaio evidenciam que de fato, há ocorrência de pite nestas condições, Figura 45 (b). 
Desta forma, optou-se por manter o potencial a $180 \mathrm{mV}$ Ag/AgCl que, como será mostrado no item 4 de Resultados e Discussão, está dentro do trecho passivo desses materiais a temperatura ambiente, $25^{\circ} \mathrm{C}$, a fim de possibilitar a análise comparativa de CPT entre as ligas em estudo com maior precisão.

Figura 45 - Ensaio de Temperatura crítica de pite realizado em acordo com a norma ASTM G150 - 99 (2004) evidenciando que o potencial recomendado de 700 mV não é adequado para os materiais analisados. (a) Curva Densidade de Corrente versus Temperatura; (b) Presença de pites na amostra imediatamente após o ensaio utilizando potencial de $700 \mathrm{mV}$ com 50x de aumento e (c) amostra levemente polida até diamante de $1 \mu \mathrm{m} 200 \mathrm{x}$.

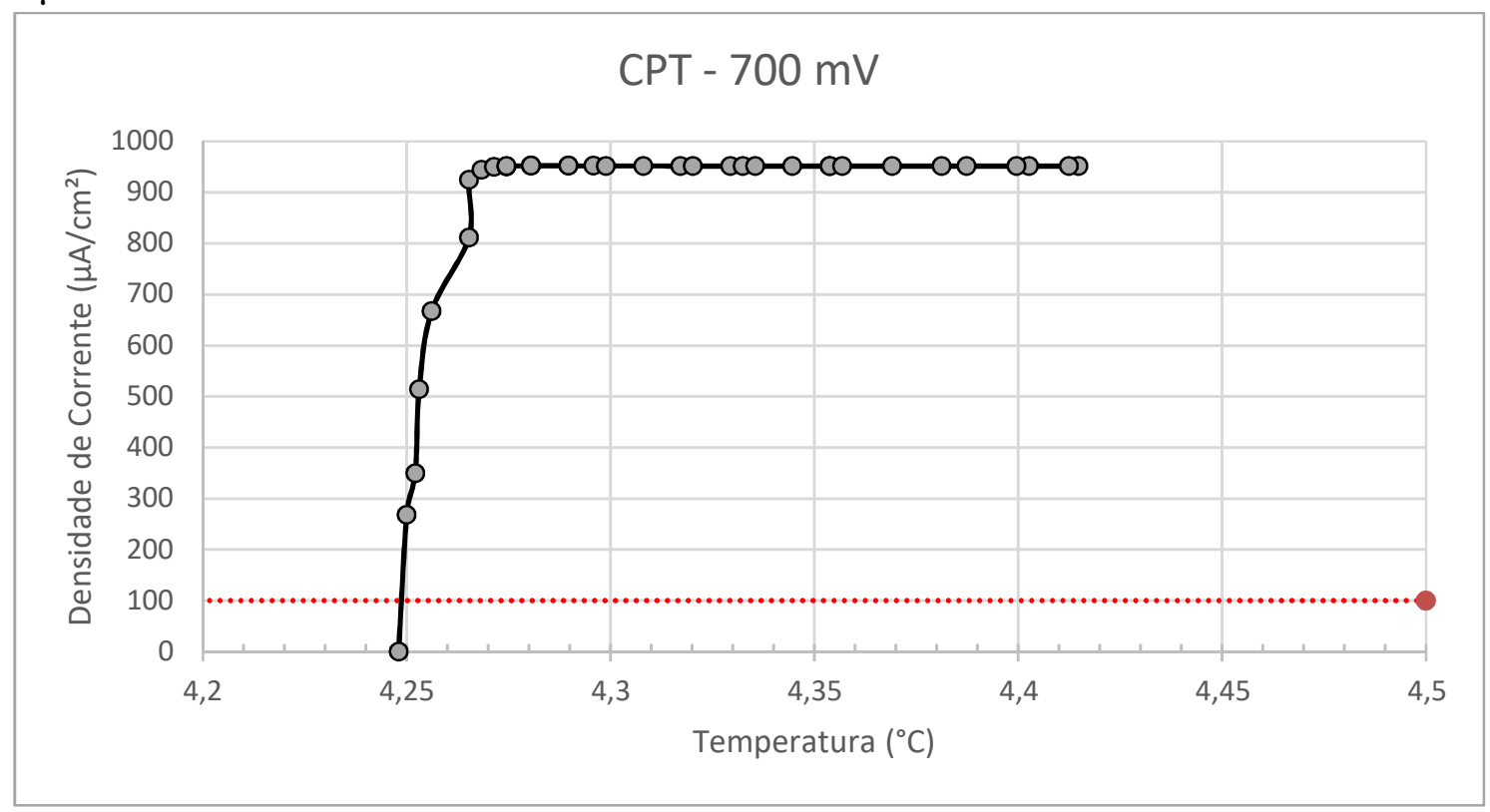

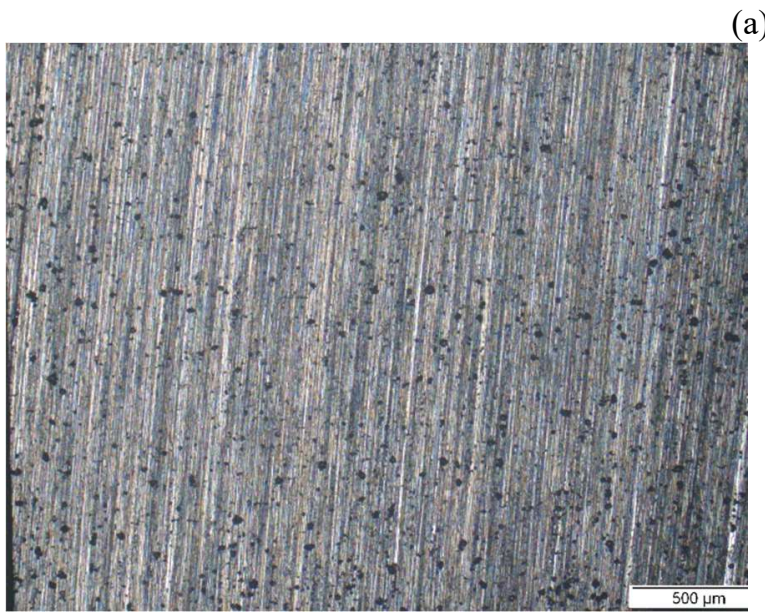

(b)

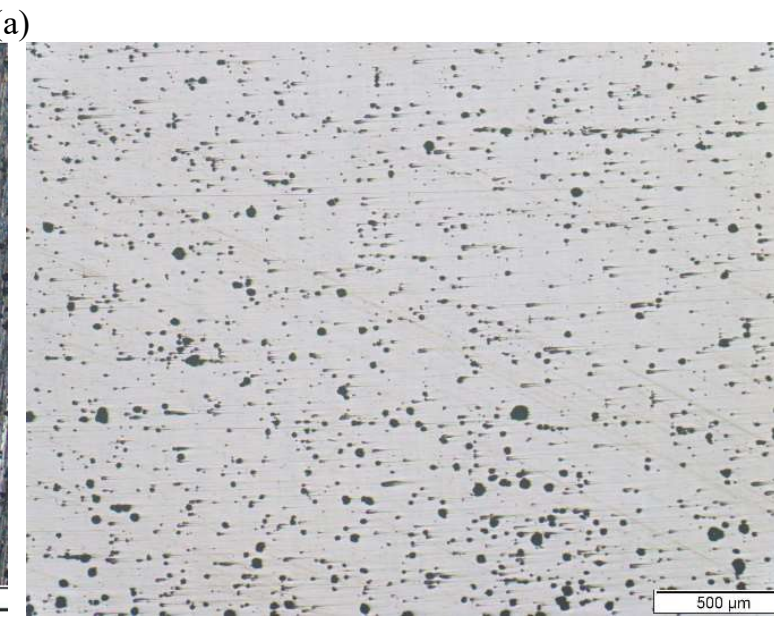

(c)

Fonte: Autor

A alteração das condições de ensaio apresentadas na norma ASTM G150-99 (2004) para a determinação da temperatura crítica de pite já foi utilizada por outros autores (AMERICAN 
SOCIETY FOR TESTING AND MATERIALS, 2004). Zakeri, Nakhaie e Moayed (2015) obtiveram curvas de temperatura crítica de pite deste mesmo aço inoxidável austenítico AISI 316 para estudo do efeito do íon dicromato $\left(\mathrm{Cr}_{2} \mathrm{O}_{7}{ }^{2-}\right)$ na resistência à corrosão por pite deste material (ZAKERI, NAKHAIE e MOAYED, 2015). Para isso, a norma ASTM G150-99 (2004) também não foi seguida, uma vez que a solução utilizada foi de $0,1 \mathrm{M} \mathrm{NaCl}$ a um potencial de $750 \mathrm{mV}$ e taxa de aquecimento de $0,6^{\circ} \mathrm{C} / \mathrm{min}$ até que a densidade de corrente de $300 \mu \mathrm{A} / \mathrm{cm}^{2}$ fosse atingida. Além disso, a temperatura considerada como CPT pelos autores foi aquela em que a densidade de corrente começou a aumentar gradualmente. Observou-se que para $0 \mathrm{M}$ de $\mathrm{Cr}_{2} \mathrm{O}_{7}{ }^{2-}$ o aço inox 316 atinge a densidade de corrente de $100 \mu \mathrm{A} / \mathrm{cm}^{2}$ quando a temperatura é de $10^{\circ} \mathrm{C}$. Portanto, de fato, para um potencial tão alto como $700 \mathrm{mV}_{\mathrm{Ag} / \mathrm{AgCl}}$ e uma concentração tão elevada de cloretos como $1 \mathrm{M}$ de $\mathrm{NaCl}$, é possível que a temperatura crítica de pite deste material seja tão baixa que torna-se difícil o cumprimento das condições exigidas em norma.

Assim, neste trabalho sugere-se uma alternativa para a determinação da CPT de aços inoxidáveis austeníticos. Como neste trabalho os resultados obtidos por este método alternativo são utilizados para comparações entre os materiais estudados, os dados podem ser comparados entre si. Porém, estes dados deverão ser usados com cuidado no futuro para comparação com outros trabalhos, uma vez que a norma ASTM G150-99 (2004) não é seguida.

\subsection{ANÁLISE ESTATÍSTICA DOS RESULTADOS}

Os resultados obtidos em cada uma das análises foram analisados estatisticamente utilizando o método de análise de variâncias. A análise de variância tem como objetivo comparar a variabilidade entre as médias dos grupos e a variabilidade dentro destes grupos. Caso a variabilidade entre as médias dos grupos seja muito maior que a variabilidade dentro dos grupos, é possível supor que as médias dos grupos não são iguais. Portanto, a análise de variância busca testar as hipóteses $H_{0}$, designada como "Hipótese Nula", e $H_{l}$, em que $\mu$ é a média de cada um dos grupos para $i$ grupos:

$$
\begin{aligned}
& H 0: \mu_{1}=\mu_{2}=\ldots=\mu_{\mathrm{i}}=\mu \\
& H 1: \mu_{\mathrm{i}} \neq \mu_{\mathrm{i}^{\prime}} \text { para pelo menos um par }\left(\mathrm{i}, \mathrm{i}^{\prime}\right), \text { com } \mathrm{i} \neq \mathrm{i},
\end{aligned}
$$

Assim, se a hipótese nula for verdadeira, todos os grupos terão uma média comum $\mu$ (UNIVERSIDADE FEDERAL DO PARANÁ, 2009). 
A análise de variância baseia-se na decomposição da variação total da variável resposta em relação aos tratamentos (variância entre os grupos) e ao erro experimental (variância dentro de cada grupo). Essa variação é medida por meio da soma dos quadrados definida para cada componente, onde SQTotal é a soma dos quadrados total, SQTrat é a soma dos quadrados do tratamento e SQRes, que corresponde a SQTotal - SQTrat, é a soma dos quadrados dentro do grupo como função das diferenças existentes entre as repetições de um mesmo tratamento (UNIVERSIDADE FEDERAL DO PARANÁ, 2009). Assim, essas somas de quadrados são usualmente organizadas em uma tabela chamada de Tabela de Análise de Variância, ou simplesmente, Tabela ANOVA, Tabela 10.

Tabela 10 - Tabela de Análise de Variância ou Tabela ANOVA.

\begin{tabular}{l|c|c|c|c}
\hline $\begin{array}{c}\text { Fontes da } \\
\text { Variação }\end{array}$ & $\begin{array}{c}\text { Soma dos } \\
\text { Quadrados }(\mathbf{S Q})\end{array}$ & $\begin{array}{c}\text { Graus de } \\
\text { liberdade }(\boldsymbol{g l})\end{array}$ & $\begin{array}{c}\text { Quadrados } \\
\text { Médios }(\mathbf{Q M})\end{array}$ & $\boldsymbol{F}_{\text {calculado }}$ \\
\hline Entre grupos & SQTrat & $\mathrm{i}-1$ & QMTrat & QMTrat/QMRes \\
\hline Dentro dos grupos & SQRes & $\mathrm{i}(\mathrm{j}-1)$ & QMRes & \\
\hline Total & SQTotal & $\mathrm{ij}-1$ & & \\
\hline
\end{tabular}

Fonte: Autor "adaptado de" Departamento de Estatística - UFPR (2009).

Em que QMTrat = SQTrat/(i-1) e QMRes/(i(j-1)).

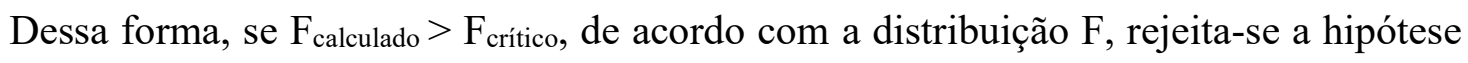
nula $H_{0}$, ou seja, existem evidências de diferença significativa entre pelo menos um par de médias dos grupos ao nível de significância $\alpha$ escolhido. Outra maneira de avaliar a significância da estatística $F$ é utilizando o valor- $p$. Se valor-p $<\alpha$, rejeita-se a hipótese nula $H_{0}$. Caso contrário, não é possível rejeitar a $H_{0}$ e, portanto, não há evidências de diferenças significativas entre os grupos, ao nível de significância $\alpha$ (BUSSAB, 1988).

Ou seja, neste trabalho, utilizando a ferramenta para análise de variância para um único fator disponibilizada no Excel e com nível de significância de 0,05, avalia-se o efeito da substituição parcial/ total do Mo por W em diversas variáveis para 5 ligas diferentes a fim de verificar se há evidências suficientes de que existem diferenças significativas entre elas. Porém, esta análise pressupõe que os dados analisados sigam uma distribuição normal e que a variância dentro dos grupos seja igual. Como neste trabalho, apesar da grande extensão de procedimentos experimentais e no mínimo 5 repetições de ensaio por cada situação, não há dados suficientes 
para checar sua normalidade, assumiu-se que a distribuição dos dados é normal e suas variâncias iguais. 


\section{RESULTADOS E DISCUSSÃO}

A seguir são apresentados os resultados obtidos relacionados à caracterização metalográfica das amostras nas condições brutas de laminação e solubilizada, e também medidas de dureza, tamanho de grão e ensaios de tração das amostras solubilizadas. São apresentados também os resultados dos ensaios de polarização cíclica em solução de 3,5\% de $\mathrm{NaCl}$, ensaios potenciodinâmicos em $0,5 \mathrm{M} \mathrm{H}_{2} \mathrm{SO}_{4}+0,01 \mathrm{M} \mathrm{KSCN}$ a $30^{\circ} \mathrm{C}$ como polarização potenciodinâmica e DL-EPR e, por fim, ensaios para determinação da temperatura crítica de pite em solução de $1 \mathrm{M}$ de $\mathrm{NaCl}$.

\subsection{CARACTERIZAÇÃO METALOGRÁFICA}

Neste item são apresentadas as micrografias dos materiais em estudo nas condições bruta de laminação e solubilizada.

\subsubsection{Amostras Brutas de Laminação}

As micrografias da seção longitudinal dos materiais brutos de laminação são mostradas na Figura 46, atacadas eletroliticamente, $5 \mathrm{~V} / 20$ s, com uma solução de $60 \%$ ácido nítrico e $40 \%$ água. Como a amostra da corrida 1107050 (100\%W) não sofreu alterações com este ataque, esta foi atacada com Marble. 
Figura 46- Micrografias da seção longitudinal das amostras brutas de laminação do aço inoxidável AISI 316XL (a) e (b) Material de Referência, corrida 1107046 (100\%at Mo), 100 e 500x de aumento, respectivamente; (c) e (d) Corrida 1107047 (25\% at W e 75\% at Mo), 100 e 500x de aumento, respectivamente; (e) e (f) Corrida 1107048 (50\%at W e 50\%at Mo), 100 e 500x de aumento, respectivamente; (g) e (h) Corrida 1107049 (75\%at W e 25\%at Mo), 100 e 500x de aumento, respectivamente; (i) e (j) Corrida 1107050 (100\%at W), atacado com Marble, 100 e 500x de aumento, respectivamente.

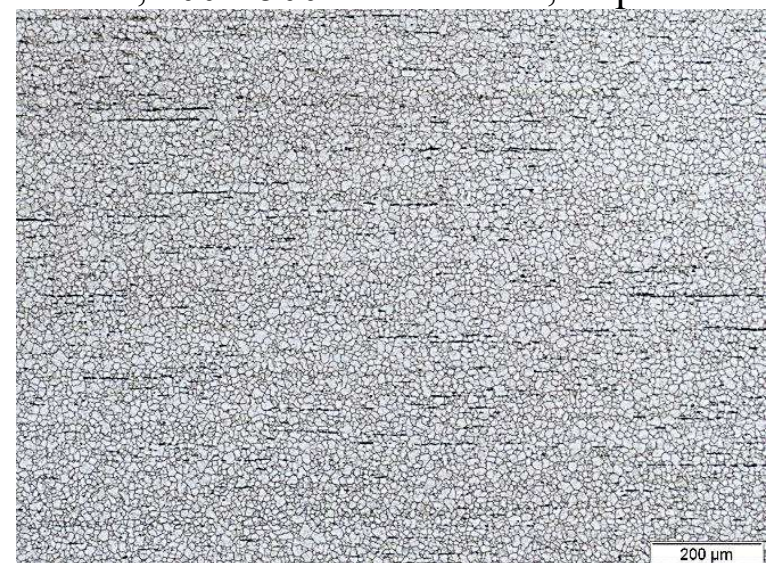

(a)

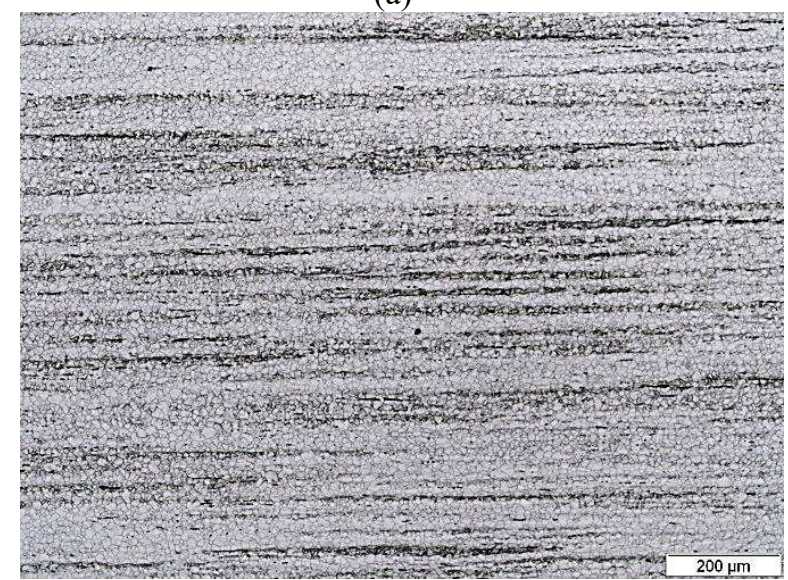

(c)

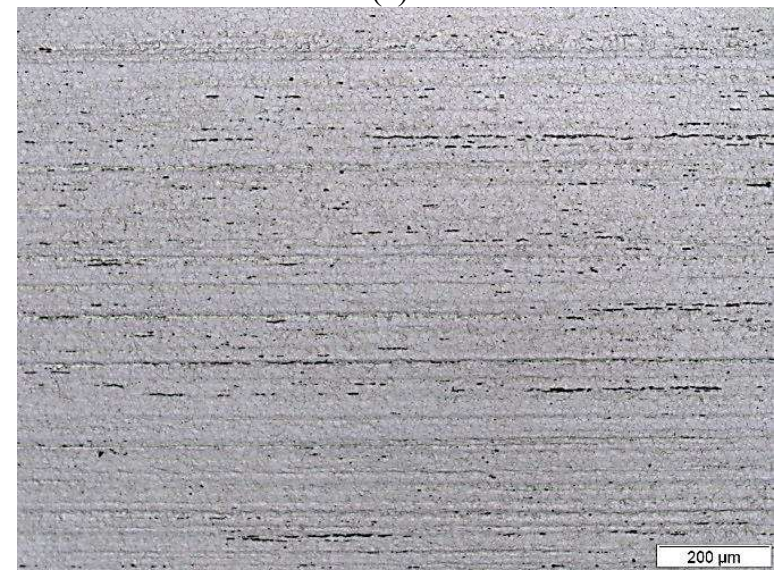

(e)

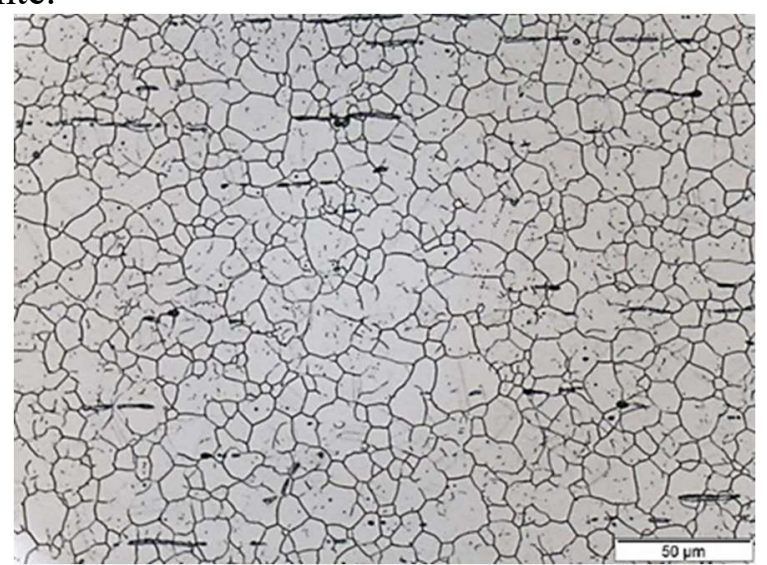

(b)

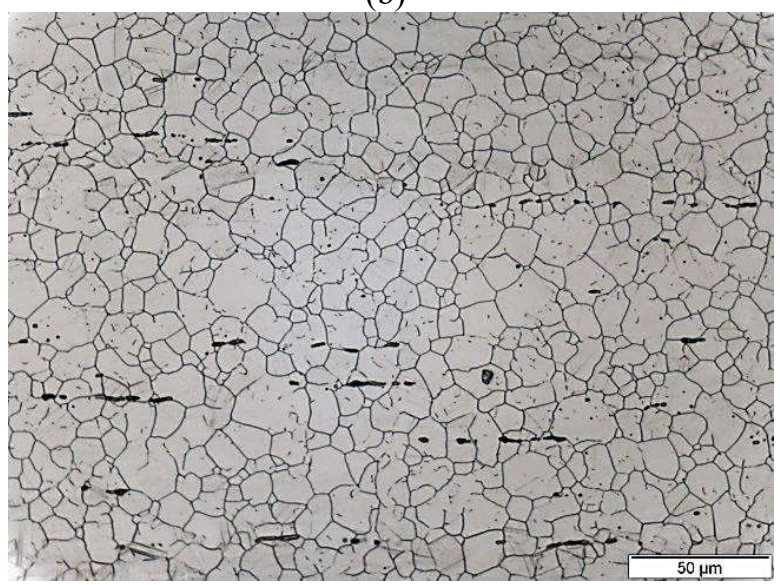

(d)

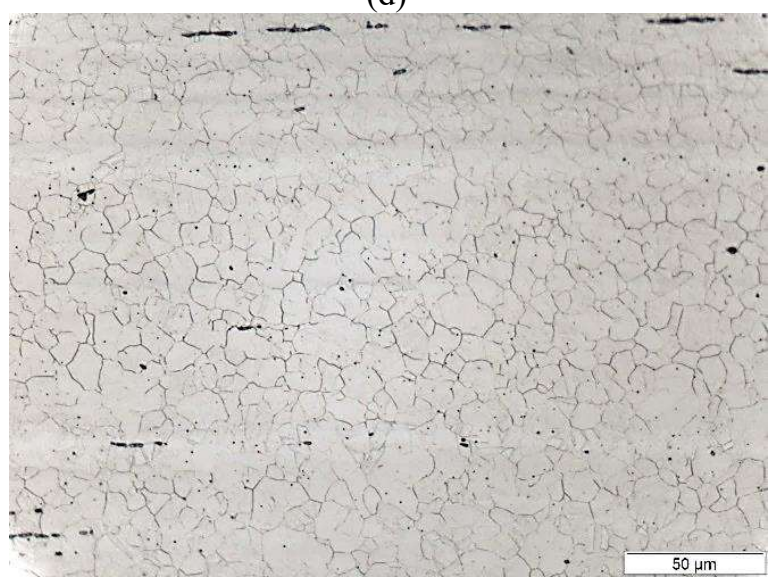

(f) 


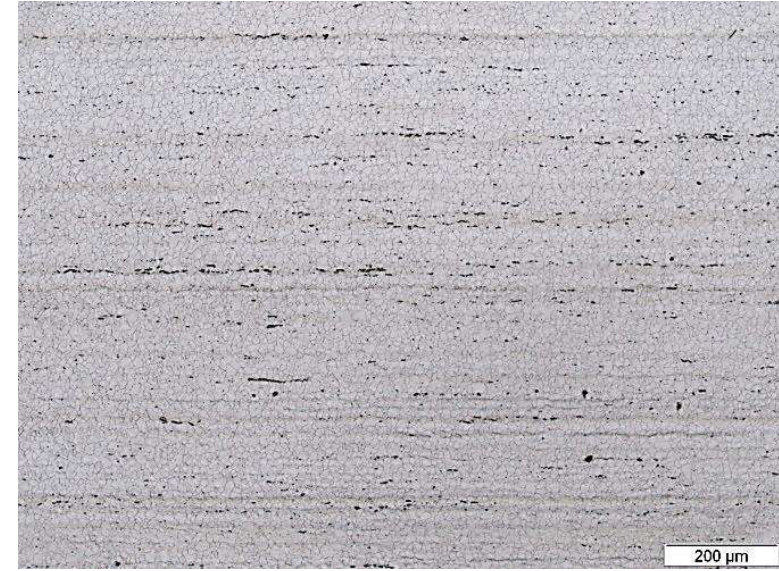

(g)

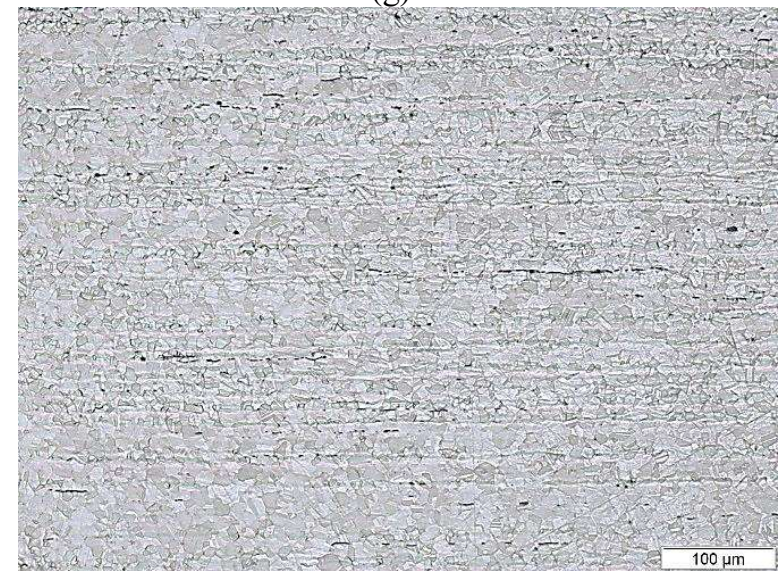

(i)

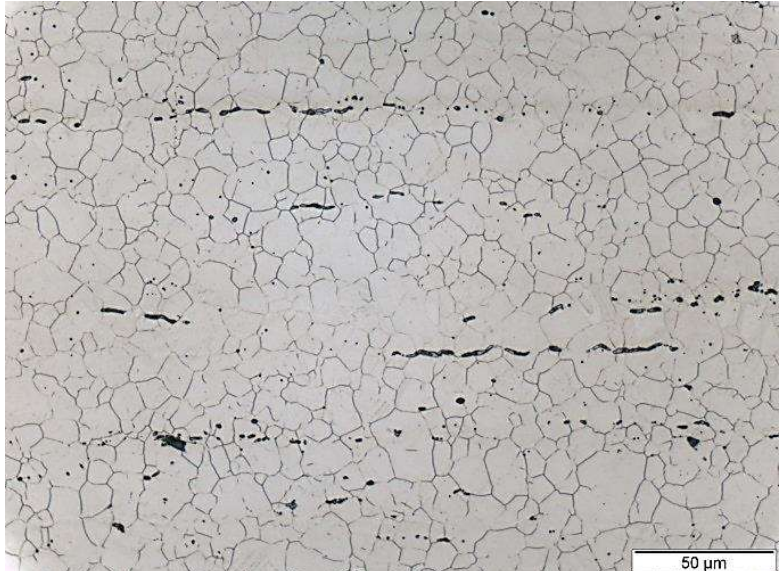

(h)

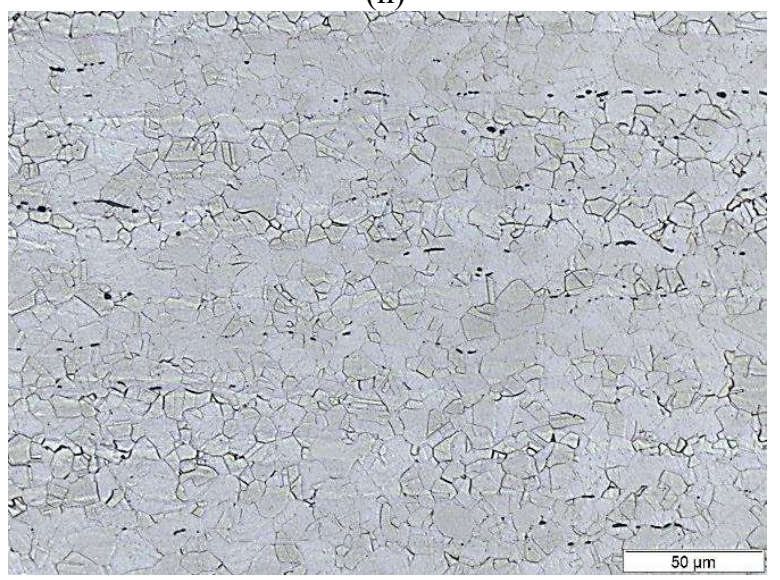

(j)

Fonte: Autor

Nessas micrografias é possível notar que de uma maneira geral, as amostras apresentaram-se bastante homogêneas e semelhantes, sendo que todas elas apresentam inclusões aparentemente de sulfetos de manganês alongados no sentido da laminação e tamanhos de grão da mesma ordem de grandeza. Além disso, foi possível notar que com o aumento do teor de $\mathrm{W}$, as amostras tornaram-se mais difíceis de serem atacadas eletroliticamente pela solução de $60 \%$ de ácido nítrico e $40 \%$ água, de forma que a amostra cujo teor de $\mathrm{W}$ é de $100 \%$ tivesse que ser atacada com o reagente Marble para que os contornos de grão fossem revelados. Este poderia ser um indício de maior resistência à corrosão causada pela adição de $\mathrm{W}$, indício este que foi verificado pelos ensaios eletroquímicos, como será mostrado na sequência.

\subsubsection{Amostras Solubilizadas}

As amostras brutas de laminação foram solubilizadas em forno tipo mufla a $1100^{\circ} \mathrm{C}$ por 1h e resfriadas em água. As micrografias da seção longitudinal destas amostras após o tratamento térmico de solubilização atacadas eletroliticamente, $5 \mathrm{~V} / 20 \mathrm{~s}$, com solução de $60 \%$ 
de ácido nítrico e $40 \%$ de água são mostradas na Figura 47. Como a amostra com $100 \%$ de substituição de Mo por W pode ser atacada com o reagente das demais amostras, o indício de que o $\mathrm{W}$ aumentaria a resistência a corrosão observado no item anterior perde força.

Figura 47 - Micrografias das amostras solubilizadas a $1100^{\circ} \mathrm{C}$ por $1 \mathrm{~h}$ e resfriadas em água atacadas eletroliticamente, $5 \mathrm{~V} / 20 \mathrm{~s}$, com solução de $60 \%$ ácido nítrico e $40 \%$ água; (a) e (b) Material de Referência, corrida 1107046 (100\% Mo), 100 e 500x de aumento, respectivamente; (c) e (d) Corrida $1107047(25 \% \mathrm{~W}$ e $75 \% \mathrm{Mo}), 100$ e 500x de aumento, respectivamente; (e) e (f) Corrida $1107048(50 \% \mathrm{~W}$ e $50 \% \mathrm{Mo}), 100$ e $500 \mathrm{x}$ de aumento, respectivamente; (g) e (h) Corrida $1107049(75 \% \mathrm{~W}$ e $25 \% \mathrm{Mo}, 100$ e 500x de aumento, respectivamente; (i) e (j) Corrida $1107050(100 \% \mathrm{~W}), 100$ e $500 \mathrm{x}$ de aumento, respectivamente.

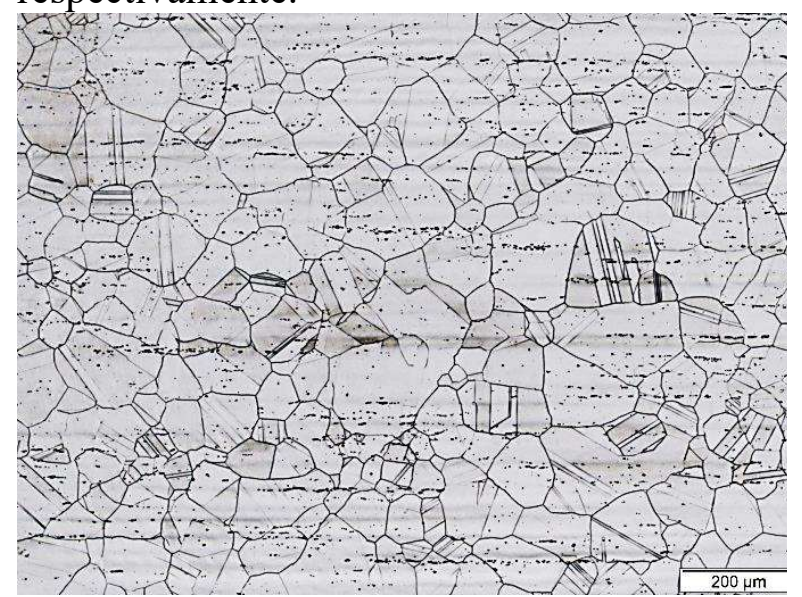

(a)

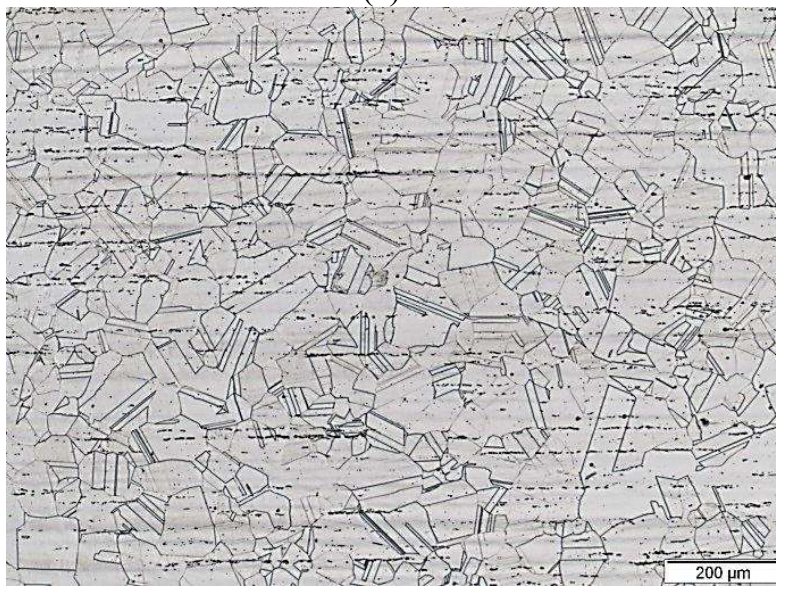

(c)

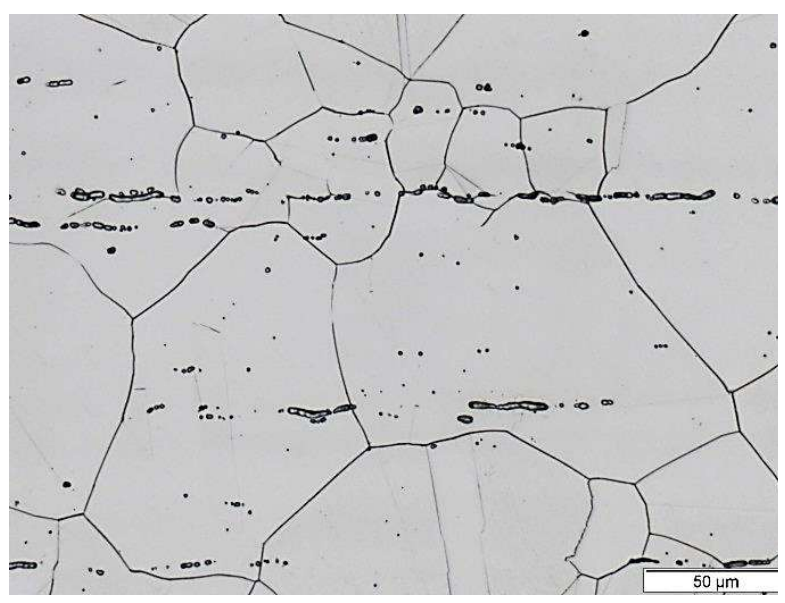

(b)

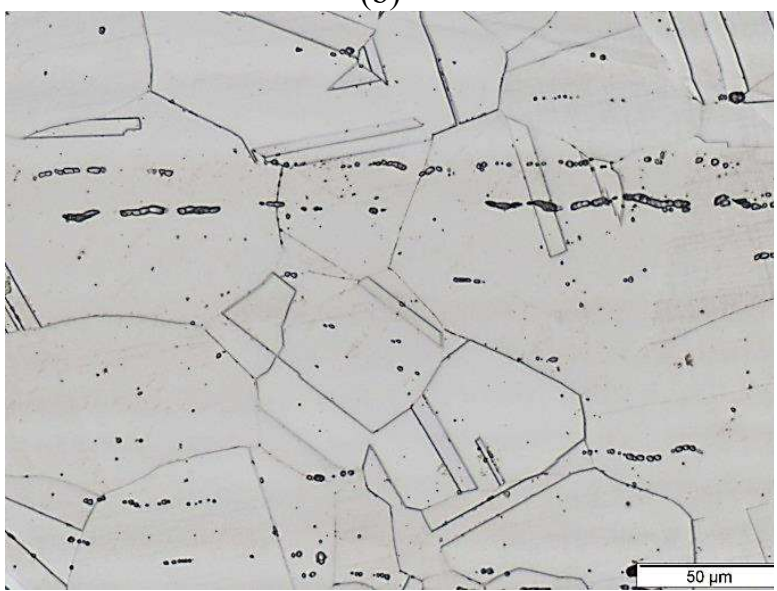

(d) 


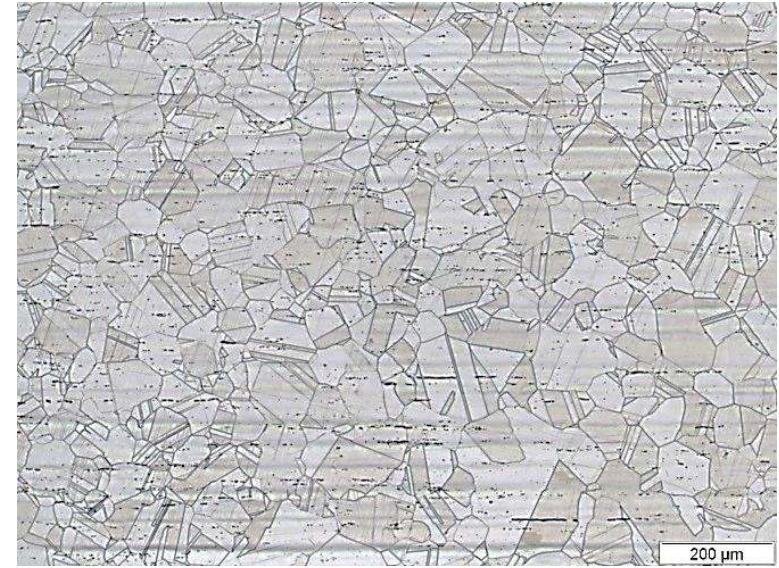

(e)

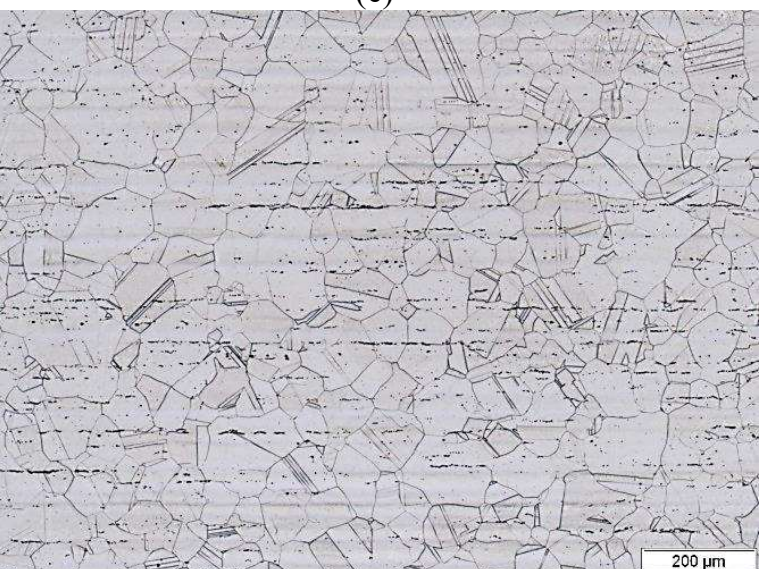

(g)

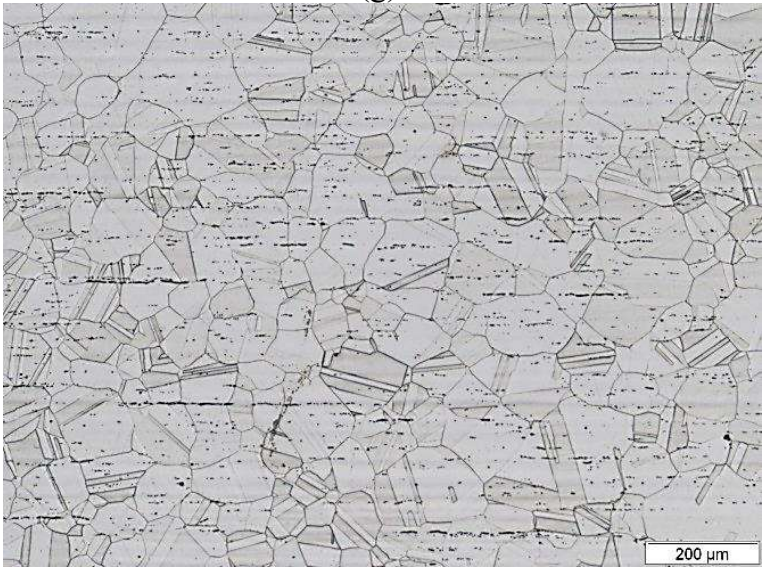

(i)

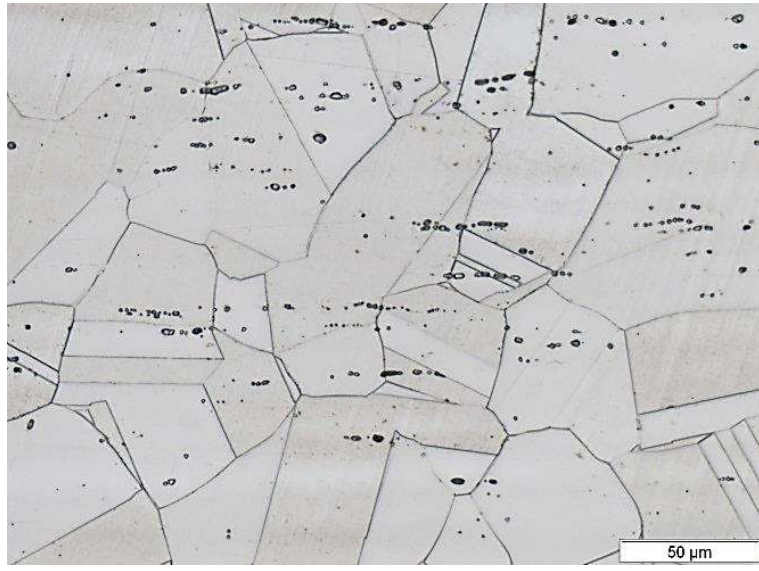

(f)

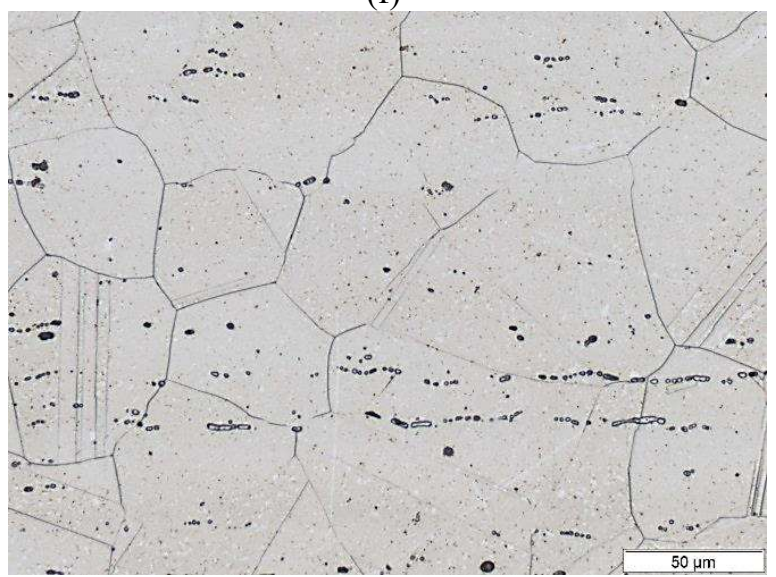

(h)

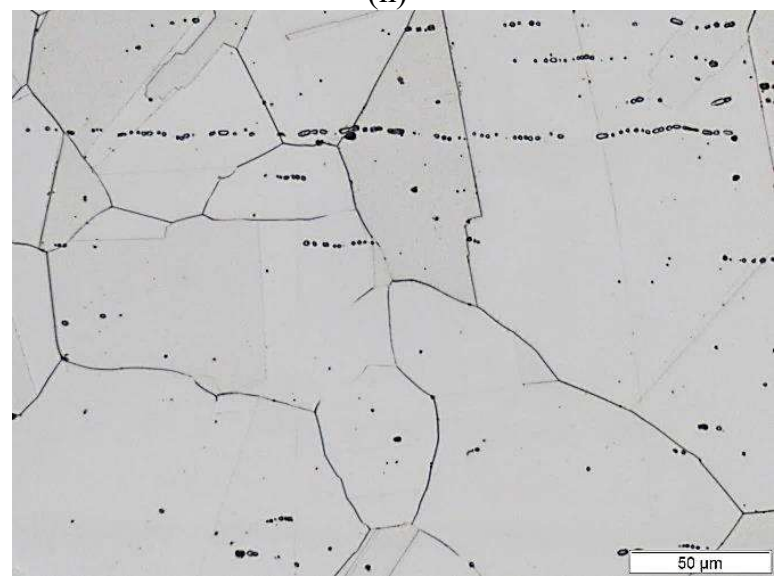

(j)

Fonte: Autor

De acordo com as micrografias apresentadas, pode-se concluir que a adição de W visualmente não alterou o tamanho de grão do material, a distribuição de carbonetos e inclusões após a solubilização. 


\subsection{ANÁLISE DE INCLUSÕES}

A Figura 48 apresenta as micrografias da seção longitudinal das amostras solubilizadas sem ataque. Conforme observado anteriormente, as micrografias de baixo aumento permitem observar que todas as amostras apresentaram distribuição e fração de inclusões semelhantes. Já nas imagens de 500x de aumento pode-se observar inclusões alongadas no sentido da laminação e também inclusões globulares.

Figura 48 - Micrografias das amostras solubilizadas a $1100^{\circ} \mathrm{C}$ por $1 \mathrm{~h}$ e resfriadas em água sem ataque; (a) e (b) Material de Referência, corrida 1107046 (100\% Mo), 100 e 500x de aumento, respectivamente; (c) e (d) Corrida 1107047 (25\%W e 75\%Mo), 100 e 500x de aumento, respectivamente; (e) e (f) Corrida $1107048(50 \% \mathrm{~W}$ e $50 \% \mathrm{Mo}), 100$ e $500 \mathrm{x}$ de aumento, respectivamente; (g) e (h) Corrida $1107049(75 \% \mathrm{~W}$ e $25 \% \mathrm{Mo}, 100$ e $500 \mathrm{x}$ de aumento, respectivamente; (i) e (j) Corrida $1107050(100 \% \mathrm{~W}), 100$ e 500x de aumento, respectivamente.

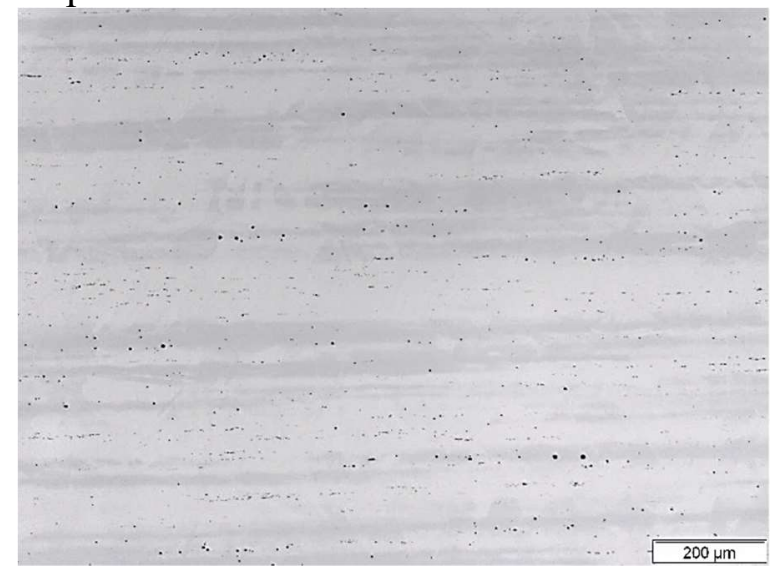

(a)

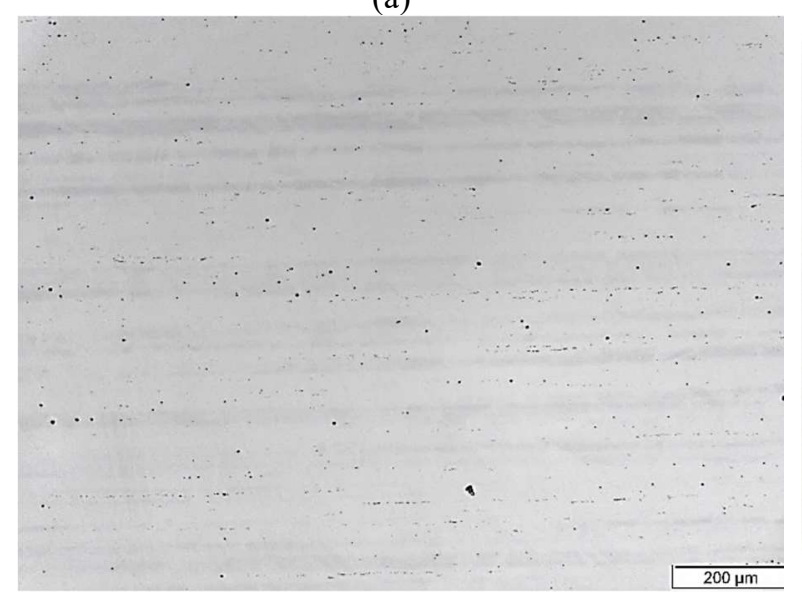

(c)

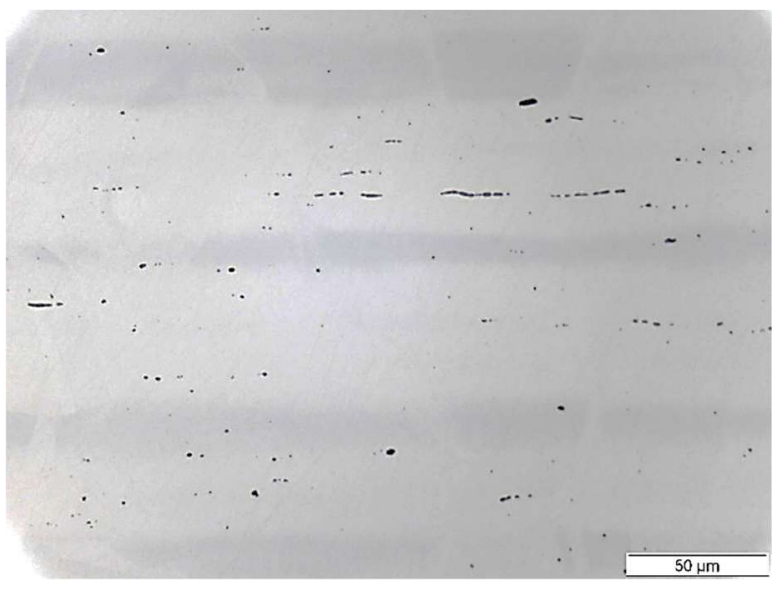

(b)

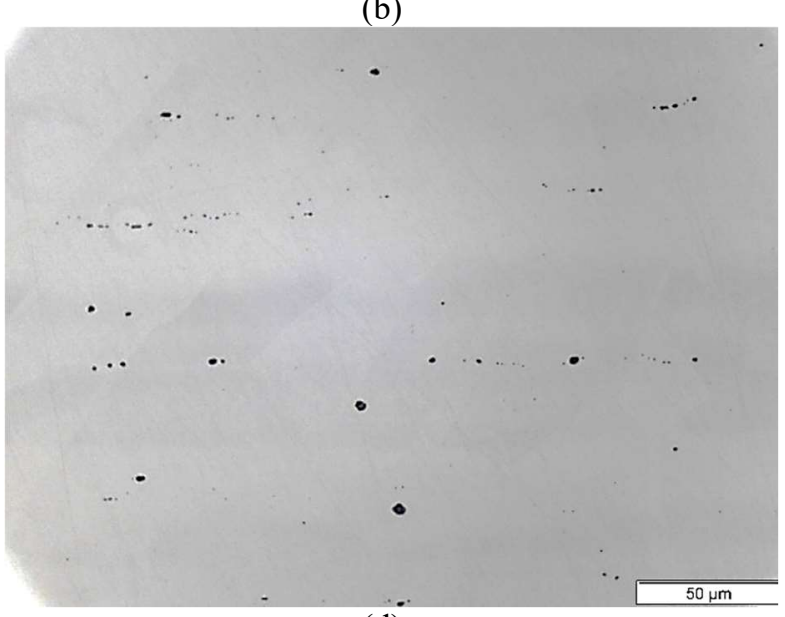

(d) 


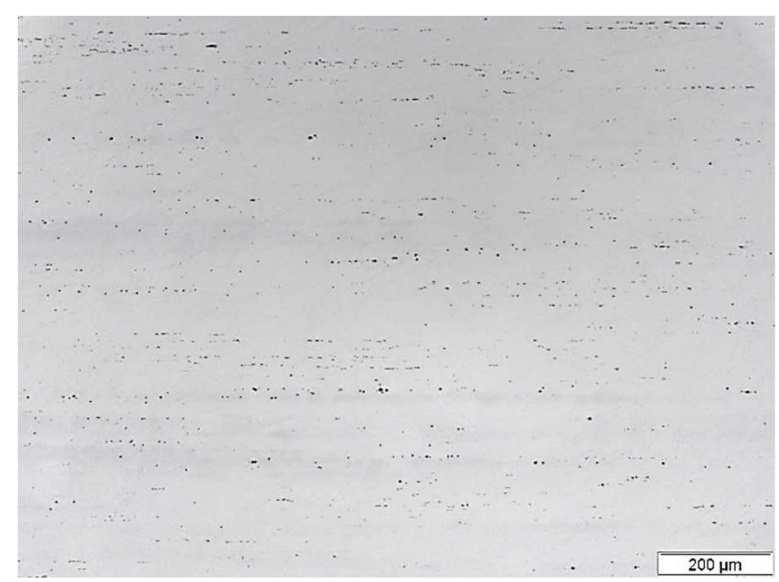

(e)

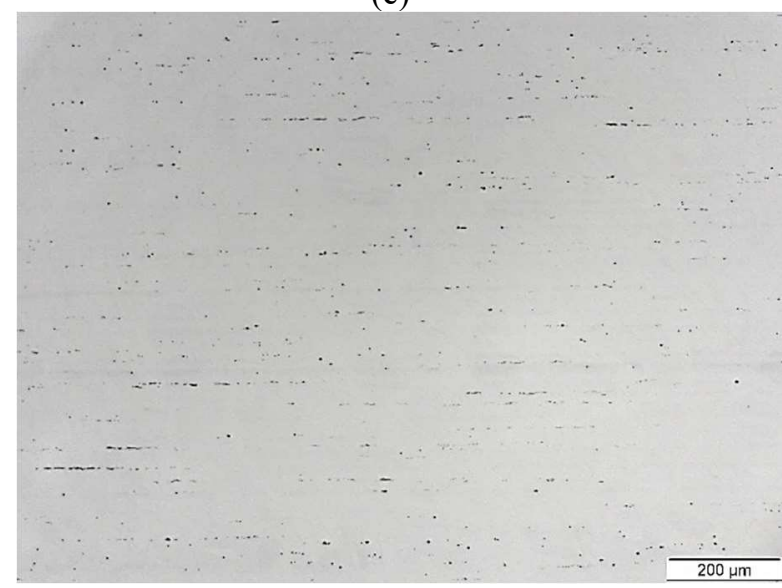

(g)

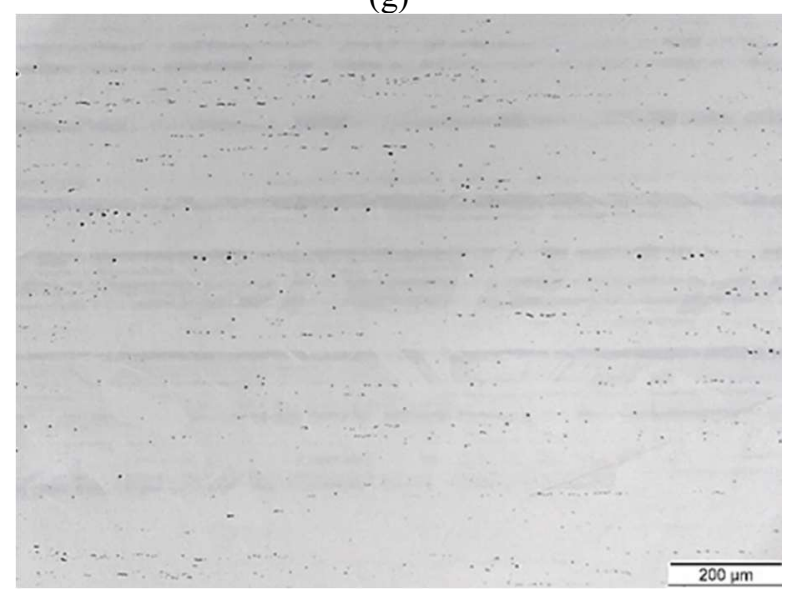

(i)

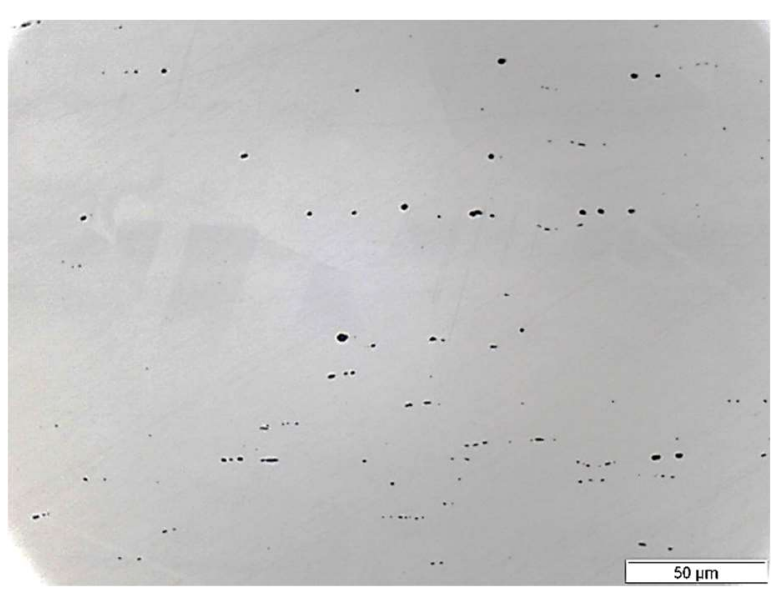

(f)

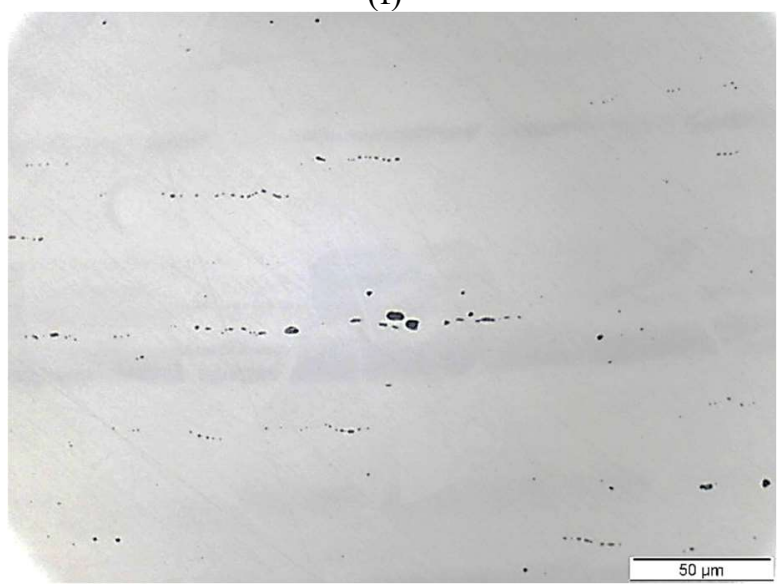

(h)

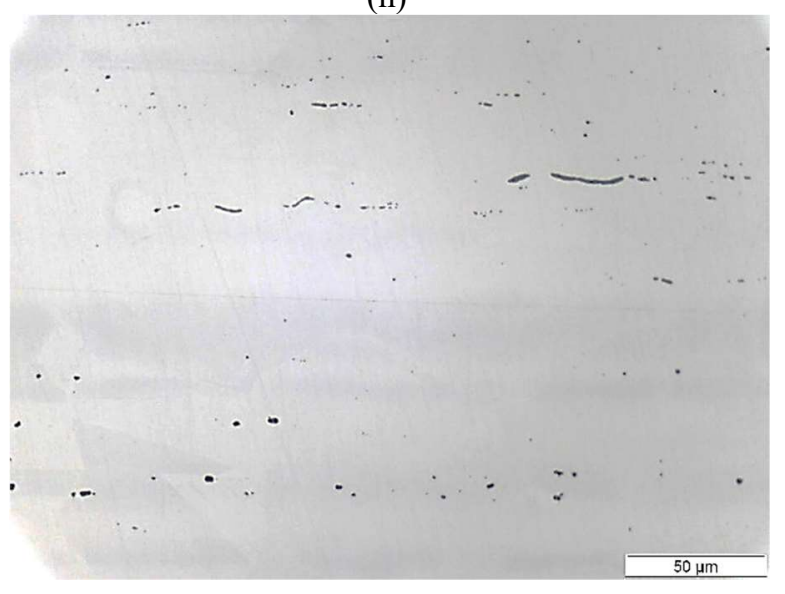

(j)

Fonte: Autor

A Figura 49 apresenta os resultados de fração em área das inclusões obtidos por análise de imagem. 
Figura 49 - Resultados de fração em área de inclusões obtidas por análise de imagem de micrografias com aumento de 500x das amostras solubilizadas do aço inoxidável AISI 316XL variando-se o teor de Mo e W.

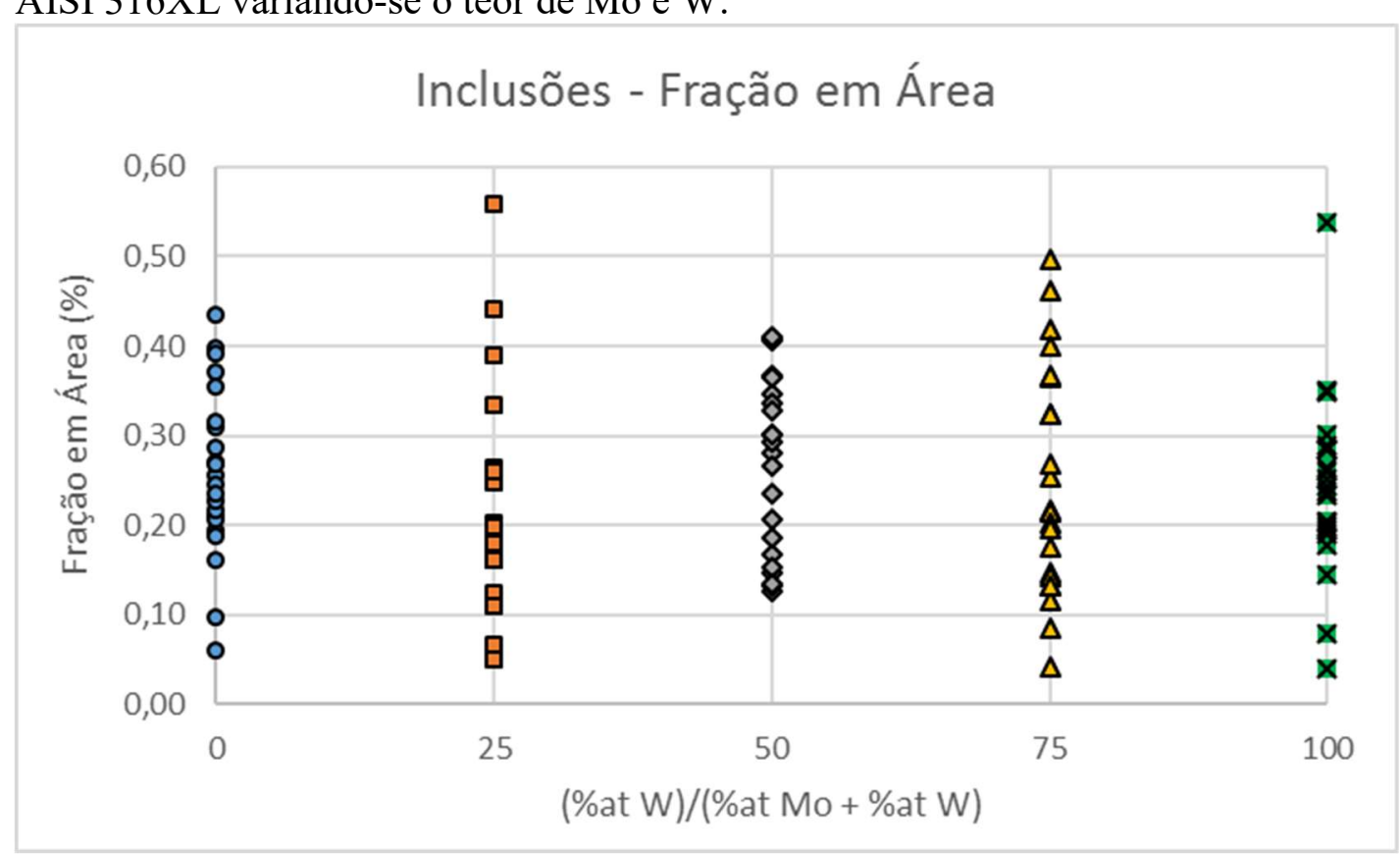

Fonte: Autor

Estes dados foram analisados estatisticamente utilizando o procedimento de Análise de Variância para um único fator disponível no Excel com nível de significância de 0,05. A Tabela 11 apresenta os resultados dessa análise. De acordo com os dados obtidos, o valor $F$ é menor que o valor de $F_{\text {crit }}$ para o nível de significância definido e que o valor- $p$ encontrado para estes dados é maior que o nível de significância adotado de 0,05 . Isto significa que não existem evidências de diferenças significativas na fração de inclusões entre os materiais analisados.

Tabela 11 - Análise de variância dos dados obtidos de fração em área das inclusões dos materiais em estudo utilizando nível de significância de 0,05.

\begin{tabular}{l|c|c|c|c|c|c}
\hline Fonte da variação & $\boldsymbol{S Q}$ & $\boldsymbol{g l}$ & $\boldsymbol{M Q}$ & $\boldsymbol{F}$ & valor-P & $\boldsymbol{F}$ crítico \\
\hline Entre grupos & 0,03 & 4 & 0,007 & 0,62 & 0,65 & 2,46 \\
\hline Dentro dos grupos & 1,26 & 105 & 0,012 & & & \\
\hline Total & 1,29 & 109 & & & & \\
\hline Fot
\end{tabular}

Fonte: Autor

Portanto, de acordo com estes dados, a semelhança observada nas micrografias em relação à quantidade de inclusões nos materiais analisados pode ser confirmada, cuja sendo a fração volumétrica média global de $0,25 \pm 0,1 \%$. De fato, observando a composição dos materiais analisados mostrados anteriormente na Tabela 9, é possível notar que os teores de 
manganês, enxofre e oxigênio variam muito pouco, o que não levaria a diferença na fração de inclusões.

Já as Figura 50 e 51 e a Tabela 12 apresentam a análise pontual típica das inclusões dos materiais analisados obtidos por MEV-EDS.

Figura 50 - Análise pontual típica das amostras solubilizadas do aço inoxidável AISI 316XL variando-se o teor de Mo e W obtida por MEV-EDS no microscópio CAMSCAN CS3200LV do CDMatM-FEI. Os detalhes referentes aos elementos presentes nos pontos 1, 2, 3 e 4 e seus respectivos teores encontram-se na Tabela 12.

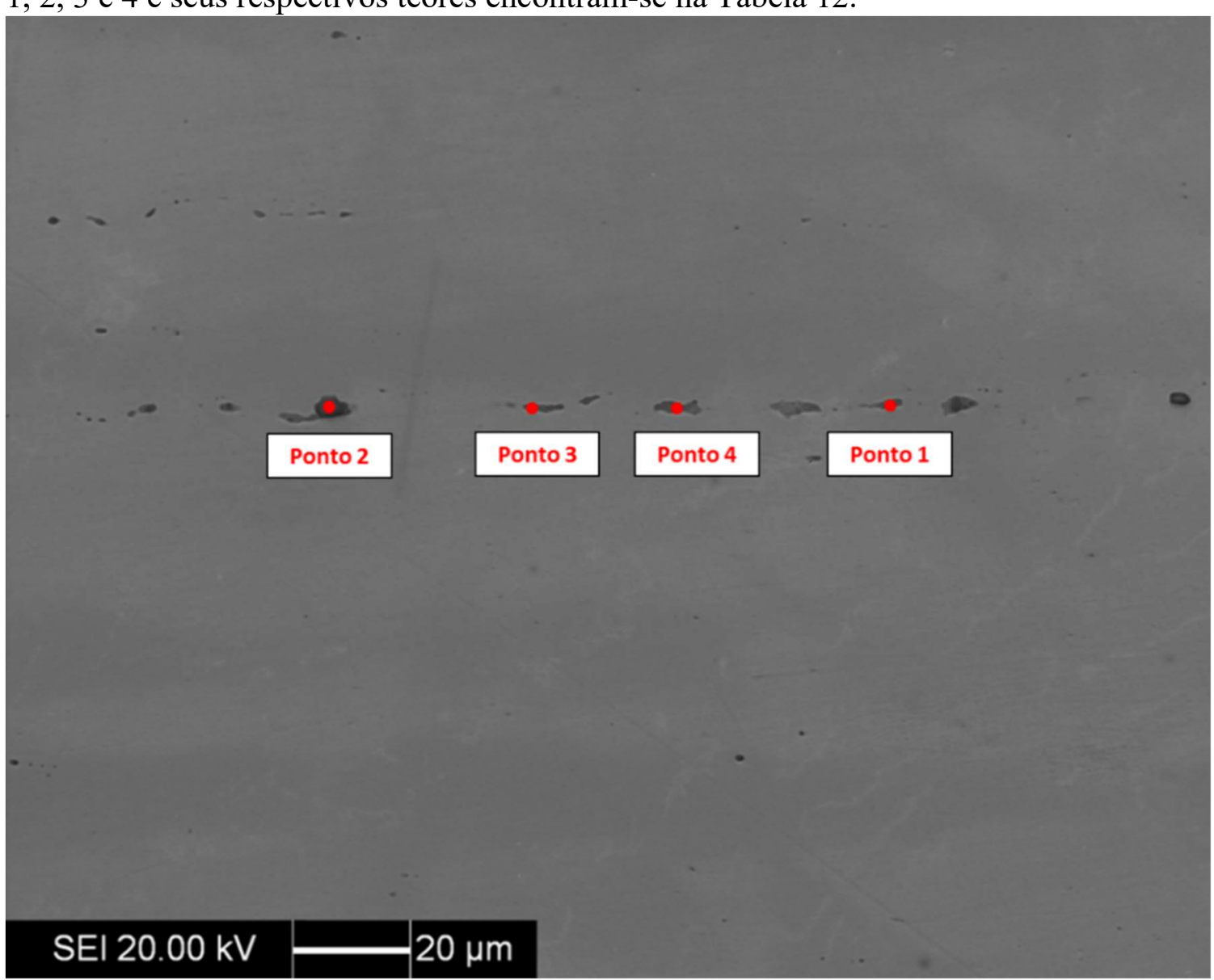

Fonte: Autor

Tabela 12 - Análise pontual (\%wt) das inclusões apresentadas na Figura 50 e espectros da Figura 51.

\begin{tabular}{c|c|c|c|c|c|c|c|c|c|c}
\hline Ponto & $\mathbf{S i}$ & $\mathbf{S}$ & $\mathbf{C r}$ & $\mathbf{M n}$ & $\mathbf{F e}$ & $\mathbf{N i}$ & $\mathbf{O}$ & $\mathbf{A l}$ & $\mathbf{T i}$ & $\mathbf{F}$ \\
\hline $\mathbf{1}$ & 0,34 & 7,81 & 15,92 & 11,70 & 56,33 & 7,89 & - & - & - & - \\
\hline $\mathbf{2}$ & - & 1,60 & 31,73 & 23,20 & 3,55 & - & 35,48 & 2,40 & 2,03 & - \\
\hline $\mathbf{3}$ & - & 12,78 & 15,55 & 23,83 & 31,08 & 3,61 & 6,71 & - & 0,26 & 6,19 \\
\hline $\mathbf{4}$ & 0,56 & 14,51 & 13,99 & 19,13 & 45,04 & 6,77 & - & - & - & - \\
\hline
\end{tabular}

Fonte: Autor 
Figura 51 - Espectros de EDS das inclusões analisadas na Figura 50 e composições mostradas na Tabela 12.
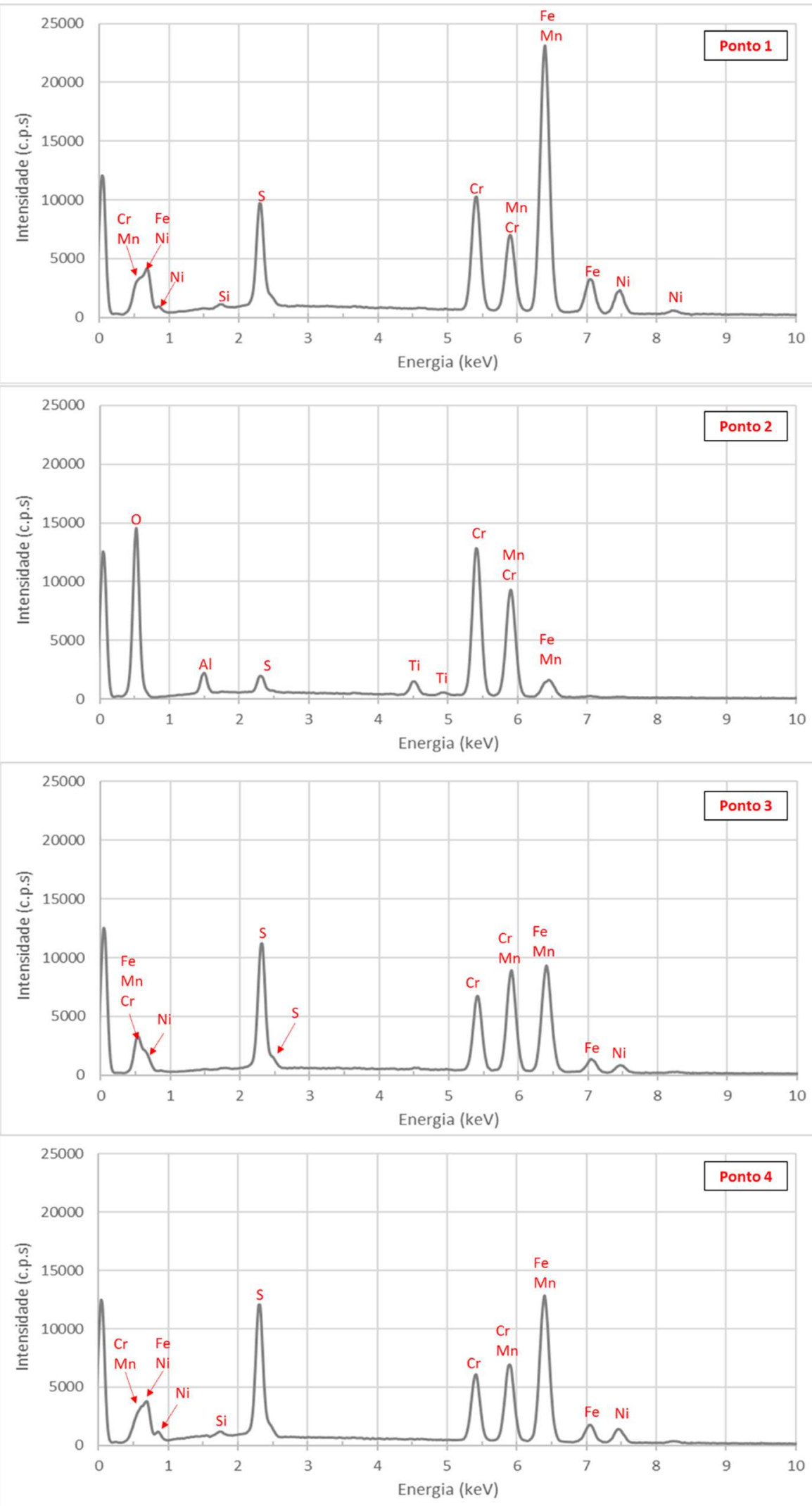

Fonte: Autor 
Destes resultados, pode-se observar que as inclusões analisadas são compostas majoritariamente por oxigênio, enxofre, manganês; os metais de transição como cromo, ferro e níquel podem tanto estar nas inclusões quanto no metal base, dado o volume de geração de raios-X durante a análise de EDS poder conter metal base. Como para todas as amostras foram observadas os mesmos tipos e composições de inclusões, é possível esperar que os resultados dos ensaios de corrosão apresentados em seguida não sejam influenciados por este parâmetro. Este assunto será melhor discutido nos itens a seguir.

\subsection{TAMANHO DE GRÃO}

A pouca variação do tamanho de grão das amostras solubilizadas observada anteriormente também foi observada pelo método do intercepto médio. Os resultados de anisotropia obtidos são apresentados na Figura 52. É possível notar que os grãos são praticamente equiaxiais, uma vez que visualmente não há diferenças significativas entre as medidas realizadas na horizontal (sentido da laminação) e na vertical.

Figura 52- Resultados de tamanho de grão obtidos pelo método dos interceptos médios da seção longitudinal das amostras solubilizadas do aço inoxidável AISI 316XL variando-se o teor de Mo e W com grades na vertical e longitudinal para verificar a anisotropia dos grãos.

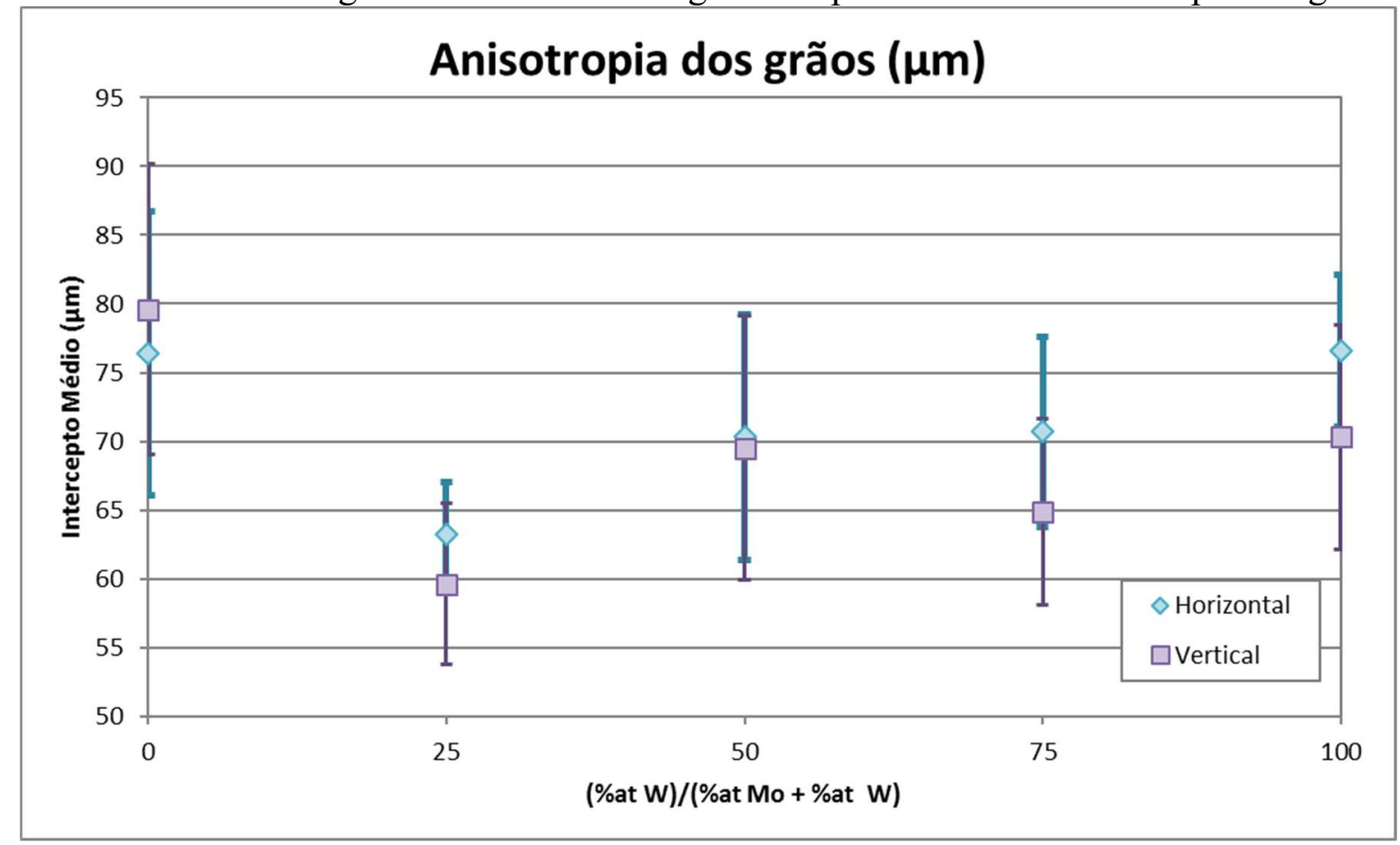

Fonte: Autor 
Utilizou-se a análise de variância para confirmar se há diferenças significativas entre as medidas realizadas na vertical e na horizontal para cada uma das ligas e assim verificar se, de fato, todas elas apresentam grãos equiaxiais, Tabelas 13 a 17.

Tabela 13- Análise de variância dos interceptos médios entre os grãos medidos na vertical e na horizontal do material de referência, corrida 1107046 (100\% Mo) utilizando nível de significância de 0,05 .

\begin{tabular}{c|c|c|c|c|c|c}
\hline Fonte da variação & $\boldsymbol{S Q}$ & $\boldsymbol{g} \boldsymbol{M}$ & $\boldsymbol{M Q}$ & $\boldsymbol{F}$ & valor-P & $\begin{array}{c}\boldsymbol{F} \\
\text { crítico }\end{array}$ \\
\hline Entre grupos & 50,88 & 1 & 50,88 & 0,46 & 0,50 & 4,41 \\
\hline Dentro dos grupos & 1964,23 & 18 & 109,12 & & & \\
\hline Total & 2015,11 & 19 & & & & \\
\hline
\end{tabular}

Fonte: Autor

Tabela 14 - Análise de variância dos interceptos médios entre os grãos medidos na vertical e na horizontal da corrida 1107047 (75\% Mo e 25\%W) utilizando nível de significância de 0,05 .

\begin{tabular}{c|c|c|c|c|c|c}
\hline Fonte da variação & $\boldsymbol{S Q}$ & $\boldsymbol{g l}$ & $\boldsymbol{M Q}$ & $\boldsymbol{F}$ & valor-P & $\begin{array}{c}\boldsymbol{F} \\
\text { crítico }\end{array}$ \\
\hline Entre grupos & 64,08 & 1 & 64,08 & 2,61 & 0,12 & 4,41 \\
\hline Dentro dos grupos & 441,09 & 18 & 24,50 & & & \\
\hline Total & 505,17 & 19 & & & & \\
\hline
\end{tabular}

Fonte: Autor

Tabela 15 - Análise de variância dos interceptos médios entre os grãos medidos na vertical e na horizontal corrida 1107048 (50\% Mo e 50\% W) utilizando nível de significância de 0,05 .

\begin{tabular}{c|c|c|c|c|c|c}
\hline Fonte da variação & $\boldsymbol{S Q}$ & $\boldsymbol{g} \boldsymbol{l}$ & $\boldsymbol{M Q}$ & $\boldsymbol{F}$ & valor-P & $\begin{array}{c}\boldsymbol{F} \\
\text { crítico }\end{array}$ \\
\hline Entre grupos & 3,04 & 1 & 3,04 & 0,03 & 0,85 & 4,41 \\
\hline Dentro dos grupos & 1547,88 & 18 & 85,99 & & & \\
\hline Total & 1550,92 & 19 & & & & \\
\hline
\end{tabular}

Fonte: Autor

Tabela 16- Análise de variância dos interceptos médios entre os grãos medidos na vertical e na horizontal corrida 1107049 (25\% Mo e 75\% W) utilizando nível de significância de 0,05 .

\begin{tabular}{c|c|c|c|c|c|c}
\hline Fonte da variação & $\boldsymbol{S Q}$ & $\boldsymbol{g l}$ & $\boldsymbol{M Q}$ & $\boldsymbol{F}$ & valor-P & $\begin{array}{c}\boldsymbol{F} \\
\text { crítico }\end{array}$ \\
\hline Entre grupos & 168,20 & 1 & 168,20 & 3,58 & 0,07 & 4,41 \\
\hline Dentro dos grupos & 845,13 & 18 & 46,95 & & & \\
\hline Total & 1013,332 & 19 & & & & \\
\hline
\end{tabular}

Fonte: Autor 
Tabela 17 - Análise de variância dos interceptos médios entre os grãos medidos na vertical e na horizontal corrida $1107050(100 \% \mathrm{~W})$ utilizando nível de significância de 0,05 .

\begin{tabular}{c|c|c|c|c|c|c}
\hline Fonte da variação & $\boldsymbol{S Q}$ & $\boldsymbol{g} \boldsymbol{l}$ & $\boldsymbol{M Q}$ & $\boldsymbol{F}$ & valor-P & $\begin{array}{c}\boldsymbol{F} \\
\text { crítico }\end{array}$ \\
\hline Entre grupos & 199,08 & 1 & 199,08 & 4,09 & 0,06 & 4,41 \\
\hline Dentro dos grupos & 875,68 & 18 & 48,65 & & & \\
\hline Total & 1074,76 & 19 & & & & \\
\hline
\end{tabular}

Fonte: Autor

Todas as ligas estudadas apresentaram $F$ menor que $F_{c r i t}$ e também valor- $p$ maior que o nível de significância utilizado de 0,05 , o que significa que realmente não há diferenças estatísticas significativas nas medidas realizadas na vertical e na horizontal. Portanto, todas as amostras apresentam grãos equiaxiais.

Assim, a média e o desvio padrão dos dados globais de cada um dos materiais analisados são mostrados na Figura 53.

Figura 53 - Intercepto médio de cada amostra, considerando as medidas em grades horizontais e verticais, e média global dos interceptos médios de todas as amostras.

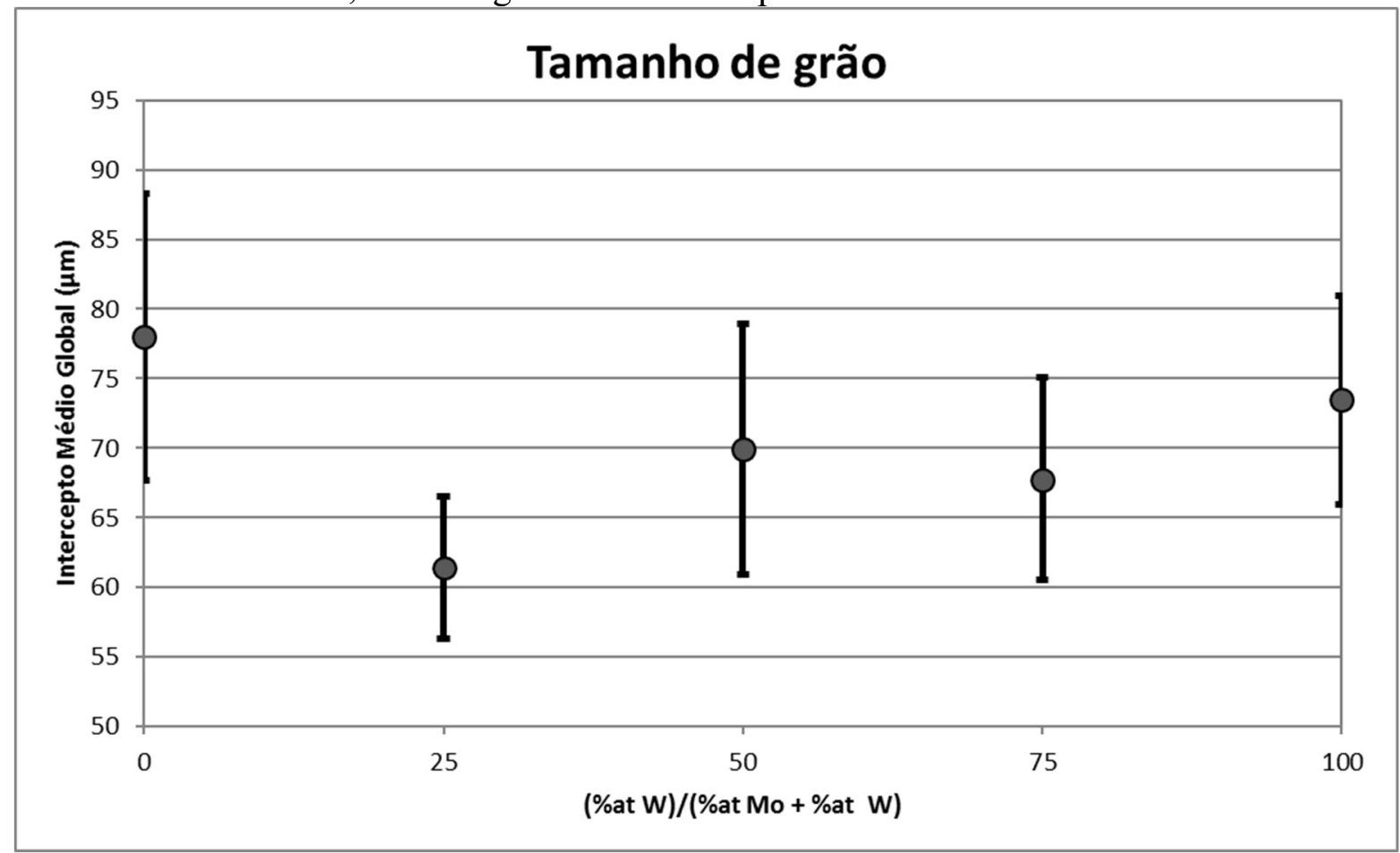

Fonte: Autor

A análise de variância de todos os dados, Tabela 18 , mostrou que $F$ é maior que $F_{\text {crit }} \mathrm{e}$ também que o valor- $p$ é menor que o nível de significância utilizado de 0,05. Ou seja, existem evidências suficientes de que pelo menos uma das amostras apresenta tamanho de grão 
significativamente diferente. De fato, na Figura 53 é possível notar que os dados obtidos para tamanho de grão da amostra de referência, que apresenta $0 \%$ de W, apresenta grãos ligeiramente maiores, $78 \pm 10 \mu \mathrm{m}$, enquanto que a substituição de $25 \%$ do teor atômico de Mo por W provoca uma ligeira queda, $61 \pm 5 \mu \mathrm{m}$. Além disso, é possível notar que as amostras que contém W apresentam grãos ligeiramente menores que a amostra que não apresenta $\mathrm{W}$ evidenciando que este elemento de liga atua como refinador de grão para o material estudado.

Tabela 18 - Análise de variância dos dados obtidos de intercepto médio dos grãos dos materiais em estudo utilizando nível de significância de 0,05.

\begin{tabular}{l|c|c|c|c|c|c}
\hline Fonte da variação & $\boldsymbol{S Q}$ & $\boldsymbol{g l}$ & $\boldsymbol{M Q}$ & $\boldsymbol{F}$ & valor-P & $\boldsymbol{F}$ crítico \\
\hline Entre grupos & 2936,82 & 4 & 734,20 & 4,70 & 0,001 & 2,47 \\
\hline Dentro dos grupos & 14832,25 & 95 & 156,13 & & & \\
\hline Total & 17769,07 & 99 & & & & \\
\hline Fonte: Auto
\end{tabular}

Fonte: Autor

\subsection{DUREZA BRINELL}

Os resultados de dureza Brinell obtidos são mostrados na Figura 54.

Figura 54 - Dados obtidos de dureza Brinell das amostras solubilizadas do material em estudo.

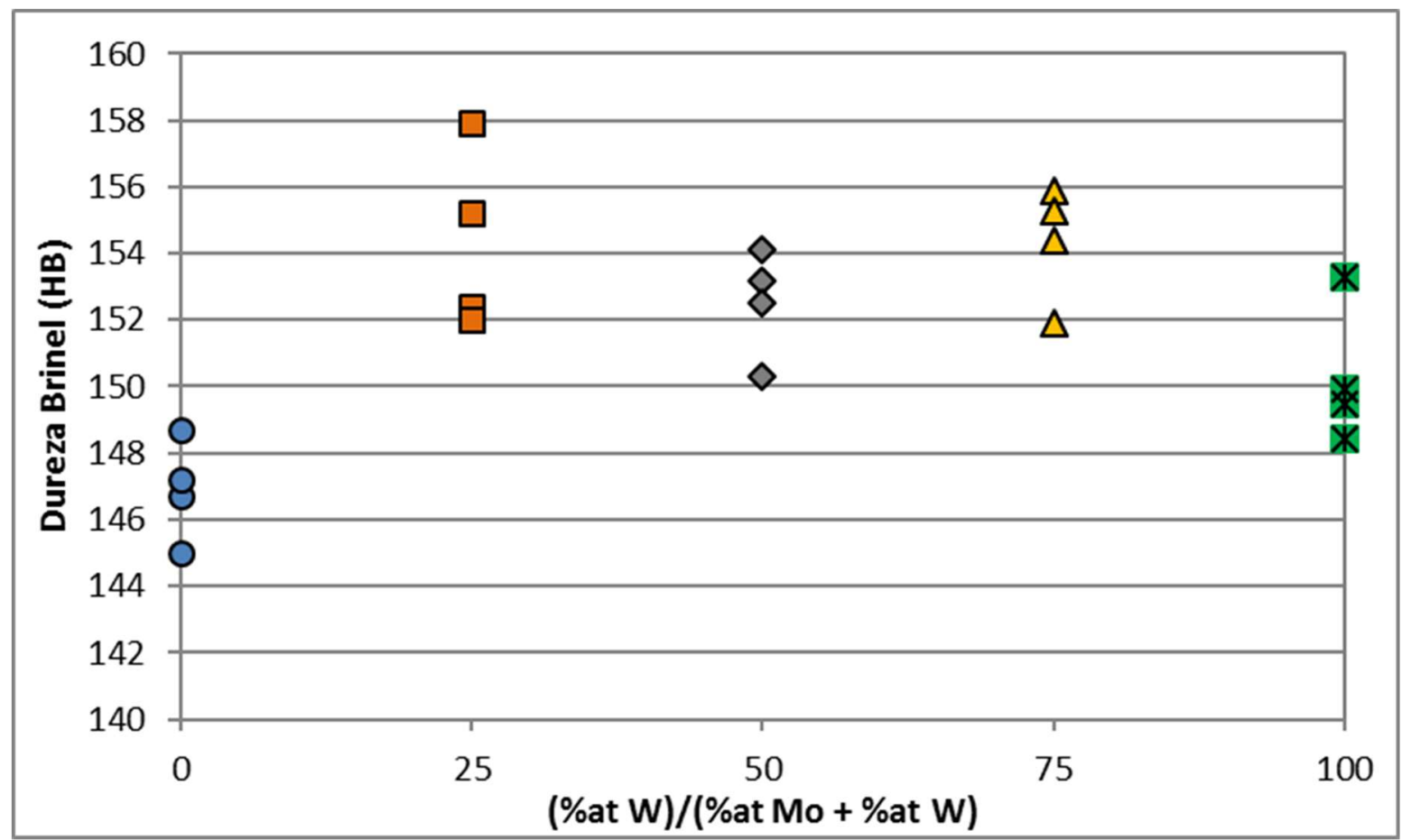

Fonte: Autor 
A análise de variância destes dados de dureza, Tabela 19, mostrou que $F$ é maior que $F_{\text {crit }}$ e também que o valor-p é menor que o nível de significância utilizado de 0,05 . Ou seja, existem evidências suficientes de que pelo menos uma das amostras apresenta dureza Brinel significativamente diferente. É possível notar na Figura 54 que, apesar dos resultados serem bastante semelhantes, de fato a amostra que não contém $\mathrm{W}$ apresenta dureza Brinel ligeiramente menor. Já a amostra que contém 25\% de W apresenta um ligeiro aumento. Como esperado, estes resultados estão de acordo com aqueles apresentados anteriormente para tamanho de grão, já que as amostras que têm o maior tamanho de grão apresentam menor dureza. Além disso, deve-se considerar o aumento de dureza provocado por solução sólida na austenita provocado pelo $\mathrm{W}$, que por ter maior raio atômico que o Mo provoca maior distorção da rede crsitalina, tendo diferente potencial de endurecimento por solução sólida.

Tabela 19 - Análise de variância dos dados obtidos de dureza Brinel dos materiais em estudo utilizando nível de significância de 0,05 .

\begin{tabular}{l|c|c|c|c|c|c}
\hline Fonte da variação & $\boldsymbol{S Q}$ & $\boldsymbol{g l}$ & $\boldsymbol{M Q}$ & $\boldsymbol{F}$ & valor-P & $\boldsymbol{F}$ crítico \\
\hline Entre grupos & 160,25 & 4 & 40,06 & 9,97 & 0,0003 & 3,05 \\
\hline Dentro dos grupos & 60,23 & 15 & 4,01 & & & \\
\hline Total & 220,47 & 19 & & & & \\
\hline
\end{tabular}

Fonte: Autor

\subsection{ENSAIO DE TRAÇÃO}

Os resultados dos ensaios de tração das amostras solubilizadas são apresentados na Figura 55. São eles: limite de resistência à tração (LR), limite de escoamento 0,2\% (LE 0,2\%), redução em área (RA) e alongamento 5D. 
Figura 55 - Resultados dos ensaios de tração das amostras solubilizadas obtidos pelos ensaios de tração. (a) Limite de resistência e limite à tração (LR) e limite de escoamento $0,2 \%$ (LE 0,2\%). (b) Redução em área (RA) e alongamento 5D.

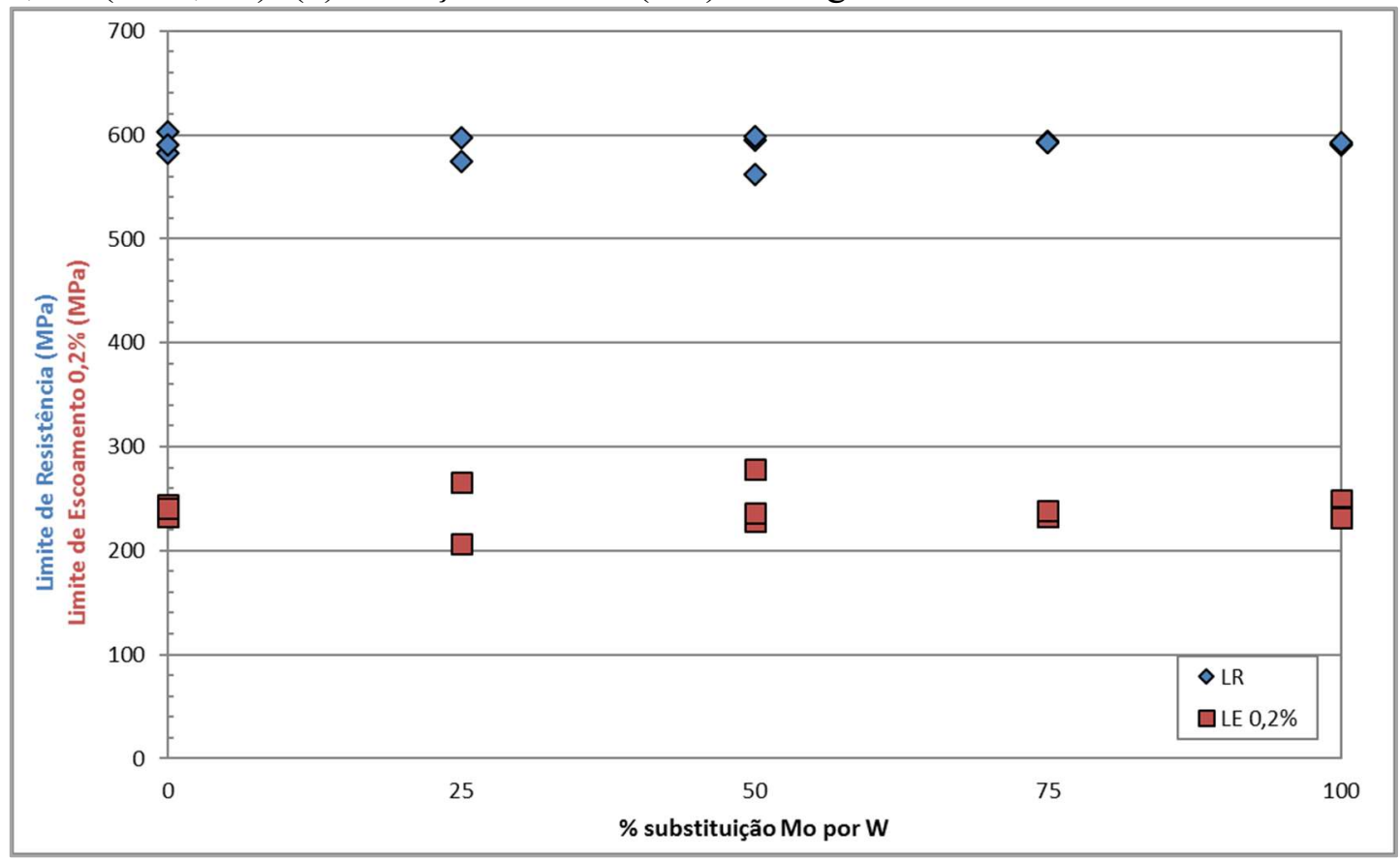

(a)

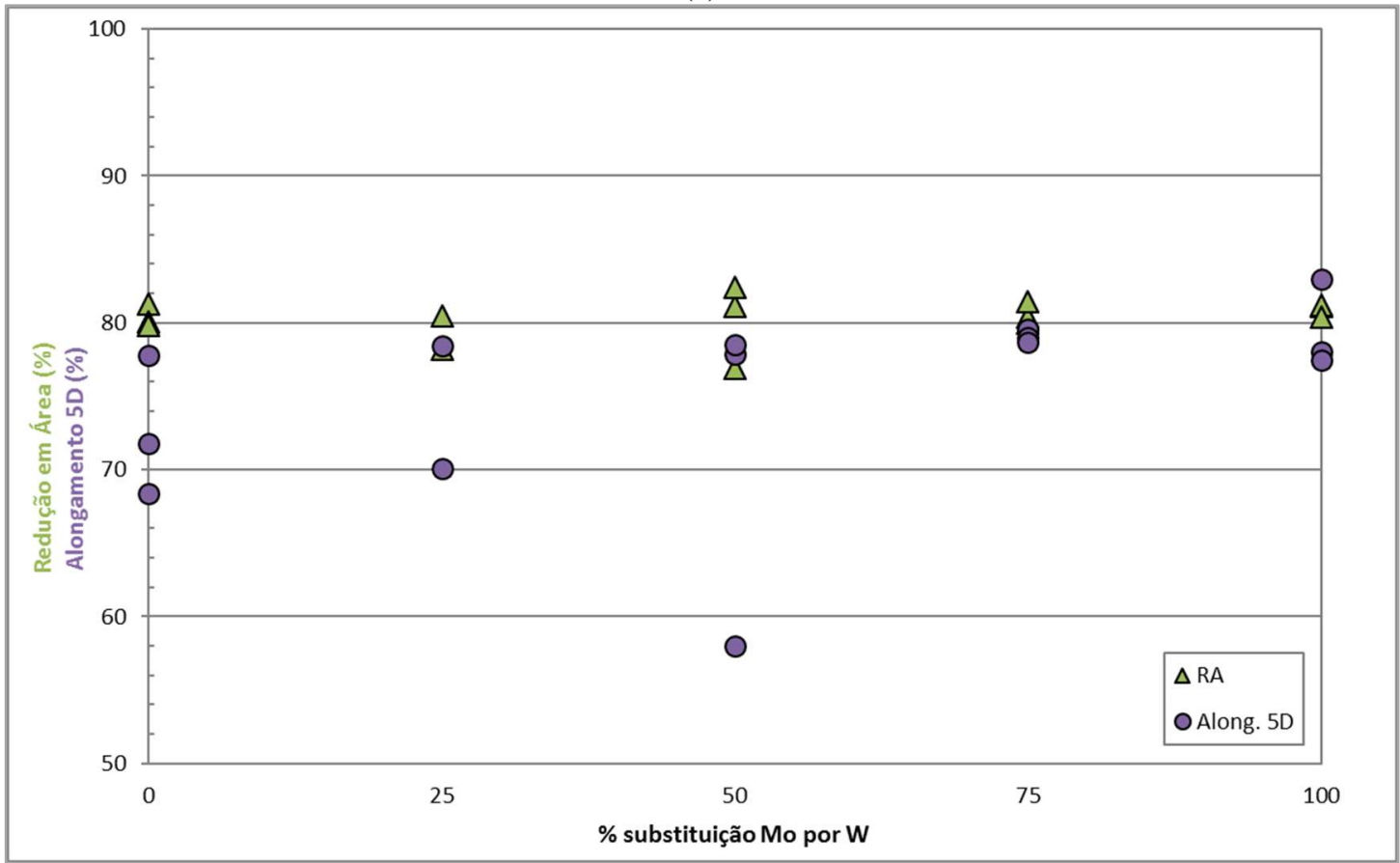

(b)

Fonte: Autor

A análise de variância de cada um dos parâmetros analisados no ensaio de tração, Tabela 20 à Tabela 23, mostrou que, para todos eles, $F$ é menor que $F_{c r i t}$ e também que o valor- $p$ é maior que o nível de significância utilizado de 0,05 . Ou seja, não existem diferenças significativas em nenhuma das variáveis analisadas no ensaio de tração, evidenciando que a 
substituição parcial e total do Mo por W não causa nenhuma mudança nas propriedades mecânicas do material.

Tabela 20 - Análise de variância dos dados de Limite de Resistência à tração (LR) obtidos por meio de ensaios de tração dos materiais em estudo utilizando nível de significância de 0,05 .

\begin{tabular}{l|c|c|c|c|c|c}
\hline Fonte da variação & $\boldsymbol{S} \boldsymbol{Q}$ & $\boldsymbol{g} \boldsymbol{M}$ & $\boldsymbol{M Q}$ & $\boldsymbol{F}$ & valor-P & $\boldsymbol{F}$ crítico \\
\hline Entre grupos & 162,65 & 4 & 40,66 & 0,29 & 0,88 & 3,63 \\
\hline Dentro dos grupos & 1257,75 & 9 & 139,75 & & & \\
\hline Total & 1420,41 & 13 & & & & \\
\hline
\end{tabular}

Fonte: Autor

Tabela 21 - Análise de variância dos dados de Limite de Escoamento a 0,2\% (LE $0,2 \%$ ) obtidos por meio de ensaios de tração dos materiais em estudo utilizando nível de significância de 0,05 .

\begin{tabular}{l|c|c|c|c|c|c}
\hline Fonte da variação & $\boldsymbol{S Q}$ & $\boldsymbol{g l}$ & $\boldsymbol{M Q}$ & $\boldsymbol{F}$ & valor-P & $\boldsymbol{F}$ crítico \\
\hline Entre grupos & 270,36 & 4 & 67,59 & 0,18 & 0,94 & 3,63 \\
\hline Dentro dos grupos & 3461,51 & 9 & 384,61 & & & \\
\hline Total & 3731,88 & 13 & & & & \\
\hline Font
\end{tabular}

Fonte: Autor

Tabela 22 - Análise de variância dos dados de Redução em Área (RA) obtidos por meio de ensaios de tração dos materiais em estudo utilizando nível de significância de 0,05 .

\begin{tabular}{l|c|c|c|c|c|c}
\hline Fonte da variação & $\boldsymbol{S Q}$ & $\boldsymbol{g l}$ & $\boldsymbol{M Q}$ & $\boldsymbol{F}$ & valor-P & $\boldsymbol{F}$ crítico \\
\hline Entre grupos & 3,25 & 4 & 0,81 & 0,33 & 0,85 & 3,63 \\
\hline Dentro dos grupos & 21,85 & 9 & 2,43 & & & \\
\hline Total & 25,09 & 13 & & & & \\
\hline
\end{tabular}

Fonte: Autor

Tabela 23 - Análise de variância dos dados de Alongamento 5D obtidos por meio de ensaios de tração dos materiais em estudo utilizando nível de significância de 0,05 .

\begin{tabular}{l|c|c|c|c|c|c}
\hline Fonte da variação & $\boldsymbol{S Q}$ & $\boldsymbol{g} \boldsymbol{l}$ & $\boldsymbol{M Q}$ & $\boldsymbol{F}$ & valor-P & $\boldsymbol{F}$ crítico \\
\hline Entre grupos & 162,88 & 4 & 40,72 & 0,99 & 0,46 & 3,63 \\
\hline Dentro dos grupos & 370,88 & 9 & 41,21 & & & \\
\hline Total & 533,76 & 13 & & & & \\
\hline
\end{tabular}

Fonte: Autor 


\subsection{ENSAIOS DE CORROSÃO}

Neste item são apresentados os ensaios de corrosão das amostras solubilizadas. São eles: polarização cíclica em solução de $3,5 \%$ de $\mathrm{NaCl}$ e temperatura ambiente, determinação da temperatura crítica de pite em solução de $1 \mathrm{M}$ de $\mathrm{NaCl}$ e por fim polarização potenciodinâmica e DL-EPR em solução de $0,5 \mathrm{M} \mathrm{H}_{2} \mathrm{SO}_{4}+0,01 \mathrm{M} \mathrm{KSCN}$ a $30^{\circ} \mathrm{C}$.

\subsubsection{Polarização Cíclica}

Da Figura 56 à Figura 60 são apresentadas as curvas típicas de polarização cíclica em solução de 3,5\% de $\mathrm{NaCl}$ de cada material variando a porcentagem atômica de $\mathrm{W}$ em relação ao teor nominal de Mo presente na liga de referência $(0 \% \mathrm{~W})$. Em todas elas, os potenciais de corrosão $\left(E_{\text {corr }}\right)$ e de pite $\left(E_{\text {pite }}\right)$ são definidos, mas não é possível observar o potencial de repassivação. Além disso, é possível observar a presença de pites metaestáveis caracterizada pelas oscilações na densidade de corrente antes do potencial de pite. A comparação das curvas, Figura 61, sugere que o comportamento de todas é bastante similar, e que o $\mathrm{W}$ não afeta suas propriedades de resistência à corrosão por pite.

Figura 56 - Curva típica de polarização cíclica do material que contém 0\% de W (c.1107046) em solução de 3,5\% de $\mathrm{NaCl}$ e temperatura ambiente.

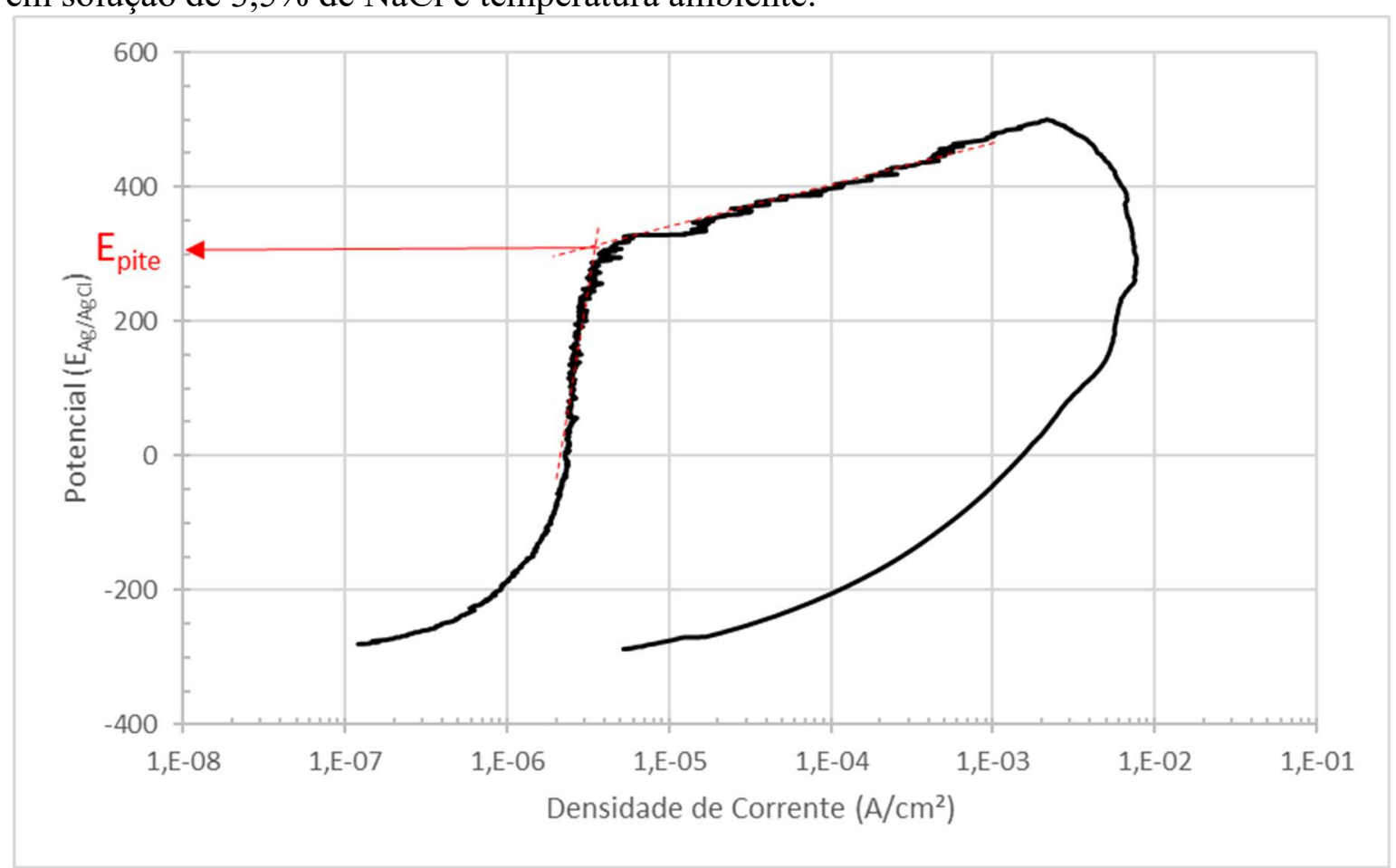

Fonte: Autor 
Figura 57 - Curva típica de polarização cíclica do material que contém 25\% de W (c.1107047) em solução de $3,5 \%$ de $\mathrm{NaCl}$ e temperatura ambiente.

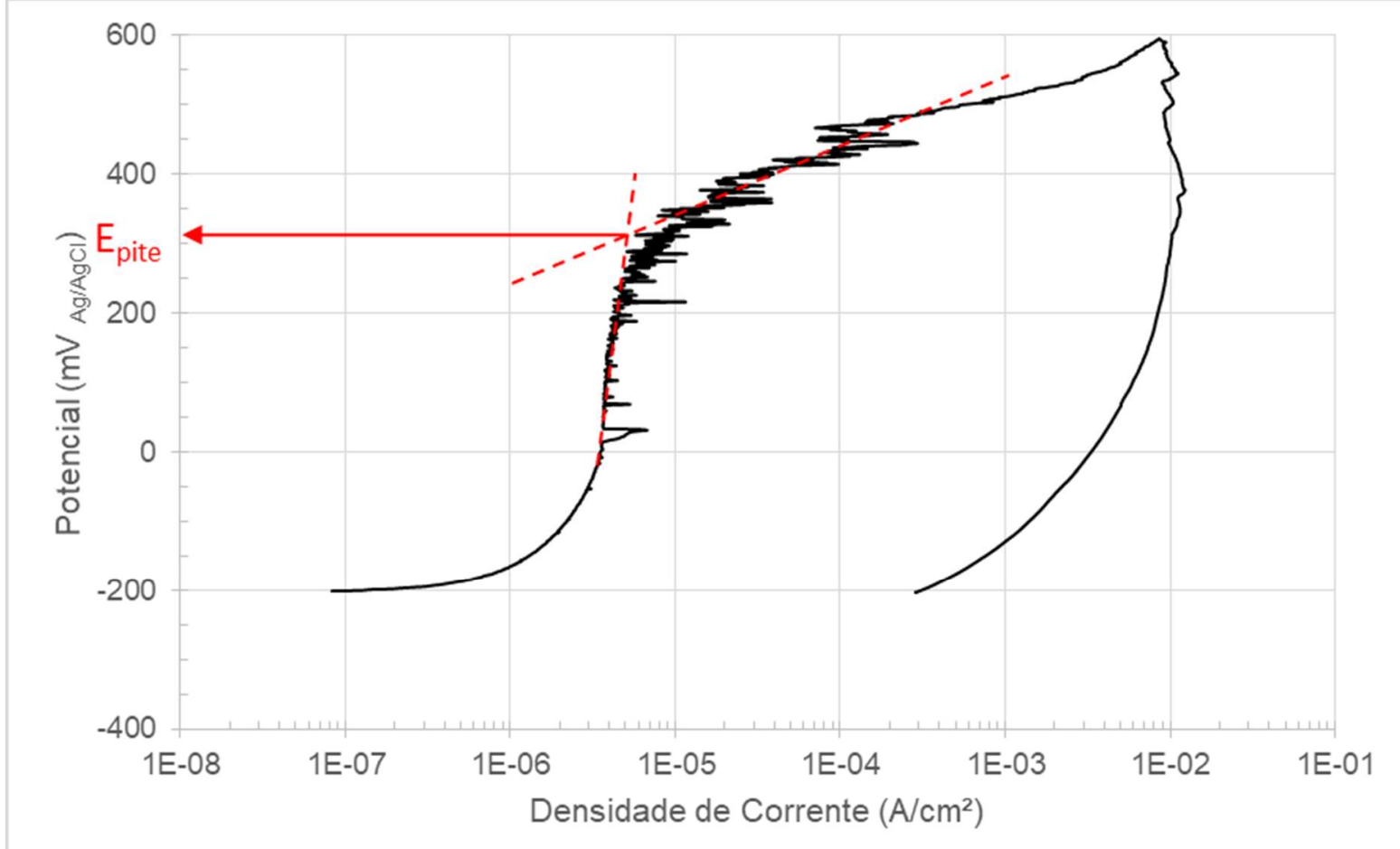

Fonte: Autor

Figura 58 - Curva típica de polarização cíclica do material que contém 50\% de W (c.1107048) em solução de $3,5 \%$ de $\mathrm{NaCl}$ e temperatura ambiente.

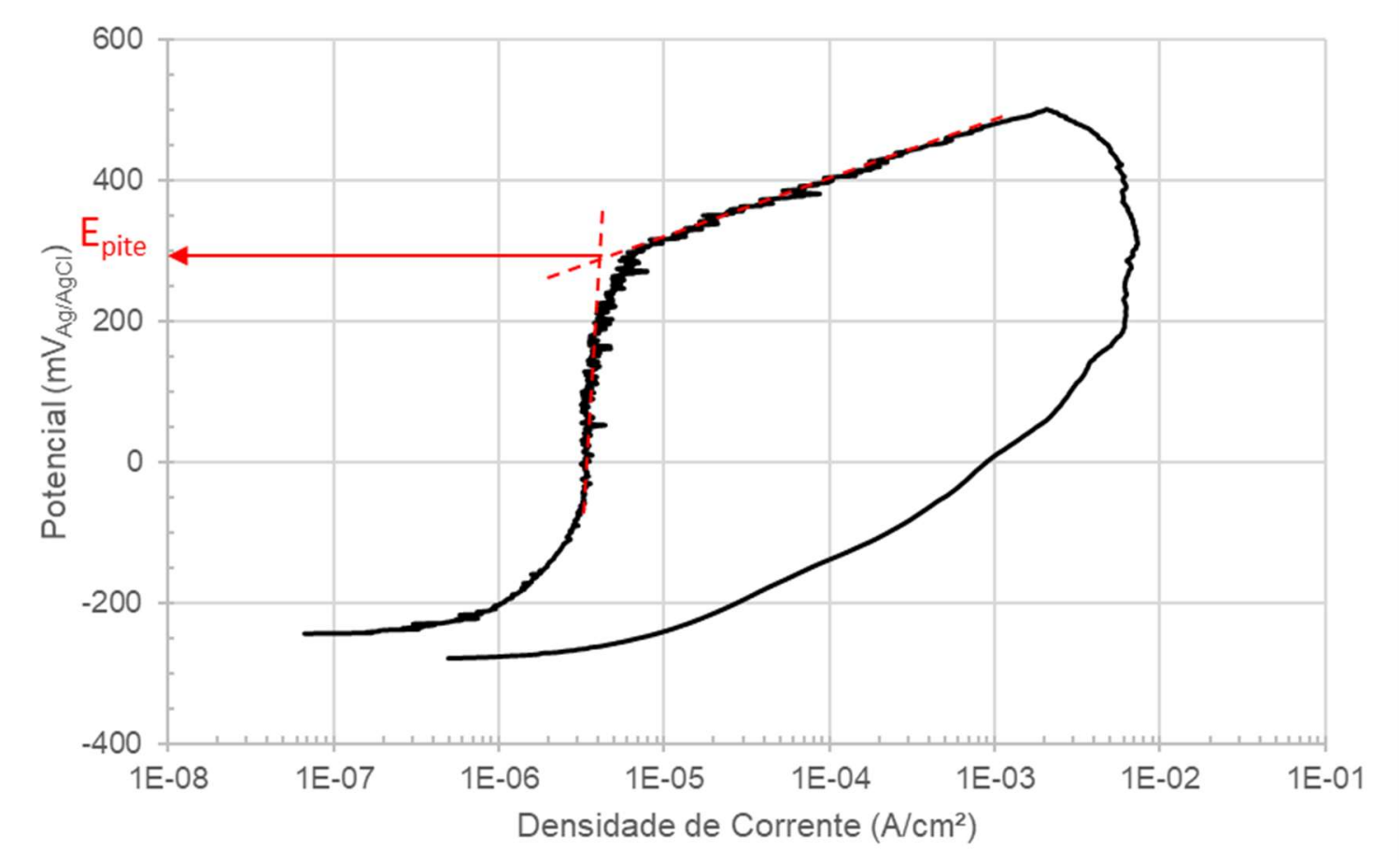

Fonte: Autor 
Figura 59 - Curva típica de polarização cíclica do material que contém 75\% de W (c.1107049) em solução de $3,5 \%$ de $\mathrm{NaCl}$ e temperatura ambiente.

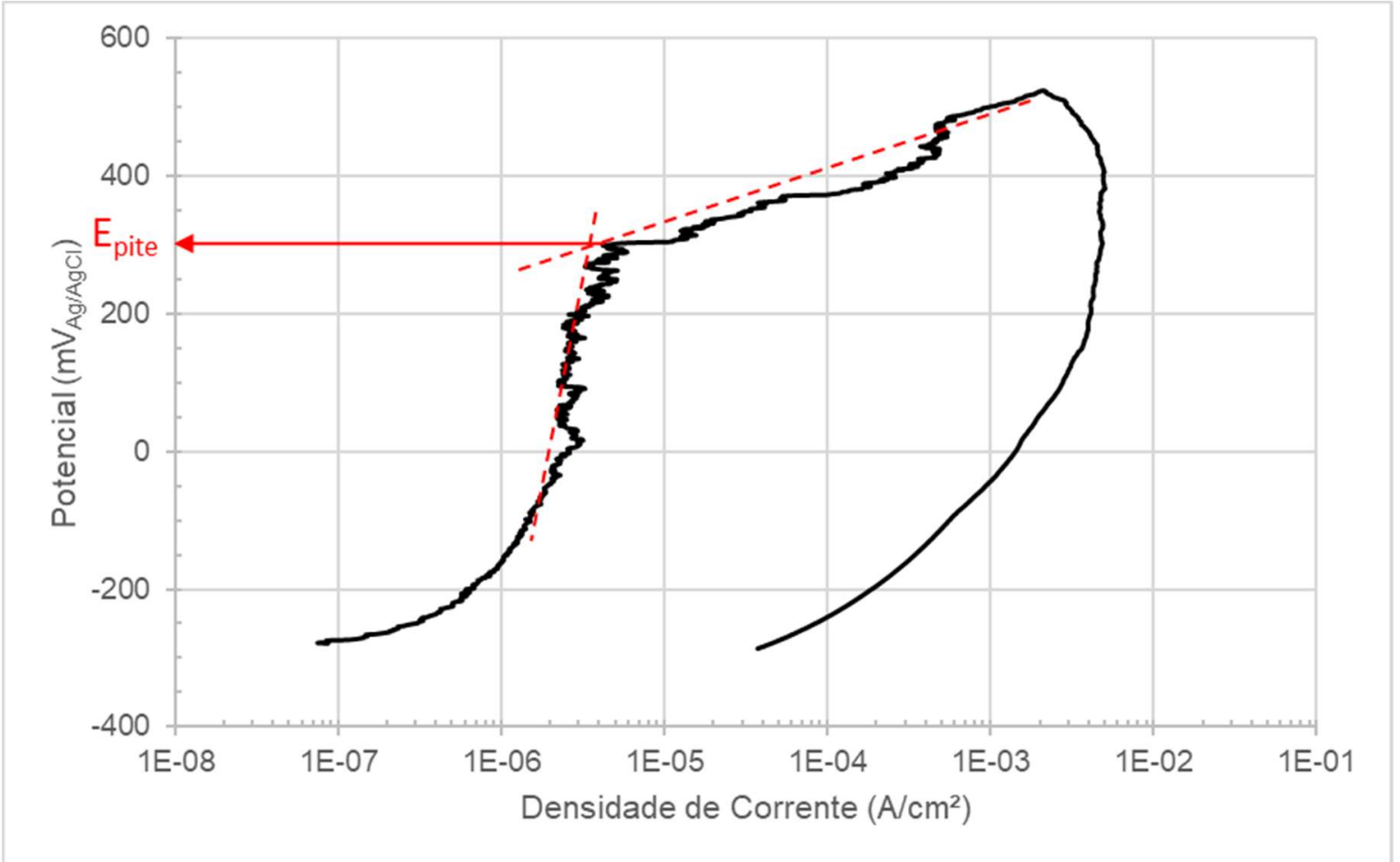

Fonte: Autor

Figura 60 - Curva típica de polarização cíclica do material que contém $100 \%$ de W (c.1107050) em solução de 3,5\% de $\mathrm{NaCl}$ e temperatura ambiente.

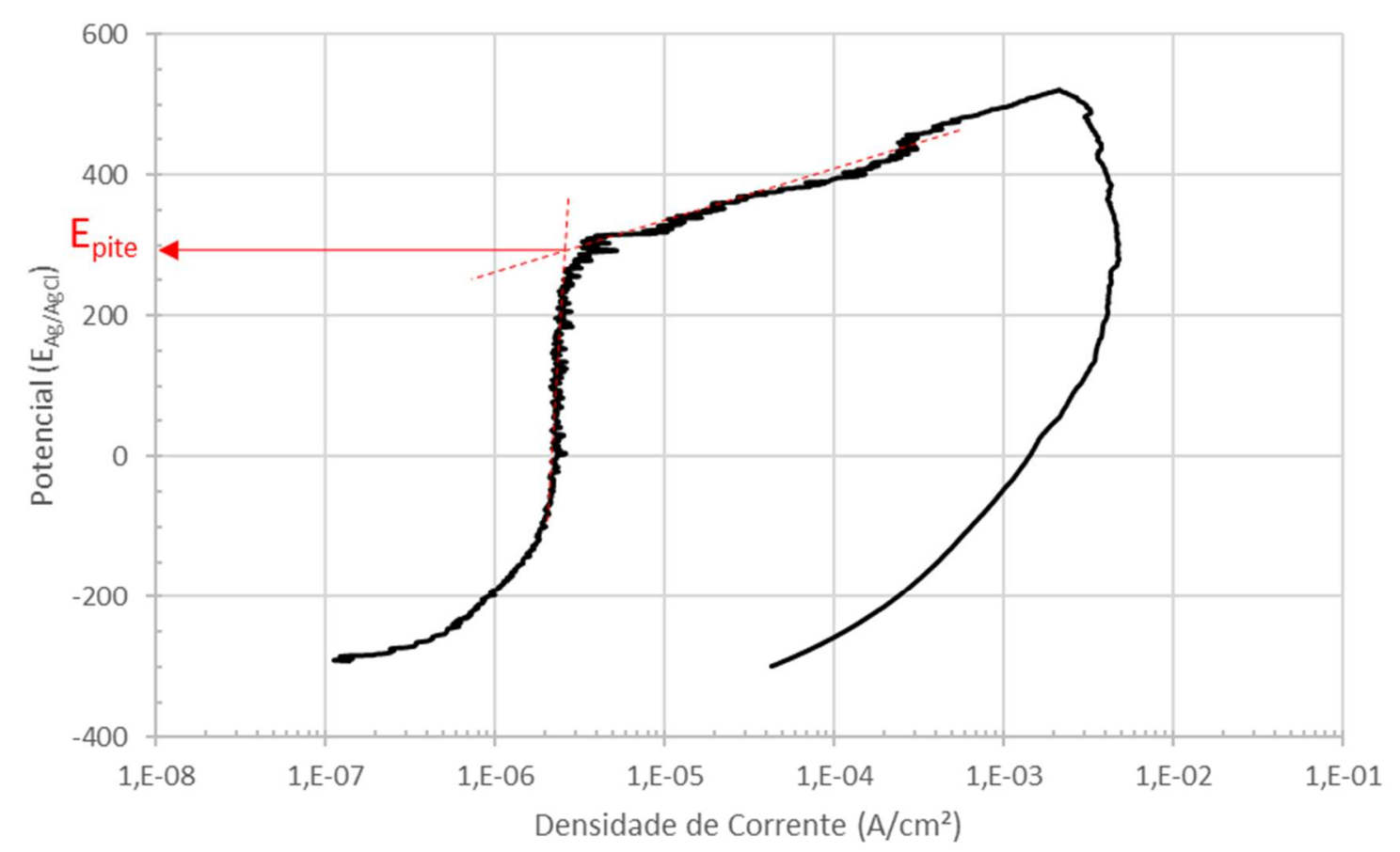

Fonte: Autor 
Figura 61 - Comparação entre as curvas de polarização cíclica em 3,5\% $\mathrm{NaCl}$ de todas as ligas solubilizadas apresentadas anteriormente, variando o teor atômico de $\mathrm{W}$ em cada uma delas em relação ao teor nominal de Mo na liga de referência $(0 \% \mathrm{~W})$.

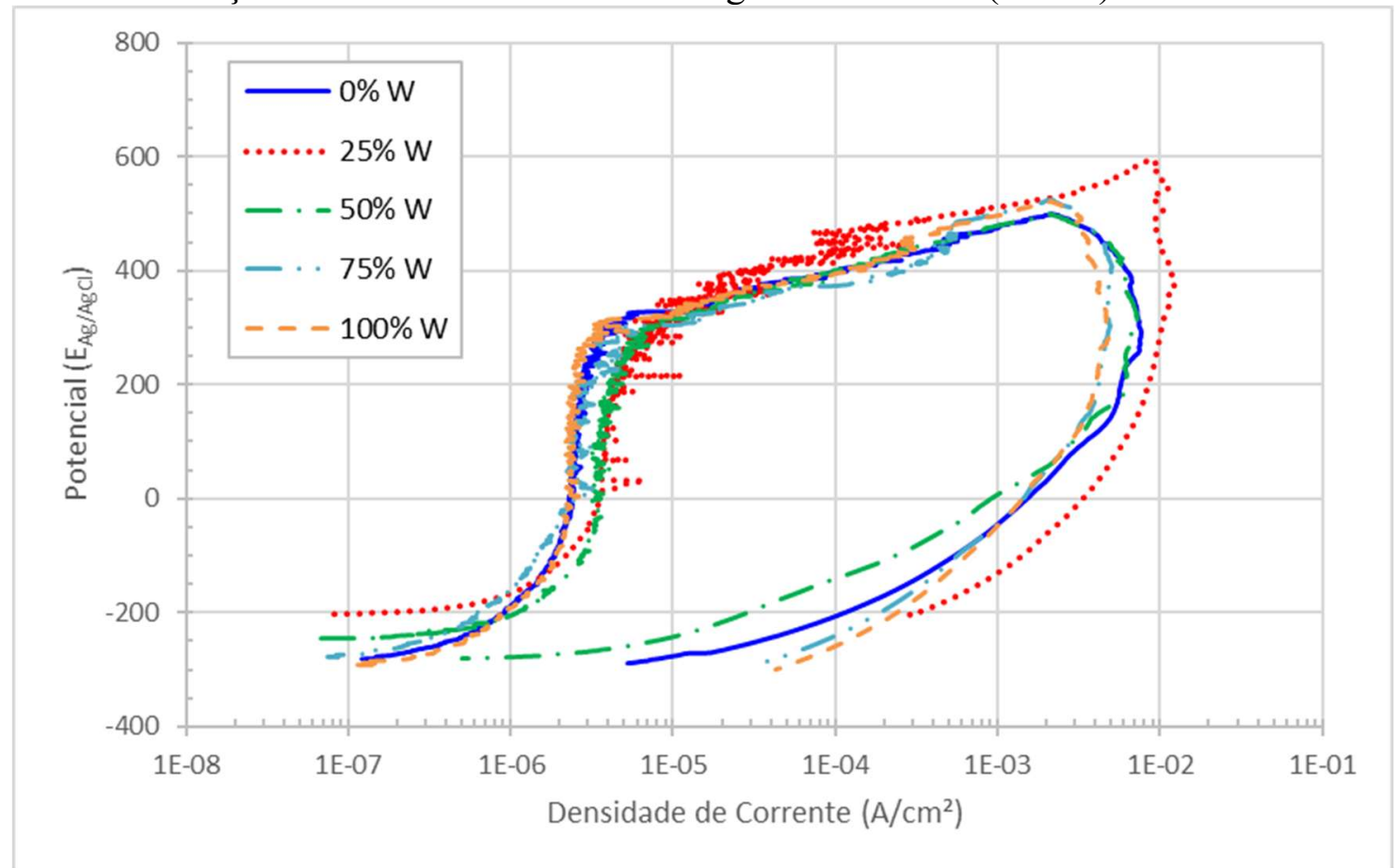

Fonte: Autor

A Figura 62 apresenta o potencial de corrosão médio, $\mathrm{E}_{\text {corr }}$, de cada uma das amostras analisadas. A análise de variância destes dados, Tabela 24, mostrou que $F$ é menor que $F_{c r i t} \mathrm{e}$ também que o valor-p é maior que o nível de significância utilizado de 0,05 . Ou seja, não existem diferenças significativas entre os potenciais de corrosão dos materiais com Mo e/ou W. Portanto, é possível afirmar que todas as amostras apresentam $\mathrm{E}_{\text {corr }}$ semelhantes e iguais a $-181 \pm 11 \mathrm{mV}_{\mathrm{Ag} / \mathrm{AgCl}}$. 
Figura 62 - Resultados de potencial de corrosão, $E_{\text {corr }}$ obtidos por meio das curvas de polarização cíclica em 3,5\% de $\mathrm{NaCl}$ das amostras solubilizadas, em função da porcentagem atômica de $\mathrm{W}$ em relação ao teor nominal de Mo presente na liga de referência $(0 \% \mathrm{~W})$.

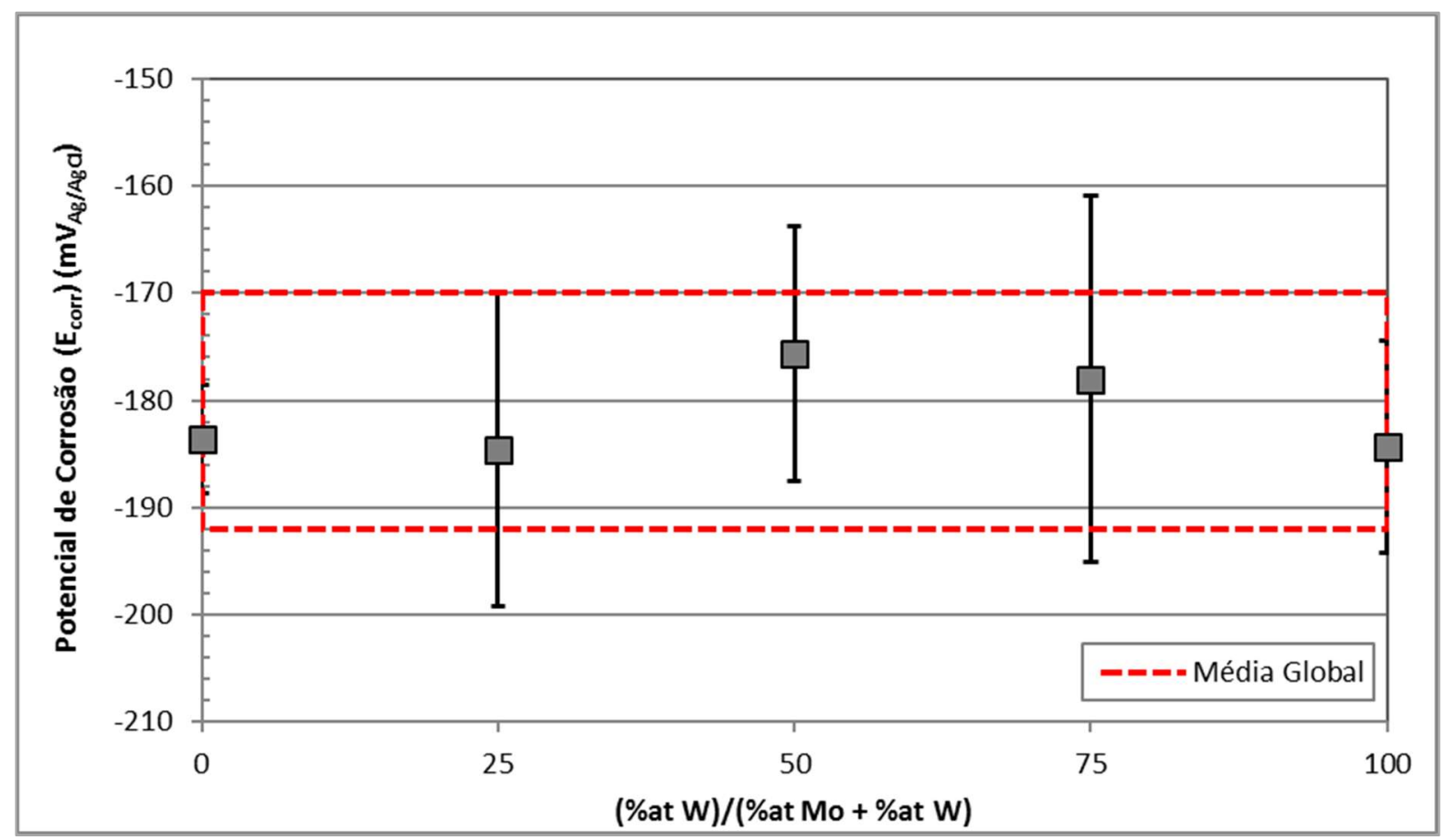

Fonte: Autor

Tabela 24 - Análise de variância dos dados de potencial de corrosão obtidos por ensaios de polarização cíclica em solução de $3,5 \% \mathrm{NaCl}$ a temperatura ambiente utilizando nível de significância de 0,05 .

\begin{tabular}{l|c|c|c|c|c|c}
\hline Fonte da variação & $\boldsymbol{S Q}$ & $\boldsymbol{g} \boldsymbol{l}$ & $\boldsymbol{M Q}$ & $\boldsymbol{F}$ & valor-P & $\boldsymbol{F}$ crítico \\
\hline Entre grupos & 206,27 & 4 & 54,57 & 0,34 & 0,85 & 3,48 \\
\hline Dentro dos grupos & 1538,67 & 10 & 153,87 & & & \\
\hline Total & 1744,93 & 14 & & & & \\
\hline
\end{tabular}

Fonte: Autor

Da mesma maneira, a Figura 63 apresenta o potencial de pite médio, $\mathrm{E}_{\text {pite, }}$ de cada uma das amostras analisadas, enquanto a análise de variância é mostrada na Tabela 25. Estes dados também mostram que $F$ é menor que $F_{\text {crit }}$ e que o valor- $p$ é maior que o nível de significância utilizado de 0,05 e, portanto, que não existem diferenças significativas no comportamento dos materiais analisados. Dessa forma, é possível afirmar que todas as amostras apresentam $\mathrm{E}_{\text {pite }}$ semelhantes iguais a $289 \pm 20 \mathrm{mV}_{\mathrm{Ag} / \mathrm{AgCl}}$. 
Figura 63 - Resultados de potencial de pite, $E_{\text {pite }}$ obtidos por meio das curvas de polarização cíclica em 3,5\% de $\mathrm{NaCl}$ das amostras solubilizadas, em função da porcentagem atômica de $\mathrm{W}$ em relação ao teor nominal de Mo presente na liga de referência $(0$ \%W).

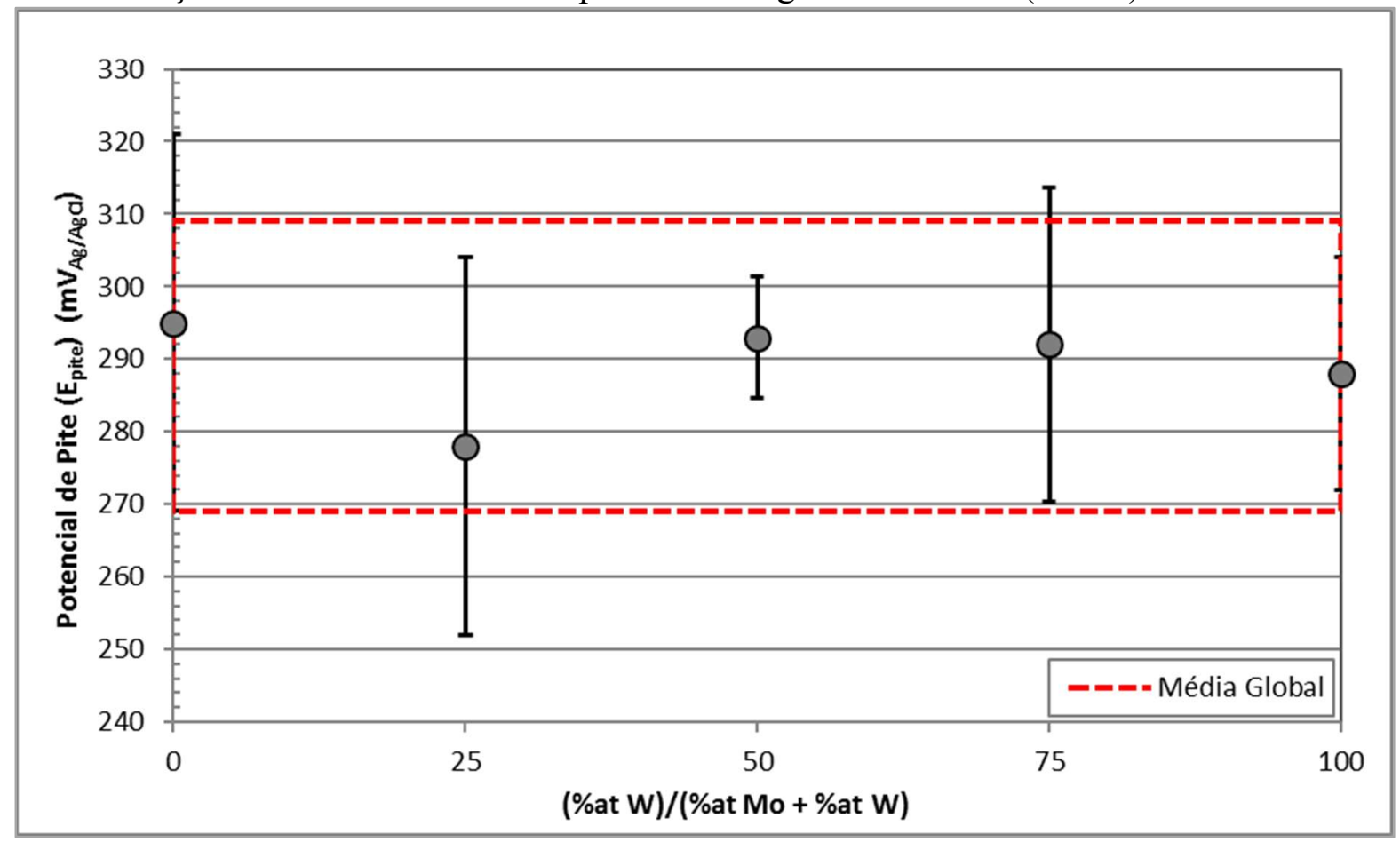

Fonte: Autor

Tabela 25 - Análise de variância dos dados de potencial de pite obtidos por ensaios de polarização cíclica em solução de $3,5 \% \mathrm{NaCl}$ a temperatura ambiente utilizando nível de significância de 0,05 .

\begin{tabular}{l|c|c|c|c|c|c}
\hline Fonte da variação & $\boldsymbol{S Q}$ & $\boldsymbol{g} \boldsymbol{M}$ & $\boldsymbol{M Q}$ & $\boldsymbol{F}$ & valor-P & $\boldsymbol{F}$ crítico \\
\hline Entre grupos & 914 & 4 & 228,5 & 0,53 & 0,71 & 2,87 \\
\hline Dentro dos grupos & 8620 & 20 & 431 & & & \\
\hline Total & 9534 & 20 & & & & \\
\hline
\end{tabular}

Fonte: Autor

Portanto, conforme notado anteriormente, de fato, observando as curvas mostradas na Figura 61 e os dados nas Figura 62 e 63, a substituição parcial/total do Mo por W não evidenciou diferenças significativas no comportamento dos materiais no ensaio de polarização cíclica realizado em solução de $3,5 \% \mathrm{de} \mathrm{NaCl}$ a temperatura ambiente em relação à resistência à corrosão por pite.

\subsubsection{Temperatura Crítica de Pite (CPT)}

Os resultados de temperatura crítica de pite (CPT) dos materiais em estudo são mostrados na Figura 64, enquanto a Tabela 26 apresenta a análise de variância destes dados. 
Figura 64 - Resultados de temperatura crítica de pite (CPT) obtidos em solução de $1 \mathrm{M}$ de $\mathrm{NaCl}$ das amostras solubilizadas, em função da porcentagem atômica de $\mathrm{W}$ em relação ao teor nominal de Mo presente na liga de referência $(0 \% \mathrm{~W})$.

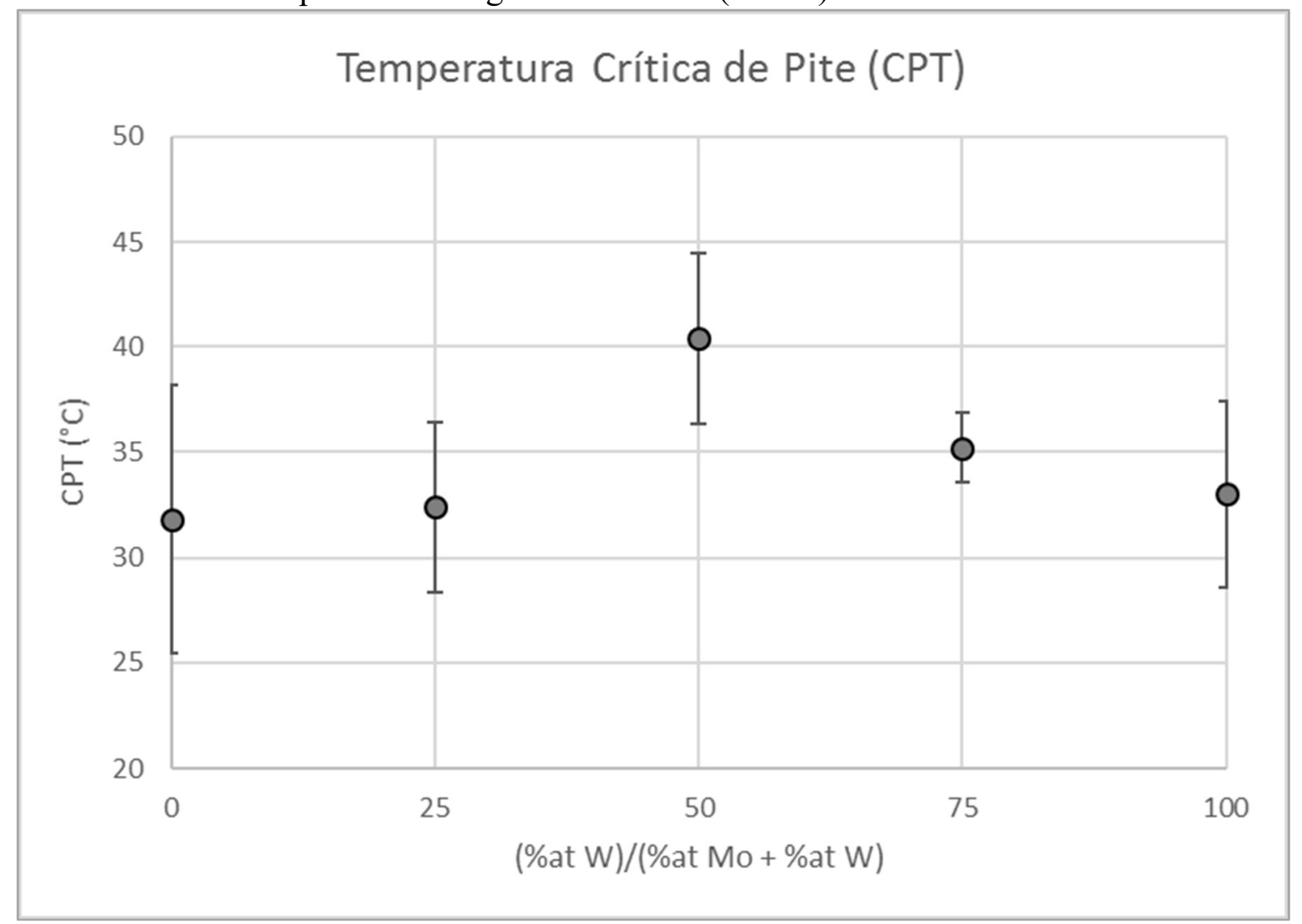

Fonte: Autor

Tabela 26 - Análise de variância dos dados de temperatura crítica de pite (CPT) em solução de $1 \mathrm{M}$ de $\mathrm{NaCl}$ utilizando nível de significância de 0,05 .

\begin{tabular}{l|c|c|c|c|c|c}
\hline Fonte da variação & $\boldsymbol{S Q}$ & $\boldsymbol{g l}$ & $\boldsymbol{M Q}$ & $\boldsymbol{F}$ & valor-P & $\boldsymbol{F}$ crítico \\
\hline Entre grupos & 246,16 & 4 & 61,54 & 3,20 & 0,035 & 2,87 \\
\hline Dentro dos grupos & 384,00 & 20 & 19,20 & & & \\
\hline Total & 630,16 & 24 & & & & \\
\hline Font: Autor
\end{tabular}

De acordo com os resultados desta análise, $F$ é maior que $F_{c r i t}$ e o valor- $p$ é menor que o nível de significância utilizado de 0,05 , ou seja, existem diferenças significativas na temperatura crítica de pite dos materiais analisados. De fato, observando a curva de CPT em função do teor de Mo substituído na Figura 64, é possível notar que a amostra que apresenta $50 \%$ de substituição apresentou CPT maior que as demais ligas, $40 \pm 4{ }^{\circ} \mathrm{C}$. Como a quantidade e os tipos de inclusões observadas em todos os materiais foram semelhantes, conforme mostrado no item 4.2, é possível que esta diferença observada para a amostra cujo teor de W 
corresponde a 50\% do teor atômico de Mo na liga nominal ocorra devido ao efeito sinérgico entre o Mo e o W para o aumento da resistência à corrosão por pite deste material, conforme observado por Oh et al. (1993) (OH, et al., 1993).

Portanto, este resultado sugere que, caso a substituição de Mo por W seja desejada no aço inoxidável austenítico AISI 316L e o principal objetivo desta substituição seja aumentar a resistência do material à corrosão por pite, o teor atômico de Mo substituído deve ser de 50\%.

\subsubsection{Polarização Potenciodinâmica}

As curvas de polarização potenciodinâmicas obtidas para cada um dos materiais analisados em solução de $0,5 \mathrm{M} \mathrm{H}_{2} \mathrm{SO}_{4}+0,01 \mathrm{M} \mathrm{KSCN}$ a $30^{\circ} \mathrm{C}$ são apresentadas da Figura 65 à Figura 69. Já a Figura 70 apresenta a comparação entre elas, sendo possível notar que todas apresentam curvas semelhantes e encontram-se passivas numa faixa entre $200 \mathrm{mV} \mathrm{Ag} / \mathrm{AgCl}$ e $600 \mathrm{mV}$ Ag/AgCl.

Figura 65 - Curva de polarização potenciodinâmica do aço inoxidável AISI 316L que contém $0 \% \mathrm{~W}$ (c.1107046) em solução de $0,5 \mathrm{M} \mathrm{H}_{2} \mathrm{SO}_{4}+0,01 \mathrm{M} \mathrm{KSCN}$ a $30^{\circ} \mathrm{C}$.

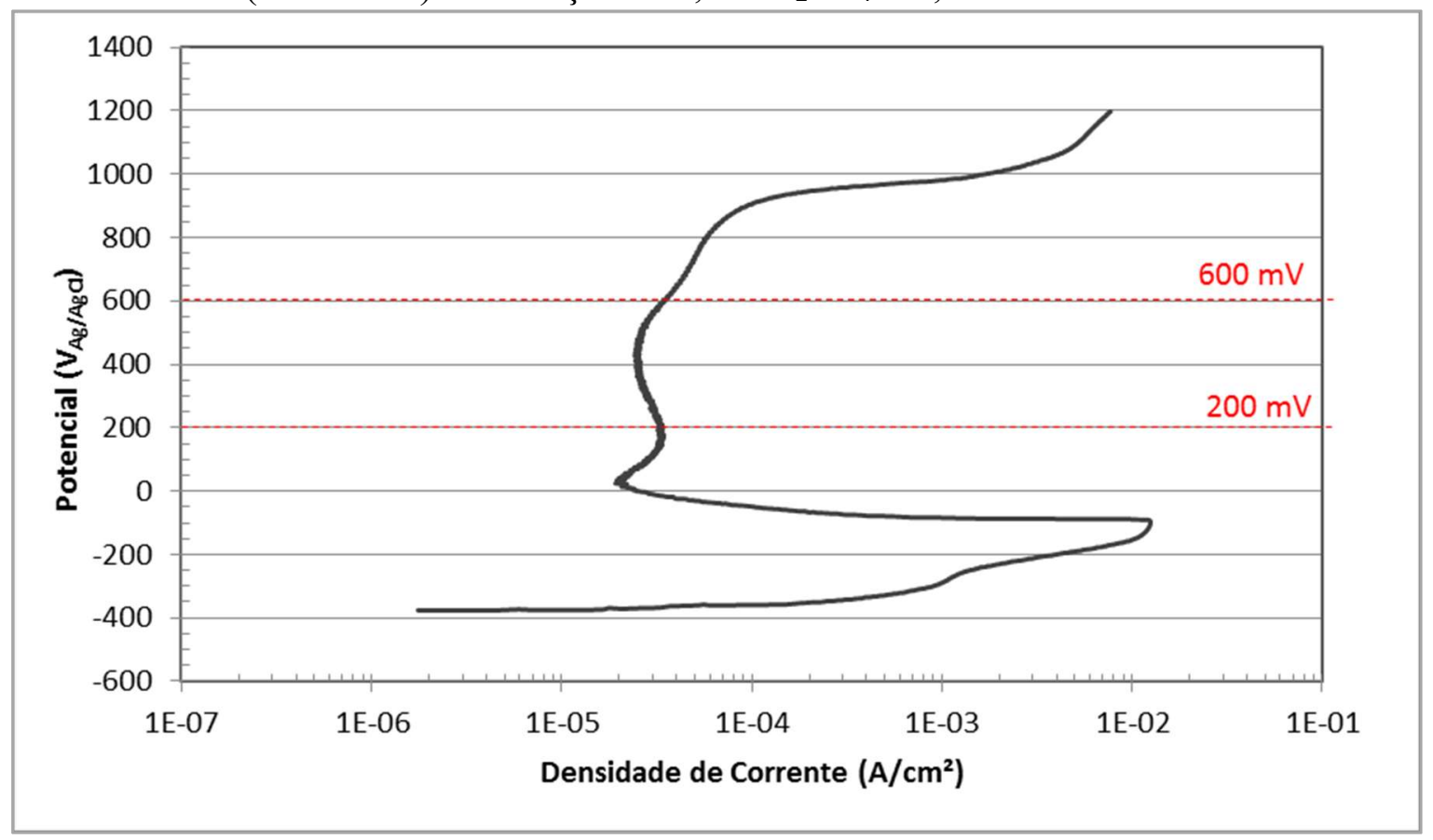

Fonte: Autor 
Figura 66 - Curva de polarização potenciodinâmica do aço inoxidável AISI 316L que contém $25 \% \mathrm{~W}$ (c. 1107047 ) em solução de $0,5 \mathrm{M} \mathrm{H}_{2} \mathrm{SO}_{4}+0,01 \mathrm{M} \mathrm{KSCN}$ a $30^{\circ} \mathrm{C}$.

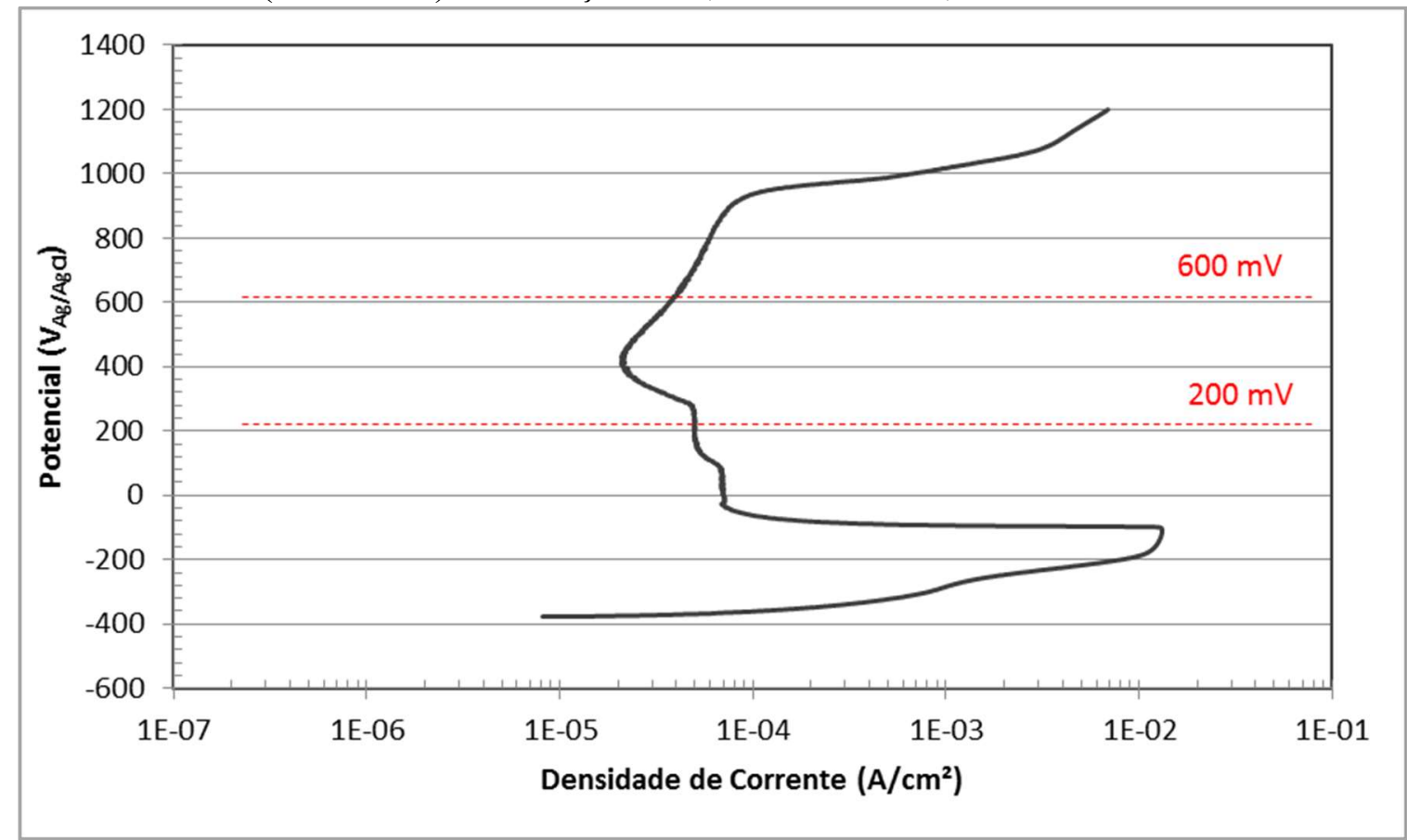

Fonte: Autor

Figura 67 - Curva de polarização potenciodinâmica do aço inoxidável AISI 316L que contém $50 \% \mathrm{~W}$ (c.1107048) em solução de $0,5 \mathrm{M} \mathrm{H}_{2} \mathrm{SO}_{4}+0,01 \mathrm{M} \mathrm{KSCN}$ a $30^{\circ} \mathrm{C}$.

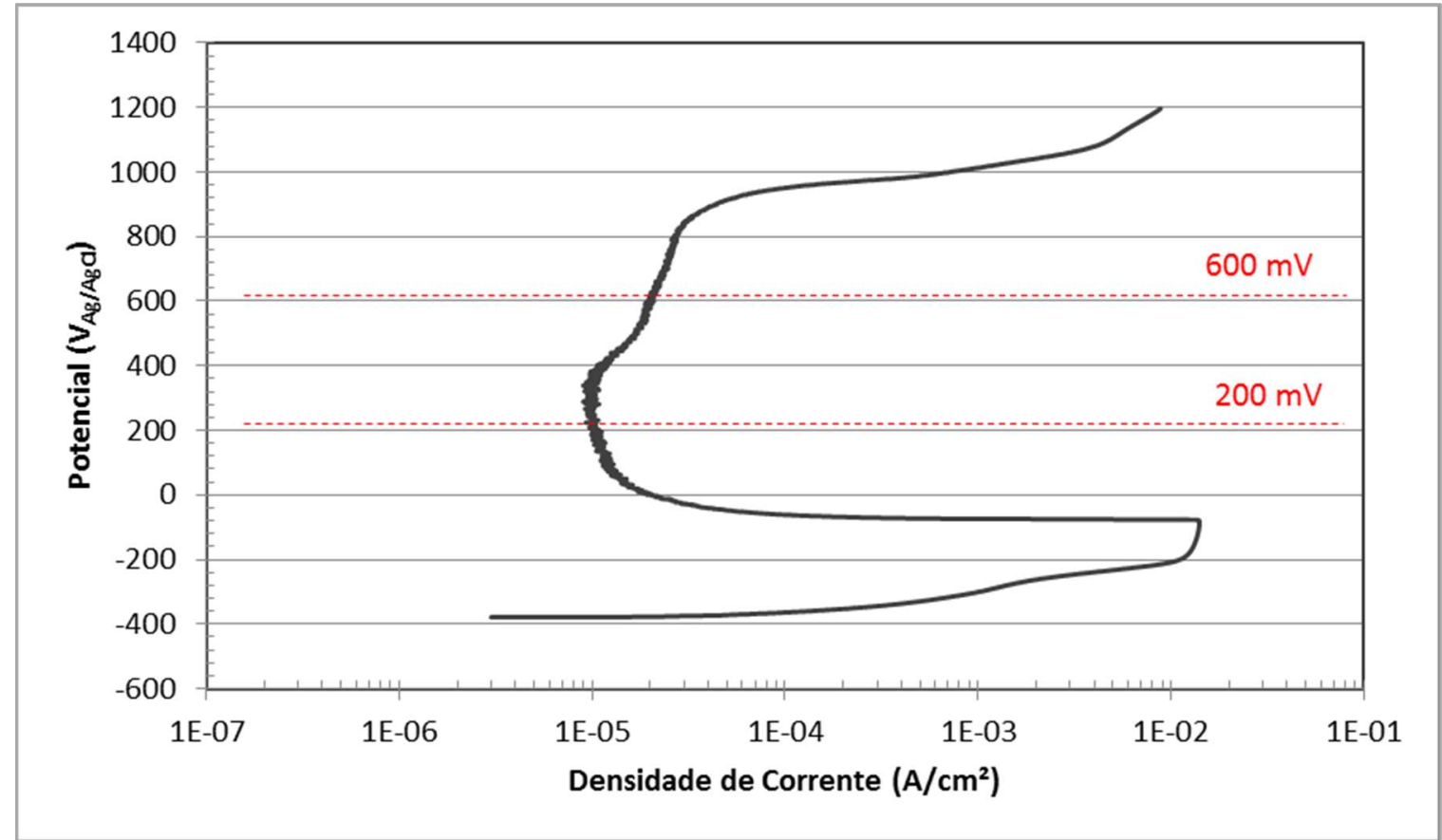

Fonte: Autor 
Figura 68 - Curva de polarização potenciodinâmica do aço inoxidável AISI 316L que contém $75 \% \mathrm{~W}$ (c.1107049) em solução de $0,5 \mathrm{M} \mathrm{H}_{2} \mathrm{SO}_{4}+0,01 \mathrm{M} \mathrm{KSCN}$ a $30^{\circ} \mathrm{C}$.

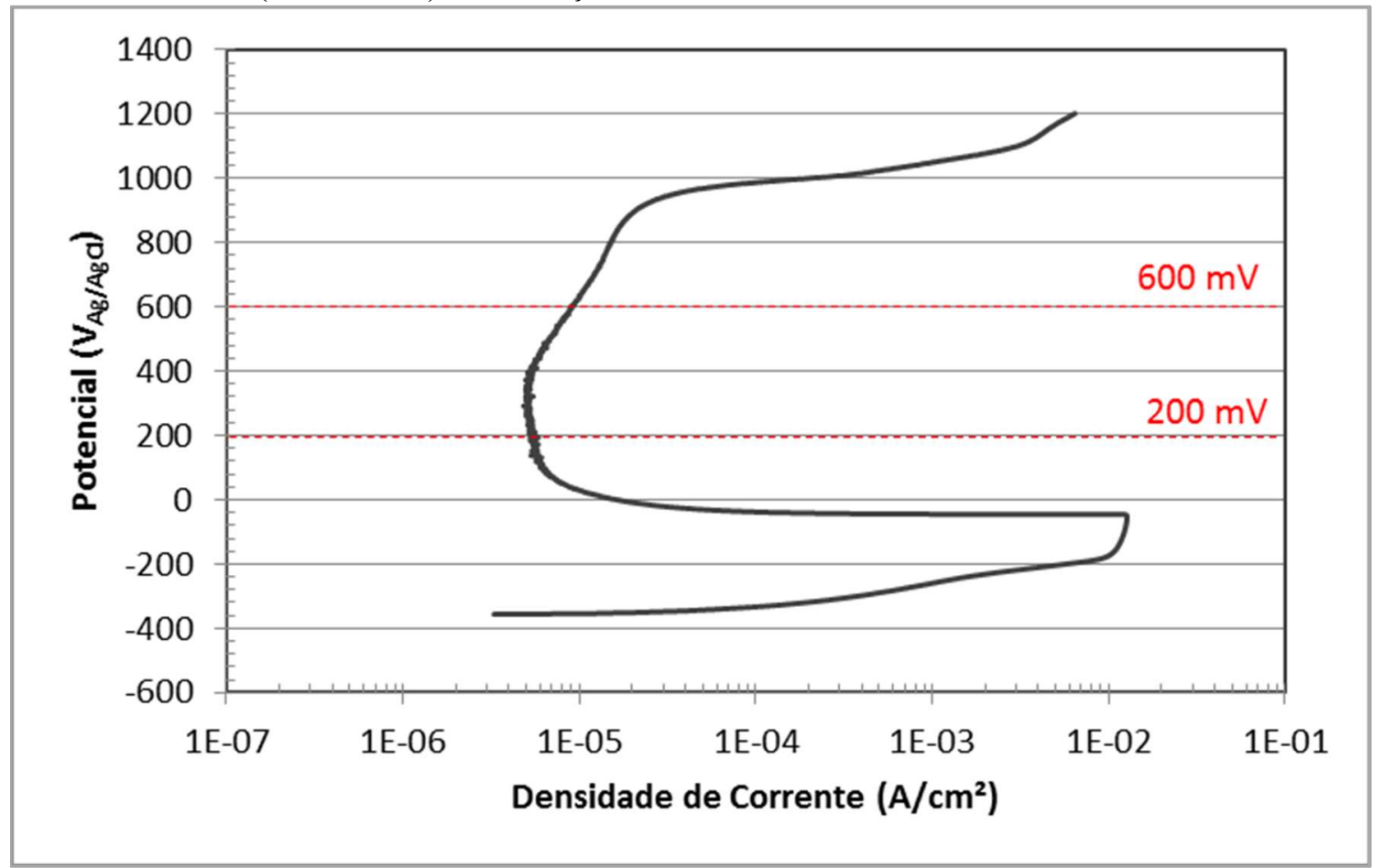

Fonte: Autor

Figura 69 - Curva de polarização potenciodinâmica do aço inoxidável AISI 316L que contém $100 \% \mathrm{~W}$ (c.1107050) em solução de $0,5 \mathrm{M} \mathrm{H}_{2} \mathrm{SO}_{4}+0,01 \mathrm{M} \mathrm{KSCN}$ a $30^{\circ} \mathrm{C}$.

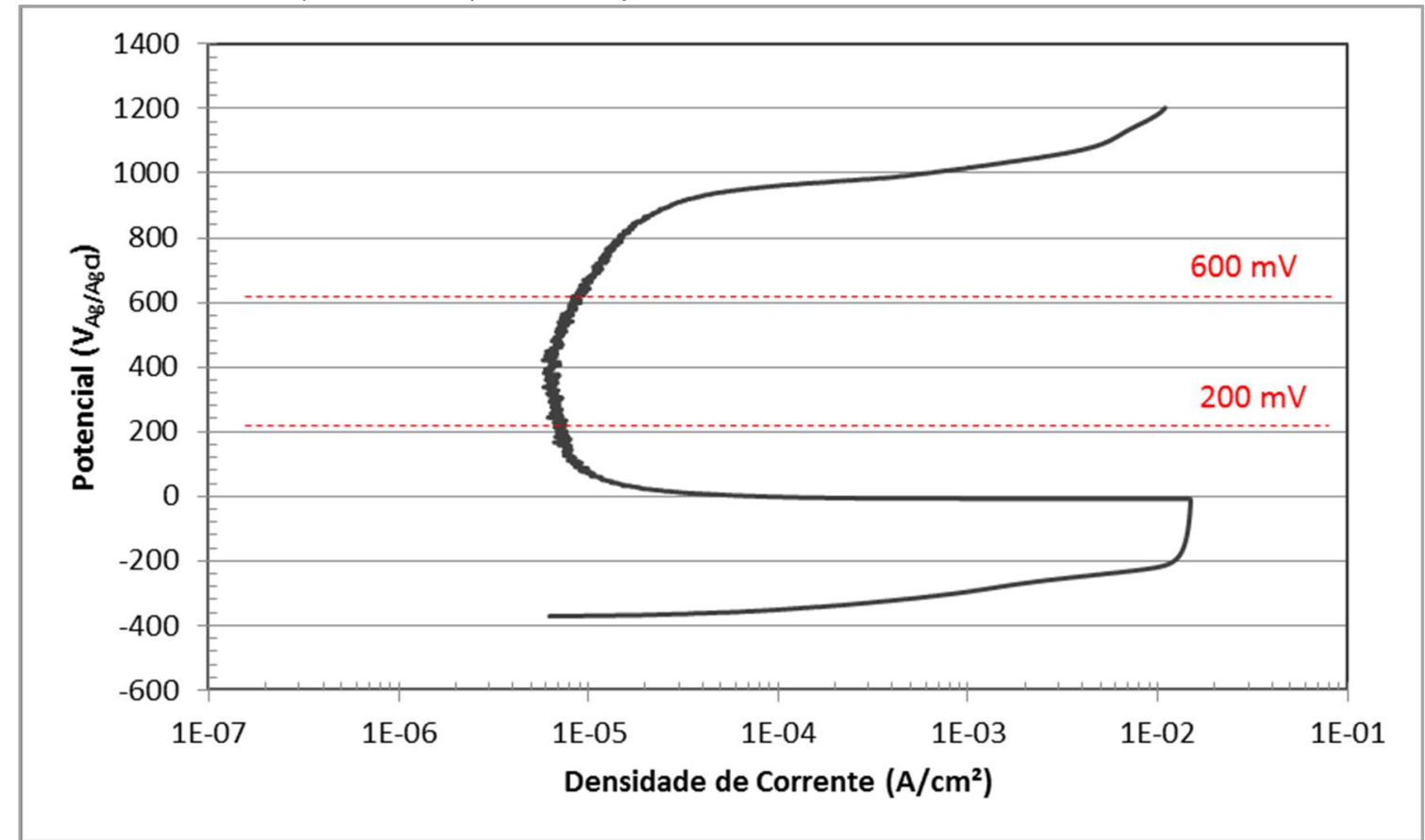

Fonte: Autor 
Figura 70 - Comparação entre as curvas de polarização potenciodinâmica em solução de $0,5 \mathrm{M} \mathrm{H}_{2} \mathrm{SO}_{4}+0,01 \mathrm{M} \mathrm{KSCN}$ a $30^{\circ} \mathrm{C}$ de todas as ligas solubilizadas apresentadas anteriormente, variando o teor atômico de $\mathrm{W}$ em cada uma delas em relação ao teor nominal de Mo na liga de referência $(0 \% \mathrm{~W})$.

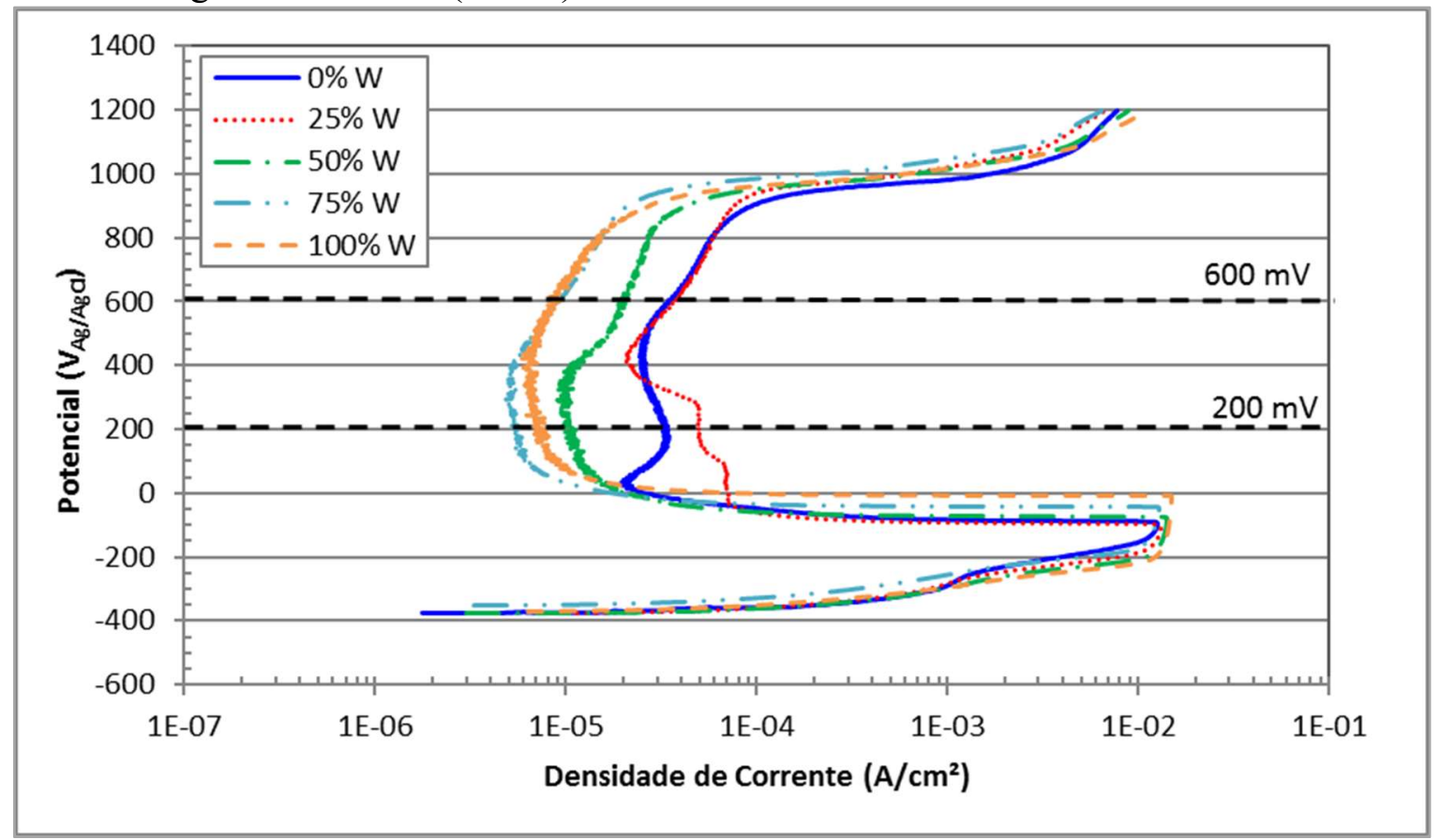

Fonte: Autor

Para todos os materiais, é possível identificar o potencial de corrosão ( $\left.\mathrm{E}_{\text {corr }}\right)$, potencial crítico ( $\left.E_{\text {crit }}\right)$, densidade de corrente crítica $\left(i_{\text {crit }}\right)$ e densidade de corrente de passivação ( $\left.i_{\text {pass }}\right)$. A variação de cada um destes parâmetros de acordo com o aumento do teor atômico de $\mathrm{W}$ em relação ao teor atômico de Mo na liga de referência $(0 \% \mathrm{~W})$ é mostrada na sequência (Figura 71 a Figura 75).

Na Figura 71 são apresentados os dados de potencial de corrosão obtidos por estes ensaios. Este gráfico evidencia que existe uma tendência no comportamento do potencial de corrosão em relação ao aumento de Mo substituído descrito por uma equação polinomial de grau 4, Equação 18, em que $X=(\%$ at $W /(\%$ at $M o+\% a t W))$.

$E_{\text {corr }}=6.10^{-6} \cdot X^{4}+0,001 \cdot X^{3}-0,08 \cdot X^{2}+1,7 \cdot X-382$ 


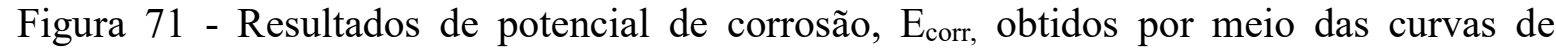
polarização potenciodinâmica em solução de $0,5 \mathrm{M} \mathrm{H}_{2} \mathrm{SO}_{4}+0,01 \mathrm{M} \mathrm{KSCN}$ a $30^{\circ} \mathrm{C}$ das amostras solubilizadas, em função da porcentagem atômica de $\mathrm{W}$ em relação ao teor nominal de Mo presente na liga de referência $(0 \% \mathrm{~W})$.

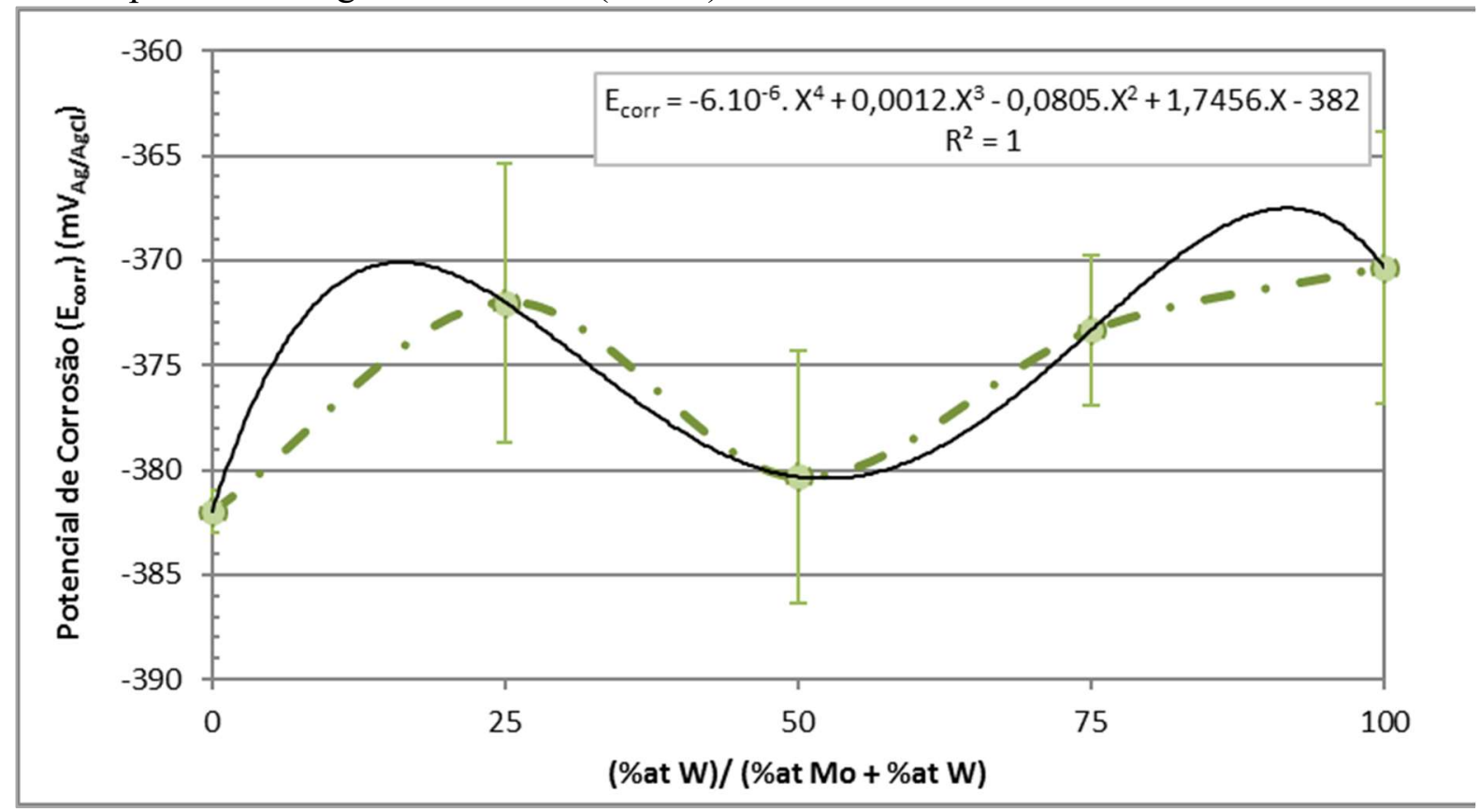

Fonte: Autor

A análise de variância destes dados, Tabela 27, mostrou que, $F$ é maior que $F_{c r i t}$ e o valor-p é menor que o nível de significância utilizado de 0,05 . Ou seja, de fato existem diferenças no potencial de corrosão, $\mathrm{E}_{\text {corr }}$, dos materiais analisados em solução de $0,5 \mathrm{M} \mathrm{H}_{2} \mathrm{SO}_{4}$ $+0,01 \mathrm{M} \mathrm{KSCN}$ a $30^{\circ} \mathrm{C}$, conforme evidenciado anteriormente.

Tabela 27 - Análise de variância dos dados de potencial de corrosão ( $\left.\mathrm{E}_{\text {corr }}\right)$ obtidos por meio do ensaios de polarização potenciodinâmica em solução de

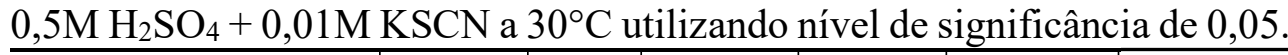

\begin{tabular}{l|c|c|c|c|c|c}
\hline Fonte da variação & $\boldsymbol{S Q}$ & $\boldsymbol{g l}$ & $\boldsymbol{M Q}$ & $\boldsymbol{F}$ & valor-P & $\boldsymbol{F}$ crítico \\
\hline Entre grupos & 327,60 & 4 & 81,9 & 8,53 & 0,003 & 3,48 \\
\hline Dentro dos grupos & 69,00 & 10 & 9,6 & & & \\
\hline Total & 423,60 & 14 & & & & \\
\hline
\end{tabular}

Fonte: Autor

Já a

Figura 72 apresenta os resultados de densidade de corrente crítica, $i_{\text {crit. }}$ De acordo com estes dados, também é possível observar uma tendência de aumento no valor de $\mathrm{i}_{\text {crit }}$ com o aumento do teor de Mo substituído por $\mathrm{W}$, sendo que para $0 \%$ de $\mathrm{W}$ icrit é igual a $12,7 \pm 0,3$ $\mathrm{mA} / \mathrm{cm}^{2}$ e para $100 \%$ de W este parâmetro chega a $14,8 \pm 0,5 \mathrm{~mA} / \mathrm{cm}^{2}$. Este comportamento 
pode ser descrito por uma equação polinomial de segundo grau, Equação 19 , em que $X=(\% a t$ $W /(\%$ at $M o+\%$ at $W))$.

$i_{\text {crit }}=-8.10^{-8} \cdot X^{2}+3 \cdot 10^{-5} \cdot X+0,0127$

Figura 72 - Resultados de densidade de corrente crítica, $i_{\text {crit, }}$ obtidos por meio das curvas de polarização potenciodinâmica em solução de $0,5 \mathrm{M} \mathrm{H}_{2} \mathrm{SO}_{4}+0,01 \mathrm{M} \mathrm{KSCN}$ a $30^{\circ} \mathrm{C}$ das amostras solubilizadas, em função da porcentagem atômica de $\mathrm{W}$ em relação ao teor nominal de Mo presente na liga de referência $(0 \% \mathrm{~W})$.

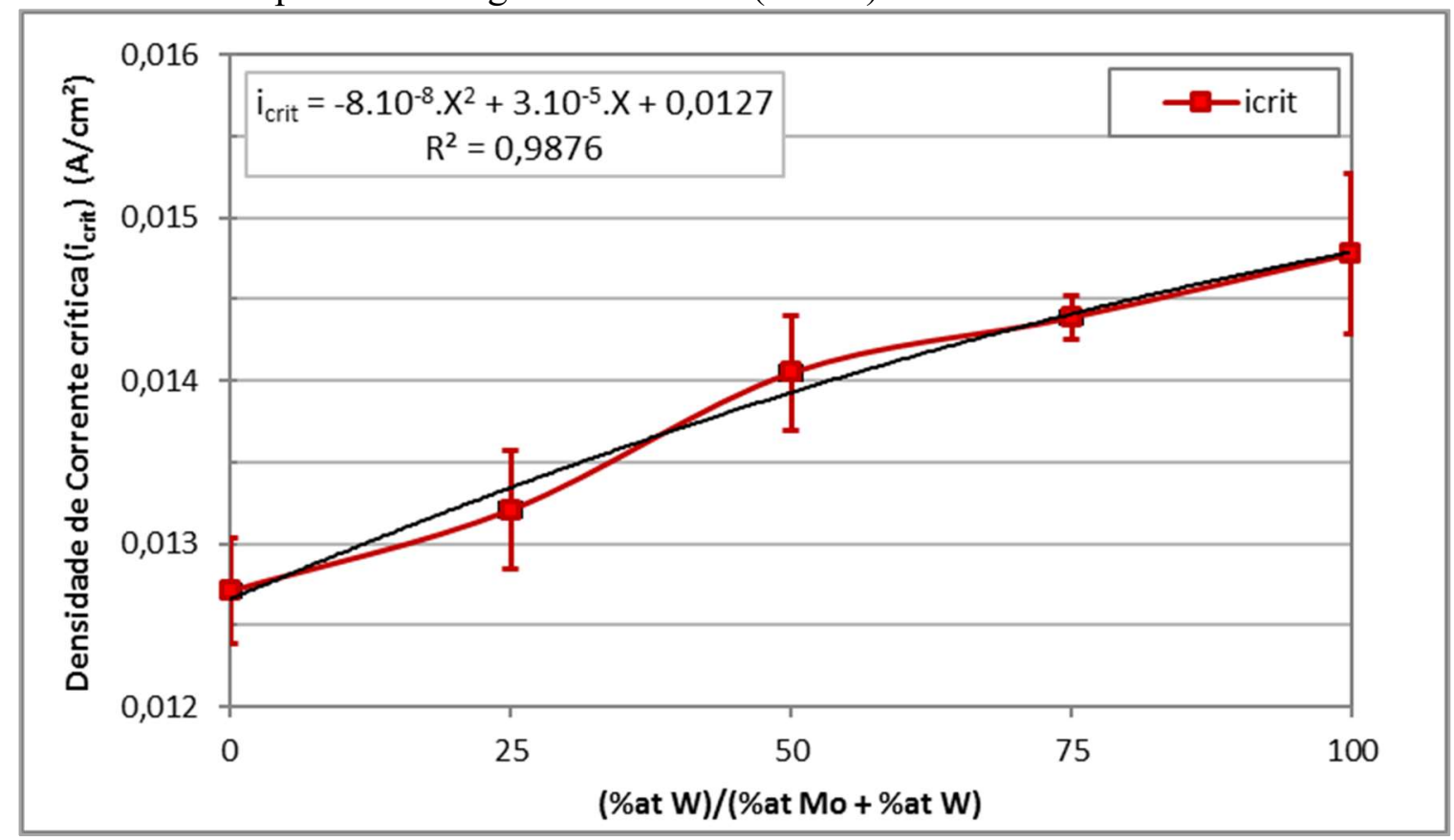

Fonte: Autor

Esta tendência pode também ser observada sutilmente pela sobreposição das curvas típicas de cada um dos materiais resultantes do ensaio de polarização potenciodinâmica apresentadas anteriormente na Figura 70 e apresentadas novamente na Figura 73 destacando a variação deste parâmetro, $\mathrm{i}_{\text {crit. }}$ 
Figura 73 - Comparação entre as curvas de polarização potenciodinâmica em solução de $0,5 \mathrm{M}$ $\mathrm{H}_{2} \mathrm{SO}_{4}+0,01 \mathrm{M} \mathrm{KSCN}$ a $30^{\circ} \mathrm{C}$ de todas as ligas solubilizadas apresentadas anteriormente, variando o teor atômico de $\mathrm{W}$ em cada uma delas em relação ao teor nominal de Mo na liga de referência $(0 \% \mathrm{~W})$, destacando a variação da densidade de corrente crítica, $\mathrm{i}_{\text {crit. }}$

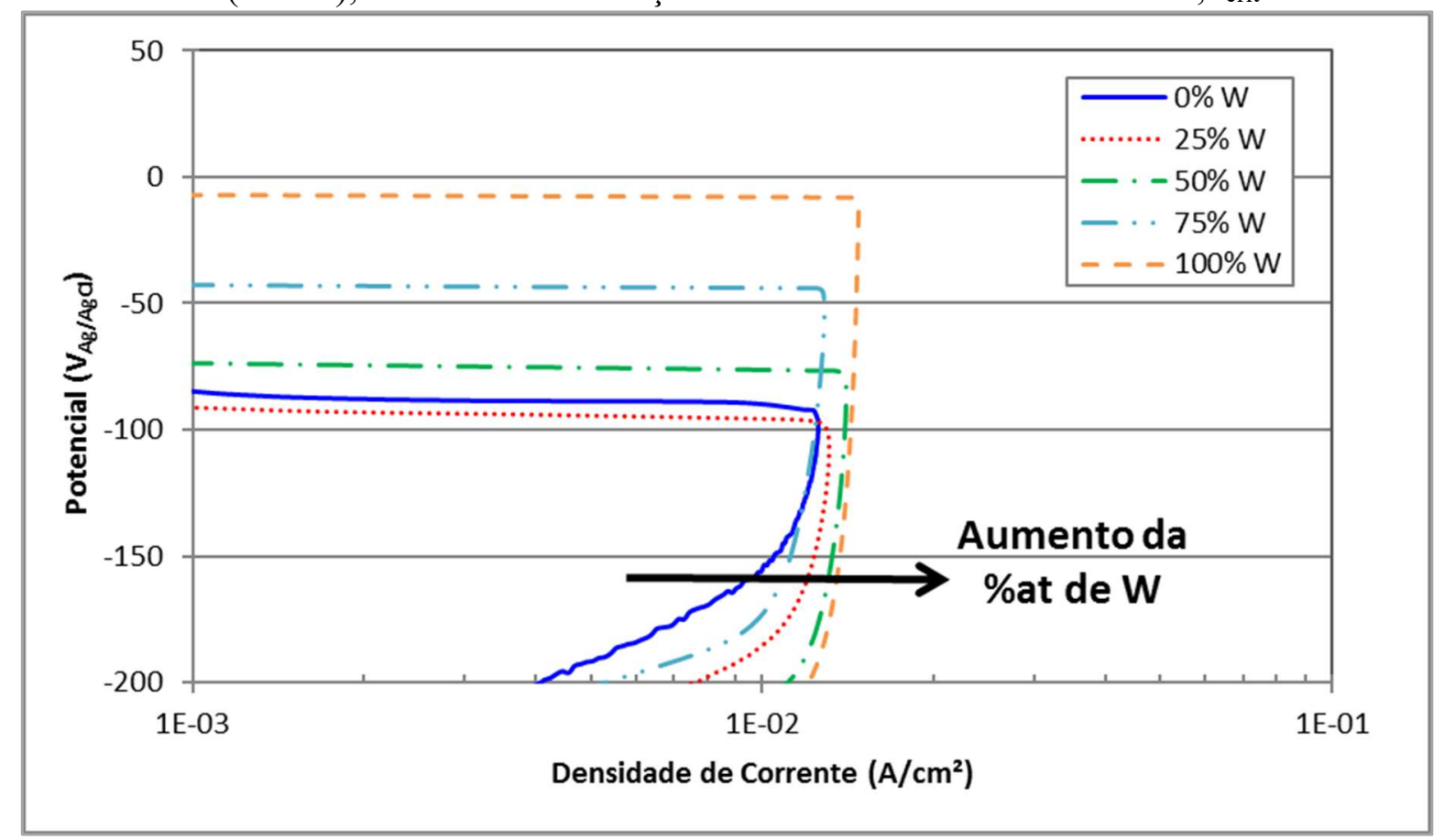

Fonte: Autor

A análise de variância dos dados de $\mathrm{i}_{\text {crit, }}$, Tabela 28 , evidenciou que $F$ é maior que $F_{c r i t} \mathrm{e}$ o valor-p é menor que o nível de significância utilizado de 0,05 . Ou seja, de fato ao menos um

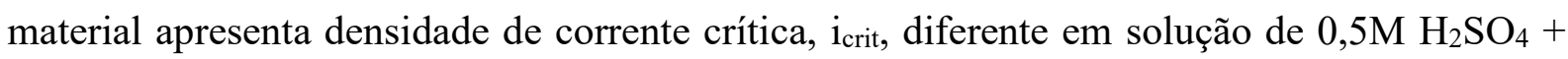
$0,01 \mathrm{M} \mathrm{KSCN}$ a $30^{\circ} \mathrm{C}$, conforme suspeitado anteriormente.

Tabela 28 - Análise de variância dos dados de densidade de corrente crítica ( $\mathrm{i}_{\text {crit }}$ ) obtidos por meio do ensaios de polarização potenciodinâmica em solução de $0,5 \mathrm{M} \mathrm{H}_{2} \mathrm{SO}_{4}+0,01 \mathrm{M} \mathrm{KSCN}$ a $30^{\circ} \mathrm{C}$ utilizando nível de significância de 0,05 .

\begin{tabular}{l|c|c|c|c|c|c}
\hline Fonte da variação & $\boldsymbol{S Q}$ & $\boldsymbol{g l}$ & $\boldsymbol{M Q}$ & $\boldsymbol{F}$ & valor-P & $\boldsymbol{F}$ crítico \\
\hline Entre grupos & $8,72.10^{-6}$ & 4 & $2,18.10^{-6}$ & 84,21 & $1,16.10^{-7}$ & 3,48 \\
\hline Dentro dos grupos & $2,58.10^{-7}$ & 10 & $2,59.10^{-8}$ & & & \\
\hline Total & $8,98.10^{-6}$ & 14 & & & & \\
\hline
\end{tabular}

Fonte: Autor 
Portanto, é possível concluir que, apesar de sutil, o aumento do teor de Mo substituído por $\mathrm{W}$ em relação ao teor atômico de Mo na liga de referência provoca um aumento também na densidade de corrente crítica do aço inoxidável austenítico AISI 316XL em solução de 0,5M $\mathrm{H}_{2} \mathrm{SO}_{4}+0,01 \mathrm{M} \mathrm{KSCN}$ a $30^{\circ} \mathrm{C}$.

Os dados de potencial crítico ( $\left.\mathrm{E}_{\text {crit }}\right)$ obtidos no mesmo ensaio são apresentados na Figura 74. Estes dados também mostram uma tendência de aumento no $E_{\text {crit }}$ com o aumento do teor atômico de W substituindo o Mo descrita por uma equação polinomial de segundo grau, Equação 20 , em que $X=(\%$ at $W /(\%$ at $M o+\% a t W))$. O E crit observado para a amostra de $0 \%$ de $\mathrm{W}$ foi de $-110 \pm 10 \mathrm{mV}$ Ag/AgCl, enquanto que substituindo $100 \%$ o teor atômico de Mo este valor sobe para $-5 \pm 11 \mathrm{mV}$ Ag/AgCl. Esta tendência pode ser observada também pela sobreposição das curvas típicas obtidas mostrada anteriormente na Figura 73, evidenciando que o $\mathrm{W}$ promove um aumento no potencial necessário para passivação.

$E_{\text {crit }}=0,016 \cdot X^{2}-0,0342 \cdot X-109,13$

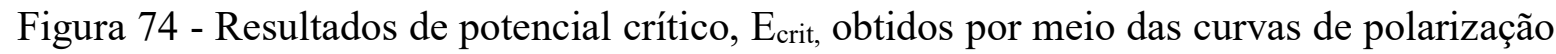
potenciodinâmica em solução de $0,5 \mathrm{M} \mathrm{H}_{2} \mathrm{SO}_{4}+0,01 \mathrm{M} \mathrm{KSCN}$ a $30^{\circ} \mathrm{C}$ das amostras solubilizadas, em função da porcentagem atômica de $\mathrm{W}$ em relação ao teor nominal de Mo xpresente na liga de referência $(0 \% \mathrm{~W})$.

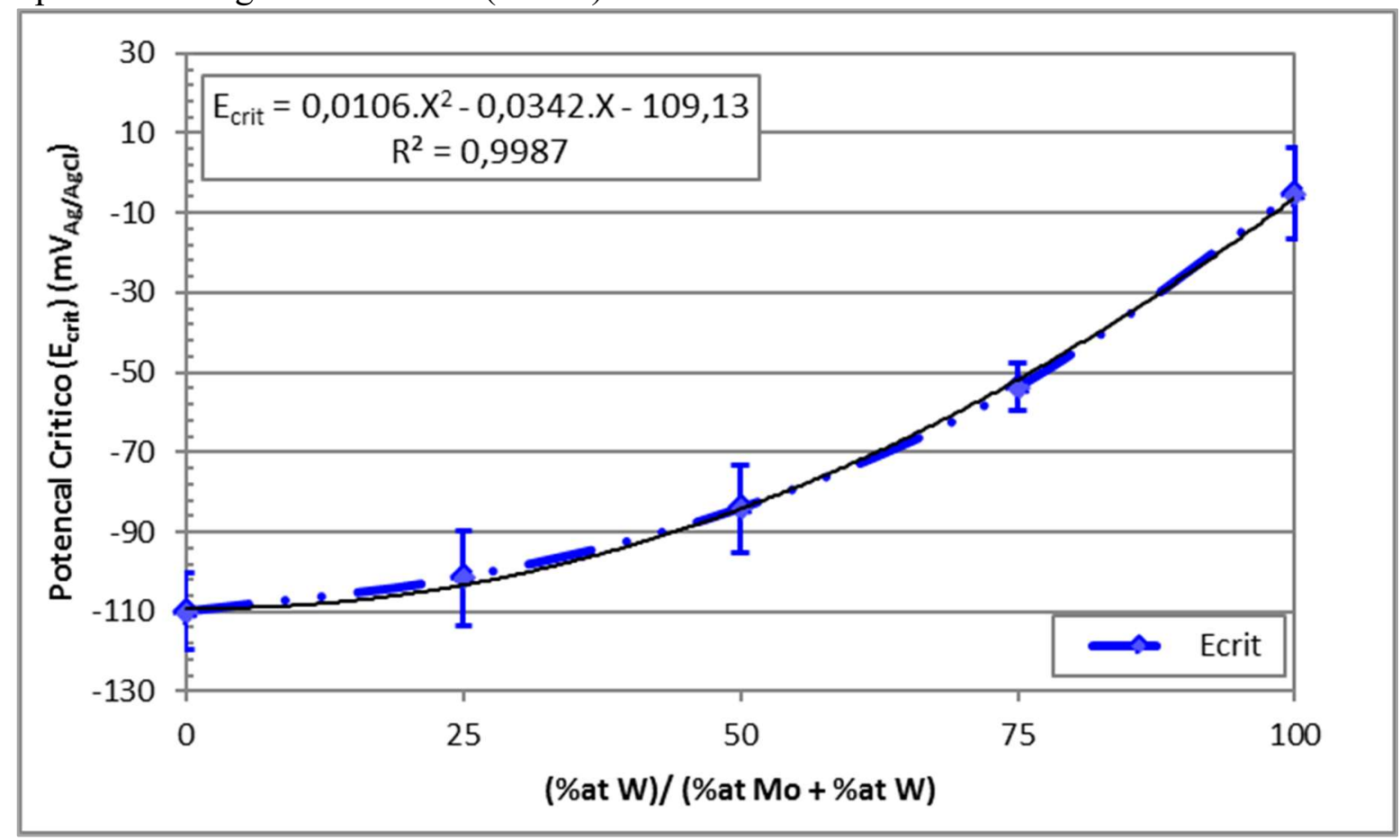

Fonte: Autor 
A análise de variância destes dados, Tabela 29, mostrou que $F$ é maior que $F_{c r i t}$ e o valor-p é menor que o nível de significância utilizado de 0,05. Então, como esperado, existem diferenças estatísticas significativas de $\mathrm{E}_{\text {crit }}$ entre as amostras, conforme observado na tendência de aumento com o aumento de $\mathrm{W}$ anteriormente.

Tabela 29 - Análise de variância dos dados de potencial crítico ( $\left.\mathrm{E}_{\text {crit }}\right)$ obtidos por meio do ensaios de polarização potenciodinâmica em solução de $0,5 \mathrm{M} \mathrm{H}_{2} \mathrm{SO}_{4}+$

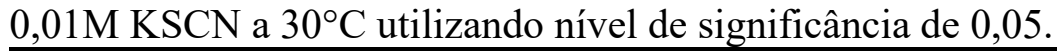

\begin{tabular}{l|c|c|c|c|c|c}
\hline Fonte da variação & $\boldsymbol{S Q}$ & $\boldsymbol{g} \boldsymbol{l}$ & $\boldsymbol{M Q}$ & $\boldsymbol{F}$ & valor-P & $\boldsymbol{F}$ crítico \\
\hline Entre grupos & 21783,96 & 4 & 5445,99 & 11,67 & 0,0008 & 3,48 \\
\hline Dentro dos grupos & 4665,21 & 10 & 466,52 & & & \\
\hline Total & 26449,17 & 14 & & & & \\
\hline Fonte: Autor
\end{tabular}

Por fim, a Figura 75 apresenta os resultados de densidade de corrente passiva, $\mathrm{i}_{\text {pass }}$ dos materiais analisados. Estes resultados evidenciam uma tendência de queda de $i_{\text {pass }}$ com o aumento do teor atômico de Mo substituindo W que pode ser descrita por uma equação quadrática mostrada na Equação 21, em que $X=(\%$ at $W /(\%$ at $M o+\%$ at $W))$, e facilmente observada na Figura 70 que apresenta a comparação das curvas típicas obtidas neste ensaio. Para $0 \%$ de $\mathrm{W}$, a densidade de corrente passiva obtida foi de $0,04 \pm 0,02 \mathrm{~mA} / \mathrm{cm}^{2}$, enquanto que substituindo $100 \%$ do Mo por W, este parâmetro cai para $0,002 \pm 0,003 \mathrm{~mA} / \mathrm{cm}^{2}$.

$$
i_{\text {pass }}=3 \cdot 10^{-6} \cdot X^{2}-7 \cdot 10^{-4} \cdot X+0,0394
$$


Figura 75 - Resultados de densidade de corrente passiva, $i_{\text {pass, }}$ obtidos por meio das curvas de polarização potenciodinâmica em solução de $0,5 \mathrm{M} \mathrm{H}_{2} \mathrm{SO}_{4}+0,01 \mathrm{M} \mathrm{KSCN}$ a $30^{\circ} \mathrm{C}$ das amostras solubilizadas, em função da porcentagem atômica de $\mathrm{W}$ em relação ao teor nominal de Mo presente na liga de referência $(0 \% \mathrm{~W})$.

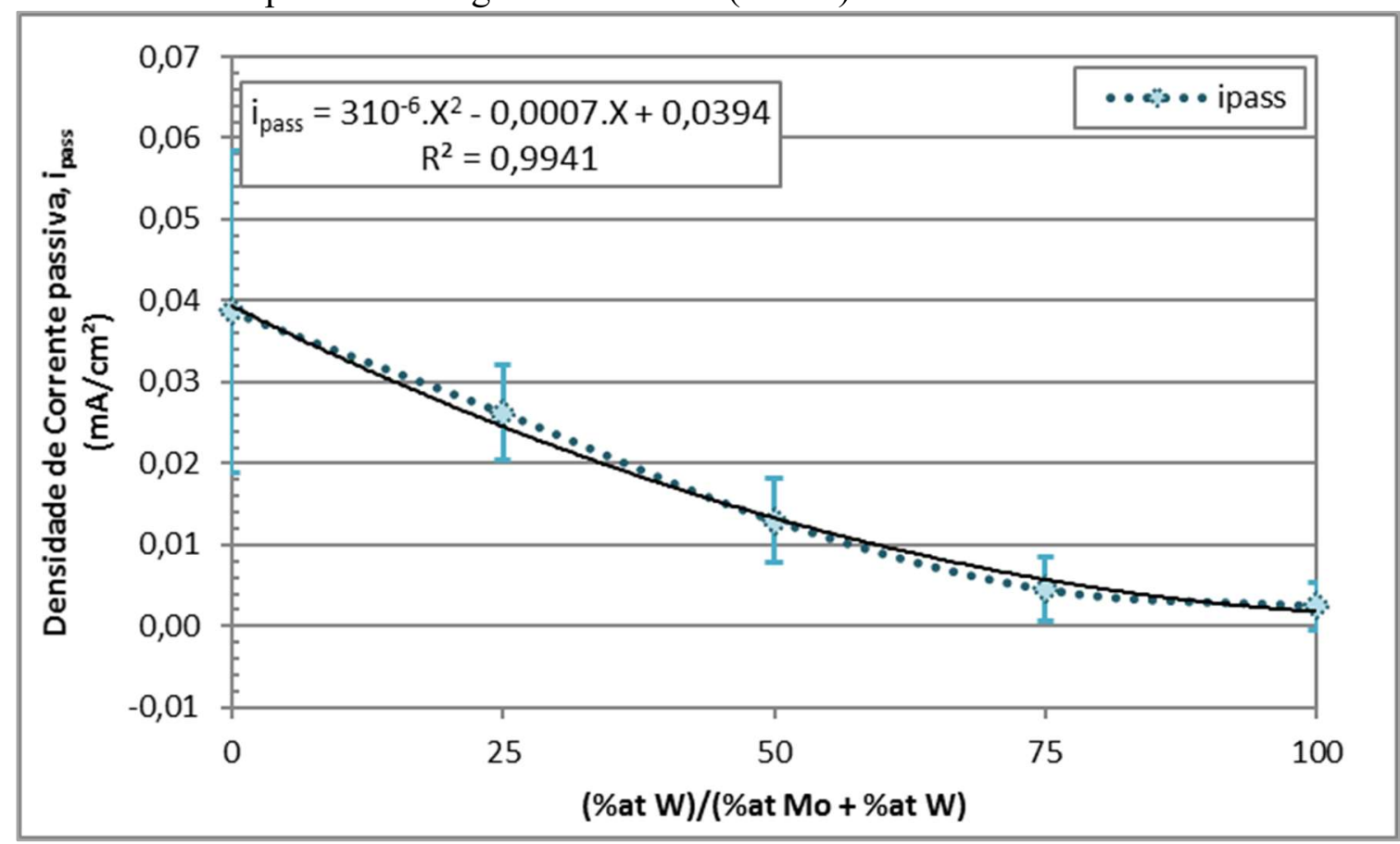

Fonte: Autor

A análise de variância destes dados obtidos para $i_{\text {pass, }}$, Tabela 30 , mostrou que $F$ é maior que $F_{\text {crit }}$ e o valor-p é menor que o nível de significância utilizado de 0,05 , confirmando que realmente existem diferenças significativas no valor de $i_{\text {pass }}$ entre os materiais analisados.

Tabela 30 - Análise de variância dos dados de densidade de corrente passiva ( $i_{\text {pass }}$ ) obtidos por meio do ensaios de polarização potenciodinâmica em solução de $0,5 \mathrm{M} \mathrm{H}_{2} \mathrm{SO}_{4}+0,01 \mathrm{M} \mathrm{KSCN} \mathrm{a} 30^{\circ} \mathrm{C}$ utilizando nível de significância de 0,05 .

\begin{tabular}{l|c|c|c|c|c|c}
\hline Fonte da variação & $\boldsymbol{S Q}$ & $\boldsymbol{g l}$ & $\boldsymbol{M Q}$ & $\boldsymbol{F}$ & valor-P & $\boldsymbol{F}$ crítico \\
\hline Entre grupos & 0,00281 & 4 & 0,00070 & 7,38 & 0,0049 & 3,47 \\
\hline Dentro dos grupos & 0,00095 & 10 & 0,00009 & & & \\
\hline Total & 0,00376 & 14 & & & & \\
\hline
\end{tabular}

Fonte: Autor

Em suma, os resultados dos ensaios de polarização potenciodinâmica conduzidos em solução de $0,5 \mathrm{M}$ de $\mathrm{H}_{2} \mathrm{SO}_{4}+0,01 \mathrm{M} \mathrm{KSCN}$ evidenciaram que o fenômeno de passivação do aço inoxidável AISI 316L é influenciado pela substituição de Mo por W em relação ao teor atômico de $1,33 \%$ at $(2,3 \%$ wt) de Mo presente na liga de referência. De acordo com estes resultados, o 
W provoca efeitos distintos na passivação do material, pois, apesar da densidade de corrente crítica ( $\left.\mathrm{i}_{\text {crit }}\right)$ e do potencial crítico $\left(\mathrm{E}_{\text {crit }}\right)$ apresentarem uma tendência de aumento com esta substituição, a densidade de corrente passiva ( $\left.\mathrm{i}_{\text {pass }}\right)$ é significativamente reduzida. Ou seja, o W dificulta a formação da película passiva, expandindo a região ativa, porém, ao ser formada, esta película é mais protetora. Sendo assim, é possível concluir que, dentre as ligas estudadas, a liga que apresenta $50 \%$ de substituição de Mo por W apresenta um ganho significativo no grau de proteção da película passiva em relação à liga de referência $(0 \% \mathrm{~W})$, devido à menor $\mathrm{i}_{\text {pass, }}$ sem que $i_{\text {crit }}$ e $E_{\text {crit }}$ aumentem expressivamente, Figura 76, e seria, portanto, a escolha para substituição parcial de Mo por W.

Figura 76 - Resultados obtidos de potencial crítico ( $\left.E_{\text {crit }}\right)$, densidade de corrente crítica ( $\left.i_{\text {crit }}\right)$ e densidade de corrente passiva ( $i_{\text {pass }}$ ) obtidos nos ensaios de polarização potenciodinâmica em solução de $0,5 \mathrm{M} \mathrm{H}_{2} \mathrm{SO}_{4}+0,01 \mathrm{M} \mathrm{KSCN}$ a $30^{\circ} \mathrm{C}$ em função do teor atômico de Mo substituído por $\mathrm{W}$ destacando a liga para $50 \%$ de substituição.

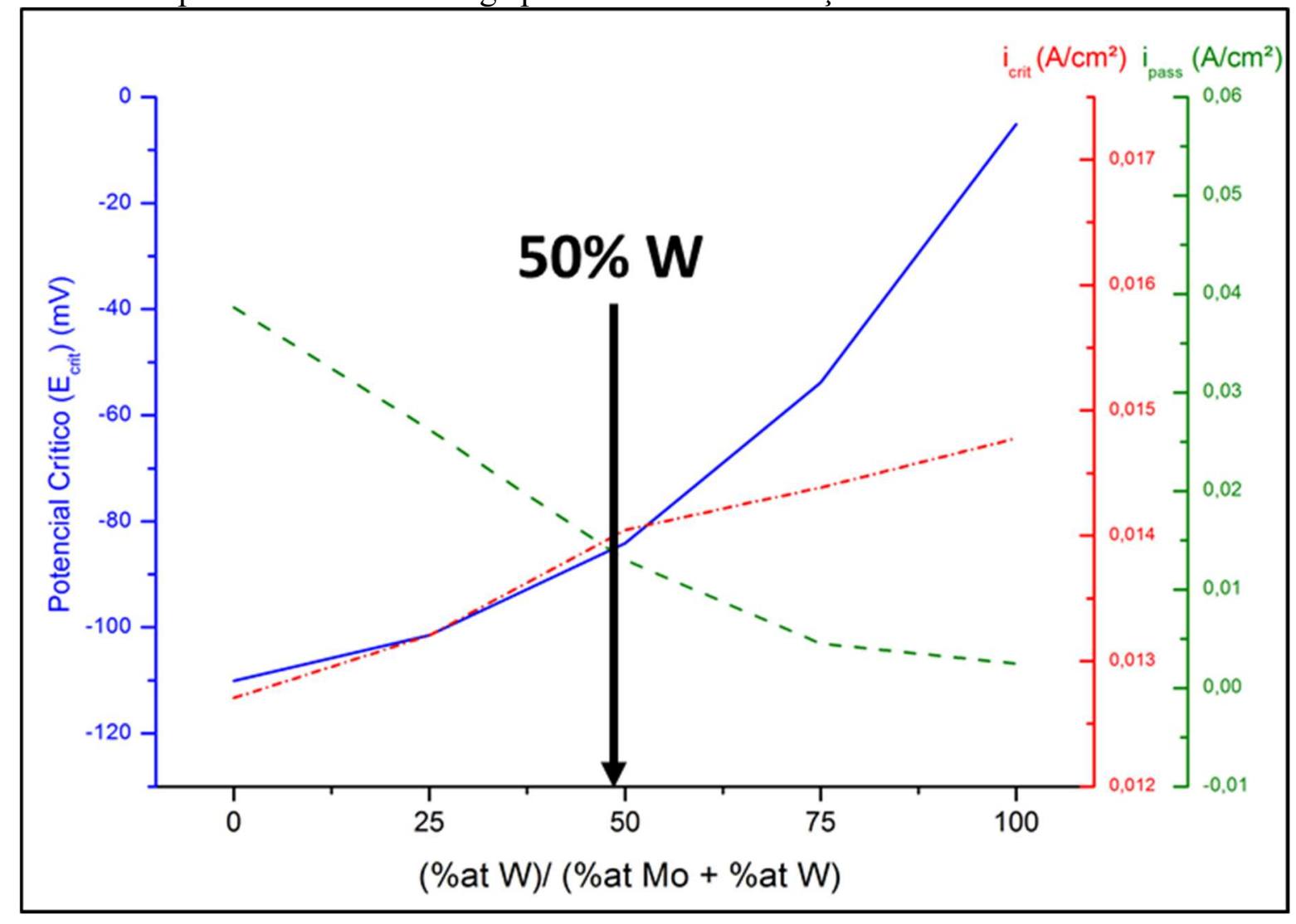

Fonte: Autor

Kim, Xiang e Kim (2005) (KIM, XIANG e KIM, 2005) observaram comportamento semelhante para o aço inoxidável AISI 317LMN. Estes autores observaram que em solução ácida de $0,5 \mathrm{M} \mathrm{H} 2 \mathrm{SO} 4+3,5 \% \mathrm{Cl}-$ a $25^{\circ} \mathrm{C}$ a substituição parcial de Mo por $\mathrm{W}$ provoca um aumento na densidade de corrente crítica $\left(\mathrm{i}_{\text {crit }}\right)$ e uma redução na densidade de corrente passiva 
( $\left.i_{\text {pass}}\right)$, evidenciando que os resultados obtidos neste trabalho estão de acordo com aqueles observados na literatura.

Já para os aços inoxidáveis ferríticos, Ahn, Kwon e Lee (1998) (AHN, KWON e LEE, 1998) observaram um comportamento distinto. De acordo com estes autores, para esta classe de materiais, o aumento do teor de $\mathrm{W}$ ou de Mo provoca não só uma redução no $\mathrm{i}_{\text {pass }}$, aumentando a estabilidade da película, como também reduz significativamente $\mathrm{E}_{\text {crit }} \mathrm{e} \mathrm{i}_{\text {crit }}$, aumentando a região passiva.

\subsubsection{Técnica Eletroquímica de Reativação Potenciodinâmica de Ciclo Duplo (DL-EPR)}

Da Figura 77 à Figura 81 são apresentadas as curvas típicas de DL-EPR em solução de $0,5 \mathrm{M} \mathrm{H}_{2} \mathrm{SO}_{4}+0,01 \mathrm{M}$ de $\mathrm{KSCN}$ a $30^{\circ} \mathrm{C}$ de cada material variando a porcentagem atômica de W em relação ao teor nominal de Mo presente na liga de referência. Em todas elas, é possível determinar a densidade de corrente de ativação $\left(I_{a}\right)$ e a densidade de corrente de reativação $\left(I_{r}\right)$ para cálculo do grau de sensitização $(D O S)$ mostrado anteriormente na Equação 17. Já a Figura 82, apresenta a comparação de todas as curvas.

Figura 77 - Curva típica de DL-EPR do material que contém 0\% de W (c.1107046) em solução de $0,5 \mathrm{M}$ de $\mathrm{H}_{2} \mathrm{SO}_{4}+0,01 \mathrm{M} \mathrm{KSCN}$ a $30^{\circ} \mathrm{C}$ destacando a densidade de corrente de ativação $\left(\mathrm{I}_{\mathrm{a}}\right)$ e a densidade de corrente de reativação $\left(\mathrm{I}_{\mathrm{r}}\right)$.

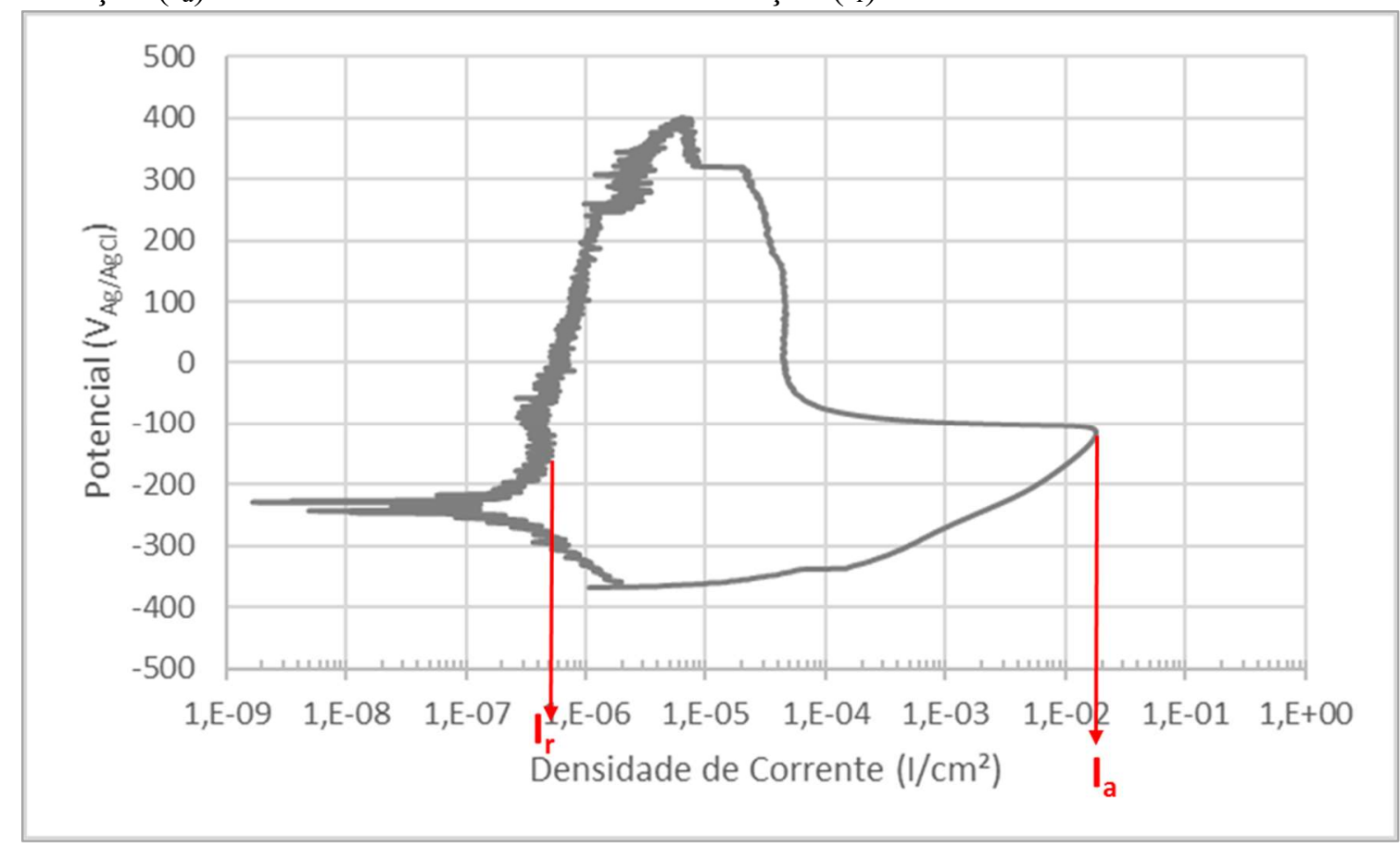

Fonte: Autor 
Figura 78 - Curva típica de DL-EPR do material que contém 25\% de W (c.1107047) em solução de $0,5 \mathrm{M}$ de $\mathrm{H}_{2} \mathrm{SO}_{4}+0,01 \mathrm{M} \mathrm{KSCN}$ a $30^{\circ} \mathrm{C}$ destacando a densidade de corrente de ativação $\left(\mathrm{I}_{\mathrm{a}}\right)$ e a densidade de corrente de reativação $\left(\mathrm{I}_{\mathrm{r}}\right)$.

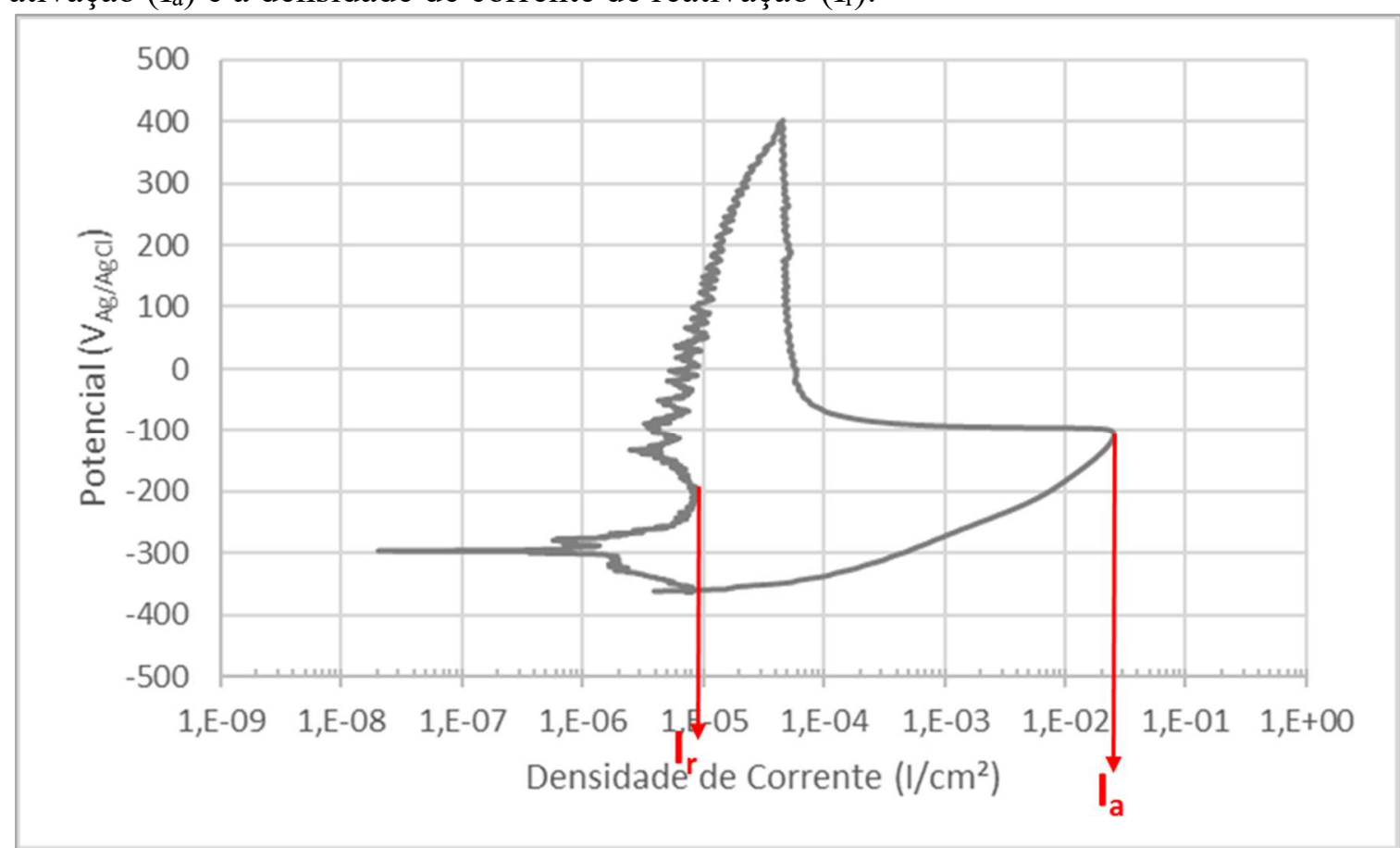

Fonte: Autor

Figura 79 - Curva típica de DL-EPR do material que contém 50\% de W (c.1107048) em solução de $0,5 \mathrm{M}$ de $\mathrm{H}_{2} \mathrm{SO}_{4}+0,01 \mathrm{M} \mathrm{KSCN}$ a $30^{\circ} \mathrm{C}$ destacando a densidade de corrente de ativação $\left(\mathrm{I}_{\mathrm{a}}\right)$ e a densidade de corrente de reativação $\left(\mathrm{I}_{\mathrm{r}}\right)$.

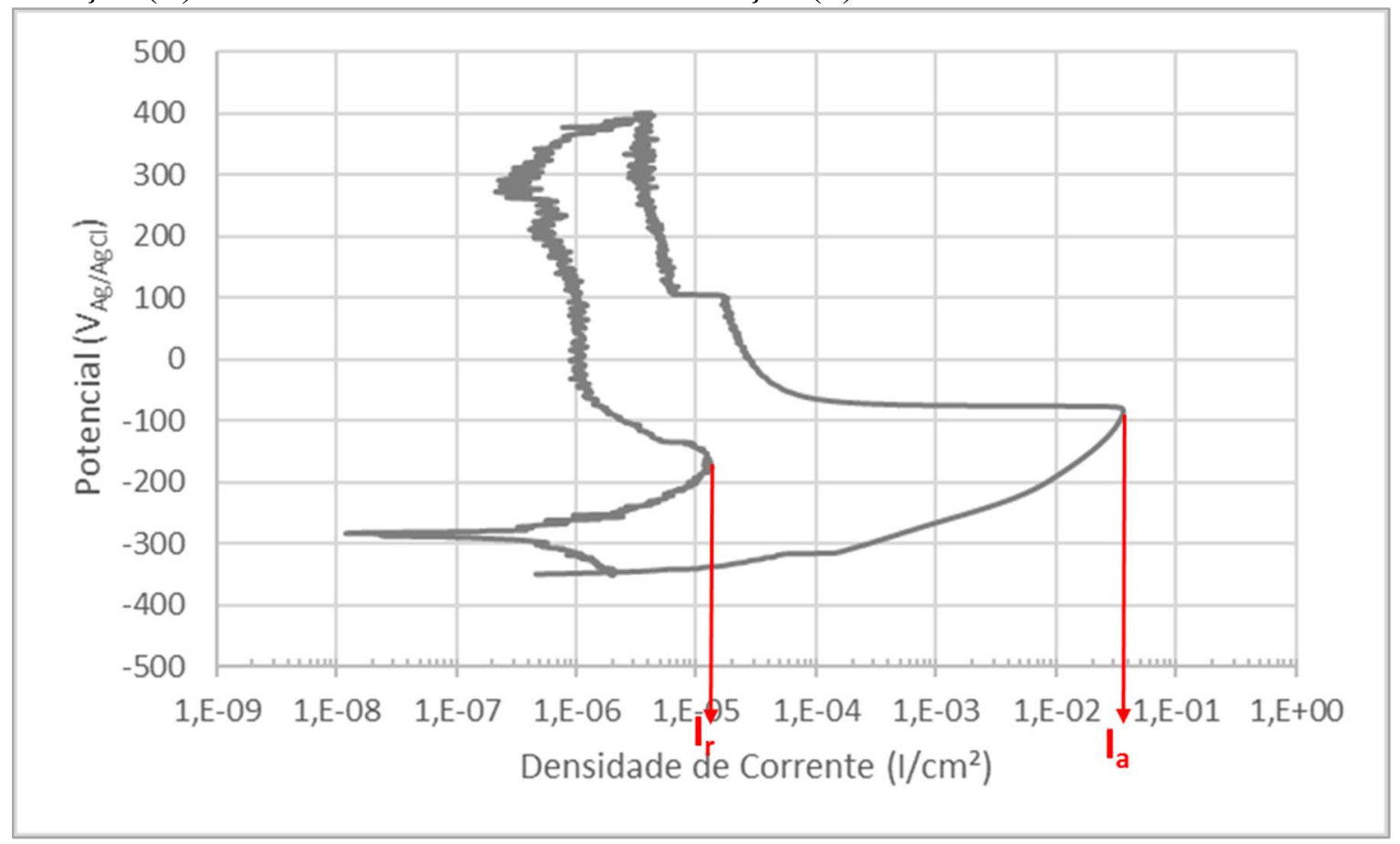

Fonte: Autor 
Figura 80 - Curva típica de DL-EPR do material que contém 75\% de W (c.1107049) em solução de $0,5 \mathrm{M}$ de $\mathrm{H}_{2} \mathrm{SO}_{4}+0,01 \mathrm{M} \mathrm{KSCN}$ a $30^{\circ} \mathrm{C}$ destacando a densidade de corrente de ativação $\left(I_{a}\right)$ e a densidade de corrente de reativação $\left(I_{r}\right)$.

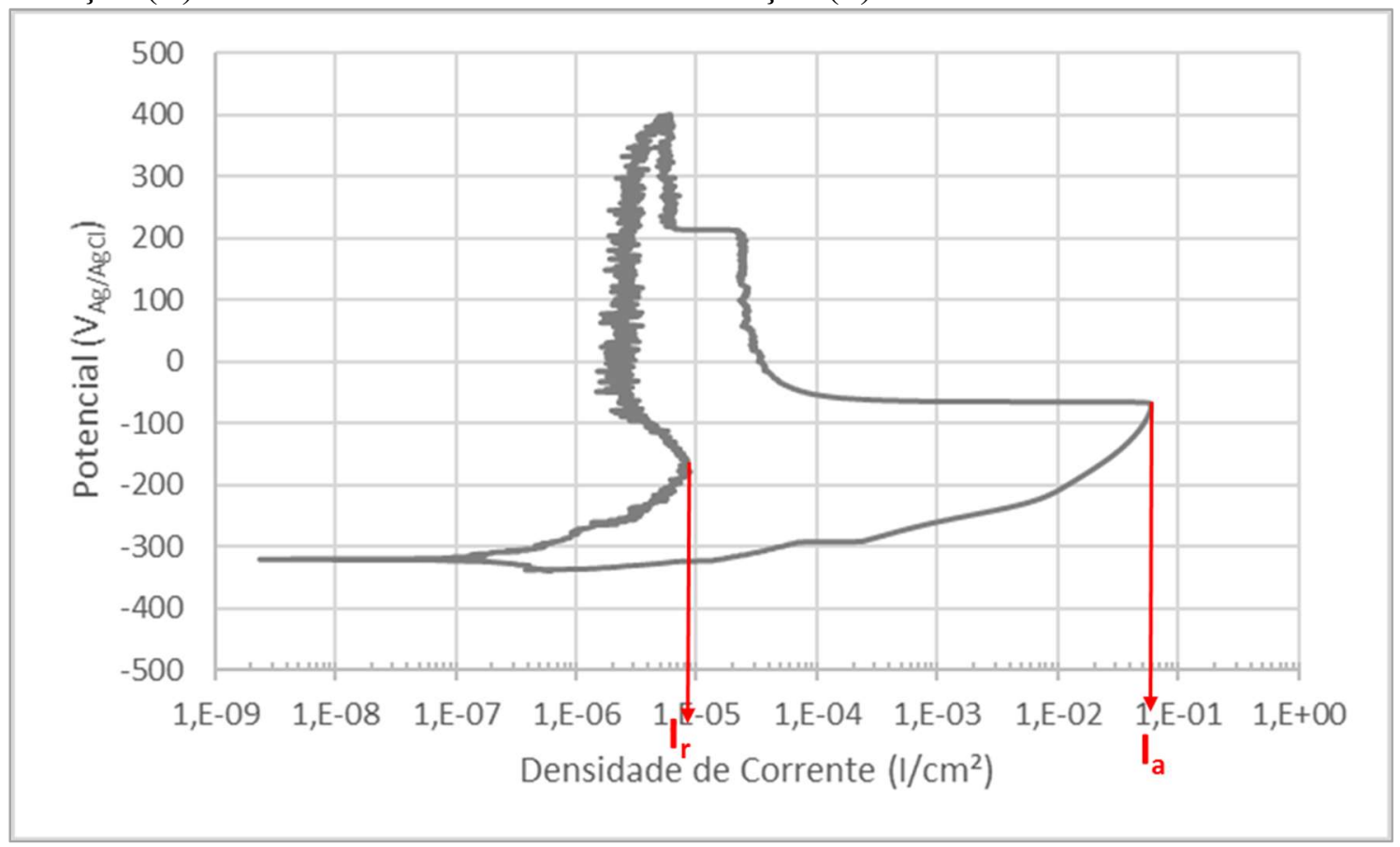

Fonte: Autor

Figura 81 - Curva típica de DL-EPR do material que contém 100\% de W (c.1107050) em solução de $0,5 \mathrm{M}$ de $\mathrm{H}_{2} \mathrm{SO}_{4}+0,01 \mathrm{M} \mathrm{KSCN}$ a $30^{\circ} \mathrm{C}$ destacando a densidade de corrente de ativação $\left(\mathrm{I}_{\mathrm{a}}\right)$ e a densidade de corrente de reativação $\left(\mathrm{I}_{\mathrm{r}}\right)$.

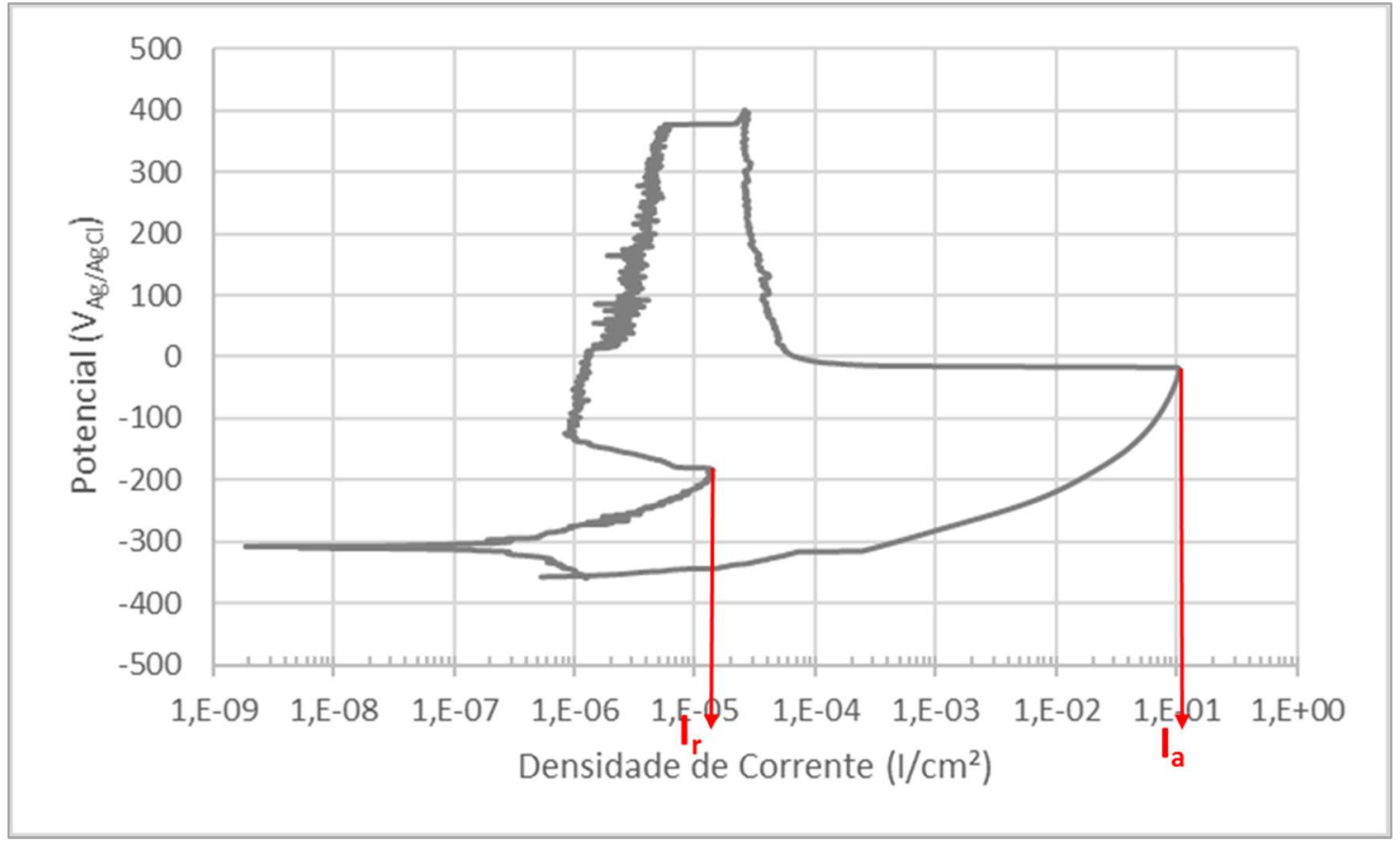

Fonte: Autor 
Figura 82 - Comparação entre as curvas de DL-EPR em solução de $0,5 \mathrm{M} \mathrm{H}_{2} \mathrm{SO}_{4}$ $+0,01 \mathrm{M} \mathrm{KSCN}$ a $30^{\circ} \mathrm{C}$ de todas as ligas solubilizadas apresentadas anteriormente, variando o teor atômico de $\mathrm{W}$ em cada uma delas em relação ao teor nominal de Mo na liga de referência.

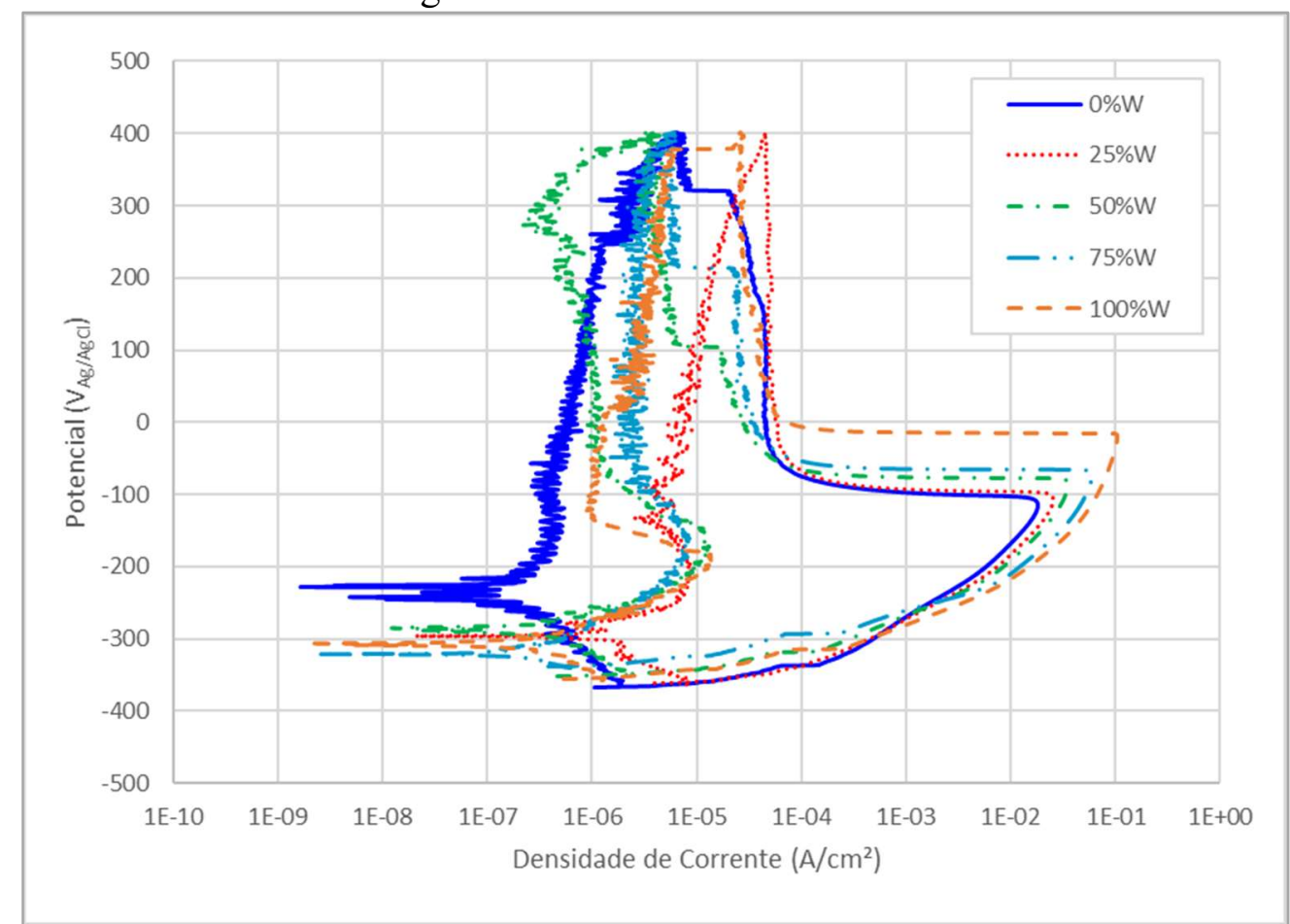

Fonte: Autor

Os dados obtidos em relação à variação do grau de sensitização em função do teor atômico de Mo substituído por W é mostrado na Figura 83. Estes resultados mostram que o grau de sensitização dos materiais avaliados é bastante pequeno, sendo que o maior valor encontrado para esta variável foi de $0,061 \%$ para a amostra que apresenta $50 \%$ de $\mathrm{W}$ em relação ao teor atômico de Mo na liga nominal. O gráfico mostra também que a substituição total do Mo por W, representada pelos resultados das amostras de 0 e $100 \%$ de $\mathrm{W}$, não apresenta diferenças relevantes para o grau de sensitização do material. 
Figura 83 - Dados obtidos de grau de sensitização (\%DOS) obtidos por meio das curvas de DL-EPR em solução de $0,5 \mathrm{M} \mathrm{H}_{2} \mathrm{SO}_{4}+0,01 \mathrm{M} \mathrm{KSCN}$ a $30^{\circ} \mathrm{C}$ das amostras solubilizadas, em função da porcentagem atômica de $\mathrm{W}$ em relação ao teor nominal de Mo presente na liga de referência.

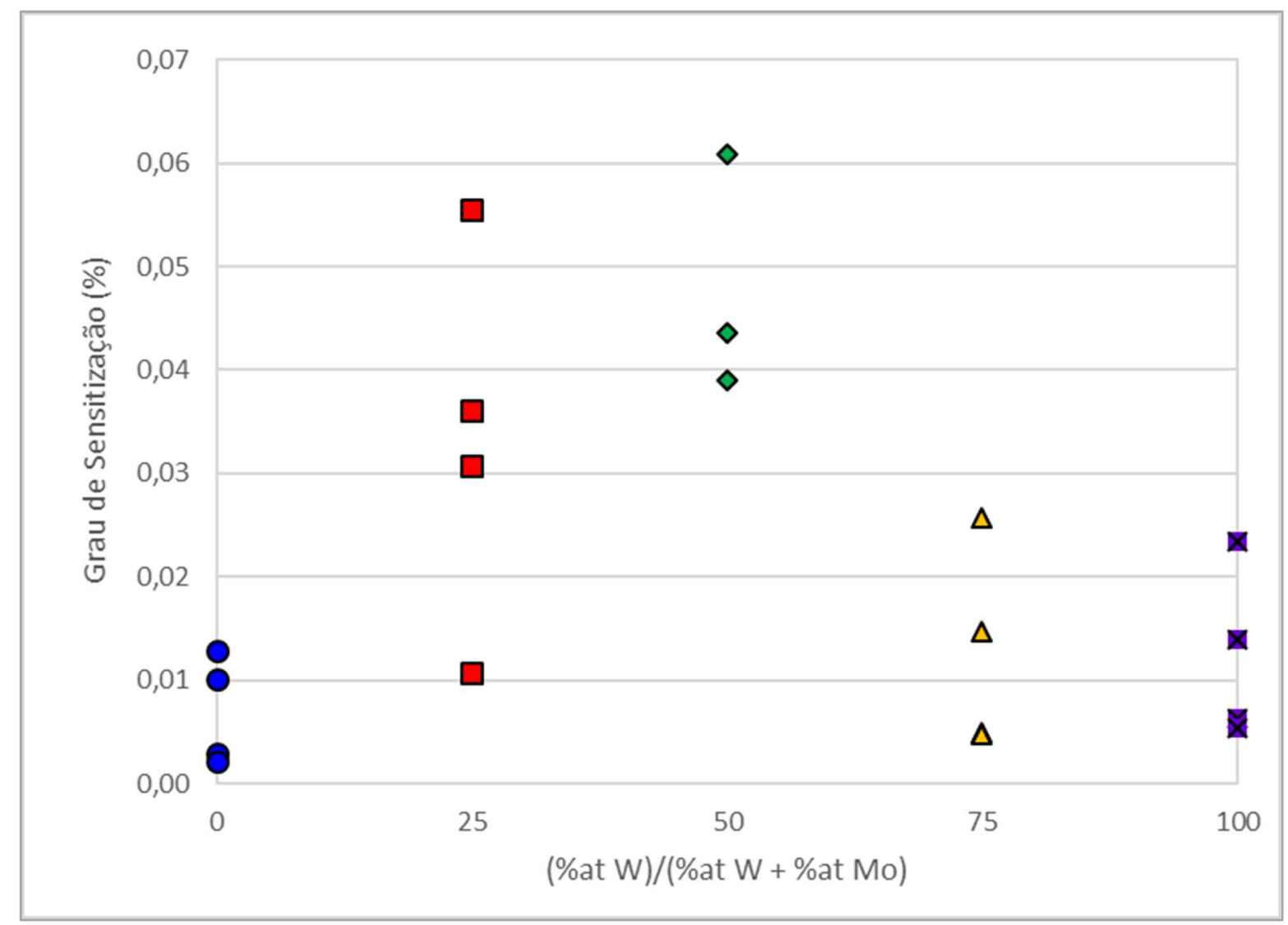

Fonte: Autor

De acordo com o anexo D da norma ISO 12732:2006 que descreve o procedimento a ser utilizado neste ensaio, o grau de sensitização do material pode ser dividido em não sensitizado, levemente sensitizado e sensitizado de acordo com o valor de $I_{r} / I_{a}$ obtido, Tabela 31. Como o maior valor encontrado entre as amostras analisadas foi de $0,061 \%$, de acordo com este critério é possível concluir que todas as amostras solubilizadas se encontram nãosensitizadas.

Tabela 31 - Correlação entre o valor de $\mathrm{I}_{\mathrm{r}} / \mathrm{I}_{\mathrm{a}}$ e o grau de sensitização de acordo com a norma ISO 12732:2006.

\begin{tabular}{c|c}
\hline Valor $\mathbf{I}_{\mathbf{r}} / \mathbf{I}_{\mathbf{a}}$ & Interpretação geral do Grau de Sensitização \\
\hline$<1 \%$ & Não Sensitizado \\
\hline 1 a $5 \%$ & Levemente Sensitizado \\
\hline$>5 \%$ & Sensitizado \\
\hline
\end{tabular}

Fonte: Autor "adaptado de” International Organization for Standardization, 2006. 
A análise de variância dos dados de Grau de Sensitização mostrados na Figura 83, Tabela 32, mostrou que $F$ é maior que $F_{c r i t}$ e o valor-p é menor que o nível de significância utilizado de 0,05. Ou seja, de acordo com essa análise, existem diferenças estatísticas significativas entre as amostras. De fato, apesar do grau de sensitização de todas elas ser bastante pequeno, a Figura 83 mostra que as amostras que apresentam 25 e $50 \%$ de W apresentam grau de sensitização sutilmente maior. Mas, pode-se dizer que este ligeiro aumento não prejudica o comportamento do material à resistência à corrosão intergranular a ponto de impedir a substituição do Mo por W em amostras solubilizadas.

Tabela 32 - Análise de variância dos dados de grau de sensitização (\%) obtidos por meio do ensaios DL-EPR em solução de $0,5 \mathrm{M} \mathrm{H}_{2} \mathrm{SO}_{4}+0,01 \mathrm{M} \mathrm{KSCN}$ a $30^{\circ} \mathrm{C}$ utilizando nível de significância de 0,05 .

\begin{tabular}{l|c|c|c|c|c|c}
\hline Fonte da variação & $\boldsymbol{S Q}$ & $\boldsymbol{g l}$ & $\boldsymbol{M Q}$ & $\boldsymbol{F}$ & valor-P & F crítico \\
\hline Entre grupos & 0,0041 & 4 & 0,0010 & 7,65 & 0,002 & 3,11 \\
\hline Dentro dos grupos & 0,0019 & 14 & 0,0001 & & & \\
\hline Total & 0,0060 & 18 & & & & \\
\hline
\end{tabular}

Fonte: Autor 


\section{CONCLUSÕES}

De acordo com os resultados obtidos em relação à substituição do teor atômico de Mo na liga de referência por $\mathrm{W}$, pode-se concluir que:

1) As amostras brutas de laminação apresentam microestrutura homogênea, sendo que todas as amostras apresentaram inclusões alongadas no sentido da laminação. Da mesma maneira, as amostras solubilizadas também se mostraram bastante semelhantes entre si. A análise da fração em área das inclusões, evidenciou que as amostras apresentam a mesma quantidade de inclusões, cuja média global é de 0,25 $\pm 0,1 \%$. Além disso, as análises de EDS mostraram que as inclusões analisadas são bastante complexas e compostas majoritariamente por oxigênio, enxofre e manganês.

2) Todas as amostras apresentaram grãos equiaxiais. Porém, a análise de variância evidenciou que existem diferenças estatísticas entre as amostras. De fato, a amostra que apresenta $0 \%$ de $\mathrm{W}$, apresenta grãos ligeiramente maiores, $78 \pm 10 \mu \mathrm{m}$, ou seja, todas as amostras que contêm $\mathrm{W}$ apresentaram tamanho de grão ligeiramente menor indicando que a presença de $\mathrm{W}$ leva à redução do tamanho de grão após o processamento.

3) As medidas de dureza obtidos estão de acordo com a análise de tamanho de grão: a amostra que não contém W apresenta dureza Brinel ligeiramente menor. Já a amostra que contém $25 \%$ de $\mathrm{W}$ apresenta um ligeiro aumento.

4) De acordo com os resultados obtidos no ensaio de tração não há diferenças estatísticas significativas de propriedades mecânicas com a substituição parcial e total do Mo por W, ou seja, o limite de escoamento, limite de resistência à tração, alongamento e redução em área foram semelhantes para todas as amostras analisadas.

5) Os ensaios de polarização cíclica realizados a temperatura ambiente e solução de 3,5\% de $\mathrm{NaCl}$ não evidenciou nenhuma alteração nos potenciais de corrosão $\left(\mathrm{E}_{\text {corr }}\right)$ e de pite (E $\left.E_{\text {pite }}\right)$ das amostras que contêm $\mathrm{W}$ em relação à amostra de referência. Por outro lado, os dados obtidos para a temperatura crítica de pite dos materiais em solução de $1 \mathrm{M}$ de $\mathrm{NaCl}$ mostrou diferenças estatísticas significativas entre o comportamento dos materiais à corrosão por pite, sendo que aquele que apresenta 50\% de substituição apresentou CPT maior que os demais, $40 \pm 4^{\circ} \mathrm{C}$, evidenciando que na presença de $50 \%$ de Mo e $50 \%$ de $\mathrm{W}$ há um efeito sinérgico entre os dois elementos de liga que promovem o aumento da resistência à corrosão por pite em relação à liga de referência, AISI 316L. Portanto, este resultado sugere que, caso a substituição de Mo por W seja desejada no aço inoxidável austenítico AISI 316L e o principal objetivo desta substituição seja 
aumentar a resistência do material à corrosão por pite, o teor atômico de Mo substituído seja de apenas $50 \%$.

6) Os resultados de polarização potenciodinâmica em solução de $0,5 \mathrm{M} \mathrm{H}_{2} \mathrm{SO}_{4}+0,01 \mathrm{M}$ $\mathrm{KSCN}$ a $30^{\circ} \mathrm{C}$ evidenciaram que o fenômeno de passivação do aço inoxidável AISI 316Lé influenciado pela substituição de Mo por W em relação ao teor atômico de 1,33\% at $(2,3 \%$ wt $)$ de Mo presente na liga de referência. De acordo com estes resultados, o W provoca efeitos distintos na passivação do material, pois, apesar da densidade de corrente crítica $\left(i_{\text {crit }}\right)$ e do potencial crítico $\left(E_{\text {crit }}\right)$ apresentarem uma tendência de aumento com esta substituição, a densidade de corrente passiva (ipass) é significativamente reduzida. Ou seja, o W dificulta a formação da película passiva, expandindo a região ativa, porém, ao ser formada, esta película é mais protetora. Porém, por mais que a substituição de Mo por W provoque uma alteração na passivação deste aço inoxidável AISI 316L, este benefício não é forte o suficiente para justificar a substituição.

7) Os resultados do ensaio DL-EPR em solução de $0,5 \mathrm{M} \mathrm{H}_{2} \mathrm{SO}_{4}+0,01 \mathrm{M} \mathrm{KSCN}$ a $30^{\circ} \mathrm{C}$ mostraram que o grau de sensitização das amostras é bastante pequeno, sendo que o maior valor encontrado para esta variável foi de $0,061 \%$ para a amostra que apresenta $50 \%$ de $\mathrm{W}$ em relação ao teor atômico de Mo na liga nominal. As amostras que apresentam 25 e 50\% de W apresentam grau de sensitização sutilmente maior. Mas, pode-se dizer que este ligeiro aumento não prejudica o comportamento do material à resistência à corrosão intergranular a ponto de impedir a substituição do Mo por W em amostras solubilizadas.

Portanto, de acordo com os ensaios realizados, a substituição total ou parcial do molibdênio por tungstênio, mantida a proporção em fração atômica, pode ser realizada sem praticamente nenhuma alteração de propriedades para o aço inoxidável austenítico AISI 316L. Porém, quando a substituição é de $50 \%$ há um ganho expressivo no comportamento de corrosão por pite evidenciado pelos resultados dos ensaios para determinação da temperatura crítica de pite promovido certamente por um efeito sinérgico entre o Mo e $\mathrm{W}$, conforme citado na literatura (OH, et al., 1993).

Além disso, há um ótimo primeiro indício de que sucatas de aço ferramenta ricas em $\mathrm{W}$ podem ser utilizadas para a fabricação de aços inoxidáveis austeníticos. Porém, outros aspectos inerentes à processabilidade devem ser analisados com cuidado para que tal substituição seja, de fato, considerada. 


\section{REFERÊNCIAS}

AHN, M. K.; KWON, H. S.; LEE, H. M. Quantitative comparison of the influences of tungsten and molybdenum on the passivity of Fe-29Cr ferritic stainless steels. Corrosion Science, v. 40, n. 2-3, 1998. 307-322.

ALMUBARAK, A.; ABUHAIMED, W.; ALMAZROUNEE, A. Corrosion Behaviour of the Stressed Sensitized Austenitic Stainless Steels of High Nitrogen Content in Seawater. International Journal of Electrochemistry, 2013. p. 1-7.

AMERICAN SOCIETY FOR METALS. Stainless Steel. Ohio: Materials Park, 1999. ISBN 087170-503-6.

AMERICAN SOCIETY FOR TESTING AND MATERIALS. ASTM G150 - 99 (2004) Eletrochemical Critical Pitting Temperature Testing of Stainless Steels. West Conshohocken: ASTM, 2004.

AMERICAN SOCIETY FOR TESTING AND MATERIALS. ASTM G108 - 94 (2010) Electrochemical Reactivation (EPR) for Detecting Sensitization of AISI Type 304 and 304L Stainless Steels. West Conshohocken: ASTM, 2010.

AMERICAN SOCIETY FOR TESTING AND MATERIALS. ASTM G48 - 11 - Pitting and Crevice Corrosion Resistance of Stainless Steels and Related Alloys by Use of Ferric Chloride Solution. West Conshohocken: ASTM, 2011.

AMERICAN SOCIETY FOR TESTING AND MATERIALS. ASTM G5 - 14 - Making Potentiodynamic Anodic Polarization Measurements. West Conshohocken: ASTM, 2014a.

AMERICAN SOCIETY FOR TESTING AND MATERIALS. ASTM G61 - 86 (2014) Conducting Cyclic Potentiodynamic Polarization Measurements for Localized Corrosion Susceptibility of Iron-, Nickel-, or Cobalt-based alloys. West Conshohocken: ASTM, 2014b.

AMERICAN SOCIETY FOR TESTING AND MATERIALS. ASTM E8/E8M - 16a Tension Testing of Metallic Materials. West Conshohocken: ASTM, 2016.

BARTERI, M.; MECOZZI, M. G.; NEMBRINI, I. DTS 25,7NWCu A new super duplex Steel with high mechanical properties and improved corrosion resistance. In: 4TH INTERNATIONAL CONFERENCE OF DUPLEX STAINLESS STEELS., 1994, Glasgow, Proceeding... Cambridge: Abington, 1995.

BERNHARDSSON, S. The Corrosion Resistance of Duplex Stainless Steels. In: DUPLEX STAINLESS STEELS., 1991, Beaune. Proceeding... Les Editions de Physique, 1991. p. 185210.

BRIGHAM, R. J.; TOZER, E. W. Temperature as a Pitting Criterion. Corrosion, v. 29, n. 1, 1973. p. 33-36. 
BRIGHAM, R. J.; TOZER, E. W. Effect of Alloying Additions on the Pitting Resistance of 18\%Cr Austenitic Stainless Steel. Corrosion, v. 30, n. 5, 1974. p. 161-166.

BRUEMMER, S. M.; CHARLOT, L. A. Development of grain boundary chromium depletion in type 304 and 316 stainless steel. Scripta Metallurgica, v. 20, p. 1019-1024, 1986.

BUI, N. et al. On the mechanism for improved passivation by additions of tungsten to austenitic stainless steels. Corrosion, v. 39, n. 12, 1983. p. 491-496.

BUSSAB, W. O. Análise de Variância e de Regressão: uma introdução. 2. ed. São Paulo: Atual Editora LTDA, 1988.

CIHAL, V. A Potentiokinetic Reactivation Method for Predicting The I.C.C. and I.G.S.C.C. Sensitivity of Stainless Steels and Alloys. Corrosion Science, v. 20, n. 6, 1980. p. 737-744.

CIHAL, V. et al. Trends in the Electrochemical Polarization Potentiodynamic Reactivation Method - EPR. Chemical and Biochemical Engineering Quartely, v. 21, n. 1, 2007. p. 4754.

DI PAOLA, A.; DI QUARTO, F.; SERRAVALLE, G. A tensiostatic study of the anodic behaviour of tungsten in acid solutions. Journal of the less common metals, v. 42, n. 3, 1975. p. 315-324.

EBRAHIMI, N. et al. A comparative study of critical pitting temperature (CPT) of stainless steels by electrochemical impedance spectroscopy (EIS), potentiodynamic and potentiostatic techniques. Corrosion Science, v. 59, 2012. p. 96-102.

FONTANA, M. G. Corrosion Engineering. 3. ed. Nova York: McGraw Hill Book Company, 1987.

GARFIAS-MESIAS, L. F.; SYKES, J. M.; TUCK, C. D. The effect of phase compositions on the pitting corrosion of $25 \mathrm{Cr}$ duplex stainless steel in chloride solutions. Corrosion Science, 38, n. 8, 1996. p. 1319-1330.

GENTIL, V. Corrosão. 3. ed. Rio de Janeiro: LTC, Livros Técnicos e Científicos, 1996.

GOETZ, R.; BOBAND, C.; LANDOLT, D. A Comparative Studay of the Anodic Behaviour of Fe-Cr-W and Fe-Cr-Mo Alloys in Chloride Solution. In: 8TH INTERNATIONAL CONGRESS ON METALLIC CORROSION., 1981, Mainz: Metalic Corrosion: Proceeding.... DECHEMM Deutch Gesellschaft fur chemisches Apparatewesen e.V., 1981 . p. 247-252.

HALL, E. L.; BRIANT, C. L. Chromium Depletion in the Vicinity of Carbides in Sensitized Austenitic Stainless Steels. Metallurgical Transactions A, v. 15A, n. 5, 1984. p. 793-811.

HAUGAN, E. B. et al. Effect of Tungsten on the Pitting and Crevice Corrosion Resistance of Type 25Cr Super Duplex Stainless Steel. Corrosion, v. 73, n. 1, 2017. p. 53-67. 
INTERNATIONAL MOLYBDENUM ASSOCIATION, IMOA. Practical Guidelines for the fabrication of high performance austenitic stainless steel. International Molybdenum Association, IMOA, 2014. Disponivel em: $<$ http://www.imoa.info/download_files/stainlesssteel/Austenitics.pdf>. Acesso em: 23 Maio 2017.

INTERNATIONAL ORGANIZATION FOR STANDARDIZATION. ISO 12732: 2006 (E) Corrosion of metals and Alloys - Electrochemical potentiokinetic reactivation measurement using the double loop method (based on Cihal's method). Geneva: ISO, 2006.

INTERNATIONAL STAINLESS STEEL FORUM (ISSF). Stainless Steel in Figures 2016. worldstainless.org, Maio $2016 . \quad$ Disponivel em: $<$ http://www.worldstainless.org/Files/issf/non-imagefiles/PDF/statistics/161014_SCF_Public.pdf>. Acesso em: 18 Janeiro 2016.

IRHZO, A. et al. The role of alloyed tungsten on the conductivity of stainless steel passive layers. Corrosion Science, v. 26, n. 10, 1986. p. 769-780.

JEON, S.-H. et al. Effects of W substitution on the precipitation of secondary phases and the associated pitting corrosion in hyper duplex stainless steels. Journal of Alloys and Compounds, v. 544, 2012. p. 166-172.

JIN, S.; ATRENS, A. ESCA-Studies of the structure and composition of the passive film formed on stainless steels by various immersion temperatures in $0.1 \mathrm{M} \mathrm{NaCl}$ solution. Applied Physics A, v. 45, n. 1, 1988. p. 83-91.

KELLY, R. G. Pitting. In: BABOIAN, R. Corrosion tests and standards: application and interpretation. Fredericksburg, VA: ASTM manual series, 1995. Cap. 18.

KELLY, R. G. et al. Eletrochemical Techniques in Corrosion Science and Engineering. 1. ed. Nova York: Marcel Dekker, Inc, 2003.

KIM, J. S.; KWON, H. S. Effects of Tungsten on Corrosion and Kinetics of Sigma Phase Formation of 25\% Chromium Duplex Stainless Steels, v. 55, n. 5, 1999. p. 512-521.

KIM, J. S.; XIANG, P. J.; KIM, K. Y. Effect of Tungsten and Nickel Addition on the Repassivation Behavior of Stainless Steel. Corrosion, v. 61, n. 2, 2005. p. 174-183.

KIM, K. Y. et al. Electrochemical and Stress Corrosion Properties of Duplex Stainless Steels Modified with Tungsten Addition. Corrosion, v. 54, n. 11, 1998. p. 910-921.

KOPELIOVICH, D. Pitting Corrosion. Site da Substech, Substances and Technologies, 2015. Disponivel em: <http://www.substech.com/dokuwiki/doku.php?id=pitting_corrosion>. Acesso em: Abril 262017.

LAI, J. K. L. A Review of Precipitation Behaviour in AISI Type 316 Stainless Steel. Materials Science and Engineering, v. 61, n. 2, 1983. p. 101-109. 
LOTHONGKUM, G.; VONGBANDIT, P.; NONGLUCK, P. Experimental determination of E-pH diagrams for 316L stainless steel in air saturated aqueous solutions containing 0-5.000 ppm of chloride using a potentiodynamic method. Anti-Corrosion Methods and Materials, v. 53, n. 3, 2006. p. 169-174.

MAJIDI, A. P.; STREICHER, M. A. The Double Loop Reactivation Method for Detecting Sensitization in Type 304 Stainless Steel. Corrosion, v. 40, n. 11, 1984. p. 584-593.

MATULA, M. et al. Intergranular corrosion of AISI 316L steel. Materials Characterization, v. 46, 2001. p. 203-210.

MISCHLER, S. et al. The chemical composition of the passive filme on Fe-24Cr and Fe-24Cr11Mo studied by AES, XPS and SIMS. Corrosion Science, v. 32, n. 9, 1991. p. 925-944.

NACE INTERNATIONAL. Pitting Corrosion. Site da Nace International, 2017. Disponivel em: <https://www.nace.org/Pitting-Corrosion/>. Acesso em: 26 Abril 2017.

NICHOLLS, J. M. Corrosion properties of duplex stainless steels: general corrosion, pitting and crevice corrosion. In: 4TH INTERNATIONAL CONFERENCE DUPLEX STAINLESS STEELS., 1994, Glasgow. Proceeding...Cambridge: Abington, 1995.

NICKEL DEVELOPMENT INSTITUT (NIDI). Guidelines for the welded fabrication of nickel-containing stainless steel for corrosion resistance services. Nickel Institute, 2017. Disponivel em: $<$ https://www.nickelinstitute.org/ /media/Files/TechnicalLiterature/GuidelinesfortheWeldedF abricationofNickelStainlessSteelsforCorrosionResistantService_11007_.ashx>. Acesso em: 07 Junho 2017.

NILSSON, J.-O. Austenitic stainless steels - from kitchen sinks to fuel cell cars. Stainless Steel World , p. 25-26, Março 2017.

NIPPON STEEL \& SUMITOMO METAL CORPORATION. Material Data Sheet. Nippon Steel \& Sumitomo Metal Corporation, 2013. Disponivel em: $<$ http://www.tubular.nssmc.com/product-services/specialty-tube/product/dp3w>. Acesso em: 23 Abril 2017.

NUNES, L. D. P. Fundamentos de Resistência à Corrosão. Rio de Janeiro: Editora Interciência, v. 1, 2007.

$\mathrm{OH}, \mathrm{B}$. W. et al. The influence of $\mathrm{W}$ on corrosion resistance and sigma phase formation in duplex stainless steels. In: INNOVATION STAINLESS STEEL (STAINLESS STEEL '93), 1993, Florence. Proceeding...Milano:Associazone italiana di metallurgia. 1993, v.3. p. 59-64.

OKAMOTO, H. The Effect of Tungsten and Molybdenum on the Performance of Super Duplex Stainless Steels. In: APPLICATIONS OF STAINLESS STEEL, 1992. Stockholm. Proceeding... Stockholm: Avesta Research Foundation, 1992. p. 360-369. 
OKAMOTO, $\mathrm{H}$. et al. Advanced performace of $2 \%$ tugnsten bearing super duplex stainless steel DP3W. In: 4TH INTERNATIONAL CONFERENCE OF DUPLEX STAINLESS STEELS., 1994, Glasgow. Proceeding... Cambridge: Abington, 1995.

OLSSON, C. O. A.; HORNSTROM, S. E. An AES and XPS study of the high alloy austenitic stainless steel 254SMO tested in a ferric chloride solution. Corrosion Science, v. 36, n. 1, 1994. p. 141-151.

OLSSON, C. O. A.; LANDOLT, D. Passive films on stainless steels - chemistry, structure and growth. Electrochimica Acta, v. 48, n. 9, 2003. p. 1093-1104.

OSOZAWA, K.; BOHNENKAMP, K.; ENGEL, H. J. Potentiostatic Study on the Intergranular Corrosion of an Austenitic Chromium-Nickel Stainless Steel. Corrosion Science, v. 6, n. 9, 1966. p. 421-433.

OUTOKUMPU STAINLESS AB. Handbook of Stainless Steel, Outubro 2013. Disponivel em: $<$ http://www.outokumpu.com/sitecollectiondocuments/outokumpu-stainless-steelhandbook.pdf>. Acesso em: 29 Agosto 2016.

PARK, C. J.; AHN, M. K.; KWON, H. S. Influences of Mo substituion by W on the precipitation kinetics of secondary phases and the associated localized corrosion and embrittlement in 29\% Cr ferritic stainless steels. Materials Science and Engineering: A, v. 418, n. 1-2, 2006. p. 211-217.

PARK, C. J.; KWON, H. S. Effects of aging at $475^{\circ} \mathrm{C}$ on corrosion properties of tungstencontaining duplex stainless steels. Corrosion Science, v. 44, n. 12, 2002. p. 2817-2830.

POURBAIX, M. Atlas of Electrochemical Equilibria in Aqueous Solutions. Tradução de James A. Franklin. Houston: NACE International, 1974.

RÉQUIZ, R.; ALVAREZ, I. The Use of EPR-DL Technique to Determine the Degree of Sensitization of Modified AISI 316 Stainless Steel. Materials Science Forum, 289-292, 1998. p. 1007-1018.

ROBERGE, P. R. Handbook of corrosion engeneering. New York: McGraw-Hill, 1999.

ROBERGE, P. R. Corrosion Engineering: Principles and Practice. 1. ed. [S.l.]: McGraW-Hill, 2008.

ROLLED ALLOYS INC. Zeron 100. Rolled Alloys Inc., 2017. Disponivel em: $<$ https://www.rolledalloys.com/alloys/duplex-stainless-steels/zeron-100/en/>. Acesso em: 23 Abril 2017.

SEDRIKS, A. J. Corrosion of stainless steels. 1. ed. Princeton: Wiley-Interscience, 1979.

SEDRIKS, A. J. Corrosion resistance of austenitic Fe-Cr-Ni-Mo alloys in marine environments. International Metals Review, v. 27, n. 1, 1982. p. 321-353. 
U.S. GEOLOGICAL SURVEY. Molybedenum: Mineral Commodity Summaries. USGS, science for a changing world, 2016. Disponivel em: $<$ https://minerals.usgs.gov/minerals/pubs/commodity/molybdenum/mcs-2017-molyb.pdf $>$. Acesso em: 24 Abril 2017.

U.S. MINERAL SURVEY. Tungsten, Mineral Commodity Summaries. USGS, science for a changing World, $2016 . \quad$ Disponivel em: $<$ https://minerals.usgs.gov/minerals/pubs/commodity/tungsten/mcs-2017-tungs.pdf $>$. Acesso em: 23 Abril 2017.

UNIVERSIDADE FEDERAL DO PARANÁ. Apostila disponibilizada para disciplina CE003 - Estatística II. Curitiba: UFPR, 2009.

WEBCORR, C. C. S. Corrosion Online Lectures. Lecture 11: Eletrochemical Techniques, 2016.

$<$ http://www.corrosionclinic.com/corrosion_online_lectures/ME303L11.HTM $>$. Acesso em: 26 Maio 2017.

WOLYNEC, S. Técnicas eletroquímicas em corrosão. 1. ed. São Paulo: Editora da Universidade de São Paulo, 2003.

ZAKERI, M.; NAKHAIE, D. . N. M.; MOAYED, M. H. The effect of dichromate ion on the pitting corrosion of AISI 316 stainless steel. Part I: Critical pitting temperature. Corrosion Science, v. 93, 2015. p. 234-241. 